\title{
Um Processo para Construção de Frameworks a partir da Engenharia Reversa de Sistemas de Informação Baseados na Web: Aplicação ao Domínio dos Leilões Virtuais
}

Reginaldo Ré

Dissertação de Mestrado apresentada ao Instituto de Ciências Matemáticas e de Computação - ICMC/USP, para a obtenção do título de Mestre na Área de Ciências de Computação e Matemática Computacional.

Orientador: Prof. Dr. Paulo Cesar Masiero

Agosto/2002 



\section{Agradecimentos}

Agradeço primeiramente a DEUS, pelo dom da vida e por permitir conviver com pessoas tão maravilhosas.

Ao meu orientador, Prof. Dr. Paulo Cesar Masiero, pelos ensinamentos, constante apoio e extremo profissionalismo na orientação durante todo o período deste trabalho.

Aos meus familiares, em especial aos meus pais Aldecir e Cidinha, minha irmã Regiani e minha avó Luzia, porque me amam muito mais do que eu possa amá-los.

À minha colega e amiga do grupo de pesquisa Rosana Teresinha V. Braga e ao Prof. Dr. Fernão Stella R. Germano, pelas contribuições durante este trabalho.

À Prof. ${ }^{a}$ Dr. ${ }^{a}$ Maria da Graça C. Pimentel e ao Prof. Dr. José Carlos Maldonado, pelas sugestões apresentadas no exame geral de qualificação.

Às professoras Prof. ${ }^{a}$ Dr. ${ }^{a}$ Renata P. M. Fortes, Prof. ${ }^{a}$ Dr. ${ }^{a}$ Rosely Sanches e Prof. ${ }^{a}$ Dr. ${ }^{a}$ Sandra C. P. F. Fabri.

Aos meus amigos: Ades, Andréia, Ana Cláudia, Aline, Auri, Camilão, Cássio, Débora, Elisa, Ellen, Emerson, Enzo, Erika, Fernando Tranquilo, Gelza, Erald o Holandês, Flávia, Juliana, Kátia, Ludimila, Lu, Luciano, Marcelão, Mário, Maris, Mayb, Matheus, Marisa, Monique, Percy, Bulcão, Rejane, Richard, Rogério, Rudinei, Sandrão, Sandro KLB, Silvio, Simone, Simone Rocio, Thaise, Tati, Valéria, Vangrei, Vivi e Willie.

Aos amigos e companheiros: Maluquinho, Amebão, Kleber, Mininim e Cabeção, pelos bons momentos que passamos juntos e que sempre serão parte importante da minha vida.

Aos amigos de Junqueirópolis, por, apesar da minha ausência, ainda serem meus amigos.

Aos professores e funcionários do ICMC, pela disposição e atenção.

A todos aqueles que, de certa forma, me apoiaram neste trabalho.

À FAPESP pelo apoio financeiro. 
1 Introdução $\quad 1$

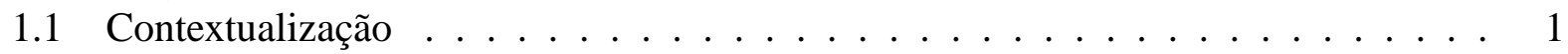

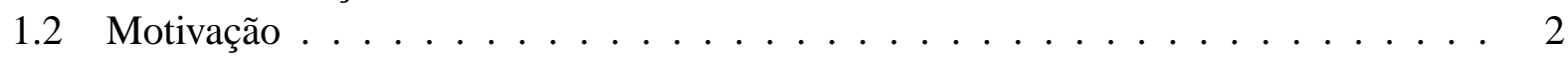

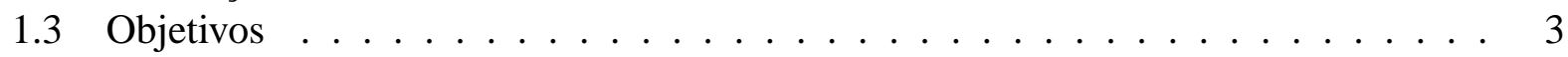

1.4 Organização da Dissertação . . . . . . . . . . . . . . . . . . . . . 3

2 Revisão da Literatura $\quad 4$

2.1 Considerações Iniciais . . . . . . . . . . . . . . . . . . . . . 4

2.2 Padrões de Software e Linguagens de Padrões . . . . . . . . . . . . . . . . . . 5

2.2.1 Componentes de um Padrão . . . . . . . . . . . . . . . . . . . 6

2.2.2 Classificação de Padrões . . . . . . . . . . . . . . . . . . . . 7

2.2 .3 Linguagens de Padrões . . . . . . . . . . . . . . . . . . . 8

2.2.4 Exemplos de Linguagens de Padrões . . . . . . . . . . . . . . . . . . . . . 9

2.2.5 A Linguagem de Padrões para Gestão de Recursos de Negócio . . . . . . . . 10

2.3 Frameworks . . . . . . . . . . . . . . . . . . . 12

2.3.1 Classificação dos Frameworks . . . . . . . . . . . . . . . . . 13

2.3.2 Frameworks "Caixa Branca" e Frameworks "Caixa Preta" . . . . . . . . . 14

2.3.3 Documentação de Frameworks . . . . . . . . . . . . . . . . . . . . . 15

2.3.4 Exemplos de Frameworks . . . . . . . . . . . . . . . . . 15

2.3.5 O Framework para Gestão de Recursos de Negócio . . . . . . . . . . . . . . 16

2.4 Sistemas de Informação baseados na Web . . . . . . . . . . . . . . . . . . . 17

2.5 Leilões Virtuais . . . . . . . . . . . . . . . . . . . . . . . . . . . . . . . 18

2.5.1 Classificação de Leilões Virtuais . . . . . . . . . . . . . . . . . . . . 19

2.5.2 Aspectos de Segurança . . . . . . . . . . . . . . . . 23

2.5 .3 Exemplos de Leilões Virtuais . . . . . . . . . . . . . . . . . . 23

2.6 Considerações Finais . . . . . . . . . . . . . . . . . . . . 24

3 O Subprocesso de Criação de um Modelo do Domínio da Aplicação para Sistemas de Informação Baseados na Web 26

3.1 Considerações Iniciais . . . . . . . . . . . . . . . . . . . . 26

3.2 O Processo de Modelagem do Domínio Proposto: Contextualização . . . . . . . . 27

3.3 Criar um Modelo do Domínio da Aplicação . . . . . . . . . . . . . . . . . . . 29 
3.3.1 Escolher Três Sistemas do Domínio . . . . . . . . . . . . . . . . . . . . 29

3.3.2 Engenharia Reversa dos Sistemas-base . . . . . . . . . . . . . 31

3.3.3 Criação dos Modelos de Classes dos Sistemas-base . . . . . . . . . . . . . 39

3.3.4 Criação do Modelo do Domínio . . . . . . . . . . . . . . . . . . . 47

3.4 Criar uma Linguagem de Padrões a partir do Modelo de Classes de um Domínio . . 54

3.5 A Linguagem de Padrões para Leilões Virtuais . . . . . . . . . . . . . . . . . . . . 62

3.5.1 Exemplo de um Padrão da Linguagem de Padrões LV . . . . . . . . . . . . . 63

3.6 Exemplo de Uso da Linguagem de Padrões para Leilões Virtuais . . . . . . . . . . 66

3.7 Considerações Finais . . . . . . . . . . . . . . . . 73

4 O Subprocesso de Construção e o Framework Qd+

4.1 Considerações Iniciais . . . . . . . . . . . . . . . . . . . . 75

4.2 O Processo de Construção do Framework Qd+ . . . . . . . . . . . . . . . . . . . . 76

4.2.1 Identificação dos Pontos Variáveis . . . . . . . . . . . . . . . . 76

4.2.2 Projeto do Framework . . . . . . . . . . . . . . . . . . . 81

4.2.2.1 Arquitetura do Framework . . . . . . . . . . . . . . . 81

4.2.2.2 Projeto das Classes do Framework . . . . . . . . . . . . . . . . 84

4.2.3 Implementação do Framework . . . . . . . . . . . . . . . . . . . . . . . 86

4.2.3.1 Implementação das Classes da Aplicação . . . . . . . . . . . . . 86

4.2.3.2 Implementação das Classes de Interface com o Usuário . . . . . 88

4.2.3.3 Documentação do Framework . . . . . . . . . . . . . . . . . . . 90

4.2.4 Validação do Framework . . . . . . . . . . . . . . . . . . . . . . . . . . . 91

4.3 Exemplo de Instanciação do Framework . . . . . . . . . . . . . . . . . . . . . . . 92

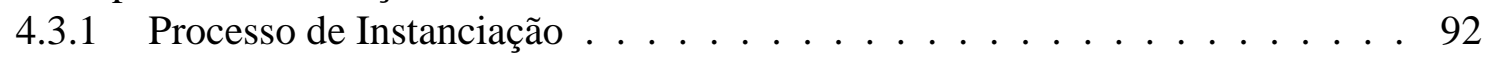

4.4 Considerações Finais . . . . . . . . . . . . . . . . . . . . 100

5 Conclusão $\quad 101$

5.1 Considerações Iniciais . . . . . . . . . . . . . . . . . . . . . . . . . . . . . . . . . . . . . . . . . .

5.2 Resultados e Contribuições . . . . . . . . . . . . . . . . . . . 101

5.3 Trabalhos Futuros . . . . . . . . . . . . . . . . . . . . 102

$\begin{array}{ll}\text { Referências } & 104\end{array}$

Apêndice A Linguagem de Padrões LV $\quad 110$

$\begin{array}{lll}\text { Apêndice B Lista de Pontos Variáveis } & 127\end{array}$

Apêndice C Hierarquia de classes do Framework Qd+ 130 


\section{Lista de Figuras}

2.1 Linguagem de Padrões para Gestão de Recursos de Negócios. . . . . . . . . . . . . . 11

2.2 Exemplo de um Padrão da Linguagem de Padrões GRN. . . . . . . . . . . . . . . 12

2.3 Arquitetura do Framework GREN. . . . . . . . . . . . . . . . . . . . . 17

2.4 Utilização de Leilões no Comércio Eletrônico. . . . . . . . . . . . . . . . . . . . . 20

2.5 Tipos de Leilões Segundo o Esquema de Reck. . . . . . . . . . . . . . . . . . . . 21

3.1 Alternativas para o Desenvolvimento de Sistemas de Informação Baseados na Web. 28

3.2 Processo de Criação do Modelo do Domínio da Aplicação de SIbWebs. . . . . . . . 30

3.3 Engenharia Reversa dos Sistemas-base. . . . . . . . . . . . . . . . . 31

3.4 Grafo de Navegação do Sistema-base Arremate.com. . . . . . . . . . . . . . . . 34

3.5 Página de Venda do Sistema-base Arremate.com. . . . . . . . . . . . . . . . . 37

3.6 Criação dos Modelos de Classe dos Sistemas-base. . . . . . . . . . . . . . . . . 40

3.7 Parte do Modelo Inicial de Classes do Sistema-base Arremate.com. . . . . . . . . . 45

3.8 Parte do Modelo de Classes Refinado do Sistema-base Arremate.com. . . . . . . . 46

3.9 Criação do Modelo do Domínio. . . . . . . . . . . . . . . . . . . . . . . 48

3.10 Criação de uma Linguagem de Padrões. . . . . . . . . . . . . . . . . . . . . 55

3.11 Modelo de Classes Contendo os Elementos que Compõem os Padrões da Linguagem. 57

3.12 Exemplo da Estrutura dos Padrões Habilitar Favoritos e Gerenciar a EMPRESA LEILOEIRA. . . . . . . . . . . . . . . . . . . . . . 58

3.13 Grafo de Fluxo de Aplicação dos Padrões da Linguagem de Padrões LV. . . . . . . 59

3.14 Exemplo da Aplicação dos Padrões 1 e 3 da Linguagem de Padrões LV. . . . . . . . 68

3.15 Exemplo da Aplicação dos Padrões 4,5 e 6 da Linguagem de Padrões LV. . . . . . 70

3.16 Exemplo da Aplicação dos Padrões 7,9 e 10 da Linguagem de Padrões LV. . . . . . 72

4.1 Abordagem para Construção e Instanciação de Frameworks. . . . . . . . . . . . . . 77

4.2 Processo para Construção de frameworks Baseado em Linguagem de Padrões. . . . 77

4.3 Arquitetura do Framework Qd+. . . . . . . . . . . . . . . . . . . . . . . . 83

4.4 Exemplo do Componente "Estrutura" do Padrão IDENTIFICAR O RECURSO. . . . . 85

4.5 Exemplo de Classes do Framework Qd+ que Representam o Padrão IDENTIFICAR o RECURSO. . . . . . . . . . . . . . . . . . . . . 85

4.6 Arquitetura Simplificada do Framework Qd+. . . . . . . . . . . . . . . . . . . . 87

4.7 Hierarquia de Classes do Modelo de Classes do Framework Qd+. . . . . . . . . . . 88 
4.8 Página de Registro de Novos Usuários do Sistema Referente a uma Instanciação do Framework Qd+. . . . . . . . . . . . . . . . . . . . . . . . . . . 90

4.9 Instanciação do padrão IdENTIFICAR o ReCURSO. . . . . . . . . . . . . . . . . 94

4.10 Parte dos Métodos e Atributos da classe UserForm. . . . . . . . . . . . . . . . 96

4.11 Página Principal do Sistema de Leilões Virtuais Instanciado. . . . . . . . . . . . . 97

4.12 Página de Login do Usuário. . . . . . . . . . . . . . . . . . . . . . . . . . 98

4.13 Página de Criação de um Leilão Normal. . . . . . . . . . . . . . . . . . . . . . . 99 


\section{Lista de Tabelas}

3.1 Atividades Básicas do Processo de Negociação por Intermédio de Leilões Virtuais. 32

3.2 Listagem de Páginas do Sistema-base Arremate.com. . . . . . . . . . . . . . . 33

3.3 Conjunto de Requisitos do Sistema-base Arremate.com. . . . . . . . . . . . . . . . 36

3.4 Exemplo de Glossário do Sistema-base Arremate.com. . . . . . . . . . . . . . . . 39

3.5 Listagem de Potenciais Classes do Sistema-base Arremate.com. . . . . . . . . . . . 41

3.6 Decisões de Análise/Projeto Referentes aos Requisitos do Sistema-base Arremate.com. . . . . . . . . . . . . . . . . . . 43

3.7 Parte da Listagem de Classe X Sistema. . . . . . . . . . . . . . . . . . . 52

4.1 Lista Parcial dos pontos variáveis do Framework Qd+ . . . . . . . . . . . . . . . . 79

4.2 Lista Parcial do Histórico de Aplicação dos Padrões da Linguagem de Padrões LV ao iBazar. . . . . . . . . . . . . . . . . . . . . . . 92

4.3 Lista Parcial dos Atributos da Instanciação do iBazar. . . . . . . . . . . . . . . 93 


\section{Lista de Quadros}

3.1 Partes dos Glossários do Domínio e dos Sistemas-base. . . . . . . . . . . . . . . 51

3.2 Exemplo de Descrição Geral do Padrão Gerenciar Empresa Leiloeira. . . . 59

3.3 Parte da Descrição do Participante Taxa. . . . . . . . . . . . . . . . . . . 60

3.4 Componente "Próximos Padrões" do Padrão Gerenciar Reputações. . . . . . 60

3.5 Parte dos Requisitos do Sistema de Leilões Virtuais iBazar. . . . . . . . . . . . . . 68

4.1 Parte da Descrição do Participante Categoria. . . . . . . . . . . . . . . . . . . 79

4.2 Parte do Componente "Variantes" do Padrão IdentifiCAR o RECURSO. . . . . . . 80

4.3 Exemplo da Hierarquia de Parte de uma Instanciação. . . . . . . . . . . . . . . . . 89

4.4 Exemplo com Parte do Código do Arquivo "UserForm.ssp". . . . . . . . . . . . . 91

4.5 Hierarquia da classe Product na Instanciação. . . . . . . . . . . . . . . . . . . 93

4.6 Exemplo com Código Fonte Parcial de Alguns Scripts dos Objetos Persistentes. . . 95 
Um processo para o desenvolvimento de frameworks para sistemas de informação baseados na Web é proposto. Esse processo é composto pelos subprocessos de engenharia reversa de sistemas baseados na Web, de criação de uma linguagem de padrões e de construção e instanciação do framework. O subprocesso de engenharia reversa utiliza sistemas presentes na Web para derivar um modelo do domínio de aplicação. O desenvolvimento da linguagem de padrões é baseado no modelo do domínio e a construção do framework utiliza essa linguagem de padrões como base de todo o processo. Os produtos resultantes do uso desse processo para o domínio dos leilões virtuais, a Linguagem de Padrões LV e o Framework Qd+, também são apresentados. 
A process for the development of web-based information systems frameworks is proposed. This process comprises a reverse engineering - for webbased information systems -, a pattern language creation, and a framework instantiation subprocesses. The reverse engineering subprocess uses existing WISs to derive an application domain model. The pattern language is created from the application domain model and the framework is developed from this pattern language. The deliverables of the application of this process to the online auctions domain, the Pattern Language for Online Auctions and the Qd+ Framework, are also presented. 


\subsection{Contextualização}

A abordagem de desenvolvimento de software orientado a objetos enfatiza o reuso de software. Com essa perspectiva, padrões de software (Boyd, 1998; Coad, 1992; Coad et al., 1997; Coplien e Schmidt, 1995; Fowler, 1997; Gamma et al., 1994; Martin et al., 1998; Vlissides et al., 1996) vêm sendo coletados e propostos na última década como uma forma promissora de reuso, não somente de código mas também de projeto, análise, arquitetura e processo de desenvolvimento. Por intermédio dos padrões podem ser documentadas soluções para diferentes tipos de problemas que ocorrem ao longo do processo de desenvolvimento de software. Essas soluções, quaisquer que sejam seus níveis de abstração, podem ser reusadas por outros desenvolvedores ao confrontarem-se com problemas similares.

Uma linguagem de padrões é um sistema de padrões organizado em uma estrutura que guia sua aplicação (Kerth e Cunningham, 1997). É também uma coleção estruturada de padrões que se apóiam uns nos outros para transformar requisitos e restrições numa arquitetura (Coplien, 1998). Os padrões que constituem uma linguagem de padrões cobrem todos os aspectos importantes de um dado domínio.

Framework é um conjunto de classes abstratas e concretas que fornece uma infra-estrutura genérica de soluções para um conjunto de problemas (Johnson e Foote, 1998). Essas classes podem fazer parte de uma biblioteca de classes ou podem ser específicas de um certo domínio de aplica- 
ção. Frameworks possibilitam reutilizar não somente componentes isolados, mas também toda a arquitetura de um domínio específico.

Essas três tecnologias - padrões de projeto, linguagens de padrões e frameworks - são base sobre a qual este trabalho está assentado. As três são incorporadas em um processo para construção de frameworks a partir da engenharia reversa de sistemas de informação baseados na Web.

\subsection{Motivação}

Como parte das pesquisas do grupo de engenharia de software do ICMC existe um grande interesse em estudar a relação e aplicação de linguagens de padrões e frameworks em sistemas de informação, bem como desenvolver técnicas que apóiem o desenvolvimento dessas linguagens de padrões e frameworks. Visando a fornecer subsídios para a aplicação de linguagens de padrões e a utilização de frameworks, dentre outros trabalhos envolvendo frameworks e linguagens de padrões (Braga et al., 1998, 1999; Braga e Masiero, 2000, 2002a), Braga e Masiero (2002b) propõem um processo para a criação de frameworks com base em uma linguagem de padrões. O processo utiliza o conhecimento sobre um determinado domínio existente na linguagem de padrões para o desenvolvimento de frameworks. Utilizando esse processo o grupo que pesquisa padrões de software e frameworks no ICMC/USP (Instituto de Ciências Matemáticas e de Computação - Universidade de São Paulo) propôs uma Linguagem de Padrões para Gestão de Recursos de Negócios (Linguagem de Padrões GRN) (Braga et al., 1999). Com base nessa linguagem de padrões foi desenvolvido um framework para Gestão de REcursos de Negócios (GREN) com o objetivo de apoiar as aplicações que a linguagem de padrões abrange. Nesse contexto, torna-se importante complementar esse processo proposto fornecendo subsídios para a aprendizagem sobre domínios de aplicação de sistemas de informação e a criação de linguagens de padrões que apóiem o desenvolvimento desses sistemas.

Com o crescimento da utilização da Internet como meio de comercialização também torna-se importante o desenvolvimento de frameworks que apóiem sistemas de informação que utilizam essa tecnologia, os sistemas de informação baseados na Web (Web-based Information Systems). Dentre as várias formas de comercialização pela Internet existem os leilões virtuais, que são um tipo alternativo de comercialização com vários motivos para serem utilizados, dentre os quais a capacidade de aumentar o público consumidor e oferecer produtos a um baixo preço. Esse tipo alternativo de comercialização, os leilões, se integra e complementa o Framework GREN.

Adicionalmente, com a forte tendência em utilizar a interface Web para todos os sistemas de informação é relevante estender a Linguagem de Padrões GRN e o Framework GREN para apoiar o desenvolvimento de sistemas de informação baseados na Web. 


\subsection{Objetivos}

Este trabalho tem como objetivo propor um processo para construção de frameworks de sistemas de informação baseados na Web. Utiliza-se como base o processo de construção e instanciação de frameworks proposto por Braga e Masiero (2002b), com uma adaptação e uma extensão. Neste trabalho, o subprocesso de criação da linguagem de padrões é estendido e detalhado e o subprocesso de modelagem do domínio da aplicação é adaptado para ser baseado em requisitos recuperados por um processo de engenharia reversa de sistemas baseados na Web.

Usa-se como exemplo para ilustrar o processo proposto, o domínio dos leilões virtuais na Web e para esse domínio são criados uma linguagem de padrões e um framework. A linguagem de padrões resultante da aplicação do processo proposto pode ser considerada uma extensão da Linguagem de Padrões GRN, complementando-a com uma forma alternativa de comercialização. Analogamente, o framework obtido por meio da aplicação do processo apresentado por Braga e Masiero (2002b) é desenvolvido de forma a poder ser, futuramente, integrado ao Framework GREN, dotando-o de uma interface Web.

\subsection{Organização da Dissertação}

O Capítulo 2 apresenta os conceitos de padrões, de frameworks e uma breve introdução aos sistemas de informação baseados na Web, inclusive os leilões virtuais. O Capítulo 3 apresenta o subprocesso de criação de um modelo do domínio da aplicação para sistemas de informação baseados na Web e o de criação de uma linguagem de padrões. Ainda nesse capítulo é apresentada a linguagem de padrões para gestão de leilões virtuais, resultado da aplicação dos dois subprocessos propostos. Apresenta-se no Capítulo 4 o subprocesso de construção do frameworks que baseia-se em uma linguagem de padrões, no caso específico a Linguagem de Padrões LV, como proposto por Braga e Masiero (2002b). Nesse capítulo é apresentado também, o subprocesso de instanciação do frameworks que, da mesma forma que o subprocesso de construção, baseia-se na Linguagem de Padrões LV. Finalizando, o Capítulo 5 apresenta as conclusões do trabalho e sugestões de trabalhos futuros. 


\subsection{Considerações Iniciais}

Linguagens de padrões e frameworks têm sido utilizados como uma forma de reuso não somente de código mas de análise e projeto. Existe um relacionamento próximo entre linguagens de padrões e frameworks que torna benéfica sua utilização conjunta no desenvolvimento de software. Neste capítulo são apresentados conceitos relativos a ambos para que se possa entender a Linguagem de Padrões GRN e o Framework GREN e as vantagens de utilizá-los em gestão de recursos de negócio. Visando a complementar o Framework GREN e, futuramente, estendê-lo, foi utilizado neste trabalho o domínio dos leilões virtuais. Os leilões virtuais são um bom exemplo de Sistemas de Informação baseados na Web (SIbWebs), pois podem atingir um público consumidor maior que aplicações cliente/servidor tradicionais e são uma forma alternativa de comercialização de recursos adequada quando outras formas convencionais não são aplicáveis.

A Seção 2.2 apresenta conceitos sobre padrões e linguagens de padrões, juntamente com alguns exemplos de linguagens de padrões e suas aplicações. Ainda nessa seção é mostrado com um pouco mais de detalhes a Linguagem de Padrões para a Gestão de Recursos de Negócios. Na Seção 2.3 são discutidos de forma sucinta alguns aspectos e características dos frameworks, bem como alguns exemplos, entre os quais o Framework GREN. Apresenta-se na Seção 2.4 uma introdução aos SIbWebs. Finalizando o capítulo, a Seção 2.5 apresenta uma introdução sobre os leilões virtuais e suas características e alguns exemplos de leilões virtuais em funcionamento na Web. 


\subsection{Padrões de Software e Linguagens de Padrões}

O reuso de software é um objetivo comum nas organizações produtoras de software, devido à necessidade de melhorar a produtividade, a manutenibilidade e a qualidade tanto do software como do processo de desenvolvimento. Programadores experientes reusam seus projetos, mas o problema central do reuso de informações de projeto é como capturá-lo e expressá-lo (Biggerstaf e Richter, 1987). Padrões de software vêm tendo destaque em reuso de software em vários níveis de abstração, não somente de código mas também de projeto, análise, arquitetura e processo de desenvolvimento. Padrões de software permitem que sejam evidenciadas características comuns que podem ser reusadas em novos projetos e aplicações.

A origem dos padrões vem do trabalho do arquiteto Christopher Alexander no fim da década de 1970. Dentre seus trabalhos destacam-se os livros A Pattern Language: Towns, Buildings, Construction (Alexander et al., 1977) e The Timeless Way of Building (Alexander, 1979) que exemplificam e apresentam seu método de documentação de padrões. Apesar do trabalho de Alexander ser voltado para a arquitetura, possui fundamentação básica que pode ser abstraída para várias áreas, incluindo o processo de desenvolvimento de software.

Padrões de software descrevem o desenvolvimento de soluções que obtiveram sucesso em problemas que ocorrem recorrentemente em certos contextos. Pode-se descrever padrões como um esquema que é composto por contexto, problema e solução. O contexto é a situação que dá origem a um problema, que por sua vez ocorre recorrentemente nesse contexto. A solução é uma maneira comprovada e consistente de resolver o problema. O padrão tenta obter a essência do problema e tornar-se a solução do problema, podendo ser aplicado a novos contextos. Essa forma é importante porque permite a definição de padrões como "uma solução para um problema em contexto", uma definição que fixa seus limites como um simples par problema-solução (Buschmann et al., 1996). No entanto, um padrão é mais que apenas uma solução comprovada para um problema recorrente. O problema ocorre em um certo contexto e com a influência de diversos fatores. A solução proposta deve apresentar uma estrutura que equilibre esses fatores ou "forças".

Projetistas familiarizados com certos padrões podem aplicá-los imediatamente a problemas sem ter que redescobri-los (Gamma et al., 1994). Além disso, desenvolvedores passam a utilizar uma linguagem própria de comunicação baseada em padrões que facilita a comunicação de equipes de desenvolvimento, por fornecer uma mesma "linguagem" ou vocabulário comum (Schmidt et al., 1996). Pode-se observar que padrões não apenas identificam soluções mas também explicam porque as soluções são necessárias (Appleton, 1997). 


\subsubsection{Componentes de um Padrão}

Um padrão fornece a possibilidade de reuso de "experiência", já que é uma solução comprovada. Geralmente não são expressos em uma linguagem de programação específica e para que possam ser utilizados de maneira eficiente devem ser documentados de forma a proporcionar uma recuperação fácil e rápida. Se o padrão não for apresentado claramente, o desenvolvedor não irá utiliza-lo pelo simples fato de não saber que existe uma solução que seja adequada. Visando a resolver tal problema existem diversos padrões sobre padrões (patterns on patterns), que fornecem as diretrizes necessárias para uma boa documentação de padrões. Porém, existem componentes essenciais que, segundo Appleton (1997) devem ser claramente identificáveis ao ler-se um padrão:

- nome: todo padrão deve possuir um nome significativo. Pode ser uma simples palavra ou uma frase curta que faça referência ao padrão e conhecimento ou estrutura descritos por ele. Se o padrão possuir mais que um nome comumente usado ou reconhecível na literatura, subseções "conhecido como" ou "nome alternativo" devem ser criadas;

- problema: estabelece o problema a ser resolvido pelo padrão, descreve a intenção e objetivos do padrão perante o contexto e as forças específicas;

- contexto: precondições dentro das quais o problema e sua solução costumam ocorrer e para as quais a solução é desejável, o que reflete a aplicabilidade do padrão. Pode também ser considerado como a configuração inicial do sistema antes da aplicação do padrão;

- forças: descrição dos impactos, influências relevantes para o problema e como eles interagem ou são conflitantes entre si e com os objetivos a alcançar. Um cenário que serve como motivação para o padrão;

- solução: relacionamentos estáticos e regras dinâmicas que descrevem como obter o resultado desejado. Equivale a dar instruções que descrevem como o problema é resolvido, podendo para isso utilizar texto, diagramas e figuras. São possíveis as seguintes subseções:

- estrutura: revela a forma e a organização estática;

- participantes: descreve os componentes do padrão;

- dinâmica: exibe o comportamento dinâmico do padrão;

- implementação: mostra detalhes de implementação;

- variantes: apresenta possíveis variações e especializações da solução;

- exemplos: uma ou mais aplicações do padrão que ilustram, num contexto inicial específico, como o padrão é aplicado e transforma aquele contexto em um contexto final;

- contexto resultante: o estado ou configuração do sistema após a aplicação do padrão, podendo ter uma subseção "conseqüências", que podem ser boas ou ruins. Descreve as póscondições e os efeitos colaterais do uso do padrão; 
- justificativa: uma explicação das regras ou passos do padrão que mostra como e porque ele trata suas influências contrárias, definidas em "forças", para alcançar os objetivos, princípios e filosofia propostos. Mostra como o padrão funciona, porquê funciona e porquê ele é útil;

- padrões relacionados: os relacionamentos estáticos e dinâmicos desse padrão com outros dentro da mesma linguagem ou sistema de padrões. Padrões relacionados geralmente compartilham as mesmas influências. São possíveis os seguintes tipos de padrões relacionados:

- padrões predecessores: cuja aplicação conduza ao padrão atual;

- padrões sucessores: que devem ser aplicados após o padrão atual;

- padrões alternativos: que descrevem uma solução diferente para o mesmo problema mas diante de influências e restrições diferentes; e

- padrões co-dependentes: que podem, ou devem, ser aplicados simultaneamente com o padrão atual; e

- usos conhecidos: descreve ocorrências conhecidas do padrão e sua aplicação em sistemas existentes. Isso ajuda a validar o padrão, mostrando que ele é realmente uma solução provada para um problema recorrente.

\subsubsection{Classificação de Padrões}

Conforme mencionado na Seção 2.2, padrões de software abrangem diferentes níveis de abstração e, portanto, podem ser classificados em diversas categorias, de modo a facilitar sua recuperação e uso. Porém, essa classificação não é rigorosa, podendo haver padrões que se encaixem em mais do que uma categoria. A seguir algumas categorias importantes são apresentadas, porém existem outras categorias de padrões que são discutidas por Coplien e Schmidt (1995), Vlissides et al. (1996) e Martin et al. (1998):

- padrões de processo: definem soluções para os problemas encontrados nos processos envolvidos na engenharia de software, por exemplo: desenvolvimento, controle de configuração, testes, etc;

- padrões arquiteturais: expressam o esquema ou organização estrutural fundamental de sistemas de software ou hardware;

- padrões de análise: descrevem soluções para problemas de análise de sistemas, embutindo conhecimento sobre o domínio de aplicação específico;

- padrões de projeto: definem soluções para problemas de projeto de software;

- padrões de interface: definem soluções para problemas comuns no projeto da interface de sistemas. É um caso particular dos padrões de projeto; 
- padrões de programação: descrevem soluções de programação particulares de uma determinada linguagem ou regras gerais de estilo de programação;

- padrões de persistência: descrevem soluções para problemas de armazenamento de informações em arquivos ou bancos de dados;

- padrões para hipertexto: descrevem soluções para problemas encontrados no projeto de hipertextos;

- padrões para hipermídia: descrevem soluções para problemas encontrados no desenvolvimento de aplicações hipermídia; e

- padrões sobre padrões: descrevem como um padrão deve ser escrito, ou seja, que padronizam a forma como os padrões são apresentados aos seus usuários;

Comparando-se as várias categorias de padrões, os padrões de projeto são os padrões que mais recebem atenção na comunidade de software, talvez pelo fato do livro de Gamma et al. (1994) ter feito com que padrões fossem utilizados no desenvolvimento de software e, portanto, tornaremse um marco referencial na utilização de padrões para esse fim. No entanto, o termo "padrão de projeto" tem sido utilizado para denominar qualquer padrão que trate de arquitetura de software, projeto ou implementação. Buschmann et al. (1996) propõe a classificação das várias categorias de padrões em três níveis:

- padrões arquiteturais: expressam uma organização estrutural fundamental para sistemas de software. Fornecem um conjunto predefinido de subsistemas, especificando suas responsabilidades e incluindo regras e diretrizes para organizar o relacionamento entre eles;

- padrões de projeto: fornecem um esquema para refinar subsistemas ou componentes de um sistema de software ou relacionamento entre eles, que descrevem a estrutura de comunicação dos componentes; e

- idiomas: são padrões de baixo nível para linguagens de programação específicas, que descrevem como implementar aspectos particulares de componentes ou relacionamentos entre eles utilizando características da linguagem.

\subsubsection{Linguagens de Padrões}

Uma linguagem de padrões (pattern language) é uma coleção estruturada de padrões que se apóiam uns nos outros para transformar requisitos e restrições numa arquitetura (Coplien, 1998). Os padrões que constituem uma linguagem de padrões cobrem todos os aspectos importantes de um dado domínio. Pelo menos um padrão deve estar disponível para cada aspecto da construção e implementação de um sistema de software: não pode haver "vazios" ou "brancos". 
Diferentemente de catálogos ou coleções de padrões, uma linguagem de padrões inclui regras e diretrizes que explicam como e quando aplicar seus padrões para resolver um problema que, geralmente, um padrão não resolverá sozinho. Uma linguagem de padrões é uma forma de subdividir um problema geral e sua solução complexa em um número de problemas relacionados e suas respectivas soluções. Cada padrão da linguagem resolve um problema específico no contexto comum compartilhado pela linguagem (Appleton, 1997; Schmidt et al., 1996). É importante notar que cada padrão pode ser usado separadamente ou com um certo número de padrões da linguagem. Isso significa que um único padrão é considerado útil mesmo se a linguagem não for usada em sua plenitude.

\subsubsection{Exemplos de Linguagens de Padrões}

Aarsten et al. (1995) propuseram uma linguagem de padrões para manufatura integrada ao computador denominada $\mathrm{G}++$. O problema abordado por essa linguagem é o projeto de sistemas de informação concorrentes e provavelmente distribuídos, com aplicações na manufatura integrada ao computador. O objetivo do trabalho é aumentar o reuso de projeto orientado a objetos desde o nível de componentes até o nível arquitetural, oferecendo um modelo conceitual para arquiteturas concorrentes e distribuídas.

Cunningham (1995) apresenta uma linguagem de padrões chamada "The CHECKS Pattern Language of Information Integrity", que mostra como fazer checagem nas entradas de dados para separar dados inválidos de dados válidos e assegurar que o menor número possível de dados inválidos seja registrado. O objetivo é fazer essa checagem sem complicar os programas e comprometer a flexibilidade futura.

Kerth (1995) propõe uma linguagem de padrões chamada "Caterpillar's Fate: A Pattern Language for Transformation from Analysis to Design". Ela é usada para apoiar a transformação dos documentos de análise em um projeto inicial de software. O nome da linguagem ("destino da lagarta”) vem da analogia que é feita entre a transição da análise para o projeto com a lagarta que se transforma em uma borboleta. A linguagem tenta captar a experiência adquirida durante o desenvolvimento de soluções de projeto a partir de modelos de análise, documentando o que deve ser feito durante a transição.

Também existem várias outras linguagens de padrões como, por exemplo, "A Pattern Language for Tool Construction and Integration Based on the Tools and Materials Metaphor" (Riehle e Zullighoven, 1995), "EPISODES: A Pattern Language of Competitive Development" (Cunningham, 1996), "Evolving Frameworks - A Pattern Language for developing object-oriented frameworks" (Roberts e Johnson, 1998), "A Pattern Language for Pattern Writing” (Meszaros, 1998), "A Pattern Language for Developing Form Style Windows" (Bradac e Fletcher, 1998), “A Pattern Language of Transport Systems (Point and Route)" (Zhao e Foster, 1998). Pode-se notar que essas lingua- 
gens de padrões possuem diferentes níveis de abstração e estão distribuídas segundo as várias classificações apresentadas na Seção 2.2.2.

\subsubsection{A Linguagem de Padrões para Gestão de Recursos de Negócio}

A Linguagem de Padrões para Gestão de Recursos de Negócios (Gestão de REcursos de Negócio) é o resultado de uma evolução de mais de dez anos de prática no desenvolvimento de sistemas para pequenas e médias empresas no domínio de gestão de recursos de negócios (Braga et al., 1998, 1999). É formada por quinze padrões de análise, alguns dos quais são aplicações ou extensões de padrões recorrentes propostos na literatura. Ela oferece a desenvolvedores inexperientes material substancial para desenvolvimento de novos sistemas, juntamente com soluções alternativas, quando necessário. A linguagem de padrões foi concebida para auxiliar os engenheiros de software a desenvolver aplicações que lidem com gestão de recursos de negócios, ou seja, nas quais seja necessário registrar transações de aluguel, comércio ou manutenção de recursos. Uma transação é um evento relevante que deve ser lembrado ao longo do tempo (Coad et al., 1997). O aluguel de recursos enfoca principalmente a utilização temporária de um bem ou serviço, como por exemplo uma fita de vídeo ou o tempo de um especialista. O comércio de recursos enfoca a transferência de propriedade de um bem, como por exemplo uma venda ou leilão de produtos. A manutenção de recursos enfoca a manutenção de um determinado produto, utilizando mão-de-obra e peças para execução, como é o exemplo de uma oficina de reparo de eletrodomésticos. A Figura 2.1 contém um diagrama que mostra as dependências entre os padrões da Linguagem de Padrões GRN e a ordem na qual eles são geralmente aplicados. Essas dependências são também apresentadas e, eventualmente, complementadas, em um elemento específico de cada padrão, o elemento "Próximos Padrões". Os principais padrões da linguagem são indicados por uma linha mais espessa. São eles: LocAr o Recurso, COMERCIALIZAR o RECURSO e MANTER O RECURSO.

Os padrões estão agrupados de acordo com seu propósito, como pode ser visto na Figura 2.1. O grupo 1 possui três padrões: IDENTIFICAR O RECURSO, QUANTIFICAR O RECURSO e ARMAZENAR O RECURSO, que dizem respeito à identificação e possível qualificação, quantificação e armazenagem dos recursos gerenciados pelo negócio. O grupo 2 contém os padrões relacionados à manipulação dos recursos de negócio pelo sistema. Existem sete padrões nesse grupo: LOCAR O Recurso, Reservar o Recurso, Comercializar o Recurso, Cotar o Recurso, ConFerir a Entrega do Recurso, Manter o Recurso e Cotar a Manutenção. O grupo 3 contém cinco padrões que cuidam de detalhes das transações efetuadas com o recurso. Os três primeiros, Itemizar TransaÇão do Recurso, PAGAR PEla TransaÇÃo do RECURSo e IDENTIFICAR O EXECUTOR DA TRANSAÇÃO, são aplicáveis a quaisquer das transações do grupo 2. Os dois últimos, IDENTIFICAR AS TAREFAS DA MANUTENÇÃO e IDENTIFICAR AS PEÇAS 


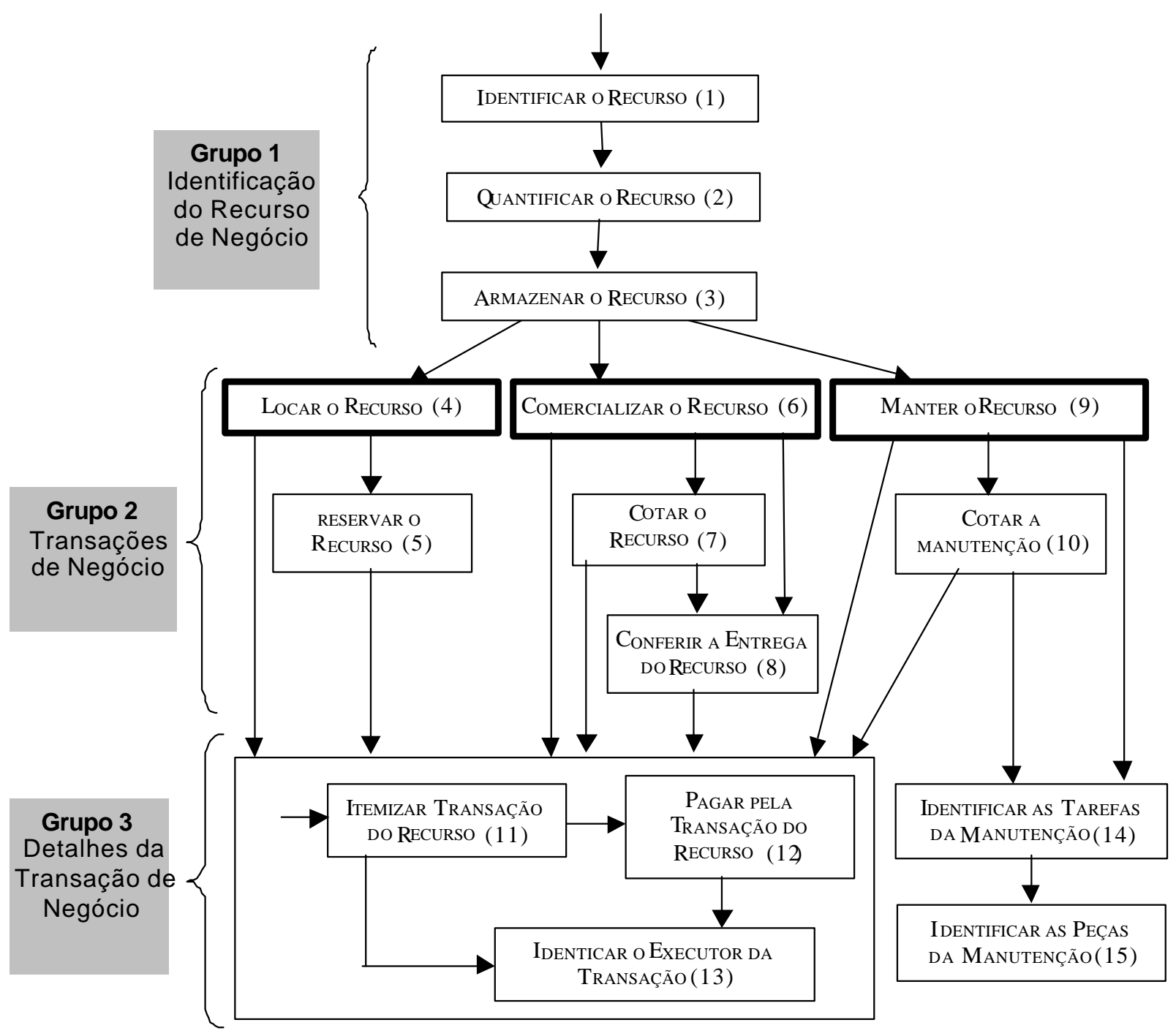

Figura 2.1: Linguagem de Padrões para Gestão de Recursos de Negócios.

DA MANUTENÇÃO, são aplicáveis às transações contidas nos padrões MANTER O RECURSO e COTAR A MANUTENÇÃO.

A Figura 2.2 apresenta parte do padrão QUANTIFICAR O RECURSO extraído da Linguagem de Padrões GRN. Pode-se observar que esse padrão possui quatro alternativas de solução, dependendo de como o recurso do negócio é quantificado. Esse padrão faz parte do grupo 1, mencionado anteriormente.

O resultado da utilização da Linguagem de Padrões GRN é o diagrama de classes para uma aplicação específica, composto de classes, relacionamentos, atributos e métodos. Esse diagrama pode ser utilizado como documento de análise, podendo ser refinado na etapa subseqüente de projeto do sistema. 


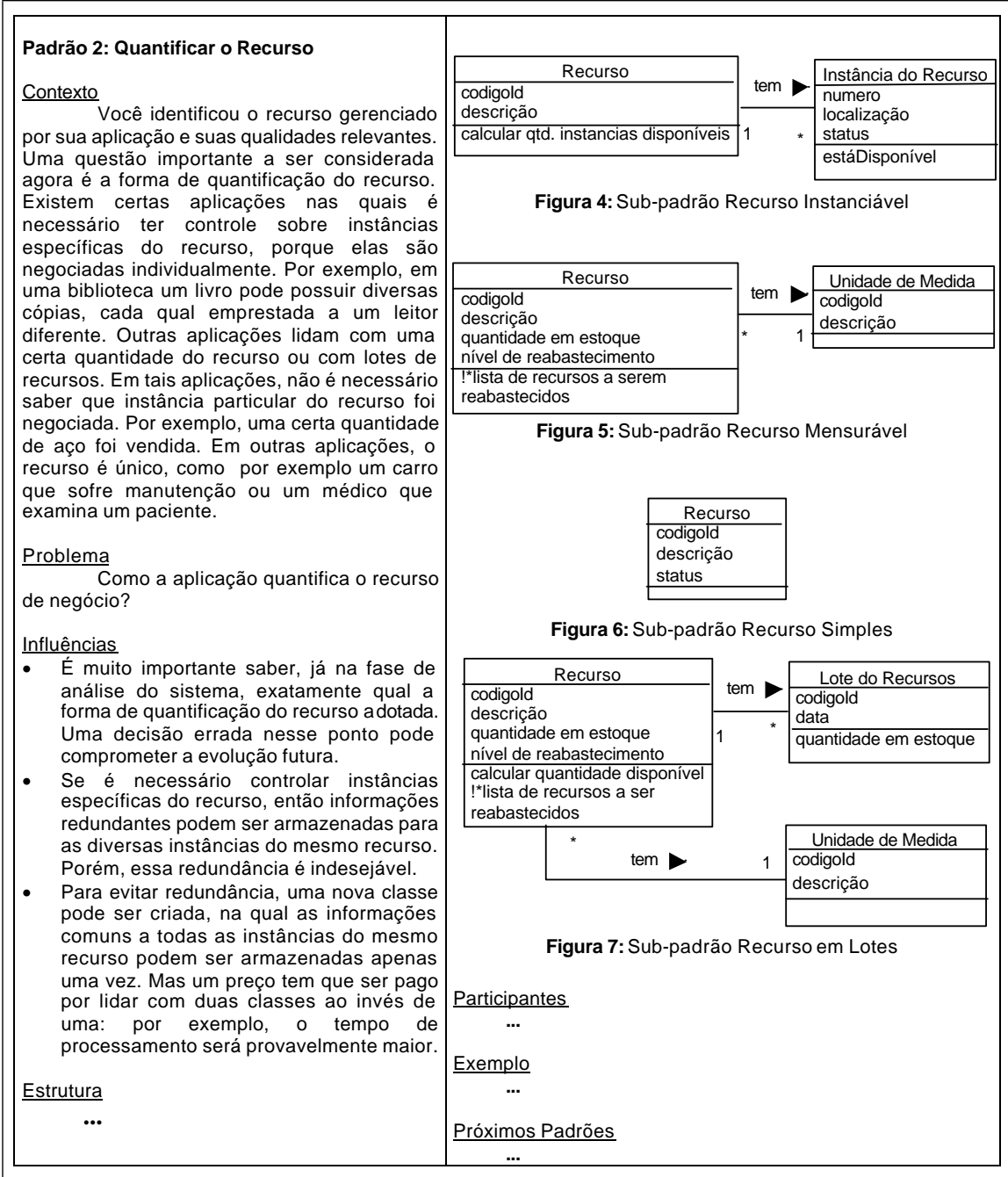

Figura 2.2: Exemplo de um Padrão da Linguagem de Padrões GRN.

\subsection{Frameworks}

No início da década de 1980, paralelamente às bibliotecas de classes, começaram a ser construídos frameworks de aplicação, que acrescentam às bibliotecas de classes os relacionamentos e interações entre as diversas classes que compõem o framework. Essas classes podem fazer parte de uma biblioteca de classes ou podem ser específicas da aplicação. Frameworks possibilitam reutilizar não somente componentes isolados, mas também toda a arquitetura de um domínio específico. Segundo Fayad e Schmidt (1997) as características de um framework que proporcionam benefícios aos desenvolvedores são:

- modularidade: melhoram a modularidade por encapsular os detalhes da implementação visível apenas pela interface. Melhoram a qualidade do software por localizar o impacto das alterações tanto no projeto como na implementação, reduzindo o esforço de manutenção; 
- reusabilidade: as interfaces proporcionam aos frameworks aumento de reusabilidade por definir componentes genéricos que podem ser reutilizados para criar novas aplicações;

- extensibilidade: proporciona extensibilidade devido aos métodos adaptáveis (hook methods) que permitem a extensão das interfaces; e

- inversão de controle: os métodos definidos pelo usuário para especializar o framework são chamados dentro do próprio framework, ao invés de serem chamados do código de aplicação do usuário. O framework geralmente faz o papel de programa principal, coordenando e seqüenciando as atividades da aplicação.

Um framework reusa análise, projeto e código. Ele reusa análise porque descreve os tipos de objetos importantes e como um problema maior pode ser dividido em problemas menores. Ele reusa projeto porque contém algoritmos abstratos e descreve a interface que o programador deve implementar e as restrições a serem satisfeitas pela implementação. Ele reusa código porque torna mais fácil desenvolver uma biblioteca de componentes compatíveis e porque a implementação de novos componentes pode herdar grande parte de seu código das super-classes abstratas. Apesar de todos esses tipos de reuso serem importantes, os reusos de análise e de projeto são os que mais compensam a longo prazo (Johnson, 1997; Johnson e Russo, 1991).

\subsubsection{Classificação dos Frameworks}

Os frameworks podem ser classificados, segundo seu escopo, em três grupos (Fayad e Schmidt, 1997; Fayad et al., 1999): frameworks de infra-estrutura do sistema, frameworks de integração middleware e frameworks de aplicação.

Os frameworks de infra-estrutura do sistema simplificam o desenvolvimento da infra-estrutura de sistemas portáveis e eficientes, como por exemplo, sistemas operacionais, sistemas de comunicação, interfaces com o usuário e ferramentas de processamento de linguagem. Em geral são usados internamente em uma organização de software e não são vendidos diretamente a clientes.

Os frameworks de integração middleware são usados, em geral, para integrar aplicações e componentes distribuídos. Eles são projetados para melhorar a habilidade de desenvolvedores em modularizar, reutilizar e estender sua infra-estrutura de software para funcionar em um ambiente distribuído.

Os frameworks de aplicação estão voltados para domínios de aplicação mais amplos e são a pedra fundamental para atividades de negócios das empresas, como por exemplo sistemas de telecomunicações, aviação, manufatura e engenharia financeira. Frameworks dessa classe são mais caros para desenvolver ou comprar, mas podem dar um retorno substancial do investimento, já que permitem o desenvolvimento de aplicações e de produtos diretamente (Fayad et al., 1999; Fayad e Johnson, 2000). 


\subsubsection{Frameworks "Caixa Branca" e Frameworks "Caixa Preta"}

Desconsiderando o escopo dos frameworks, eles também podem ser classificados pelas técnicas utilizadas para estendê-los, que permitem estender continuamente de um framework caixa branca até um framework caixa preta (Fayad e Schmidt, 1997; Johnson e Foote, 1998). O comportamento específico de um framework de aplicação é geralmente definido adicionando-se métodos às subclasses de uma ou mais de suas classes.

No framework caixa branca o reuso é provido por herança, ou seja, o usuário deve criar subclasses das classes abstratas contidas no framework para criar aplicações específicas. Para tal, ele deve entender detalhes de como o framework funciona para poder usá-lo. As aplicações instanciadas freqüentemente requerem a criação de muitas subclasses novas, dificultando a aprendizagem do projeto da aplicação. Dessa forma, aprender a usá-lo é o mesmo que aprender a como construi-lo (Johnson e Foote, 1998). Já no framework caixa preta o reuso é por composição, ou seja, o usuário combina diversas classes concretas existentes no framework para obter a aplicação desejada. Assim, ele deve entender apenas a interface para poder usá-lo.

Um aspecto variável de um domínio de aplicação é chamado de ponto de especialização ou ponto variável ou parte variável (Buschmann et al., 1996). Diferentes aplicações dentro de um mesmo domínio são distinguidas por um ou mais pontos variáveis. Os pontos variáveis são projetados para serem genéricos, podendo ser adaptados às necessidades da aplicação. Pontos Fixos ou partes fixas definem a arquitetura geral de um sistema de software (seus componentes básicos e os relacionamentos entre eles). Os pontos fixos permanecem sem mudar em todas as instanciações do framework de aplicação.

Resumindo, um framework caixa branca é mais fácil de projetar, pois não há necessidade de prever todas as alternativas de implementação possíveis. Já o framework caixa preta é mais difícil de projetar por haver a necessidade de fazer essa previsão. Em contrapartida, o framework caixa preta é mais fácil de usar, pois basta escolher a implementação desejada, enquanto no caixa branca é necessário completar a implementação.

Frameworks caixa branca podem evoluir para se tornar cada vez mais caixa preta (Johnson, 1997). Isso pode ser conseguido de forma gradativa, implementando-se várias alternativas que depois são aproveitadas em instanciações do framework. Ao mesmo tempo não se fecha totalmente o framework, permitindo ao usuário continuar usando-o como caixa branca. Após um certo tempo, estarão disponíveis diversas alternativas e então pode-se decidir tornar o framework caixa preta de fato. Pode-se também construir ferramentas de apoio que ajudem a especificar as aplicações. Essas ferramentas têm como objetivo facilitar a instanciação do framework, usando-se componentes visuais que facilitam o trabalho do usuário. 


\subsubsection{Documentação de Frameworks}

Um framework é um projeto reusável de um programa ou parte de um programa que é expresso como um conjunto de classes. Frameworks são projetos reusáveis e não apenas código, são mais complexos de desenvolver do que softwares, tornando sua documentação mais difícil.

A documentação de um framework deve atender a diversos requisitos. Estes requisitos podem ser alcançados estruturando a documentação como um conjunto de padrões ou uma linguagem de padrões. O principal propósito desse conjunto de padrões é mostrar como utilizar um framework, não apenas mostrar como ele funciona. Padrões podem descrever o propósito de um framework, podem permitir a programadores utilizar um framework sem ter a necessidade de conhecer os detalhes de seu funcionamento e podem mostrar muitos detalhes de projeto que estão incorporados em um framework.

Geralmente a documentação dos frameworks descreve primeiramente como um framework trabalha e em seguida como utilizá-lo. No entanto, não é possível entender completamente um framework até que ele tenha sido usado efetivamente. Exemplos são um bom modo de comprovar se a utilização foi ou não entendida corretamente pelo usuário, além de tornar os frameworks mais completos e facilitarem o entendimento do fluxo de controle (Johnson, 1992).

Padrões podem ser empregados tanto para projeto de um framework como documentação de um framework, pois possuem um certo relacionamento (Brugali e Sycara, 2000; Johnson, 1992, 1997). Um framework engloba diversos padrões, podendo ser visualizado como a implementação de um sistema ou linguagem de padrões. Apesar de serem relacionados dessa maneira, é importante reconhecer que frameworks e padrões de projeto são elementos distintos.

\subsubsection{Exemplos de Frameworks}

A maioria dos frameworks existentes aplica-se a domínios técnicos (ou básicos), tais como interfaces com o usuário ou distribuição, como por exemplo os frameworks MacApp, específicos para aplicações Macintosh, o Lisa Toolkit, o Interviews e o Smalltalk Model-View-Controller. O Model-View-Controller foi o primeiro framework amplamente utilizado. Foi inicialmente implementado em Smalltalk-80, mas atualmente conta com implementações em todas as versões existentes de Smalltalk, como o VisualWorks, VisualAge, Dolphin, Squeak, etc. O MVC (Model-ViewController) é usado pelo Smalltalk como interface com o usuário, tendo mostrado a adequação da orientação a objetos para implementação de interfaces gráficas com o usuário. Outro exemplo é o HotDraw, que é um framework gráfico bidimensional para editores de desenho estruturado, escrito no VisualWorks Smalltalk. Ele tem sido usado para criar diversos editores diferentes. Pode-se facilmente criar novas figuras e ferramentas especiais de manipulação para seus desenhos. 
Muitos frameworks de aplicação não são de domínio público. Exemplos são o ET++, ACE, Microsoft Foundation Classes (MFC) e DCOM, JavaSoft's RMI, implementações do OMG CORBA e o IBM San Franciso. O IBM San Francisco é um framework de aplicação para domínios específicos de negócio. Seu propósito é ajudar a criar aplicações de negócio que sejam apropriadas para uma grande variedade de aplicações nesse domínio. Ele utiliza padrões de projeto para gerenciar e organizar sua documentação, além de se beneficiar das características que os padrões proporcionam (Carey et al., 2000). O San Francisco apóia aplicações de gerenciamento de armazenamento, gerenciamento de pedido, livro razão, contas a pagar, contas a receber etc.

\subsubsection{O Framework para Gestão de Recursos de Negócio}

Com base na Linguagem de Padrões GRN (detalhes na Seção 2.2.5), foi construído o Framework GREN (Gestão de REcursos de Negócios) (Braga e Masiero, 2002b). O Framework GREN permite criar aplicações no domínio de sistemas de gestão de recursos de negócios. Foi implementado com a linguagem Smalltalk, mais especificamente o ambiente VisualWorks Non-Commercial 5i. $3^{1}$. A base de dados (relacional) utilizada na persistência dos objetos é a MySQL ${ }^{2}$. A Figura 2.3 mostra a arquitetura do Framework GREN. A camada de persistência possui três classes para cuidar da conexão com a base de dados, gerenciamento dos identificadores dos objetos e persistência dos objetos. A camada de aplicação comunica-se com a camada de persistência sempre que precisa persistir um objeto. Dentro da camada de aplicação existem diversas categorias como a GRENApplication, que contém as classes derivadas diretamente dos padrões de análise que compõem a Linguagem de Padrões GRN; a GREN-Wizard, que contém as classes que implementam o instanciador do GREN; e a GREN-Report Writer, que contém as classes específicas para impressão de relatórios. As aplicações específicas construídas a partir do GREN situam-se numa camada mais externa, pois podem fazer uso de todas as camadas mais internas. A camada de interface com o usuário contém todas as classes relacionadas a formulários de interface, janelas e menus. Comunica-se com a camada de aplicação para obtenção de objetos a serem mostrados na interface com o usuário e para devolver informações a serem processadas pelos métodos da camada de aplicação.

Uma característica marcante das aplicações geradas a partir do Framework GREN é sua interface com o usuário, que foi elaborada de maneira convencional, ou seja, para ser executada em micro-computadores com Windows 98 (ou superior) que possuam instalado o software VisualWorks. Portanto, não pode ser executada em navegadores do tipo Netscape ou Explorer. A interface atual supõe que o usuário do sistema é um funcionário da empresa, que tem acesso à

\footnotetext{
${ }^{1}$ VisualWorks NonCommercial, Release 5i.3, 1999 Copyright Cincom Systems, Inc. disponível na URL: http: //www. cincom.com.

${ }^{2}$ MySQL Database, Release 3.23.25-beta, Copyright MySQL disponível na URL: http : / / www . mysql . com.
} 


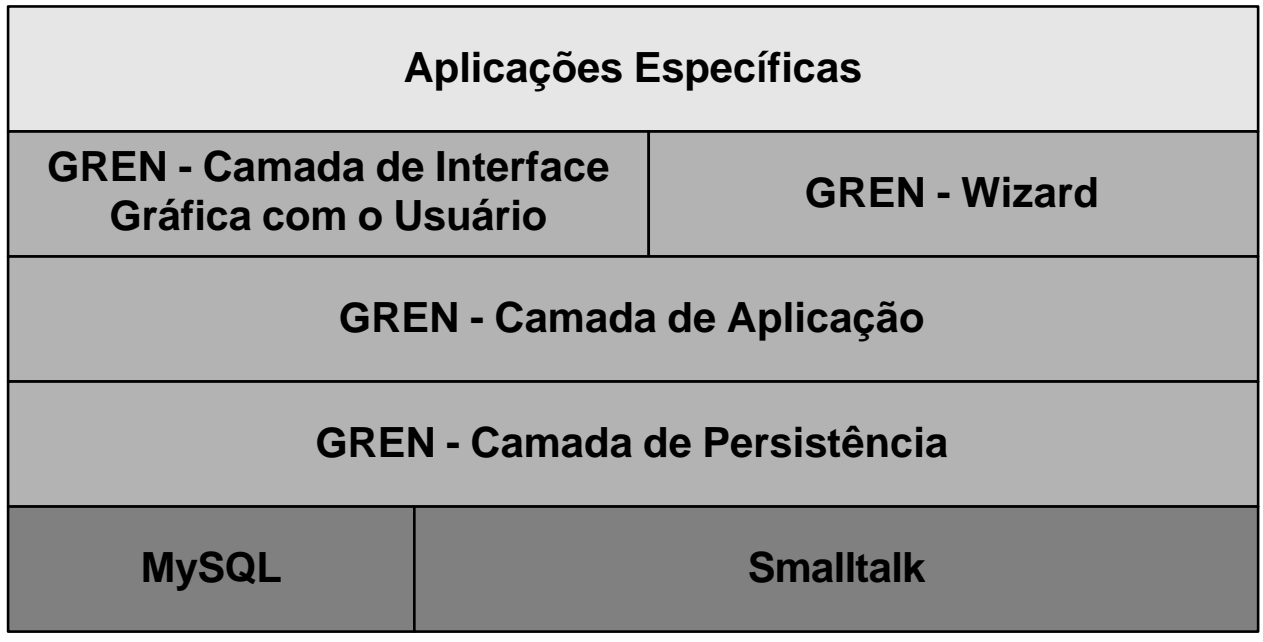

Figura 2.3: Arquitetura do Framework GREN.

base de dados e pode efetuar quaisquer operações disponíveis. Está prevista uma segunda versão do Framework GREN na qual haverá diferentes usuários, com senhas especiais, que poderão executar apenas algumas operações, de acordo com diferentes níveis de permissão cadastrados pelo supervisor do sistema.

A criação das aplicações por meio do framework é guiada pela aplicação da Linguagem de Padrões GRN. Após a aplicação da linguagem de padrões são obtidos diagramas de classes da aplicação desejada. Com base nesses diagramas utilizam-se classes pré-programadas do Framework GREN para criar o código da nova aplicação.

\subsection{Sistemas de Informação baseados na Web}

A Web transformou-se em poucos anos de apenas um modo de fazer propaganda para uma plataforma que pode apoiar grande parte do trabalho organizacional. Como resultado, são crescentes os esforços para que sistemas de informação possam explorar os benefícios dessa plataforma, conduzindo assim ao desenvolvimento de sistemas de informação baseados na Web, os WIS (Web-based Information Systems). Estes sistemas se tornarão mais comuns e usados que os sistemas cliente/servidor existentes e causarão grande impacto na economia e na vida das pessoas, pelo fato de que a Web possui um maior potencial de alcance de audiência do que os sistemas cliente/servidor baseados em redes de propriedade privada. Pode-se identificar quatro tipos gerais de sistemas baseados na Web:

- Intranet: apóiam o trabalho interno de uma empresa;

- sites de presença na Web: sites que são ferramentas de propaganda para conseguir aumentar o número de consumidores; 
- Extranets: uma mistura de sistemas externos e internos que apóiam a comunicação empresaempresa; e

- comércio eletrônico: sistemas que apóiam as negociações com o consumidor.

Existe uma diferença clara entre um conjunto de páginas na Web e os SIbWebs. Os SIbWebs apóiam o trabalho e, usualmente, são fortemente integrados com sistemas que não são baseados na Web como, por exemplo, base de dados e sistemas de processamento de transação.

As aplicações tradicionais cliente/servidor normalmente utilizam a arquitetura fat client, já as aplicações para a Web que implementam processos de negócios geralmente requerem a arquitetura thin client, para não sobrecarregar a máquina cliente, para permitir que não seja necessário mais do que um navegador para sua execução e para não exigir que os navegadores possuam recursos específicos, como plug-ins, para a utilização da aplicação.

SIbWebs também são diferentes de sistemas de informação tradicionais, pois atingem um maior número de usuários e necessitam de novas abordagens para projeto e desenvolvimento. Essas diferenças introduzem um maior desafio gerencial e técnico.

\subsection{Leilões Virtuais}

Um dos tipos de comércio eletrônico existentes na Web é a intermediação, que são mercados caracterizados por trazerem até si compradores e vendedores e assim facilitarem as transações entre eles. Dentre os vários tipos de negócios existentes na Web, os leilões virtuais vêm crescendo e movimentando uma considerável soma financeira. As vantagens são significativas tanto para compradores como para vendedores. Economias são feitas pela redução dos custos de transação, aumento do círculo potencial de consumidores, bem como melhoria da capacidade de "procurar e encontrar" de todas as partes interessadas (Heck e Vervest, 1998).

Os leilões virtuais são basicamente processos de comercialização quando outros procedimentos de comercialização não têm sucesso ou um processo de determinação de preço torna-se necessário. Do ponto de vista econômico existem dois principais motivos para utilização de leilões (Engebretsen, 1999):

- leilões são mecanismos para determinação de preço, estabelecendo um equilíbrio de preços de mercado; e

- leilões são um mecanismo de distribuição de recursos, comercializam produtos que são difíceis de encontrar em mercados normais devido a:

- produtos com tempo de vida limitado, como passagens de avião ou flores; 
- produtos que estão em estoque e precisam ser comercializados separadamente de novos lançamentos.

Da perspectiva dos compradores e vendedores existem três diferentes pares de partes envolvidas na comercialização que podem ser observados em leilões virtuais (Engebretsen, 1999; Rappa, 2000):

- consumidor-consumidor ( $\mathrm{C} 2 \mathrm{C}$, do inglês consumer-to-consumer): representam nos leilões a versão moderna dos anúncios de classificados, exigindo que as duas partes estejam localizadas próximas uma da outra de forma que o custo do transporte não torne o negócio inviável;

- empresa-consumidor (B2C, do inglês business-to-consumer): podem ser identificados como empresas que tentam comercializar estoques excedentes ou estabelecer preços para novos produtos ou criar novos canais de venda; e

- empresa-empresa (B2B, do inglês business-to-business): são usadas principalmente por empresas e entidades governamentais para vender contratos públicos e bens. Leilões B2B tendem a ser fechados a empresas identificadas e qualificadas como potenciais compradoras.

Os processos dos leilões são definidos por seus eventos significativos. Os lances são controlados pelos participantes e a revelação do lance vencedor e o fechamento do leilão são controlados pelo próprio leilão. Saber quando um evento ocorre pode ser tão importante quanto saber o que acontece, e por isso é essencial que os leilões mantenham uma certa consistência temporal durante sua operação. A Internet tem algumas limitações particulares quando se trata de consistência temporal. Portanto é claro que o leilão não tem controle sobre o tempo de resposta das transmissões e, conseqüentemente, mensagens contendo os lances e notificações de preços podem ter tempo arbitrário. Além disso, o processamento do leilão pode ser complexo, dependendo do número, tamanho e regras dos leilões, já que devem permanecer disponíveis o tempo todo (Wellman e Wurman, 1998).

\subsubsection{Classificação de Leilões Virtuais}

Vários são os tipos de leilões virtuais e a Figura 2.4 apresenta como eles podem ser divididos segundo o número de participantes:

- leilões de venda: existe um vendedor e vários compradores, vários produtos são oferecidos e os vencedores são escolhidos pela ordem de preço, quantidade e cronologia; 


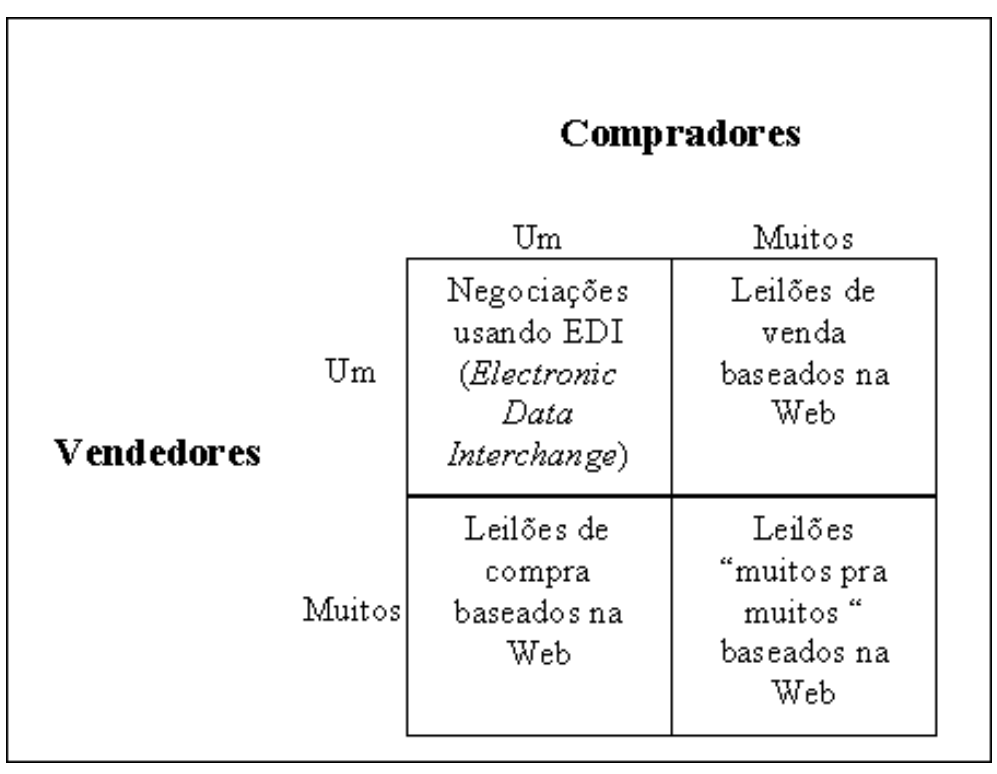

Figura 2.4: Utilização de Leilões no Comércio Eletrônico (Heck e Vervest, 1998).

- leilões de compra ${ }^{3}$ : um comprador declarando o interesse em algum produto necessário e vários fornecedores tentando fornecê-lo; e

- leilões do tipo "muitos para muitos": muitos fornecedores oferecendo para muitos potenciais compradores.

Pode-se também classificar os leilões existentes na Internet de maneira mais detalhada para que se possa identificar claramente o seu funcionamento segundo algumas características, tais como:

- número de lances e ofertas de cada lado do mercado;

- a forma dos lances;

- o número de itens comprados e vendidos por transação;

- as regras do leilão; e

- o mecanismo de ordenação e o modo da ocorrência da transação.

Observando-se esses atributos foi possível desenvolver a taxonomia mostrada na Figura 2.5. Existem vários tipos de leilão e, segundo Kumar e Feldman (1998b), uma aplicação para leilões virtuais deve apoiar esses vários tipos. No entanto, é possível identificar alguns dos leilões mais utilizados na Web e que, portanto, merecem maior atenção (Engebretsen, 1999; Wellman e Wurman, 1998):

\footnotetext{
${ }^{3}$ Esse tipo de leilão é freqüentemente chamado na Internet de leilão reverso.
} 
Número de lances/ofertas de cada lado do mercado

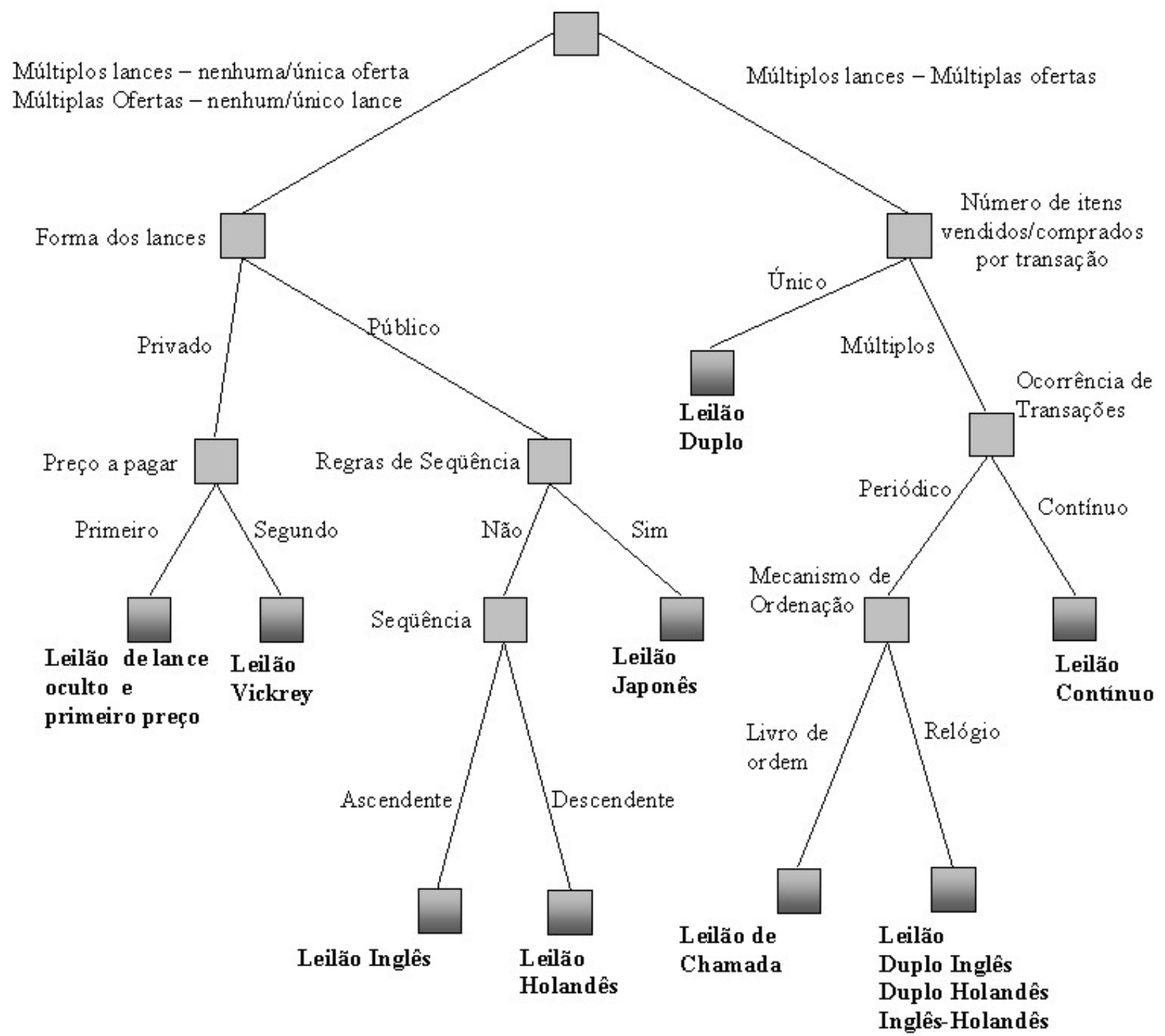

Figura 2.5: Tipos de Leilões Segundo o Esquema de Reck (Reck, 1994).

- leilão inglês: um dos formatos mais comuns de leilão, também conhecido como leilão de lance aberto ou leilão de preço ascendente. A princípio não possui limite de tempo, e o leiloeiro inicia pelo preço de reserva ${ }^{4}$, continuando enquanto os lances forem dados. Os concorrentes são freqüentemente anônimos, interagindo principalmente por meio eletrônico;

- leilão holandês: possui limite de tempo e é conhecido também como leilão de preço descendente. O preço inicial é extremamente alto e, em intervalos predefinidos, o preço decresce em pequenos montantes até que algum comprador interessado arremate o produto. Quando existirem vários itens do mesmo produto a serem leiloados, diferentes consumidores podem

\footnotetext{
${ }^{4}$ Preço mínimo preestabelecido pelo leiloeiro ou pelo proprietário do bem que está sendo leiloado.
} 
arrematá-los por diferentes valores. Esse tipo de leilão é mais indicado para itens perecíveis, por exemplo, flores;

- leilão de preço oculto e primeiro lance: esse tipo de leilão é dividido em duas fases: os lances e a resolução. Durante a primeira fase os lances são coletados secretamente. Posteriormente, na segunda fase, são abertos, e o vencedor é determinado. Os lances são organizados do valor mais alto para o valor mais baixo e dessa forma, se apenas um item for leiloado o lance mais alto é o vencedor. Caso existam vários itens a serem leiloados eles são distribuídos pela ordem de lances. Esse tipo de leilão é conhecido como leilão de preço oculto discriminatório; $\mathrm{e}$

- leilão Vickrey: Semelhante ao leilão de preço oculto e primeiro lance. Difere apenas no fato de que quem ofereceu o lance mais alto é vencedor, porém não paga o valor oferecido no lance mais alto, e sim o do segundo lance mais alto.

Apesar de existirem todos esses tipos de leilão, usualmente na Internet os tipos de leilões são adaptados às necessidades impostas pela classe de usuários, por decisão de negócio, ou pelas próprias implicações da Web. Alguns dos detalhes que podem variar dos tipos apresentados são (Kumar e Feldman, 1998a):

- anonimato das partes interessadas;

- restrições quanto ao montante do lance, de forma que os lances somente podem ser oferecidos com a soma de incrementos predefinidos baseados no valor de reserva do produto, assim torna-se proporcional ao montante total do item que está sendo leiloado;

- regras de fechamento do leilão;

- regras de avaliação e desempate de lances; e

- serviços fornecidos para vendedores e compradores, tais como: certificação de qualidade do produto, coleta de pagamento e remessa do bem leiloado.

Independentemente do tipo de leilão virtual, algumas atividades básicas podem ser observadas na quase totalidade das formas de leilões virtuais (Kumar e Feldman, 1998b):

- registro inicial do comprador e do vendedor;

- configuração dos eventos de um leilão particular;

- programação e anúncio;

- os lances;

- avaliação dos lances e fechamento do leilão; e

- determinação da venda. 


\subsubsection{Aspectos de Segurança}

A Internet implica em adotar políticas de segurança que são indispensáveis para o comércio eletrônico. Mecanismos de segurança baseados em métodos de criptografia e auditorias são necessários como prevenção contra sabotagem de hackers, ou compradores e vendedores que tentem fraudar ou interromper os leilões. Mecanismos eficientes de notificação dos últimos lances para os participantes são indispensáveis.

A política do leilão, juntamente com as instruções do vendedor, ditam se um leilão é amplamente acessível ao público, ou somente a compradores/vendedores registrados, ou ainda apenas a compradores registrados para participar de um leilão específico. Mecanismos de controle de acesso são necessários para reforçar as regras de funcionamento do leilão. Mecanismos de segurança são necessários para garantir que o anúncio do leilão e as regras não sejam sabotadas por invasores. Essa prevenção inclui postagens não autorizadas e alterações, bem como prevenção de ataques aos serviços disponíveis (Kumar e Feldman, 1998b).

\subsubsection{Exemplos de Leilões Virtuais}

Atualmente existem vários sistemas de leilões virtuais em funcionamento na Web. Esses leilões podem ser encontrados por qualquer engenho de busca ou em sites que possuem listas específicas com endereços de sistemas desse tipo. Alguns exemplos são encontrados em:

-http://br.cade.dir.yahoo.com/compras_e_servicos/Leiloes;

- http://www.aonde.com/indicacao/compras/15012.htm; e

- http://www. internetauctionlist.com.

Os sites citados possuem o endereço de vários sistemas de leilões virtuais cujo foco vai desde a prestação de serviços de leilões para empresas de equipamentos eletrônicos até leilões de gado. Como exemplo pode-se citar o sistema do site SuperBid (http: / / www . lei lao . superbid. com.br), o sistema do site Nosso Leilão (http: / / www. nossoleilao.com.br) e o sistema do site BanLeilão (http: / / www. banleilao.com.br). O SuperBid é um site de leilões virtuais - leilões públicos oficiais - que presta serviço para empresas em geral (Banco HSBC, Motorola, Compaq e Natura, entre outros), avaliando e comercializando, segundo consta no próprio site da empresa, "ativos industriais, excedente de inventário e resíduos", isto é, imóveis, automóveis, peças de veículos para serviços pesados e equipamentos eletrônicos, entre outros. Esse site fornece apoio para essas empresas comercializarem os bens tanto para pessoas físicas como jurídicas, que devem ser identificadas previamente pois são leilões públicos oficiais. Portanto, esse leilão é classificado como um comércio eletrônico do tipo "empresa-consumidor" e "empresa-empresa". 
O site Nosso Leilão também presta serviços para bancos e seguradoras para comercialização de imóveis, veículos máquinas e equipamentos, de forma semelhante ao SuperBid. O BanLeilão é um leilão específico para agronégocios, especialmente a agropecuária. Nesse site são comercializados touros reprodutores, bezerros, vacas matrizes e doses de sêmen provenientes de criadores e fazendas reconhecidas. Obviamente, esse sistema de leilões possui detalhes específicos à sua atividade de negócio, assim como o SuperBid e o Nosso Leilão.

Outros sistemas de leilões, não tão específicos como o BanLeilão, podem ser utilizados por um público maior na internet. São leilões do tipo "consumidor-consumidor”, no qual são comercializados itens pessoais, como cds, livros e itens de coleção. Qualquer tipo de produto, usado ou não, pode ser encontrado nesses sites de leilões virtuais. No Brasil, o primeiro sistema de leilões virtuais a entrar em funcionamento foi o Arremate.com (http://www . arremate.com), mas logo em seguida outras empresas disponibilizaram seus serviços para o público interessado nesse tipo de comercialização, como por exemplo, o iBazar (http://www. ibazar.com.br), o Lokau (http://www. lokau.com), o Mercado Livre (http://www.mercadolivre.com.br) e o Yahoo Leilões (http://br.auctions . yahoo.com). Esses sistemas de leilões têm basicamente as mesmas funções, não apresentando grandes diferenças em sua funcionalidade.

Semelhantes a esses sistemas brasileiros, os sites americanos eBay (http://www . ebay . com) e o Yahoo Shopping Auctions (http: / / auctions. shopping • yahoo.com/) possuem sistemas de leilões virtuais direcionados para o mesmo tipo de público alvo, sendo o eBay um dos sites mais conhecidos e utilizados do mundo.

O leilão reverso é um tipo peculiar de leilão no qual os clientes declaram o interesse por um produto ou serviço e vários fornecedores oferecem lances, que visam a atender às necessidades do cliente por um certo preço. Dessa forma, são os fornecedores que competem para poder vender seus bens. Alguns exemplos desse tipo de leilão, todos do tipo empresa-empresa, são o australiano LowestBid (http: / / www. lowestbid.com.au/), o americano Commonwealth of Kentucky - Division of Purchases (http://purch.state.ky.us) e o brasileiro Bolsa Eletrônica de Compras do Governo do Estado de São Paulo (http: / / www . bec . sp . gov • br/).

\subsection{Considerações Finais}

Mostrou-se nesse capítulo de revisão bibliográfica o relacionamento próximo entre as linguagens de padrões e os frameworks, bem como os benefícios por eles proporcionados no desenvolvimento de sistemas de informação tradicionais. Ainda neste capítulo, foram discutidos os SIbWebs, especialmente um tipo específico desses sistemas, os leilões virtuais. Visando a oferecer ao processo de desenvolvimento de SIbWebs os mesmos benefícios proporcionados por linguagens de padrões e frameworks no desenvolvimento de sistemas de informação tradicionais, torna-se rele- 
vante pesquisar soluções que apóiem a criação e aplicação de linguagens de padrões e frameworks no desenvolvimento de SIbWebs. A revisão bibliográfica, por outro lado, permitiu constatar a ausência de propostas de linguagens de padrões para o domínio dos sistemas de leilões virtuais na Web e de frameworks para apoiar o desenvolvimento desse tipo de sistema.

Nos próximos capítulos é apresentado um processo genérico para redesenvolvimento de SIbWebs. Esse processo é composto por três subprocessos interdependentes: um processo de engenharia reversa para elicitação dos requisitos, um processo de criação de uma linguagem de padrões e um processo de desenvolvimento e instanciação de frameworks baseado em uma linguagem de padrões. Este último subprocesso é baseado na proposta de Braga e Masiero (2002b). O processo é ilustrado com o desenvolvimento de uma linguagem de padrões e um framework para o domínio dos sistemas de gestão de leilões virtuais na Web. 


\section{O Subprocesso de Criação de um Modelo do Domínio da Aplicação para Sistemas de Informação Baseados na}

\subsection{Considerações Iniciais}

O modelo do domínio de uma aplicação pode ser constituído de vários elementos, como casos de uso, diagramas de classe, diagramas de estado, etc. Neste trabalho usa-se uma linguagem de padrões para modelar o domínio. Este capítulo apresenta o processo geral de desenvolvimento de uma linguagem de padrões a partir de um modelo de classes do domínio e como essa linguagem pode ser usada para criar modelos de análise que possibilitam implementar sistemas baseados na Web. O processo geral toma como entrada pelo menos três sistemas do domínio, chamados de sistemas-base. Um processo de engenharia reversa baseada na interface Web é conduzido para esses sistemas-base, visando a produzir a especificação de requisitos e, por intermédio dessa especificação, criar um modelo de classes do domínio. Neste capítulo apresenta-se, ainda, como é o processo de desenvolvimento de uma linguagem de padrões tomando como base um modelo de classes do domínio, exemplificando esse processo por meio da Linguagem de Padrões para Leilões Virtuais (Linguagem de Padrões LV) e um exemplo de sua utilização. 
Apresenta-se na Seção 3.2 a contextualização do processo proposto neste capítulo para o desenvolvimento de sistemas de informação baseados na Web, o qual é constituído por um subprocesso de criação de um modelo do domínio da aplicação de SIbWebs, apresentado na Seção 3.3, e pelo subprocesso de criação da linguagem de padrões a partir do modelo de classes do domínio presente na Seção 3.4. Na Seção 3.5 é apresentada em detalhes a Linguagem de Padrões LV. Na Seção 3.6 apresenta-se um exemplo do uso da Linguagem de Padrões LV em um sistema de leilões virtuais existente na Web.

\subsection{O Processo de Modelagem do Domínio Proposto: Contextualização}

O objetivo final deste trabalho é a proposição de um processo que facilite o desenvolvimento de frameworks orientados a objetos para o domínio dos Sistemas de Informação baseados na Web. Como objetivo do trabalho quer-se usar o processo proposto por Braga e Masiero (2002b), em que isso é feito usando-se como passo intermediário uma linguagem de padrões de um subdomínio específico dos SIbWebs. No caso deste trabalho o subdomínio escolhido foi o de leilões virtuais. Esses autores mostram que o uso de uma linguagem de padrões facilita o desenvolvimento do framework e também a instanciação de aplicações, agindo como um elemento integrador e como uma alternativa de modelagem de domínio. Além disso, o subdomínio escolhido, de leilões virtuais, complementa a linguagem de padrões criada por Braga et al. (1999) e o framework correspondente pode ser integrado ao framework desenvolvido por Braga e Masiero (2000).

Esse processo possui três grandes fases: na primeira deve-se criar um modelo de classes genérico do domínio de aplicações, na segunda cria-se a linguagem de padrões e na terceira desenvolve-se o framework. As duas primeira fases são apresentadas neste capítulo e a terceira é apresentada no Capítulo 4. A primeira fase baseia-se fortemente na engenharia reversa de aplicações do subdomínio escolhido ${ }^{1}$. Não é difícil encontrar aplicações do domínio para usar como base da engenharia reversa, já que o subdomínio é de SIbWebs. Esse processo de engenharia reversa é fortemente baseado na interface do sistema disponível na Web, mas pode contar com o apoio de outras técnicas, como a análise de documentos relativos ao domínio (livros, artigos, etc) e conhecimento próprio do domínio. É possível também definir os requisitos do sistema usando métodos tradicionais de análise de sistemas. A segunda fase envolve a criação de uma linguagem de padrões para representar o subdomínio escolhido, a partir do modelo de classes genérico criado na fase anterior. As duas primeiras fases são propostas originais desta dissertação. As duas fases seguintes, de desenvolvimento do framework e de instanciação de aplicações do subdomínio, seguem a proposta de

\footnotetext{
${ }^{1}$ Quando não houver necessidade de diferenciar a hierarquia, os termos domínio e subdomínio serão usados como sinônimos.
} 
Braga e Masiero (2002a,b), com adaptações para o domínio de SIbWebs. Esse processo geral é descrito na Figura 3.1 e cada fase é descrita em detalhes nas próximas seções.

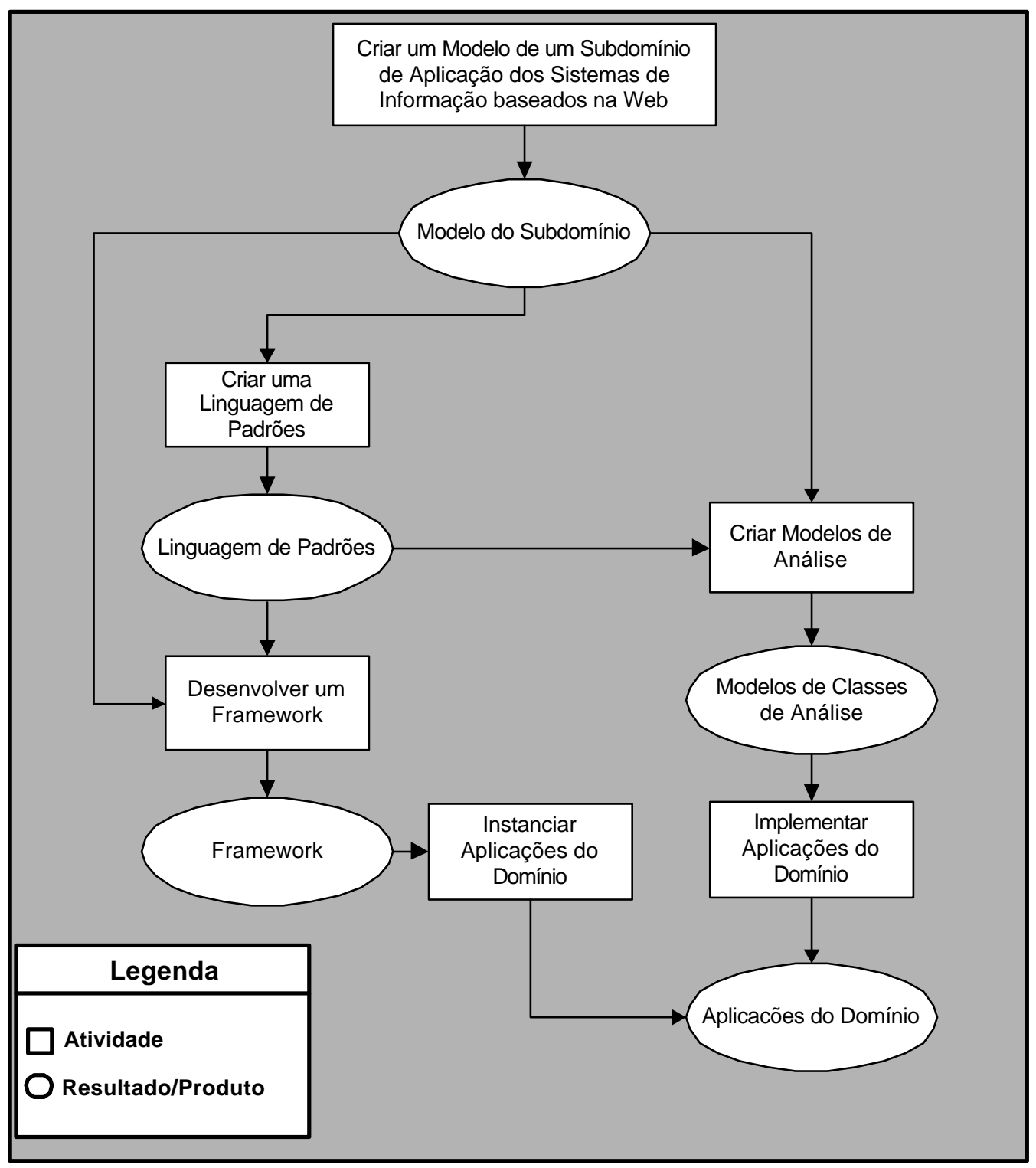

Figura 3.1: Alternativas para o Desenvolvimento de Sistemas de Informação Baseados na Web.

Obviamente, aplicações genéricas podem ser desenvolvidas diretamente do modelo de classes ou da linguagem de padrões, que são apoiadas pelas duas primeiras fases do processo geral. Essas aplicações genéricas não são, portanto, frameworks, mas poderiam servir de base para um processo de generalização, como proposto por Pree (1999), Roberts e Johnson (1998) e Schmid (1997, 1999).

Deve-se notar que o processo de criação da linguagem de padrões é genérico, isto é, não depende do processo inicial, já que os modelos de classes dos sistemas escolhidos como base para a engenharia reversa poderiam ter sido projetados de diferentes modos. $\mathrm{O}$ uso de engenharia reversa 
é adequado para SIbWebs porque a interface está publicamente disponível e torna-se uma alternativa interessante elicitar os requisitos do sistema dessa maneira. O resultado da engenharia reversa pode ser complementado com informações obtidas de forma tradicional. Neste trabalho, optou-se por obter os requisitos por meio da engenharia reversa pelo interesse acadêmico em explorar-se esse tipo de atividade.

\subsection{Criar um Modelo do Domínio da Aplicação}

Várias definições descrevem o processo de engenharia reversa como um esforço para criar uma representação em um nível de abstração mais alto que o código fonte (Chikofsky e Cross, 1990; Pressman, 2000; Sage, 1995; Sommerville, 1996; Stephen e Lynn, 1995; Waters e Chikofsky, 1994). Um sistema pode ser visualizado em diferentes níveis de abstração (Costa, 1997). O processo de engenharia reversa baseado na interface de SIbWebs trata das visões funcionais do domínio e tem seu foco no contexto em que o sistema está inserido e nas relações lógicas entre as funções que compõem o sistema.

O processo proposto para a criação de um modelo do domínio de aplicação de SIbWebs é apresentado na Figura 3.2. Esse processo é constituído de quatro atividades principais: escolher três SIbWebs do domínio que serão chamados de sistemas-base, conduzir a engenharia reversa dos sistemas-base, criação dos modelos de classes dos sistemas-base e criação do modelo do domínio. O objetivo do processo é obter um modelo genérico do domínio referente aos SIbWebs analisados. O conhecimento adquirido pela análise desse domínio é a base para o desenvolvimento de novos SIbWebs que pertençam a essa mesma família de sistemas, como por exemplo, comércio eletrônico de livros ou CDs, leilões virtuais ou sistemas de reservas de passagens.

\subsubsection{Escolher Três Sistemas do Domínio}

A primeira atividade deste processo é a escolha de três SIbWebs do domínio. Roberts e Johnson (1998) sugerem que para desenvolver frameworks devem ser desenvolvidas primeiramente três aplicações concretas que irão fornecer conhecimento suficiente para gradativamente permitir a generalização dessas aplicações. Ao desenvolver e generalizar os três sistemas é possível aprender sobre o domínio em que essas três aplicações se inserem. É necessário que no mínimo três SIbWebs sejam escolhidos para que se possa obter um conjunto básico de funções que represente uma parte considerável da funcionalidade de SIbWebs desse domínio. A escolha dos sistemas-base é uma atividade humana e não é determinística. Algumas sugestões podem auxiliar nessa escolha:

- Escolher sistemas o mais heterogêneos possíveis, pois quanto mais heterogêneos forem os sistemas-base maior será o número de funções diferentes elicitadas; 


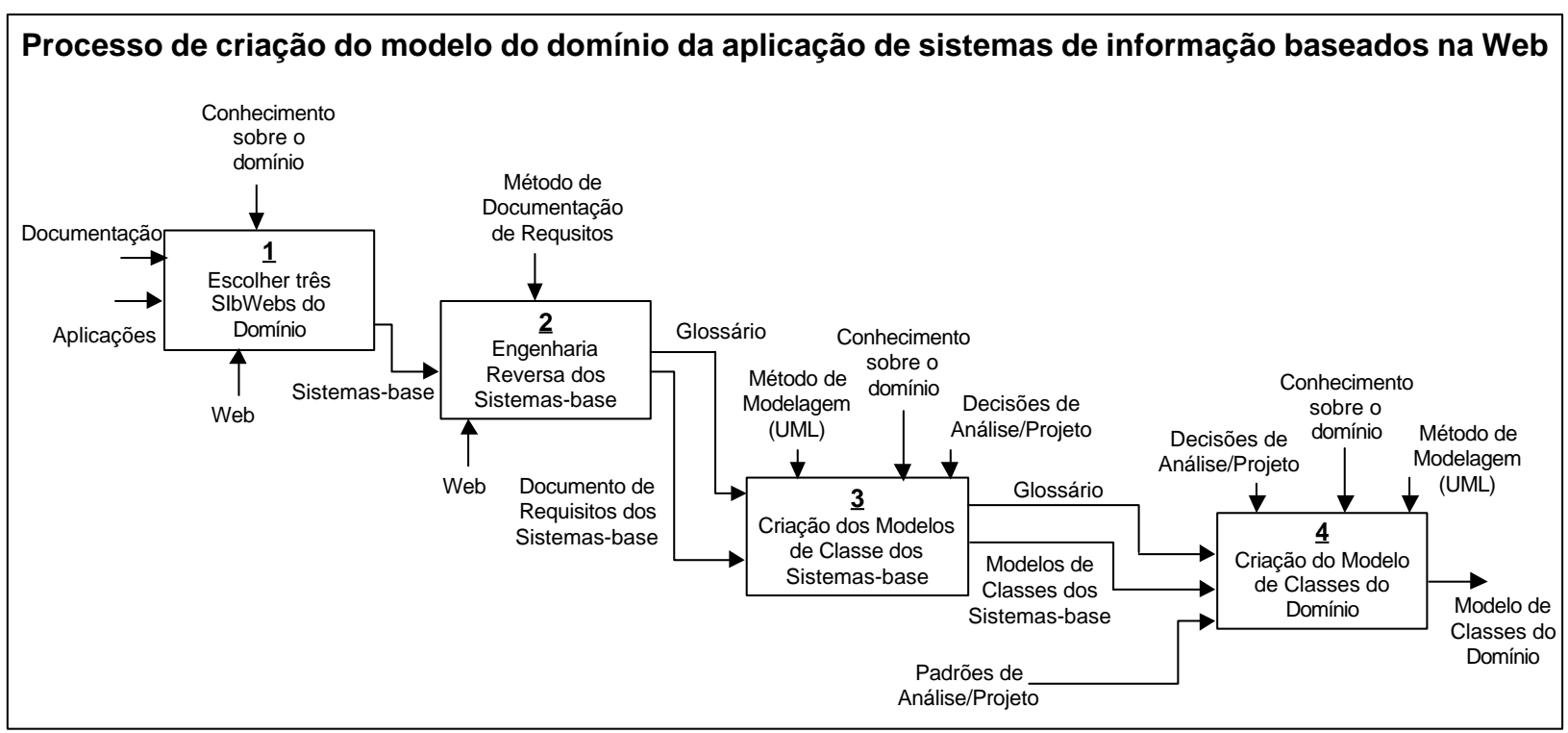

Figura 3.2: Processo de Criação do Modelo do Domínio da Aplicação de SIbWebs.

- Analisar sistemas que são líderes de mercado, isto é, sistemas muito usados e outros menos conhecidos para obter visões mais complexas e mais simples de sistemas do domínio;

- SIbWebs provenientes de países diferentes podem indicar funções que atendam a diferentes características culturais, econômicas e tecnológicas;

- Organizações que possuam diferentes fins, ramos e objetivos de negócio possuem funções relacionadas à sua própria natureza e podem fornecer uma gama variada de funções; e

- Se possível, analisar sistemas que funcionam em Intranet, pois podem ser mais completos e apresentarem outras funções, como as relacionadas com segurança, por exemplo.

O acesso ao conteúdo dos sistemas-base é importante para a aplicação dessa atividade já que existem SIbWebs que são totalmente públicos, enquanto outros restringem de alguma maneira $\mathrm{o}$ acesso mediante a exigência de cadastramento ou fornecimento de informações. O resultado da aplicação do processo é diretamente ligado às interfaces utilizadas. O processo é aplicável a qualquer SIbWeb desde que as condições de acesso sejam atendidas.

No caso deste trabalho foram escolhidos três sistemas-base do domínio de leilões virtuais: o Arremate.com, o iBazar e o eBay. Esses três sistemas-base ofereceram as condições mínimas para a execução da primeira atividade do processo, ter acesso a interface pública e rastrear suas funções. A escolha dos sistemas-base seguiu as sugestões anteriormente apresentadas, sistemas de diferentes países (EUA e América do Sul), sistemas-base conhecidos (eBay) e com diferentes objetivos de negócio (o iBazar oferece seus serviços gratuitamente). Poderiam ter sido escolhidos sistemas-base que tratam de assuntos governamentais ou, que fossem dirigidos a um público alvo específico como colecionadores de antigüidades ou ainda, leilões filantrópicos. 


\subsubsection{Engenharia Reversa dos Sistemas-base}

O objetivo geral desta atividade é rastrear e documentar de maneira rigorosa e o mais completa possível as funções dos sistemas-base escolhidos. Assim, após serem escolhidos os três sistemas como base da engenharia reversa deve-se, para cada um desses sistemas, executar todas as subatividades apresentadas na Figura 3.3. A fase de engenharia reversa dos sistemas-base deve ser executada completamente para cada sistema-base escolhido.

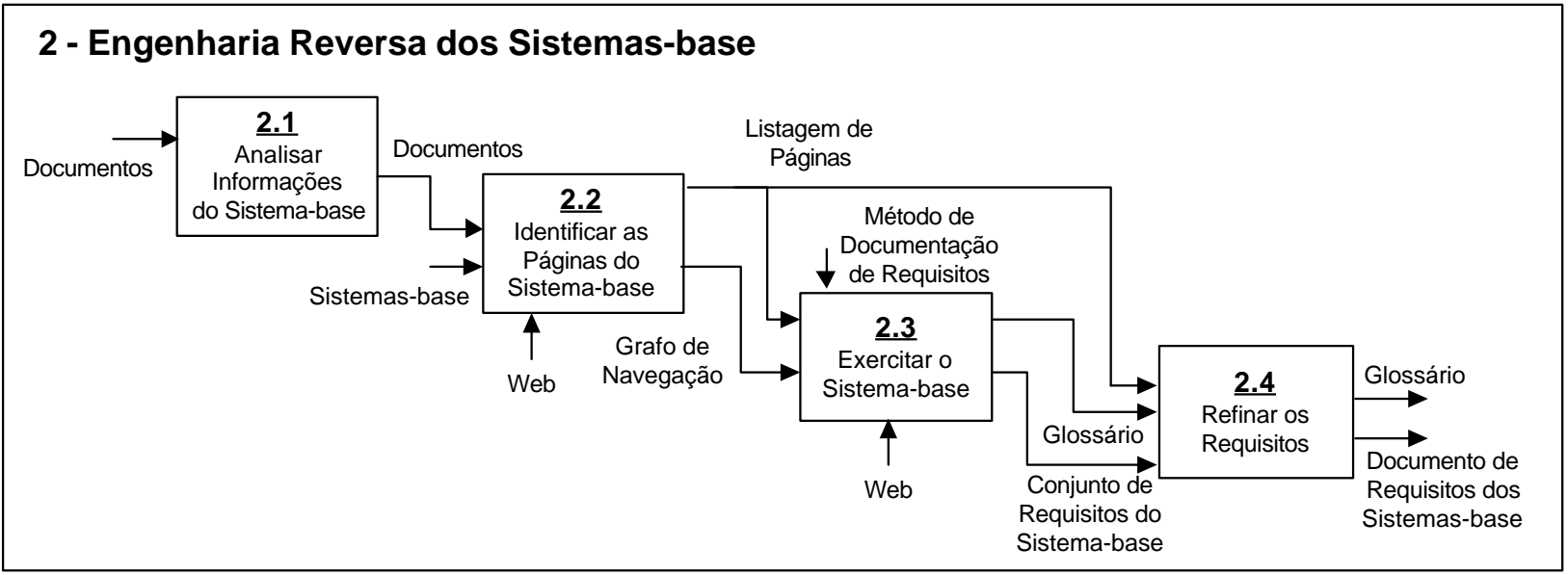

Figura 3.3: Engenharia Reversa dos Sistemas-base.

Costa (1997) propôs um método de engenharia reversa baseado na interface de sistemas que, embora não tenha sido desenvolvido para SIbWebs nem tampouco para a obtenção do modelo do domínio da aplicação, possui atividades com fins semelhantes à atividades aqui propostas. A primeira etapa desse método é constituída de dois passos: obter informações do sistema e de técnicas relacionadas aos conceitos pertinentes e recuperar o modelo de objetos do sistema. Dessa forma, algumas informações relacionadas aos passos da primeira etapa do método proposto por Costa (1997) foram utilizadas em alguns pontos da atividade 2 e da atividade 3 do processo proposto.

A atividade 2.1 tem o objetivo de coletar e analisar informações do sistema (manuais, livros, artigos, etc...) e informações técnicas (domínio, aplicação, tecnologia, etc...) que são importantes para o entendimento e aprendizado do domínio da aplicação. Essas informações ajudam o analista a familiarizar-se com os conceitos do sistema e do domínio, facilitando decisões que devem ser tomadas ao longo do processo. No trabalho proposto foi utilizado o conhecimento tácito sobre os leilões, bem como teoria de sistemas de informação e artigos sobre sistemas de leilões virtuais, tais como os de Kumar e Feldman (1998b) e de Wellman e Wurman (1998). A Tabela 3.1 mostra parte das atividades básicas de um processo de negociação por meio de leilões, apresentadas por Kumar e Feldman (1998b). Essas atividades básicas dão uma visão geral do funcionamento de sistemas de leilões virtuais. 
Tabela 3.1: Atividades Básicas do Processo de Negociação por Intermédio de Leilões Virtuais.

\begin{tabular}{|l|l|}
\hline \multicolumn{1}{|c|}{ Atividade } & \multicolumn{1}{c|}{ Descrição } \\
\hline \hline $\begin{array}{l}\text { Registro inicial dos } \\
\text { compradores e vende- } \\
\text { dores }\end{array}$ & $\begin{array}{l}\text { Assuntos relacionados com a autenticação de compradores e vendedores, troca de chaves } \\
\text { de criptografia e, talvez, criação de perfis de compradores e vendedores, com base em } \\
\text { diferentes categorias de bens e poder aquisitivo. }\end{array}$ \\
\hline $\begin{array}{l}\text { Configuração dos even- } \\
\text { tos de um leilão }\end{array}$ & $\begin{array}{l}\text { Descrição dos bens a serem negociados, configuração das regras do leilão (tipo do leilão, } \\
\text { preço do bem, dados de entrega, termos do pagamento), data de início e término do leilão } \\
\text { e regras de fechamento, entre outros. }\end{array}$ \\
\hline Programação e anúncio & $\begin{array}{l}\text { Com o intuito de atrair potenciais compradores, deve haver uma estratégia de anúncio } \\
\text { dos bens (por exemplo: bens com maior possibilidade de comercialização podem ser } \\
\text { anunciados com os de menor possibilidade e leilões com a mesma categoria de bens } \\
\text { podem ter a mesma data de inicio) e potenciais compradores podem ser notificados de } \\
\text { leilões que iniciaram. } \\
\ldots\end{array}$ \\
\hline
\end{tabular}

O objetivo da atividade 2.2 é criar um grafo de navegação e uma listagem de páginas do sistema-base. Esse grafo de navegação irá orientar o analista e mostrar o caminho a ser percorrido para localizar as páginas desejadas do sistema-base. Cada vértice deve possuir um nome único que representa uma página e suas arestas indicam as ligações dessa página para as demais páginas. Juntamente com o grafo de navegação deve-se registrar separadamente em uma listagem de páginas do sistema-base uma breve descrição das funções de cada página a ser utilizada. Essa descrição deve apenas fornecer uma visão geral das operações que compõem as funções implementadas em cada página. Utilizando o grafo de navegação e a listagem, o analista irá determinar a ordem em que as páginas do sistema-base serão analisadas e, eventualmente, exercitadas.

A atividade 2.3 trata da determinação da ordem de utilização das páginas e principalmente do uso efetivo do sistema. O sistema-base pode possuir dados já inseridos e portanto, operações relacionadas a esses dados podem ser executadas normalmente, por exemplo, em um sistema de comércio eletrônico que pode-se ler os comentários sobre um livro antes de adquiri-lo. Uma primeira estratégia para estabelecer a ordem de utilização das páginas pode ser baseada na existência de dados no sistema-base. Assim, as operações relacionadas aos dados já existentes são executadas primeiramente. Posteriormente, o analista deve identificar no sistema-base quais páginas são relacionadas às operações de entrada do sistema e estabelecer, usando essas páginas, a ordem em que o sistema-base será exercitado. As páginas com essas operações de entrada inserem os dados necessários para o restante das operações do sistema-base. Para a determinação da ordem das páginas deve-se considerar a dependência das operações, tanto de entrada como de saída, aos dados do sistema-base. Dentre as operações de entrada deve-se analisar quais são dependentes umas das outras e ordená-las segundo essa dependência. Em um segundo momento, deve-se estabelecer a ordem das páginas relacionadas às operações de saída.

Uma segunda estratégia de ordenação das páginas é baseada na divisão da ordem de execução das páginas com operações de entrada das páginas que contenham operações de saída. Primei- 
ramente devem ser executadas as páginas que contenham operações de entrada e somente depois as operações de saída. Essa estratégia ignora a existência prévia de dados no sistema-base e concentra esforços em prover ao sistema-base todos os dados necessários para o seu funcionamento. A dependência que as operações têm dos dados do sistema também deve ser levada em consideração nesta estratégia, de forma que operações com menor dependência devem ser executadas primeiramente. A escolha da estratégia a ser utilizada fica a cargo do analista que deve observar a melhor aplicação para cada domínio. Em ambas as estratégias, a determinação da ordem em que as páginas serão utilizadas deve ser anotada na listagem de páginas do sistema.

Tabela 3.2: Listagem de Páginas do Sistema-base Arremate.com.

\begin{tabular}{|l|l|l|}
\hline \multicolumn{1}{|c|}{ Página } & \multicolumn{1}{|c|}{ Descrição } & Ordem \\
\hline \hline Vender Bem & Permite inserir um bem e dados que iniciarão um leilão. & 1 \\
\hline Navegar-1 & Lista as categorias de bens e permite a seleção de uma categoria. & 2 \\
\hline Navegar-2 & Lista as subcategorias de bens e permite a seleção de uma subcategoria. & 3 \\
\hline Navegar-3 & Lista as subsubcategorias de bens e permite a seleção de uma subsubcategoria. & 4 \\
\hline Navegar-4 & Lista os leilões de uma categoria e permite a seleção de um leilão. & 5 \\
\hline Buscar & $\begin{array}{l}\text { Executa uma busca entre os leilões e fornece uma listagem com os leilões que } \\
\text { satisfazem a determinadas opções de filtro. Permite a seleção de um leilão. }\end{array}$ & 6 \\
\hline $\begin{array}{l}\text { Comprar } \\
\ldots\end{array}$ & $\begin{array}{l}\text { Apresenta os detalhes de um leilão e permite a inclusão de lances. } \\
\ldots\end{array}$ & 7 \\
\hline
\end{tabular}

Usando a ordem de utilização contida na listagem de páginas do sistema-base o analista deve exercitar página por página, observando as funções que ela implementa. Deve existir uma coleção de dados para cada página do sistema-base e essa coleção deve exercitar o mais completamente possível a função contida na página. A definição do conjunto de dados que deve ser inserido nos sistemas-bases durante a utilização das páginas é uma atividade humana pois, além de depender do domínio em que o sistema-base se encontra, depende também de características específicas de cada sistema-base. Os documentos analisados na atividade 2.1 podem fornecer uma base para a criação de alguns dados. Outra fonte de informação para a criação do conjunto de dados pode ser encontrada nas descrições das páginas. Esse tipo de análise trata as páginas como use cases (Rumbaugh et al., 1999) e concentra os esforços em torno de aspectos ligados a cada página individualmente. Os detalhes para a criação dos dados devem ser observados diretamente em cada página. Dessa forma, a criação do conjunto de dados pode ser facilitada se for executada conjuntamente com a determinação da ordem das páginas. Durante a análise das funções das páginas o analista pode usar os detalhes das funções verificadas para a criação do conjunto de dados. O conjunto de dados utilizado para o primeiro sistema-base pode ser utilizado como base para a criação dos conjuntos de dados dos outros sistemas-base. No entanto, adequações devem ser feitas para que esse conjunto de dados possa ser aplicado aos demais sistemas-base.

A Tabela 3.2 apresenta um exemplo com parte de uma listagem de páginas referentes ao sistema-base de leilões virtuais Arremate.com. A terceira coluna, denominada "ordem", mostra 
a ordem de utilização das páginas. Nessa listagem existem duas páginas referentes a operações de entrada ("Vender Bem" e "Comprar") que, portanto, foram utilizadas primeiramente que as outras páginas. As demais páginas dessa listagem são referentes a operações de saída.

A Figura 3.4 apresenta parte de um grafo de navegação que foi utilizado para auxiliar na execução das páginas do sistema-base Arremate.com. É importante observar que ligações para outros sistemas ou páginas não devem fazer parte do escopo do sistema-base. Assim, tanto o grafo de navegação quanto a listagem de páginas deve conter apenas páginas que representem funções do domínio de aplicação estudado. As páginas que contêm uma marcação - “*” - podem ser acessadas de qualquer outra página do sistema por meio de uma barra de menu, como por exemplo a página "Serviços". A página "Home" possui duas páginas, "Buscar" e "Navegar" que indicam funções diferentes dentro da mesma da página. A Tabela 3.2 apresenta a listagem de páginas que contém as páginas ilustradas na Figura 3.4.

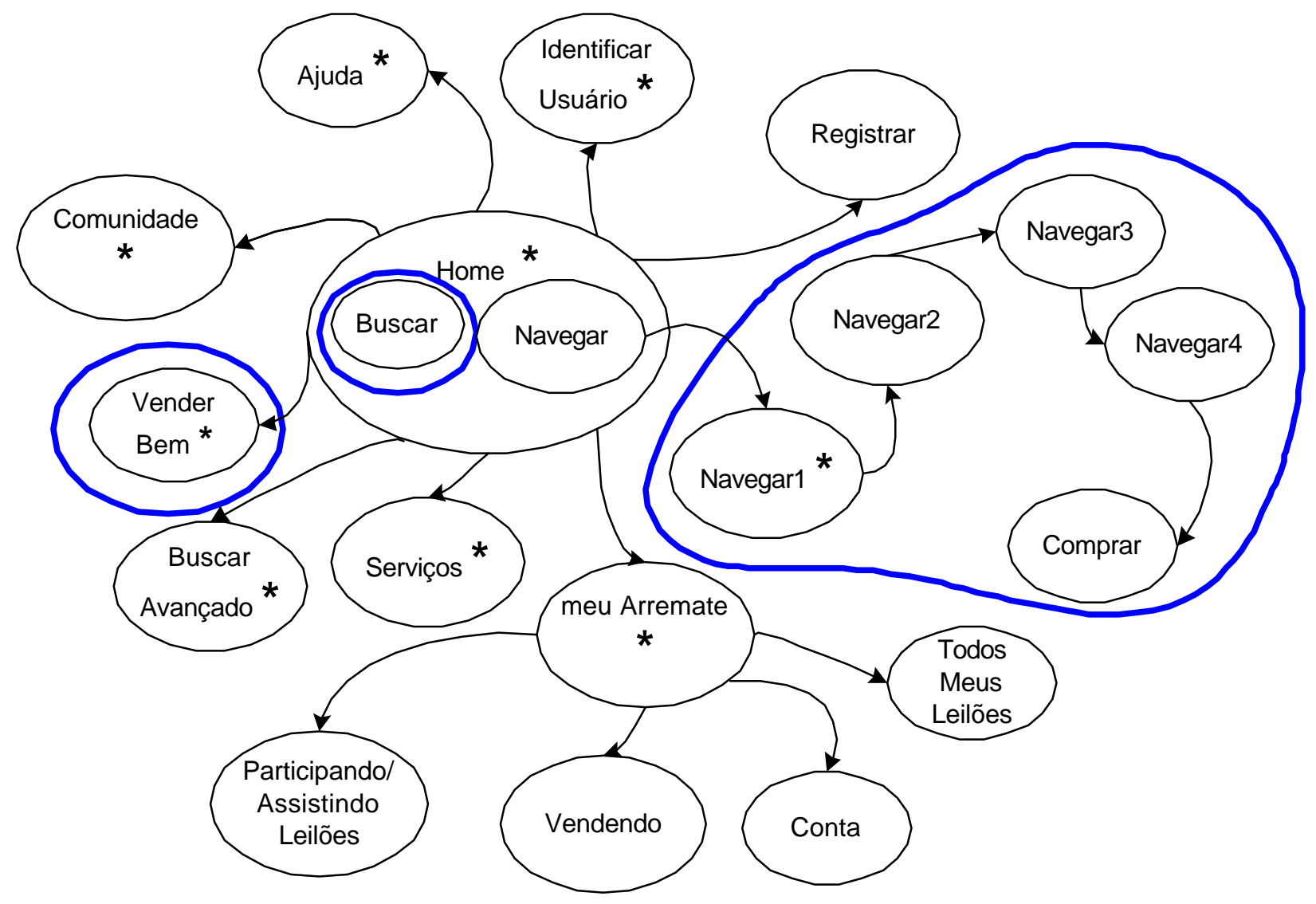

Figura 3.4: Grafo de Navegação do Sistema-base Arremate.com.

A listagem de páginas do sistema-base é usada como uma lista de verificação para garantir que todas as funções da página tenham sido registradas. Uma marcação deve ser feita nessa listagem de acordo com as páginas que são utilizadas. Geralmente as funções de uma página representam ou operações de entrada ou operações de saída. Nesse caso as funções da página são rastreadas e os 
requisitos são registrados. No entanto, podem existir páginas que implementam funções que representem conjuntamente operações de entrada e operações de saída. É freqüente que essas operações (de entrada e de saída) existentes em uma mesma página sejam dependentes dos mesmos dados e, portanto, podem ser executadas sem maiores problemas. No entanto, caso não seja possível a utilização completa da página, pelo fato das operações serem dependentes de dados diferentes, o analista deve marcar individualmente tal página como parcialmente utilizada e restabelecer para a página uma nova ordem de utilização. Essa nova ordem deve ser anotada juntamente com a antiga ordem de utilização. Essa medida garante que todas as páginas sejam utilizadas completamente.

A atividade 2.3 visa a obter a funcionalidade do sistema-base exercitando as páginas e verificando as funções contidas nas páginas desse sistema-base. Segundo a ISO/IEC9126 (1991), a funcionalidade de um sistema é o conjunto de requisitos que evidenciam a existência de um conjunto de funções e suas propriedades especificadas. Portanto, para obter e expressar a funcionalidade do sistema-base, o analista deve registrar suas funções por meio de requisitos. No entanto, o termo "requisito" não é tratado de maneira consistente no desenvolvimento de software. Em alguns casos esse termo é utilizado em definições matemáticas formais e em outros tem uma conotação relacionada a um nível mais alto de abstração, estabelecendo quais são as limitações, serviços ou funções que o sistema deve executar. Neste trabalho entende-se que os requisitos estabelecem as limitações, serviços ou funções do sistema-base.

O processo aqui proposto tem seu foco na obtenção de requisitos funcionais do sistema-base. No entanto, o analista pode, eventualmente, obter também por meio da interface Web alguns requisitos não funcionais. Por exemplo, alguns aspectos de segurança que podem ser observados durante o exercício de algumas páginas (confirmação de endereço eletrônico, senhas, número do cartão de crédito, etc). Aspectos de usabilidade podem ser citados como outro exemplo, pois o analista pode observar como o sistema-base auxilia o usuário durante a navegação das páginas, ou como eventuais ícones, diagramas e figuras podem ser usados para ilustrar o funcionamento do processo do negócio que o sistema-base apóia. Podem ser observados estes e outros requisitos não funcionais que devem estar presentes no conjunto de requisitos do sistema-base.

O método utilizado para documentar os requisitos é de livre escolha, desde que registre com detalhes o requisito e observe os padrões de qualidade necessários a uma especificação de requisitos. É preferível que cada requisito possua uma indicação referenciando a página da qual foi obtido para que, posteriormente, possa auxiliar no rastreamento e refinamento desses requisitos. Independentemente do método, é importante fornecer, juntamente com o conjunto de requisitos, um glossário com os termos mais comuns utilizados pelo sistema-base. O glossário ajuda a compreender os detalhes do sistema-base, a elucidar possíveis ambigüidades nos requisitos de um mesmo sistema-base e a evitar requisitos redundantes ou repetidos. O glossário também ajuda a encon- 
trar os conceitos distintos de diferentes sistemas-base com o mesmo significado. A determinação desses conceitos é importante em futuras atividades do processo.

A Tabela 3.3 apresenta um conjunto de requisitos provenientes do sistema-base Arremate.com. A forma de representação utilizada é a proposta por Turine e Masiero (1996), que mostram como um documento de requisitos deve ser organizado e redigido para que seja legível, não ambíguo e siga as diretrizes propostas por padrões como a ISO/IEC9126 (1991) quanto à especificação de requisitos.

Tabela 3.3: Conjunto de Requisitos do Sistema-base Arremate.com.

\begin{tabular}{|c|c|c|}
\hline Nro. Requisito & Descrição & Página \\
\hline 1.1 & $\begin{array}{l}\text { O sistema deve permitir a inserção, alteração e exclusão de categorias de bens pela } \\
\text { empresa leiloeira }\end{array}$ & Vender Bem \\
\hline 1.2 & $\begin{array}{l}\text { O sistema deve permitir a inserção, alteração e exclusão de subcategorias de bens } \\
\text { pela empresa leiloeira. Várias subcategorias podem pertencer a uma categoria, } \\
\text { porém uma subcategoria não pode pertencer a mais de uma categoria. }\end{array}$ & Vender Bem \\
\hline 1.3 & $\begin{array}{l}\text { O sistema deve permitir a inserção, alteração e exclusão de subsubcategorias de } \\
\text { bens pela empresa leiloeira. Várias subsubcategorias podem pertencer a uma sub- } \\
\text { categoria, porém uma subcategoria não pode pertencer a mais de uma subcategoria. }\end{array}$ & Vender Bem \\
\hline 1.4 & O sistema deve dar a um leilão um número de identificação único & Vender Bem \\
\hline 1.5 & $\begin{array}{l}\text { O sistema deve permitir a um vendedor inserir um bem e criar um novo leilão } \\
\text { que, a princípio, é um leilão normal, requerendo as seguintes informações: sub- } \\
\text { subcategoria em que o bem se enquadra, título, descrição, quantidade, no máximo } \\
3 \text { fotos, descrição precisa da localização, localidade, país, preço inicial, incre- } \\
\text { mento (o incremento deve estar entre } \mathrm{R} \$ 1,00 \text { e o preço inicial), duração (de um } \\
\text { a quatorze dias), modo de pagamento, modo de transporte e pagamento da taxa de } \\
\text { transporte. Existem três tipos de leilões e a escolha de um tipo inibe a utilização } \\
\text { dos outros dois tipos: } \\
\text { - se o vendedor informar um valor para o atributo preço de reserva então, } \\
\text { automaticamente o leilão é um leilão com preço de reserva; e } \\
\text { - se o vendedor informar um valor para o atributo preço fixo então, o leilão } \\
\text { é um leilão ganhador. }\end{array}$ & Vender Bem \\
\hline 1.6 & $\begin{array}{l}\text { O sistema deve, caso o leilão seja um leilão com preço de reserva, permitir que o } \\
\text { vendedor altere o preço de reserva. }\end{array}$ & Vender Bem \\
\hline 1.7 & $\begin{array}{l}\text { O sistema deve permitir que o vendedor altere o preço inicial porém, apenas para } \\
\text { um valor abaixo do que o anteriormente estabelecido. }\end{array}$ & Vender Bem \\
\hline 1.8 & $\begin{array}{l}\text { O sistema deve permitir que o vendedor altere informações na descrição do pro- } \\
\text { duto. }\end{array}$ & Vender Bem \\
\hline
\end{tabular}

A aplicação da atividade 2.3 ao sistema-base Arremate.com consistiu na utilização das páginas como se um "usuário" comum estivesse efetivamente interessado em leilões. Bens foram colocados à venda e lances foram oferecidos para observar como é o processo de compra e venda e, assim, obter informações mais detalhadas de todo o processo de negociação. Alguns lances e ofertas de leilões não foram honrados para observar como é a política de reputações de participantes. Dessa forma, conforme a necessidade dos dados foi gradativamente sendo satisfeita, o 
conhecimento sobre as funções contidas nas diversas páginas do sistema-base também foi gradativamente aumentando. Pode-se observar na tabela que os requisitos 1.5, 1.6, 1.7 e 1.8 representam funções da página "Vender Bem" que são obtidas por meio de apenas uma operação de entrada. Assim, com algumas execuções de uma mesma operação de entrada pôde-se rastrear um conjunto de requisitos. A Figura 3.5 apresenta uma das páginas do sistema-base Arremate.com, em que é possível observar alguns detalhes que constituem o requisito 1.5 da Tabela 3.3.

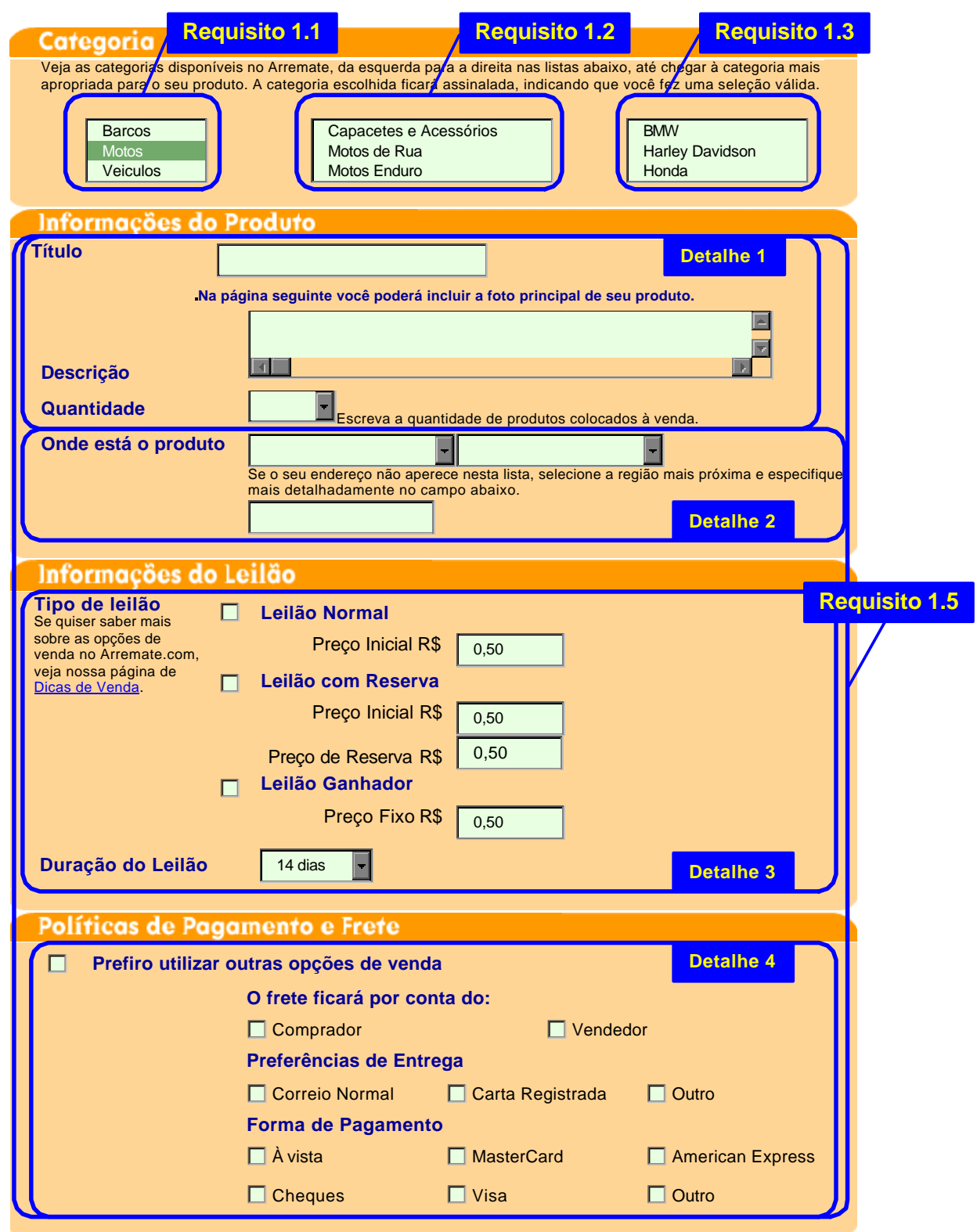

Figura 3.5: Página de Venda do Sistema-base Arremate.com.

Como citado anteriormente, durante a utilização de cada página o analista poderá observar dados já existentes no sistema-base como por exemplo, regras, prazos ou valores predeterminados. 
Esses dados foram inseridos no sistema-base ou por intermédio de uma interface que não é apresentada ao analista, ou por outro sistema com o qual o sistema-base se comunica. Se esses dados são essenciais para o funcionamento do sistema-base, então deve-se inferir as funções diretamente relacionados a esses dados já existentes e registrar os requisitos referentes a essas funções. Embora essas funções não representem a totalidade do outro sistema ou interface, elas permitirão que o sistema-base possa ser exercitado normalmente.

Alguns exemplos de requisitos inferidos são apresentados na Tabela 3.3. Os requisitos 1.1, 1.2 e 1.3 representam funções que não puderam ser observadas diretamente. Esses requisitos foram inferidos quando, no momento da operação de entrada que tratava do oferecimento de um leilão (Figura 3.5), seria necessário fornecer uma subsubcategoria em que o bem contido nesse leilão pertencesse. Para selecionar essa subsubcategoria é preciso selecionar primeiramente uma categoria dentre uma listagem de categorias, posteriormente escolher uma subcategoria entre uma listagem de subcategorias pertencentes à categoria anteriormente selecionada e por fim uma subsubcategoria entre uma listagem de subsubcategorias pertencentes à subcategoria já selecionada. No entanto, não existia interface alguma em que categorias, subcategorias e subsubcategorias pudessem ser inseridas no sistema-base. Portanto, seriam necessários formulários para manipular essas categorias, subcategorias e subsubcategorias. Pode-se inferir que esses formulários fazem parte de uma interface de serviço que não é pública, ou seja, seu uso é disponível apenas para a empresa proprietária do sistema-base. Outro exemplo de requisitos que podem ser inferidos são os requisitos originados pelas regras de funcionamento do leilão e as regras de pagamento do serviço prestado, ambos estabelecidos pela empresa leiloeira. Ainda na Tabela 3.3, pode-se notar alguns termos que estão destacados em negrito. Essa diferenciação denota que esse termo faz parte do glossário que explica com detalhes seu significado. A Tabela 3.4 mostra parte do glossário do sistema-base Arremate.com.

O objetivo da atividade 2.4 é avaliar, confrontar e refinar o conjunto de requisitos de maneira a torná-los consistentes e não ambíguos. É muito provável que a execução da atividade anterior resulte em alguns requisitos ambíguos, inconsistentes ou incompletos, já que ela tem seu foco voltado para o rastreamento e coleta individual dos requisitos e não na visão geral do sistema-base. Pode ainda existir requisitos cuja descrição esteja confusa devido à atenção dada à execução das páginas. Esta atividade visa a detectar e resolver esses problemas e, para tanto, técnicas de revisão e de descrição de requisitos podem auxiliar (Davis, 1995; von Mayrhauser, 1990; Pressman, 2000; Sommerville, 1996). O analista pode necessitar esclarecimento sobre alguns requisitos e, para esclarecer as dúvidas ele pode utilizar a referência que o requisito faz à página que o originou e, executá-la novamente. O analista deve também revisar o glossário, já que podem existir erros provenientes da atividade de rastreamento ou mudanças devido ao refinamento dos requisitos. Os erros e alterações mais comuns encontrados na revisão dos sistema-base estudados foram: 
Tabela 3.4: Exemplo de Glossário do Sistema-base Arremate.com.

\begin{tabular}{|l|l|}
\hline \multicolumn{1}{|c|}{ Termo } & \multicolumn{1}{c|}{ Significado } \\
\hline \hline bem & É um produto ou serviço que pode ser comercializado por meio de um leilão. \\
\hline incremento & $\begin{array}{l}\text { Para simplificar o processo de compra, os valores dos lances são aumentados por inter- } \\
\text { médio de incrementos. O incremento é o mínimo que o comprador pode aumentar sobre } \\
\text { um lance já oferecido para poder oferecer um novo lance. }\end{array}$ \\
\hline leilão & $\begin{array}{l}\text { É um processo de comercialização no qual um bem é colocado à venda por um vendedor } \\
\text { e para o qual vários potenciais compradores eventualmente oferecem lances. Um leilão } \\
\text { pode ser de vários tipos, possuindo suas próprias regras de funcionamento. Essas várias } \\
\text { regras de funcionamento regem a forma como o leilão funciona, como devem ser os } \\
\text { lances e como o vencedor é escolhido. }\end{array}$ \\
\hline leilão normal & $\begin{array}{l}\text { É o tipo de leilão mais comum, em que o vendedor põe um bem à venda com um preço } \\
\text { inicial e os compradores oferecem lances no decorrer do tempo. Vence o leilão o lance } \\
\text { de valor mais alto ao término do leilão. }\end{array}$ \\
\hline preço inicial & $\begin{array}{l}\text { É um valor monetário que o vendedor estabelece como sendo o valor mínimo do bem } \\
\text { que ele está oferecendo. }\end{array}$ \\
\hline vendedor & $\begin{array}{l}\text { É um usuário do sistema que em um determinado momento é caracterizado como ven- } \\
\text { dedor de um bem, isto é, um usuário que está colocando um bem à venda. } \\
\ldots\end{array}$ \\
\hline
\end{tabular}

- replicação, omissão ou erro de características: o analista esqueceu ou duplicou um detalhe durante a observação de uma função ou ainda, erro na descrição do detalhe e proveniente da determinação de outros requisitos, como por exemplo erro no nome de um atributo, duplicação desse atributo ou omissão do atributo;

- mudança na seção do requisito: um requisito foi originalmente colocado em uma seção do documento de requisitos mas, durante a atividade de refinamento constatou-se que a função por ele evidenciada encaixa-se melhor em outra seção;

- duplicação de requisito: ocorreu o registro de dois requisitos que tratam de uma mesma função devido a erro ou esquecimento da marcação na lista de páginas do sistema-base; e

- funções diferentes referenciadas por um mesmo requisito: um requisito originalmente descreve mais do que uma função porém, durante a atividade de refinamento constatou-se que ele tratava de funções diferentes ou que possuíam uma leve diferenciação, como por exemplo, os requisitos 1.6 e 1.7 apresentados na Tabela 3.3.

\subsubsection{Criação dos Modelos de Classes dos Sistemas-base}

A Figura 3.6 apresenta as subatividades necessárias para a criação dos modelos de classes dos sistemas-base. Similarmente às anteriores, deve-se executar todas as subatividades da atividade 3 para um sistema-base de cada vez e assim sucessivamente até que todos os sistemas-base tenham sido analisados. Com a existência do documento de requisitos dos sistemas-base, a atividade 3 é, basicamente, um processo de engenharia avante para cada sistema-base escolhido. Pode-se utilizar 
qualquer método de desenvolvimento de software orientado a objetos, já que o principal propósito desta atividade é criar um modelo de classes dos sistemas-base.

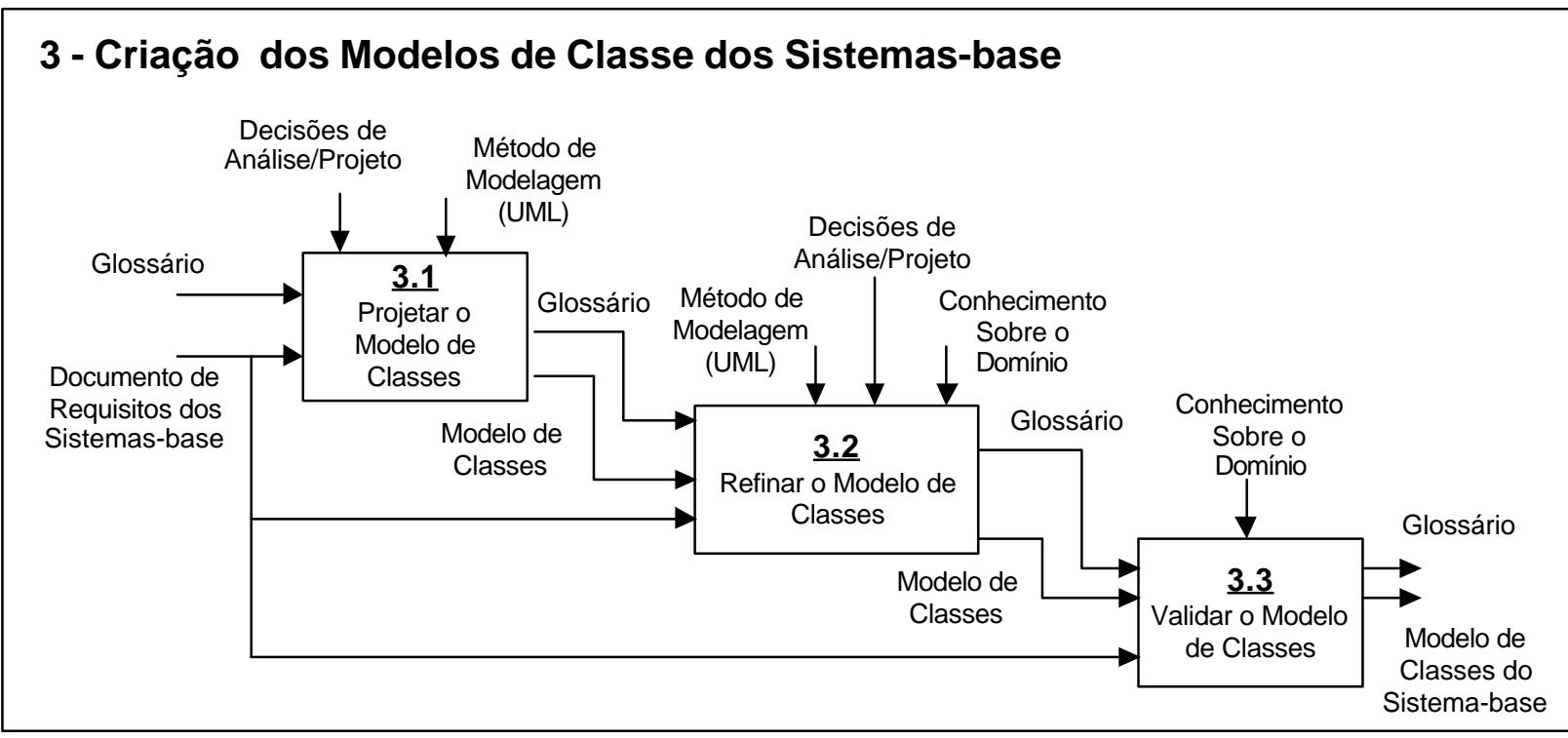

Figura 3.6: Criação dos Modelos de Classe dos Sistemas-base.

O primeiro problema encontrado no desenvolvimento do modelo de classes é como identificar as classes ou candidatos a classes e seus relacionamentos, suas operações e seus atributos. Além de métodos de desenvolvimento que podem auxiliar nessa atividade, pode-se encontrar diretrizes sobre como identificar classes e objetos nos livros de Booch (1994), Booch e Rumbaugh (1996), Coad e Yourdon (1991), Coleman et al. (1996), Jacobson (1998) e Rumbaugh (1991).

A atividade 3.1 trata do projeto de classes dos sistemas-base frente aos requisitos obtidos na fase anterior. Essa atividade visa a construir o modelo de classes com o auxílio de uma linguagem de modelagem. Pode-se utilizar qualquer linguagem de modelagem orientada a objeto que permita modelar classes ou objetos pertinentes ao sistema-base. Um ponto importante é a capacidade de expressar os elementos do sistema-base em termos de elementos pertencentes à abordagem de desenvolvimento orientado a objeto. O foco da atividade 3.1 é propor uma solução no nível de análise por meio do refinamento dessas entidades. Iniciar identificando classes pode ser uma entre várias formas de identificar as entidades presentes no documento de requisitos. $\mathrm{O}$ documento de requisitos contêm basicamente objetos porém, ao se identificar potenciais objetos, automaticamente identificam-se potenciais classes (Pressman, 2000). Deve-se registrar cada potencial classe encontrada no documento de requisitos. Praticamente qualquer substantivo, ou frase substantiva é uma potencial classe. Entretanto, para que seja considerado uma potencial classe, o substantivo deve estar relacionado a um conceito importante para o entendimento do domínio. O glossário, por possuir elementos significativos ao domínio, pode fornecer ao analista um conjunto inicial de 
potenciais classes. A Tabela 3.5 mostra um exemplo parcial das potenciais classes identificadas com o apoio do glossário e do documento de requisitos do sistema-base Arremate.com.

Tabela 3.5: Listagem de Potenciais Classes do Sistema-base Arremate.com.

\begin{tabular}{|l|l|}
\hline \multicolumn{1}{|c|}{ Potencial Classe } & \multicolumn{1}{c|}{ Descrição } \\
\hline \hline Incremento & $\begin{array}{l}\text { Valor de acréscimo sobre o valor do último lance oferecido em leilão para que } \\
\text { o próximo lance oferecido tenha um valor válido }\end{array}$ \\
\hline Lance & Valor oferecido por usuários interessados em adquirir o bem de um Leilão \\
\hline Leilão & Tipo de comercialização de bens \\
\hline Leilão com Preço de Reserva & $\begin{array}{l}\text { Tipo de leilão com regras específicas para atrair o público garantindo um valor } \\
\text { mínimo aceito pelo vendedor }\end{array}$ \\
\hline Leilão Ganhador & Tipo de leilão específico para a comercialização rápida de em bem \\
\hline Leilão Normal & Um tipo de leilão que possui regras tradicionais \\
\hline Bem & Produto ou serviço que é oferecido em um leilão \\
\hline Vendedor & Usuário do sistema-base que oferece um leilão \\
$\ldots$ & $\ldots$ \\
\hline
\end{tabular}

Após ter estudado o glossário o analista deve estudar o documento de requisitos. Ao analisar os requisitos pode ser necessária a alteração da lista de classes potenciais. Podem existir nessa lista candidatos a classes que não são de fato classes. Ainda nessa fase de análise dos requisitos da atividade 3.1, o analista deve identificar além de classes, os demais elementos do sistemabase: relacionamentos, cardinalidades, atributos, métodos, operações e detalhes que influenciam o funcionamento do sistema-base. Algumas diretrizes podem ajudar a identificar essas entidades:

- Para identificar possíveis relacionamentos entre as classes, deve-se procurar no documento de requisitos por comunicações, associações físicas, inclusões e ações;

- As cardinalidades dos relacionamentos podem ser estabelecidas pela determinação de um conjunto de tuplas que sirvam como exemplo para o relacionamento;

- Qualquer classe que não possua atributos e que esteja relacionada a apenas uma outra classe, pode ser transformada em um atributo. Os atributos correspondem a características relevantes de um determinado objeto;

- As operações do sistema são sempre ativadas por um agente, e não por um objeto. As operações geralmente representam as funções principais das páginas do sistema-base; e

- Por meio das operações pode-se inferir os principais métodos para o seu funcionamento.

Além de elementos pertinentes ao sistema-base, os requisitos podem representar detalhes do funcionamento do sistema-base ou características não funcionais que não correspondem diretamente a qualquer entidade do modelo de classes. Esses requisitos devem ser marcados para posterior verificação em atividades futuras, pois são importantes para o entendimento e funcionamento do sistema-base. 
Pode-se utilizar o documento de requisitos como uma lista de verificação, analisando cada requisito para tomar uma decisão de projeto/análise. Essas decisões estabelecem as entidades, anteriormente apresentadas, que farão parte do modelo de classes do sistema-base. Utilizando os requisitos do sistema-base Arremate.com foi possível identificar as entidades e registrá-las em uma tabela que consiste de uma referência ao requisito e uma decisão ou várias decisões de análise/projeto para que o requisito fosse atendido, apresentado na Tabela 3.6. Na decisão sobre o requisito 1.6, por exemplo, existe uma nota indicando que ele pode ser atendido apenas com detalhes de projeto e implementação e não por meio de elementos do modelo de classes. Como mencionado anteriormente, esses detalhes devem ser observados em futuras atividades do processo. Para atender ao requisito 1.9 foi necessária a criação de uma operação de entrada, pois é uma ação que pode ser desempenhada por um "ator" (Rumbaugh et al., 1999). Esse "ator" é quem vai utilizar essa operação para encerrar antecipadamente o leilão.

Pode-se observar na Tabela 3.6 que um requisito pode dar origem a várias entidades, por exemplo, o requisito 1.5. Algumas classes, atributos, métodos, operações e relacionamentos com são um exemplo da diversidade de elementos envolvidos para atende-lo. Dentre as entidades originárias desse requisito existem as classes Recurso e Leilão, alguns atributos dessas classes, como por exemplo título e duração na classe leilão e descrição e foto na classe Recurso, que podem ser observadas diretamente nos requisitos. No entanto, existem alguns elementos do modelo que não podem ser verificados diretamente nos requisitos. Esses elementos são inferidos pelo analista levando em consideração a função que o requisito ou requisitos descreve. Como exemplo pode-se citar os atributos dataInicio, horaInicio, dataTermino, horaTermino e o método encerrar (Tabela 3.6). Esses atributos não podem ser observadas diretamente na página "Vender bem" (Tabela 3.2) e por conseqüência no requisito que descreve sua função (Tabela 3.3). No entanto, pode-se concluir que são elementos importantes para o funcionamento do sistema-base e devem ser registrados. Por exemplo, sem o atributo data Inicio não seria possível determinar quando o leilão deveria poder começar a receber lances, também não seria possível saber quando terminar, já que o usuário informa a duração do leilão e não a data do término (Figura 3.5). Outro exemplo é o atributo dataInicio, que é importante pois, apesar da classe leilão possuir o atributo dataInicio e o atributo duração, pode ocorrer do leilão terminar antes da data prevista, por motivo de cancelamento. Dessa forma, é importante armazenar a data real do término do leilão.

Além das entidades que podem ser observadas diretamente nos requisitos e das entidades inferidas pelo analista, existem outras entidades originárias de decisões de análise/projeto. Diferentemente das entidades inferidas ou observadas pelo analista, fazem parte da solução proposta pelo analista em relação ao conjunto de entidades já identificadas. Como exemplo pode-se citar o relacionamento das classes Leilão Normal, Leilão ganhador e Leilão com Preço de Reserva com a classe Leilão. A decisão de que as primeiras classes 
Tabela 3.6: Decisões de Análise/Projeto Referentes aos Requisitos do Sistema-base Arremate.com.

\begin{tabular}{|c|c|}
\hline $\begin{array}{l}\text { Nro. } \\
\text { Requi- } \\
\text { sito }\end{array}$ & Decisão Tomada \\
\hline 1.1 & $\begin{array}{l}\text { Criação da classe Categoria com os seguintes atributos: nome, descrição. } \\
\text { Criação da operação ?criar (categoria), da operação ?destruir (categoria) e da opera- } \\
\text { ção ?alterar (categoria) na classe Categoria. }\end{array}$ \\
\hline 1.2 & $\begin{array}{l}\text { Criação da classe Subcategoria com os seguintes atributos: nome e descrição. } \\
\text { Criação do operação ?criar (subcategoria), do operação ?destruir (subcategoria) e } \\
\text { do operação ?alterar (subcategoria) na classe Subcategoria. }\end{array}$ \\
\hline 1.3 & $\begin{array}{l}\text { Criação da classe Subsubcategoria com os seguintes atributos: nome, descrição. } \\
\text { Criação do operação } \quad \text { ?criar (subsubcategoria), do operação } \\
\text { ?destruir (subsubcategoria) e do operação ?alterar(subsubcategoria) na } \\
\text { classe Subsubcategoria. }\end{array}$ \\
\hline 1.4 & Detalhes de Projeto/Implementação. \\
\hline 1.5 & $\begin{array}{l}\text { Criação da classe Recurso com o atributo descrição e atributo foto. } \\
\text { Criação da classe Categoria com os seguintes atributos: nome, descrição. } \\
\text { Criação do relacionamento Recurso } \Leftarrow \star \text { Pertence a } 1 \Rightarrow \text { Categoria. } \\
\text { Criação do relacionamento Categoria } \Leftarrow 1 . \star \star \text { Pertence a } 1 \Rightarrow \text { Subcategoria. } \\
\text { Criação do relacionamento Subcategoria } \Leftarrow 1 . \text { * Pertence a } 1 \Rightarrow \text { Subsubcategoria. } \\
\text { Criação da classe Leilão. } \\
\text { Criação do relacionamento Leilão } \Leftarrow 1 \text { Possui } 1 \Rightarrow \text { Recurso. } \\
\text { Criação dos atributos: título, garantia, formaRemessa, formaPagamento, } \\
\text { políticaPagamento, pagadorDespesasRemessa, localidade, quantRecursos, } \\
\text { inicio, duração, preçoInicial, na classe Leilão. } \\
\text { Criação dos atributos: dataInicio, horaInicio, dataTérmino, horaTérmino, na classe } \\
\text { Leilã̃o. } \\
\text { Criação do método determinarVencedor (leilão) na classe Leilão. } \\
\text { Criação da classe Leilão Reserva com o atributo preçoReserva. } \\
\text { Criação do relacionamento Leilão } \Rightarrow \text { Leilão Reserva. } \\
\text { Criação do método determinarVencedor (leilão) na classe Leilão Reserva. } \\
\text { Criação da classe Leilão Normal. } \\
\text { Criação do relacionamento Leilão } \Rightarrow \text { Leilão Normal } \\
\text { Criação do método determinarVencedor (leilão) na classe Leilão Normal. } \\
\text { Criação do classe Leilão Ganhador. } \\
\text { Criação do relacionamento Leilão } \Rightarrow \text { Leilão Ganhador } \\
\text { Criação do método determinarVencedor (leilão) na classe Leilão Ganhador. }\end{array}$ \\
\hline 1.6 & $\begin{array}{l}\text { Criação da operação } \quad \text { ?alterarPreçoReserva (precoReserva) } \\
\text { Leilão Reserva. }\end{array}$ \\
\hline 1.7 & $\begin{array}{l}\text { Criação da operação ?alterarPreçoInicial (precoInicial) na classe Leilão. } \\
\text { Detalhes de Projeto/Implementação }\end{array}$ \\
\hline 1.8 & Criação da operação ?alterarDescrição (descrição) na classe Recurso. \\
\hline $\begin{array}{l}1.9 \\
\ldots\end{array}$ & $\begin{array}{l}\text { Criação da operação ?encerrarAntecipado (leilão) na classe Leilão. } \\
\text {.. }\end{array}$ \\
\hline
\end{tabular}

são subclasses da classe Leilão foi tomada pelo analista seguindo diretrizes da análise orientada a objeto.

O método utilizado para identificar as entidades do sistema-base Arremate.com, apresentado na Tabela 3.6, caracteriza-se por analisar os requisitos e tomar as respectivas decisões de forma 
linear. Essa característica faz com que as decisões gradualmente complementem o modelo de classes, sendo freqüente encontrar a necessidade de tomar uma decisão sobre um requisito já tomada anteriormente em relação a outro requisito, como por exemplo, a criação de uma classe ou relacionamento. Deve-se omitir decisões já tomadas, relacionadas a requisitos analisados anteriormente, evitando duplicações. Uma decisão de análise/projeto pode entrar em conflito com um requisito anteriormente analisado ou não ser a ideal para atender a esses requisitos. Nesse caso, os requisitos devem ser verificados e, tanto as decisões quanto os requisitos devem ser corrigidos. Adotando-se essa estratégia pode-se, ao novamente analisar requisito a requisito, identificar possíveis defeitos na especificação de requisitos.

Pode-se observar na Tabela 3.6 a existência de uma notação para auxiliar na descrição das decisões de análise/projeto. Essa notação foi utilizada para facilitar a posterior construção dos modelos de análise utilizando a UML (do inglês, Unified Modeling Language) (Rumbaugh et al., 1999). Caso outra linguagem de modelagem seja aplicada, a notação utilizada no processo para descrever as decisões dos sistemas-base pode não ser adequada. Portanto, fica a cargo do analista definir o modo de representação das entidades pertencentes ao modelo do sistema-base. A notação utilizada para descrever as decisões de análise/projeto dos sistemas-base estudados é a seguinte:

- classe: nome-classe;

- herança: superclasse $\Rightarrow$ subclasse;

- relacionamento: $\mathrm{n}-\mathrm{classe} 1 \Leftarrow$ card $\mathrm{n}$-relacionamento card $\Rightarrow \mathrm{n}$-classe2;

- atributo: nome-atributo;

- método: nome-método;

- operação de entrada: ?nome-operação-entrada ();

- operação de saída: !nome-operação-saída ();

- operação de entrada em que a mensagem é enviada para uma coleção de objetos da mesma classe: ?*nome-operação-saída ();

- operação de saída em que a mensagem é enviada para uma coleção de objetos da mesma classe: ! *nome-operação-saída (); e

- descrição dos detalhes: Detalhes de Projeto/Implementação .

É importante ressalvar que a Tabela 3.6 é apenas um registro das decisões de análise/projeto sobre os requisitos do sistema-base. Na medida que o analista cria a tabela vai também criando o modelo de classes. Neste trabalho, a criação do modelo de classes do sistema-base Arremate.com, parcialmente apresentado na Figura 3.7, foi feita utilizando uma ferramenta de modelagem denominada Rational Rose ${ }^{2}$. Os métodos e operações canônicas (criar, alterar, destruir) não foram

\footnotetext{
${ }^{2}$ Ferramenta produzida pela empresa Rational Software Corporation, http: / / www . rational . com/.
} 
adicionados ao modelo de classes para diminuir a complexidade sem no entanto, alterar a representação da funcionalidade do sistema-base. O conceito de operação utilizado na linguagem de padrões é o proposto por Larman (1997). As operações de saída do sistema são denotadas pelo prefixo “!” e as operações de entrada do sistema por um prefixo “?”. Quando uma mensagem é enviada para uma coleção de objetos ao invés de uma simples instância, o prefixo “*” é utilizado.



Figura 3.7: Parte do Modelo Inicial de Classes do Sistema-base Arremate.com.

A atividade 3.2 visa a refinar o modelo de classes por meio da análise do modelo, tomando decisões de análise/projeto para propor melhores soluções, confrontando o conjunto dos requisitos e o modelo de classes. Este proporciona ao analista uma visão geral do sistema-base, diferentemente da visão obtida por meio dos requisitos. Os requisitos descrevem individualmente funções do sistema-base por intermédio de uma ou mais entidades ou de detalhes, enquanto que o modelo de classes proporciona uma visão da estrutura de todo o sistema-base. Isso ocorre porque o modelo de classes apresenta não somente as entidades individualmente, mas também a relação existente entre elas.

Durante a construção do modelo de classes o analista obtém a visão parcial do modelo de classes e é provável que o analista aplique um certo grau de refinamento tendo como auxílio essa visão parcial. Com essa visão parcial o analista pode estudar qual a melhor solução para a inserção de novas entidades frente a entidades já presentes no modelo de classes. Com isso o modelo de classes vai gradativamente sendo refinado para atender aos requisitos. 
Nesta fase do processo o analista já possui um modelo de classes completo e deve refinar esse modelo por meio de decisões de análise/projeto, sempre em conformidade com os requisitos. Esse refinamento depende da experiência do analista em relação ao domínio do sistema-base. No entanto, nesse estágio do processo torna-se mais fácil para o analista tomar essas decisões, pois ele é auxiliado pela visão global proporcionada pelo modelo de classes e pela experiência que adquiriu com a aplicação do processo. A Figura 3.8, ainda do sistema-base Arremate.com, mostra uma dessas decisões de análise/projeto em que as classes Categoria, Subcategoria e Subsubcategoria e seus relacionamentos foram substituídas pela classe Categoria e por um auto-relacionamento.

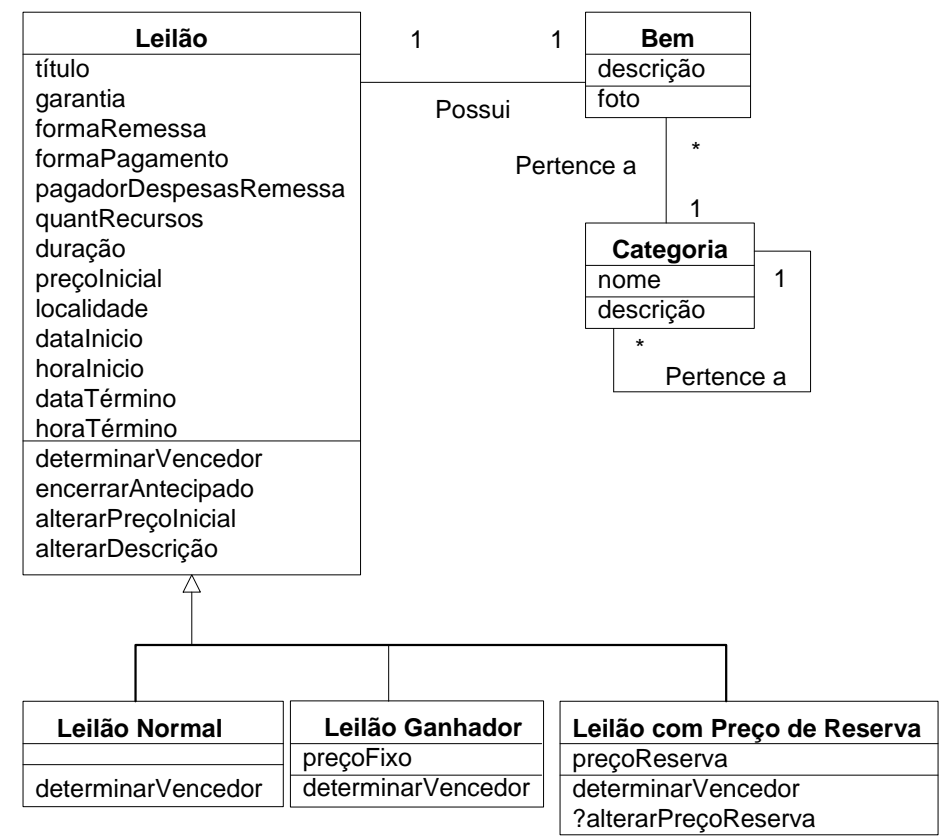

Figura 3.8: Parte do Modelo de Classes Refinado do Sistema-base Arremate.com.

É importante para o refinamento do modelo de classes que tanto os detalhes de projeto/implementação que descrevem ou influenciam as entidades presentes na tabela de entidades, como aqueles reconhecidos pelo analista durante a aplicação do processo, estejam presentes nas respectivas descrições do modelo de classes. Os "detalhes de Projeto/Implementação" presentes na Tabela 3.6 indicam o requisito que geralmente descreve essas características das operações, métodos atributos ou classes. Como exemplo, pode-se citar detalhes que são importantes para outros requisitos, restrições de uma operação, regras de funcionamento do sistema-base ou o papel de uma entidade no contexto do sistema-base. Um exemplo específico pode ser observado na Tabela 3.6 em que são apresentadas as decisões sobre o requisito 1.7, no qual é possível observar a indicação "Detalhes de Projeto/Implementação". Essa observação informa que existe uma regra de restrição na operação ?alterarPreçoInicial (precoInicial) que restringe a alteração 
do preço inicial, de forma que o novo preço deve ser sempre mais baixo que o preço inicial vigente, nunca mais alto.

A atividade 3.3 tem por objetivo a validação do modelo de classes criado pelo analista. Essa validação é constituída basicamente de revisões feitas no documento de requisitos e na tabela de entidades para obter completitude e consistência. Deve-se confrontar os modelos de análise não somente com os requisitos mas também com o conhecimento sobre o domínio, tentando capturar todas as abstrações significativas do domínio do problema e evitar contradições mútuas entre as entidades. Algumas diretrizes para validação do modelo de classes foram mostradas por Booch (1994), Booch e Rumbaugh (1996), Coad e Yourdon (1991), Coleman et al. (1996), Jacobson (1998) e Rumbaugh (1991).

Como citado anteriormente, é possível que o analista encontre eventuais defeitos no documento de requisitos e no glossário. Esses defeitos devem ser corrigidos para que se possa executar a próxima fase do processo.

\subsubsection{Criação do Modelo do Domínio}

O resultado desta atividade é um modelo de classes do domínio que oferece um conjunto de funções correspondente à funcionalidade encontrada nos sistemas-base ou, suas principais funções. A Figura 3.9 apresenta as subatividades a serem seguidas: identificar as classes, tratar as classes similares, tratar as classes parcialmente similares, tratar as classes distintas e refinar o modelo de classes do domínio. Enquanto nas atividades anteriores o analista executa as subatividades individualmente para cada sistema-base, nesta atividade o trabalho do analista deve concentrar-se na análise do conjunto dos sistemas-base. Para tanto, o analista pode necessitar consultar produtos intermediários das atividades anteriores, como por exemplo, a especificação de requisitos. Esse fato ocorre devido às decisões tomadas em relação ao problema de abstrair a funcionalidade dos outros sistemas-base em um único modelo, tornando necessário verificar possíveis dúvidas ou observar maiores detalhes dos sistemas-base.

Apesar dos diferentes sistemas-base serem do mesmo domínio, algumas de suas funções podem ser as mesmas, outras funções podem diferir umas das outras em alguns detalhes e podem existir também funções totalmente distintas. Para que seja possível criar um modelo do domínio, é necessário compreender as funções dos sistemas-base e determinar o grau de similaridade entre elas. Com esse intuito, é importante compreender como os conjuntos de elementos dos modelos de classe se relacionam para representar as funções dos sistemas-base e, por meio da análise da similaridade desses elementos, determinar novos conjuntos para representar as funções pertinentes ao domínio.

Identificar a similaridade dos elementos é uma tarefa que necessita de conhecimento sobre o domínio, já que a decisão sobre sua similaridade é subjetiva. Um importante fator ao longo desta 


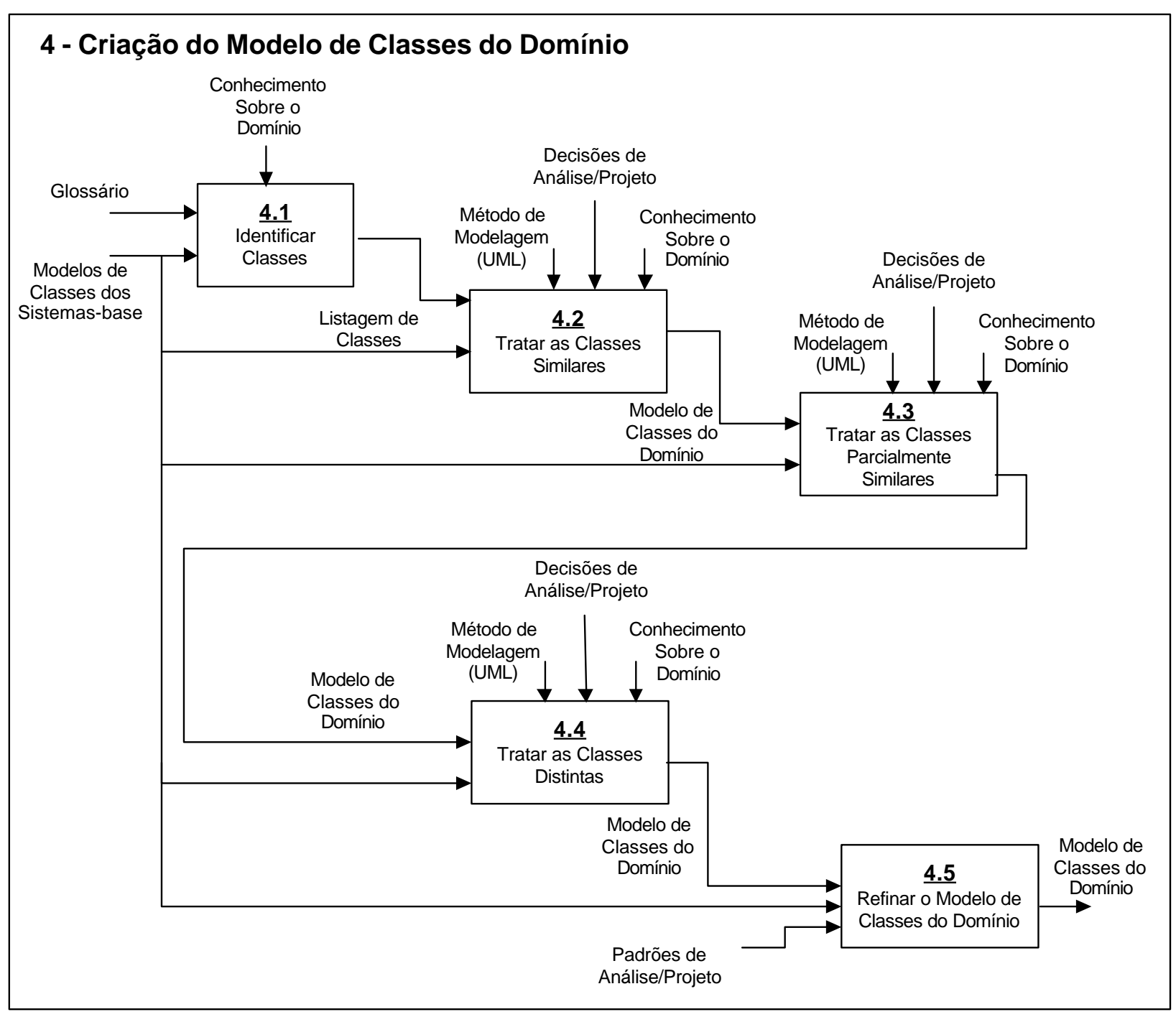

Figura 3.9: Criação do Modelo do Domínio.

atividade é a constante tomada de decisão em relação à permanência de elementos do modelo de classes dos sistemas-base no modelo de classes do domínio. Fica a cargo do analista decidir se um elemento, seja uma classe, um método ou qualquer outro, deve ser adicionado ao modelo de classes do domínio.

Assumindo que as classes encapsulam um conjunto de elementos menores referentes a si mesmas e que esses elementos descrevem detalhes de funções relacionadas à classe, pode-se propor que ao estudar a classe o analista obtém tanto a visão do relacionamento dos elementos que representam a classe como a visão do conjunto de funções que esses elementos representam. Dessa forma, é possível determinar de maneira facilitada a similaridade das classes e, consequientemente, de seus elementos menores. Portanto, iniciar a construção do modelo analisando primeiramente as classes, permite que o analista comece o estudo das funções em um nível de abstração adequado. 
O estudo inicial das funções deve manter seu foco no papel que a classe exerce no contexto do domínio e não nos elementos menores que ela possui. Muito provavelmente os elementos dessas classes, bem como seus relacionamentos e cardinalidades, não são totalmente similares. Primeiramente deve-se identificar a similaridade entre as classes e, posteriormente, nas atividades que seguem, os outros elementos são analisados em função da similaridade das classes.

A atividade 4.1, apresentada na Figura 3.9, tem por objetivo categorizar as classes segundo o estabelecimento do grau de similaridade entre elas nos sistemas-base, quando observados seus papéis em relação ao domínio. Deve-se produzir uma listagem de classes do domínio que contenha as classes de todos os sistemas-base categorizando-as como: similares, parcialmente similares ou distintas. No entanto, é um problema compreender os significados dos vários elementos contidos nos modelos de classe e determinar sua similaridade, devido à variedade dos sistemas-base e de suas funções.

A especificação de requisitos possui um glossário que apresenta a descrição dos termos relevantes para o domínio. Como apresentado na Seção 3.3, muitos desses termos são relacionados diretamente a classes do modelo de classes dos sistemas-base e apresentam detalhes que podem auxiliar o analista na determinação e compreensão do papel que a classe representa no domínio. Assim, desenvolver um glossário único auxilia na identificação de similaridade entre as classes dos sistemas-base.

Para familiarizar o analista quanto à similaridade dos termos e, adicionalmente, obter a generalização dos termos dos sistemas-base e auxiliar na documentação do modelo de classes, o analista deve analisar o glossário dos sistemas-base e desenvolver um glossário do domínio. Deve haver uma identificação dos termos dos diversos glossários segundo a seguinte classificação, baseada na nomenclatura e significado desses termos:

1. Termos iguais com significados iguais: esses termos devem ser inseridos em um glossário do domínio. Em cada termo do glossário do domínio deve haver uma indicação referente ao termo do glossário do sistema-base ao qual ele pertence.

2. Termos diferentes com significados iguais: deve-se criar um termo genérico único que possa ser utilizado para referenciar os vários termos com o mesmo significado. Esse novo termo deve ser inserido no glossário do domínio e ter referências para os termos dos sistemas-base que o originaram.

3. Termos iguais com significados diferentes: nesse caso é necessário inserir referências nos termos dos glossários dos sistemas-base, identificando a existência desses termos nos diferentes glossários. Essa referência deve registrar a não similaridade dos termos, denotando que apesar de iguais possuem um significado diferente. Deve-se, também, criar um termo genérico único para cada termo diferente que possui o mesmo significado e inclui-lo no glossário do domínio. Nesse glossário deve haver uma referência ao termo que o originou. 
O Quadro 3.1 apresenta parcialmente termos dos glossários do domínio e dos sistemas-base. Nessa tabela é possível observar alguns termos classificados segundo as três possibilidades de nomenclatura e significado anteriormente apresentadas. Os termos "leilão" e "lance" são classificados como termos iguais com significados iguais $\left(1^{\circ} \mathrm{caso}\right)$, pois estão presentes em todos os glossários com o mesmo significado. Pode-se, ainda, perceber que os termos "formulário de reembolso" (Arremate.com) e "formulário de restituição de crédito de valor final" (eBay) bem como os termos "taxa de sucesso" (Arremate.com) e "taxa sobre valor final" (eBay) são termos diferentes com o mesmo significado $\left(2^{\circ} \mathrm{caso}\right)$. O Quadro 3.1 apresenta também as referências entre os glossários indicando quais termos dos glossários, tanto dos sistemas-base como do domínio, relacionam-se entre si. Como exemplo pode-se citar o "leilão ganhador" (Arremate.com) que possui a referência "[eBay, leilão de compra] [Domínio, leilão de compra]", indicando os termos que são relacionados. Adicionalmente, pode-se observar que os termos respectivos do "eBay" e do "Domínio" também referenciam o termo no glossário do "Arremate.com".

Por meio do glossário do domínio o analista pode estabelecer diretamente a similaridade entre as classes que são relacionadas aos termos do glossário dos sistemas-base segundo os três níveis de similaridade anteriormente mencionados. Para tanto, deve-se adicionar, com a ajuda do glossário do domínio, as classes dos sistemas-base na listagem de classes do domínio. É importante manter a consistência entre os termos e os nomes das classes do domínio para que, caso o analista deseje obter detalhes das classes originais em futuras atividades do processo, seja possível rastreá-las por meio das referências cruzadas contidas no glossário.

Nem todas as classes são diretamente relacionadas a termos do glossário. Assim, é necessário que o analista estude essas classes diretamente no modelo de classes, tentando determinar quais delas podem ser consideradas similares. Como nos termos dos glossários, as classes podem ser classificadas segundo sua nomenclatura e significado. As várias alternativas que ocorrem com os termos do glossário podem acontecer com o nome das classes. Portanto, o mesmo procedimento para determinação dos termos e seus significados deve ser aplicado aos nomes das classes. Por exemplo, em caso de classes que possuam nomes diferentes com a mesma função, deve-se determinar um nome comum ao inseri-la na listagem de classes do domínio. Deve haver uma referência para as classes que a originaram, possibilitando que o analista rastreie sua origem.

A Tabela 3.7 apresenta o exemplo de uma listagem utilizada para auxiliar na determinação da similaridade das classes. Essa listagem é constituída basicamente de uma referência cruzada entre as classes e os sistemas-base. A tabela apresenta uma visão geral do relacionamento das classes com os sistemas-base, denotando quais classes são similares, parcialmente similares e distintas. As classes pertencentes a todos os sistemas-base são classes similares, como por exemplo, Vendedor, Leilão e Leilão Normal. As classes parcialmente similares são aquelas que pertencem a mais de um sistema-base mas não a todos, como por exemplo Leilão de Compra e 
Quadro 3.1: Partes dos Glossários do Domínio e dos Sistemas-base.

\begin{tabular}{|c|c|}
\hline \multicolumn{2}{|r|}{ Arremate.com } \\
\hline $\begin{array}{l}\text { formulário } \\
\text { de reembol- } \\
\text { so }\end{array}$ & $\begin{array}{l}\text { Formulário enviado pelo vendedor à empresa lei- } \\
\text { loeira pedindo reembolso da taxa de sucesso } \\
\text { pela... }\end{array}$ \\
\hline lance & $\begin{array}{l}\text { Oferta, em valor monetário, de um comprador a } \\
\text { um bem em um determinado leilão. . }\end{array}$ \\
\hline leilão & $\begin{array}{l}\text { É um processo de comercialização no qual um } \\
\text { bem é colocado à venda. . }\end{array}$ \\
\hline $\begin{array}{l}\text { leilão ga- } \\
\text { nhador }\end{array}$ & $\begin{array}{l}\text { Esse tipo de leilão é como se fosse uma venda con- } \\
\text { vencional. O vendedor estabelece um preço que } \\
\text { determina a venda do bem... }\end{array}$ \\
\hline $\begin{array}{l}\text { leilão reco- } \\
\text { mendado }\end{array}$ & $\begin{array}{l}\text { São leilões escolhidos pelo sistema, dentre alguns } \\
\text { leilões candidatos estabelecidos por regras de ne- } \\
\text { gócio ... }\end{array}$ \\
\hline $\begin{array}{l}\text { taxa de su- } \\
\text { cesso }\end{array}$ & $\begin{array}{l}\text { Taxa cobrada vendedor sobre o valor final da } \\
\text { transação... }\end{array}$ \\
\hline$\ldots$ & \\
\hline
\end{tabular}

\begin{tabular}{|c|c|}
\hline \multicolumn{2}{|r|}{ eBay } \\
\hline $\begin{array}{l}\text { formulário } \\
\text { de resti- } \\
\text { tuição de } \\
\text { crédito de } \\
\text { valor final }\end{array}$ & $\begin{array}{l}\text { É um documento preenchido pelo vendedor que } \\
\text { por algum problema não tenha efetuado a transa- } \\
\text { ção e pede a restituição do débito referente a taxa } \\
\text { sobre o valor final. . }\end{array}$ \\
\hline favoritos & $\begin{array}{l}\text { É um conjunto de no máximo quatro categorias e } \\
\text { subcategorias de recurso... }\end{array}$ \\
\hline lance & $\begin{array}{l}\text { Oferta, em valor monetário, de um comprador a } \\
\text { um bem em um determinado leilão... }\end{array}$ \\
\hline leilão & $\begin{array}{l}\text { É um processo de comercialização no qual um } \\
\text { bem é colocado à venda... }\end{array}$ \\
\hline $\begin{array}{l}\text { leilão de } \\
\text { compra }\end{array}$ & $\begin{array}{l}\text { Esse tipo de leilão é como se fosse uma venda } \\
\text { convencional. O vendedor estabelece um preço de } \\
\text { compra que... }\end{array}$ \\
\hline $\begin{array}{l}\text { taxa sobre } \\
\text { valor final }\end{array}$ & $\begin{array}{l}\text { É uma taxa cobrada do vendedor sobre o lance } \\
\text { vencedor final, é claro, respeitando as regras do } \\
\text { tipo de leilão... }\end{array}$ \\
\hline$\ldots$ & $\ldots$ \\
\hline
\end{tabular}

\begin{tabular}{|c|c|}
\hline \multicolumn{2}{|r|}{ Domínio } \\
\hline favoritos & $\begin{array}{l}\text { É um conjunto de no máximo quatro categorias e } \\
\text { subcategorias de recurso... [eBay, favoritos] }\end{array}$ \\
\hline formulário & É um documento preenchido pelo vendedor que \\
\hline de resti- & por algum problema não tenha efetuado a transa- \\
\hline $\begin{array}{ll}\text { tuição } & \text { de } \\
\text { crédito } & \text { de }\end{array}$ & $\begin{array}{l}\text { ção e pede a restituição do débito referente a taxa } \\
\text { sobre o valor final. . . [Arremate.com, formulário }\end{array}$ \\
\hline valor final & $\begin{array}{l}\text { de restituição de crédito de valor final] [eBay, for- } \\
\text { mulário de restituição de crédito de valor final] }\end{array}$ \\
\hline lance & $\begin{array}{l}\text { Oferta, em valor monetário, de um comprador a } \\
\text { um bem em um determinado leilão... [Arrema- } \\
\text { te.com, lance] [eBay, lance] [Domínio, lance] }\end{array}$ \\
\hline leilão & $\begin{array}{l}\text { É um processo de comercialização no qual um } \\
\text { bem é colocado à venda. . . [Arremate.com, leilão] } \\
\text { [iBazar, leilão] [eBay, leilão] }\end{array}$ \\
\hline $\begin{array}{l}\text { leilão de } \\
\text { compra }\end{array}$ & $\begin{array}{l}\text { Esse tipo de leilão é como se fosse uma venda con- } \\
\text { vencional. O vendedor estabelece um preço de } \\
\text { compra que. . . [Arremate.com, leilão ganhador] } \\
\text { [eBay, leilão de compra] }\end{array}$ \\
\hline recomendado & $\begin{array}{l}\text { São leilões escolhidos pelo sistema, dentre alguns } \\
\text { leilões candidatos estabelecidos por regras de ne- } \\
\text { gócio ... [Arremate.com, leilão recomendado] }\end{array}$ \\
\hline $\begin{array}{l}\text { taxa sobre } \\
\text { valor final }\end{array}$ & $\begin{array}{l}\text { É uma taxa cobrada do vendedor sobre o lance } \\
\text { vencedor final, é claro, respeitando as regras do } \\
\text { tipo de leilão... [Arremate.com, taxa de sucesso] } \\
\text { [eBay, taxa sobre valor final] }\end{array}$ \\
\hline$\ldots$ & $\ldots$ \\
\hline
\end{tabular}

Taxa Valor Final. Classes distintas são aquelas que estão presentes em apenas um sistemabase, como é o caso de Favorito e Recomendado.

A atividade 4.2 tem por objetivo tratar as classes similares e elementos a ela relacionados. Nesta atividade deve-se efetivamente iniciar a criação do modelo de classes do domínio. Iniciar a criação do modelo pelas classes semelhantes propicia ao analista a formação de um conjunto básico de elementos que formam a estrutura inicial para auxiliar a inserção de novos elementos. A partir dessa estrutura básica, que representa as funções comuns aos sistemas-base e, portanto, básicas do modelo do domínio, pode-se gradativamente inserir novos elementos não similares. 
Tabela 3.7: Parte da Listagem de Classe X Sistema.

\begin{tabular}{|l|c|c|c|}
\hline \multicolumn{1}{|c|}{ Domínio } & Arremate.com & iBazar & eBay \\
\hline \hline Favorito & & & $\bullet$ \\
Vendedor & $\bullet$ & $\bullet$ & $\bullet$ \\
Leilão & $\bullet$ & $\bullet$ & $\bullet$ \\
Leilão Normal & $\bullet$ & $\bullet$ & $\bullet$ \\
Leilão de Compra & $\bullet$ & $\bullet$ & $\bullet$ \\
Leilão com Preço de Reserva & $\bullet$ & $\bullet$ & $\bullet$ \\
Lance & $\bullet$ & & $\bullet$ \\
Pedido Restituição & $\bullet$ & $\bullet$ & \\
Reputação & $\bullet$ & & $\bullet$ \\
Recomendado & $\bullet$ & $\ldots$ & $\ldots$ \\
Taxa Valor Final & $\bullet$ & $\ldots$ & $\bullet$ \\
... & $\bullet$ & & $\bullet$ \\
\hline
\end{tabular}

O analista deve, por intermédio da listagem de classes, inserir as classes similares. Para cada classe do modelo do domínio, deve-se estudar suas classes correspondentes no modelo de classes dos sistemas-base para determinar a similaridade dos elementos a ela relacionados, como atributos, métodos, operações, relacionamentos e cardinalidades.

Os primeiros elementos a serem tratados são os atributos e posteriormente, aplicando a mesma estratégia mostrada a seguir, devem ser tratados os métodos e operações. O tratamento dos relacionamentos e cardinalidades não segue as mesmas diretrizes dos atributos, operações e métodos e são analisados depois que os outros elementos estão estabelecidos.

É necessário estabelecer uma estratégia para inserir os atributos, métodos e operações no modelo de classes. A estratégia adotada nesse trabalho foi identificar esses elementos da mesma forma que os termos do glossário e as classes, ou seja, analisando sua similaridade com o auxílio da classificação baseada na nomenclatura e significado. De forma análoga às classes, elementos similares são aqueles que pertencem a todos os modelos de classe, distintos são aqueles que pertencem somente a um modelo de classe e parcialmente similares são aqueles que pertencem a mais de um modelo de classes mas não a todos. Tanto os elementos similares podem ser inseridos diretamente no modelo como também os elementos distintos podem ser inseridos sem modificações, estes últimos desde que julgados importantes pelo analista. Os elementos parcialmente similares podem ser considerados similares se forem analisados apenas os sistemas-base que os possuem. Se confrontarmos um determinado elemento com os sistema-base que não o possuem então ele é distinto e, como mostrado anteriormente, um elemento distinto pode ser incluído diretamente no modelo de classes do domínio.

$\mathrm{O}$ analista deve primeiramente estudar os atributos em suas respectivas classes dos sistemasbase e, como mencionado anteriormente, estabelecer sua similaridade. Os atributos descrevem 
de alguma maneira a classe a que eles pertencem e, para que o analista consiga determinar sua similaridade, deve observar alguns aspectos do atributo, como por exemplo, tipo do atributo e o nível de detalhamento de algum aspecto da classe que o atributo descreve. Decidir sobre a similaridade dos métodos e operações é uma tarefa mais complexa, pois eles são procedimentos que manipulam classes e atributos. Dessa forma, eles dependem de como são as classes e como são os atributos e devem ser adaptados segundo as decisões tomadas sobre essas classes e atributos.

Os relacionamentos e cardinalidades não possuem as mesmas características dos atributos, métodos e operações, quando observada sua similaridade. Enquanto os últimos são intimamente ligados à classe à qual pertencem e, por isso, podem ser analisados em relação à classe, os relacionamentos e cardinalidades descrevem a relação entre as classes. Quanto mais similares forem as classes, mais provável é que elas possuam os mesmos relacionamentos. O analista deve observar como a classe se relaciona nos sistemas-base para tentar utilizar esses mesmos relacionamentos. As cardinalidades também podem ser as mesmas dos modelos de classes dos sistemas-base. Porém, relacionamentos e cardinalidades merecem uma atenção maior do analista, pois não possuem uma função direta associada, como nos atributos, métodos e operações. Os relacionamentos e cardinalidades são coerentes quanto se analisa a relação que as classes possuem frente a todo o sistema-base. Portanto, ao invés de analisar um ponto específico, o analista deve observar todo o modelo de classes. Assim, os relacionamentos e cardinalidades são dependentes das decisões de quais elementos estão presentes no modelo de classes e qual é o papel de cada um deles.

A atividade 4.3 trata tanto as classes parcialmente similares como os elementos relacionados a elas. Os passos para executar essa atividade são semelhantes aos da atividade 4.2. Para inserir as classes no modelo o analista deve simplesmente decidir sobre sua importância. É muito provável que nessa atividade existam muitos elementos parcialmente similares e distintos, exigindo maior estudo por parte do analista. Esse fato ocorre porque na fase atual não existem classes similares e, portanto, não existem elementos similares. O maior trabalho do analista concentra-se em adequar os elementos para serem inseridos no modelo.

$\mathrm{Na}$ atividade $4.4 \mathrm{o}$ analista deve manter o foco em quais classes são importantes para o domínio, pois esse é o objetivo dessa atividade. Ela concentra-se em isolar as classes que estão presentes em apenas um dos modelos dos sistemas-base. Aqui, o analista pode observar funções que, apesar de não serem básicas, podem apresentar interessantes melhorias que podem ser incorporadas no modelo do domínio. Deve-se acomodar as classes escolhidas nessa atividade no modelo de classes do domínio que, nesta fase, já possui sua estrutura bem sedimentada.

A atividade 4.5 visa a refinar o modelo de classes, pois o analista tem o modelo de classes do domínio pronto porém, acertos podem ser feitos para melhorá-lo e para corrigir possíveis erros. Com o conjunto de elementos sendo refinados, classes, atributos, métodos, operações, relacionamentos e cardinalidades, o analista começa a ter uma visão real da relação dos diversos elementos. 
Até então, cada elemento foi analisado individualmente em relação a outros elementos semelhantes, atributos com atributos, classes com classes entre outros. As decisões de análise e projeto foram tomadas para, de alguma forma, harmonizar esses elementos. Agora, o analista pode tomar decisões relativas a todo o modelo. Usando o conhecimento adquirido pela aplicação do processo é possível, por exemplo, prever novas funcionalidades e adicionar maior flexibilidade ao modelo, melhorar a qualidade do modelo com decisões técnicas e criar especializações, generalizações ou relacionamentos para otimizar as funções. Para tanto, o analista pode utilizar padrões de análise e projeto, que são soluções amplamente conhecidas e aplicadas. Os padrões de análise e projeto podem ajudar a estruturar de uma melhor forma as funções presentes no modelo do domínio.

\subsection{Criar uma Linguagem de Padrões a partir do Modelo de Classes de um Domínio}

A Figura 3.1, apresentada na Seção 3.2, ilustra as diferentes alternativas de desenvolvimento de SIbWebs, dentre elas, a alternativa de utilizar uma linguagem de padrões. Linguagens de padrões podem ser desenvolvidas diretamente, sem a necessidade de um modelo de classes do domínio da aplicação. No entanto, utilizar um modelo de classes do domínio é útil no desenvolvimento de uma linguagem de padrões pois, segundo Riehle e Zullighoven (1996), padrões representam uma estrutura bem sucedida de soluções para problemas de um mesmo contexto. Além do processo apresentado neste trabalho para criação do modelo de classes, outras técnicas de análise de domínios, como por exemplo, as propostas por Gomaa (1996) e Prieto-Diaz e Arango (1991) podem ser utilizadas para auxiliar na criação de um modelo de classes do domínio.

Nesta seção é apresentado um conjunto de atividades que, a partir do modelo de classes do domínio, obtido pela aplicação da primeira fase do processo geral, tem como objetivo criar uma linguagem de padrões. As atividades a serem conduzidas para a criação da linguagem de padrões, os recursos necessários para sua execução e os resultados obtidos para cada atividade são apresentados na Figura 3.10.

A atividade 1.1 visa a agrupar as classes de acordo com as funções que elas representam, formando um conjunto de classes que, conjuntamente com as descrições e os nomes dos padrões, fornece a base para a linguagem. Para concluir tal atividade o analista deve primeiramente identificar quais são as funções básicas ou principais representadas no modelo do domínio. Essas funções são aquelas que caracterizam os sistemas do domínio e, de maneira geral, estão presentes em todos os sistemas desse domínio. Para auxiliar nessa tarefa, o analista pode coletar informações que indicam quais são as funções básicas do domínio, como por exemplo: livros, artigos e documentos relacionados ao domínio estudado. Neste trabalho, o artigo de Kumar e Feldman (1998b) foi 


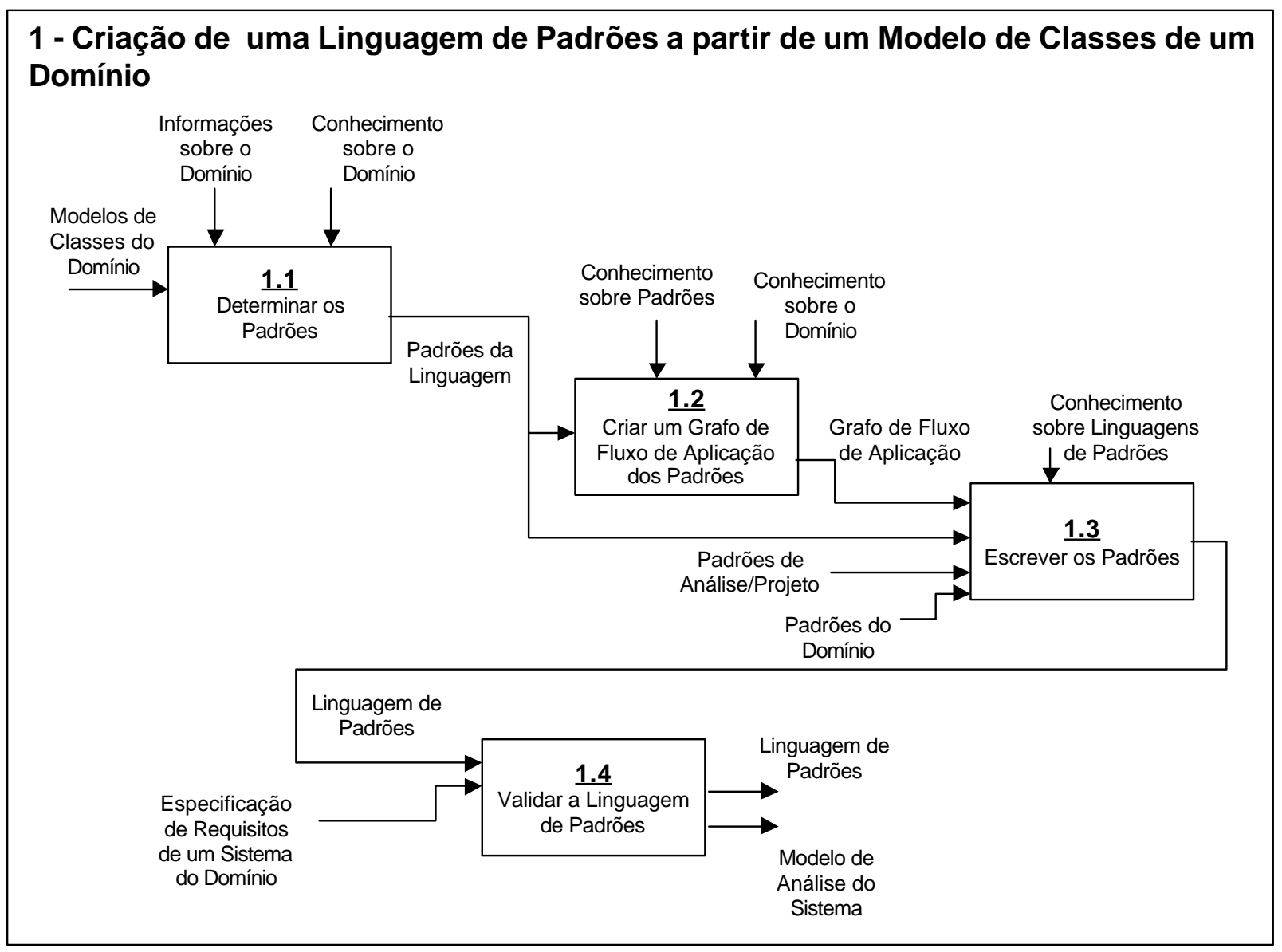

Figura 3.10: Criação de uma Linguagem de Padrões.

de grande utilidade porque apresenta quais são as atividades de um leilão, e com isso auxiliou a identificar quais são as funções básicas necessárias ao seu funcionamento.

O analista deve selecionar e agrupar as classes que representam as funções básicas já identificadas, ou seja: as classes básicas. Isso pode ser feito no próprio modelo de classes do domínio, como por exemplo, circundar as classes relacionadas a uma função, marcar regiões do modelo de classes com diferentes cores ou, por meio de vários modelos menores (ou submodelos), cada um referente a uma função. Neste trabalho foi constatado que a maioria das classes básicas são as mesmas consideradas similares na atividade 4.2 do processo de criação de modelos do domínio de aplicações baseadas na Web, apresentada na Seção 3.3.4. Dessa forma, caso o analista tenha criado o modelo de classes do domínio por intermédio desse processo ele pode utilizar a listagem de "Classe X Sistema" ilustrada pela Tabela 3.7. Tal listagem apresenta uma visão da similaridade das classes, fornecendo, assim, auxílio na definição das classes básicas. As classes que não são básicas representam um conjunto de funções que complementam a funcionalidade dos sistemas do domínio analisado, devendo ser identificadas e agrupadas da mesma forma que as classes básicas, constituindo um grupo de classes denominadas complementares. 
O grupo de classes básicas, o grupo de classes complementares, padrões de análise e projeto e padrões do domínio formam o conjunto de recursos necessários para que o analista possa determinar quais são os padrões da linguagem de padrões. O analista pode iniciar a determinação dos padrões pelas classes básicas, criando um conjunto inicial que represente os principais padrões da linguagem. Geralmente, cada função básica dá origem a um padrão da linguagem. Podem existir funções que de certa forma sejam semelhantes e, se agrupadas, podem formar um mesmo padrão, dando origem a classes, atributos, métodos ou operações opcionais ou um variante do padrão. Nesse contexto, o analista deve definir quais funções formam os padrões e quais classes constituem a estrutura desses padrões.

As classes complementares, diferentemente das classes básicas, adicionam melhorias em relação a um padrão, ou adicionam uma função diferente em relação às funções básicas do modelo do domínio. As classes complementares geralmente representam funcionalidades que são prescindíveis para o funcionamento de sistemas do domínio estudado. Assim, classes complementares têm maior possibilidade de serem padrões opcionais, ou de se juntarem a padrões já existentes na linguagem, formando variantes dos padrões principais e se tornando elementos opcionais dos padrões principais. Novamente, fica a cargo do analista a decisão de como estabelecer quais classes fazem parte de um padrão.

As funções, sejam básicas ou não, podem também auxiliar o analista a nomear o padrão. $\mathrm{O}$ analista deve dar nomes aos padrões, tarefa que pode ser facilitada por meio da observação dos objetivos das funções. Esse nome é importante pois deve abstrair o conteúdo do padrão, facilitando sua identificação e utilização por outros analistas.

A Figura 3.11 ilustra a identificação das classes que formam a estrutura dos padrões, na qual pode-se notar a complexidade de classes e seus elementos para formarem padrões. A figura mostra, entre outros detalhes, que existem classes que pertencem a vários padrões. Essas classes independentemente se são básicas ou complementares, contêm elementos que estão presentes apenas em um padrão, enquanto outros elementos podem pertencer a vários padrões ${ }^{3}$. Na Figura 3.12 pode-se observar a classe Participante que pertence aos padrões HABILITAR FAVORITOS e GERENCIAR A EMPRESA LEILOEIRA, entre outros. Observando, ainda, a classe Participante nos dois padrões, é possível perceber que existem atributos que estão presentes em um padrão e não em outro. Isso ocorre porque existem certos elementos das classes que são importantes para um padrão e outros elementos são importantes para outros padrões. Por exemplo, o atributo formaPagamento, que representa a forma como o usuário do leilão irá pagar o serviço prestado pela empresa leiloeira, é pertinente quando essa classe está presente no padrão GERENCIAR A EMPRESA LEILOEIRA. No entanto, quando a classe está presente no padrão HABILITAR FAVORITOS esse atributo não é necessário.

\footnotetext{
${ }^{3}$ A notação utilizada para denotar os diferentes tipos de operações apresentadas nos diagramas de classe (os prefixos "!", “?” e “*”) é apresentada em detalhes na Seção 3.3.3.
} 


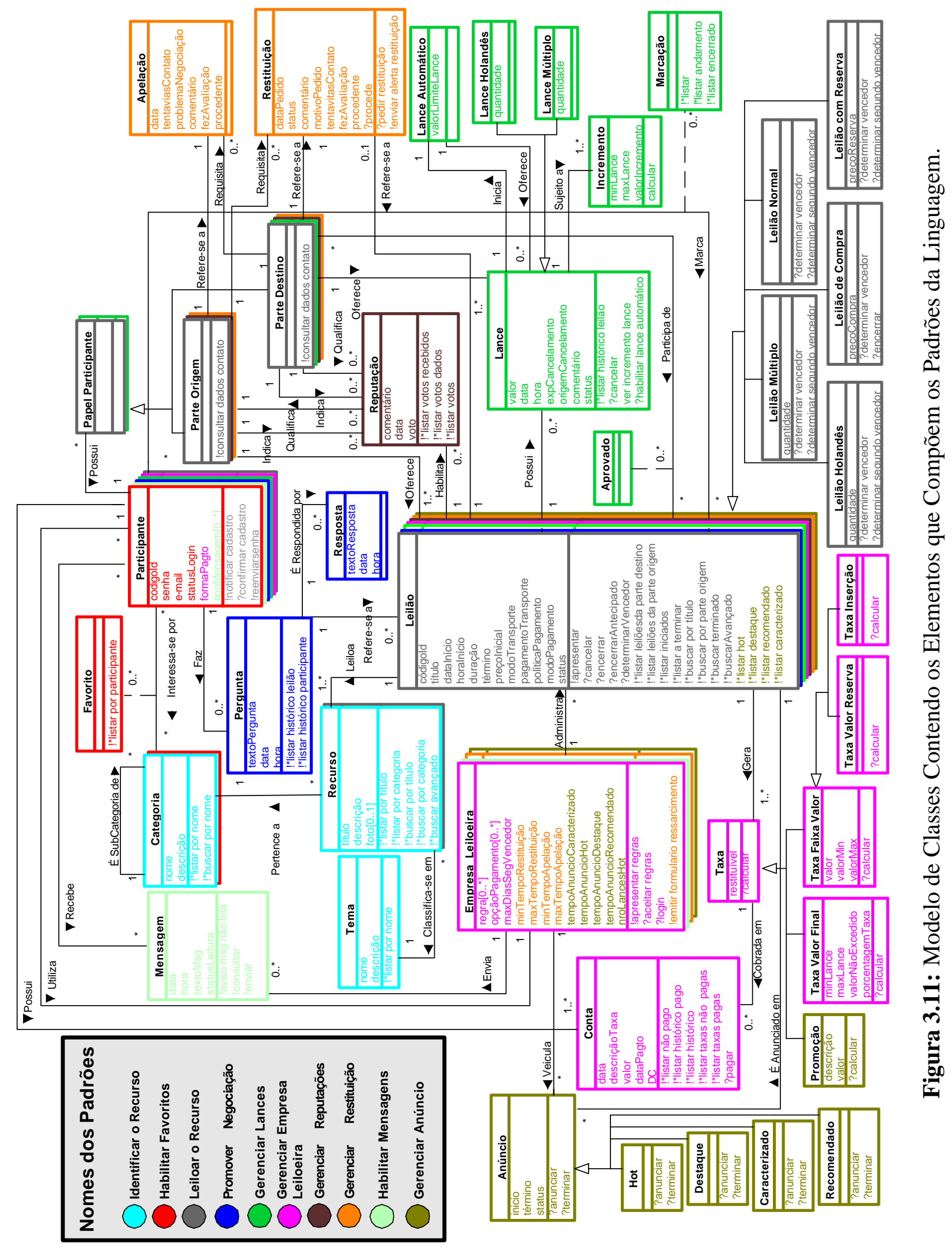




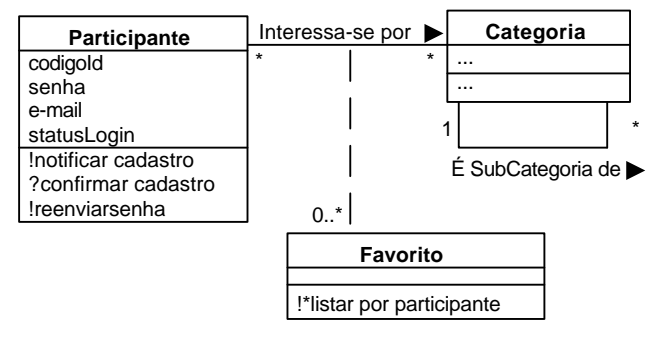

(a)

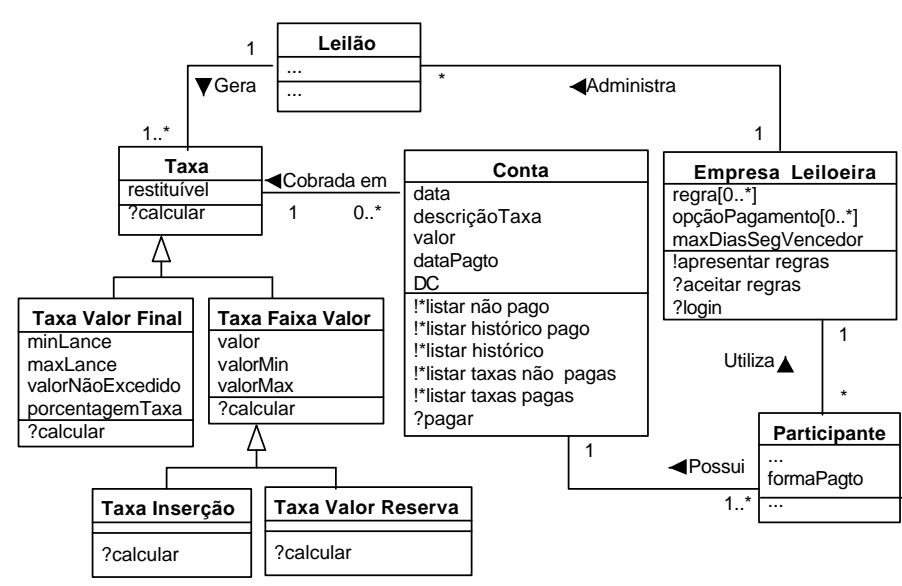

(b)

Figura 3.12: (a) Exemplo da Estrutura do Padrão HABILITAR FAVORITOS.

(b) Exemplo da Estrutura do Padrão GERENCIAR A EMPRESA LEILOEIRA.

O analista deve tomar cuidado com os elementos dos padrões, pois assim ele isola em um padrão o que é importante somente ao padrão, fazendo com que no momento da utilização da linguagem os elementos pertencentes ao padrão sejam inseridos no modelo de classes somente se o padrão for aplicado.

Para finalizar a atividade 1.1 o analista deve descrever os detalhes sobre os elementos que compõem os padrões, as funções que eles implementam, as restrições da aplicação e as alternativas de aplicação dos padrões e seus elementos, enfim informações relevantes para uma descrição geral dos padrões. Essa descrição geral, juntamente com a estrutura de classes a que são relacionadas e os nomes que o analista propõe para os padrões, são utilizados para a determinação do fluxo de aplicação dos padrões e a escrita detalhada da linguagem de padrões. O Quadro 3.2 apresenta o exemplo da descrição de um padrão.

$\mathrm{Na}$ atividade 1.2 deve-se definir um grafo do fluxo de aplicação dos padrões que indica como os padrões interagem. Basicamente, o grafo contém os nomes dos padrões e a ordem em que os padrões devem ser aplicados, mostrando inclusive quais são os padrões principais e opcionais da linguagem, informações que são obtidas por intermédio da descrição geral do padrão. Esse grafo deve mostrar como os padrões são dispostos e como devem ser aplicados para obter o modelo de classes desejado. A ordem de aplicação dos padrões também pode constar de uma seção que compõe o padrão, como por exemplo, no componente "Próximos Padrões". É importante salientar que o grafo deve indicar a interação entre os padrões, isto é, como deve ser a ordem de aplicação dos padrões, e não tem a intenção de mostrar como é a ordem de funcionamento do sistema ou seja, um fluxograma. O grafo de fluxo apresenta uma maneira coerente de aplicação ou operação dos padrões para chegar à solução desejada. Por exemplo, as regras da ordem de aplicação dos padrões Gerenciar Restituição, Habilitar Mensagens e Gerenciar AnúnCio, são apresentadas no componente "Próximos Padrões" do padrão GerenCIAR REPUTAÇõEs (Quadro 3.4) e 
Quadro 3.2: Exemplo de Descrição Geral do Padrão GERENCIAR EMPRESA LEILOEIRA.

\section{Gerenciar Empresa Leiloeira}

O sistema de leilões é mantido por uma organização que gerencia todo o processo de comercialização. Essa organização estabelece as regras de funcionamento dos leilões, a maneira pela qual os participantes utilizam o sistema, os prazos de entrega dos recursos, o funcionamento específico dos leilões, taxas de utilização e dados de outras empresas que fornecem serviços interessantes à organização como por exemplo, empresas de entrega e recebimento dos pagamentos dos participantes. As taxas de utilização são referentes à utilização do sistema de leilões pelos participantes. Essas taxas são armazenadas para posterior cobrança pela organização que gerencia os leilões. Algumas dessas taxas podem ser restituíveis, dependendo das regras estabelecidas pela organização para determinar o procedimento em problemas ocorridos durante a negociação (mais detalhes no padrão GERENCIAR RESTITUIÇÕES). Dependendo das regras de negócio da organização, pode não existir taxa alguma referente ao uso do sistema de leilões. A escolha de representar as taxas por meio de diferentes classes ao invés de por meio de atributos deve-se ao fato de adicionar flexibilidade.

Os parâmetros de funcionamento geral do sistema também são responsabilidade da organização gerenciadora, como por exemplo, desconto ou isenção de taxas (estratégias de marketing), o período em que o participante pode se beneficiar dessa isenção ou desconto recolocando um recurso à venda, ou o número de vezes que ele pode recolocar o recurso beneficiando-se de desconto ou isenção.

ilustradas na Figura 3.13, envolvendo aspectos do padrão GERENCIAR A EMPRESA LEILOEIRA. A Figura 3.13 ilustra o grafo de padrões da Linguagem de Padrões LV obtida por intermédio da aplicação do processo proposto.

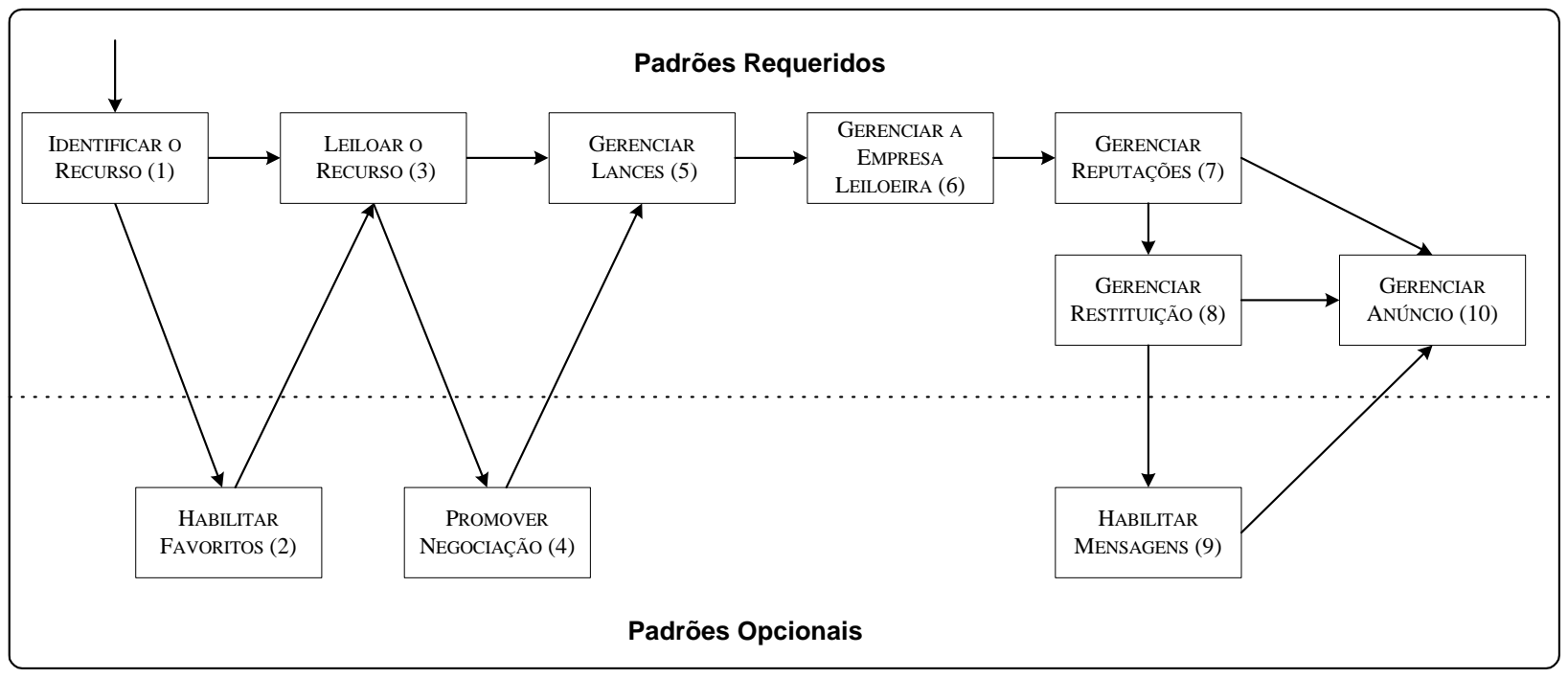

Figura 3.13: Grafo de Fluxo de Aplicação dos Padrões da Linguagem de Padrões LV.

O fluxo de aplicação dos padrões, além de ser influenciado pelos padrões opcionais, também é influenciado por outros elementos dos padrões, como por exemplo, os variantes, as classes e 
os elementos opcionais. Podem ocorrer casos em que a aplicação de um determinado padrão implica na adição de elementos em outros padrões, casos em que a aplicação de um padrão pede a aplicação de outro padrão ou ainda casos em que um padrão pode ser aplicado somente se outro padrão for aplicado também. Por exemplo, a classe Taxa, Figura 3.12b, e suas especializações são classes opcionais do padrão GERENCIAR A EMPRESA LEILOEIRA e podem ser aplicadas ou não, conforme ilustra sua descrição na linguagem (Quadro 3.3).

Quadro 3.3: Parte da Descrição do Participante Taxa.

...é uma classe abstrata que representa taxas que podem ser cobradas pela empresa leiloeira. $O$ atributo restituível indica se essa é uma taxa que pode ser restituída para o participante. Essa classe e todas as suas especializações são opcionais, pois as taxas podem ser cobradas ou não, dependendo da aplicação.

Assim, o padrão Gerenciar Restituição só é aplicável se a classe taxa do padrão GeRENCIAR A EMPRESA LEILOEIRA, (Figura 3.12), ou qualquer uma de suas especializações for aplicada, como é apresentado no padrão GERENCIAR REPUTAÇÕES da linguagem de padrões (Quadro 3.4).

Quadro 3.4: Componente "Próximos Padrões" do Padrão Gerenciar REPUTAÇões.

Se no padrão GeRENCIAR A EMPRESA LEILOEIRA a classe Taxa ou qualquer uma de suas especializações foi utilizada aplique o padrão GERENCIAR RESTITUIÇÃo. Caso contrário tente utilizar o padrão Habilitar Mensagens. Se o padrão HABILiTAR Mensagens não for aplicável utilize o padrão Gerenciar AnÚnCiO.

A atividade 1.3 trata literalmente da escrita da linguagem de padrões. O analista deve estabelecer um padrão para descrever os padrões da linguagem, como por exemplo, "nome", "contexto", "problema”, "estrutura", "participantes", "padrões relacionados" e "próximos padrões", entre outros. Existem várias propostas de formatos de padrões, dentre elas, as propostas por Alexander (1977), Coplien (1999), Harrison (1999), Meszaros (1998) e Sane (1995). A partir do formato do padrão, o analista deve basear-se na descrição geral dos padrões e nas classes que compõem os padrões, para começar a escrita. É importante notar que um padrão é muito mais que uma estrutura de classes e uma descrição sobre elas, ele apresenta basicamente todas as informações do contexto no qual pode ser aplicado, o problema que resolve, bem como as forças que atuam para formar a solução (Fowler, 1997). Independente dos componentes escolhidos para escrever o padrão, os componentes básicos de um padrão, são:

- nome: deve sugerir o que é o padrão. 
- contexto: o contexto descreve como e quando o padrão ocorre. No trabalho realizado observou-se que, de maneira geral, o contexto de um padrão pode ser descrito como as razões para que uma função tenha sido implementada, quais os fatores que influenciam a função, como esses fatores são relacionados a padrões anteriores e, de forma superficial, qual o objetivo da função. O glossário do domínio, discutido na Seção 3.3.4, contém detalhes que pode auxiliar analista.

- problema: este componente descreve de maneira direta o problema que o padrão se propõe a resolver, frente ao contexto anteriormente especificado.

- forças: deve mostrar quais são os fatores que, frente ao contexto especificado e ao problema estabelecido, influenciam a solução proposta e como ela é implementada. Esse componente foi determinado neste trabalho como sendo um dos principais fatores que levaram o analista a propor a solução. Esses fatores apresentam os motivos pelo qual as funções identificadas na atividade 2.3 (Figura 3.3 da Seção 3.3.2) dos sistemas-base são importantes e foram trazidas para o modelo do domínio. É importante lembrar que essas funções não são as funções principais que, geralmente, se tornam padrões. Esse componente também é composto por limitações e restrições da solução, desvantagens em utilizar o padrão ou o porquê da solução não utilizar outras estratégias.

- solução: este componente pode ser escrito de várias formas, desde que apresente de maneira clara a solução proposta pelo padrão. Neste trabalho não existe um componente denominado solução, ao invés, optou-se por apresentar a solução por intermédio de vários outros componentes: "portanto", "estrutura", "participantes" e "exemplo". O componente "portanto" apresenta de forma sucinta e direta a solução frente ao contexto, forças e problema. A "estrutura" é representada pelo conjunto de classes que formam o padrão e os "participantes" são as classes que formam o conjunto. Nesse componente descreve-se o papel que cada classe exerce na solução, bem como os principais atributos, métodos e operações. Para auxiliar o entendimento da estrutura existem também referências a outros padrões que, eventualmente, façam parte da solução. São descritos ainda quais elementos da estrutura são opcionais e quais elementos devem ser inseridos em outros padrões da linguagem em caso de aplicação do padrão descrito. O "exemplo" do padrão pode ser uma parte de um sistema-base que originou o padrão.

Visando a escrever os padrões da melhor forma possível o analista pode utilizar estratégias para generalizar os nomes das classes, relacionamentos, atributos, métodos e operações. Essa generalização melhora a linguagem e facilita a identificação de sua aplicabilidade pelos analistas. Um exemplo pode ser observado pela Figura 3.11, no qual nota-se que a classe Recurso foi nomeada dessa maneira por representar de forma satisfatória os "bens" ou "produtos" comercializados por intermédio dos leilões. 
Além dos componentes já descritos, a linguagem de padrões criada pelo processo aqui proposto apresenta os seguintes componentes: "variantes", "padrões relacionados" e "próximos padrões". O componente "variantes" apresenta as possíveis variações do padrão, explicando as diferenças em relação ao padrão original, a estrutura de classes do padrão e os casos em que ele deve ser aplicado. Os "padrões relacionados" apresentam quais padrões são, de alguma forma, relacionados ao padrão que está sendo descrito. Por fim, o componente "próximos padrões" apresenta quais são os próximos padrões que podem ser aplicados de acordo com a utilização do padrão que está sendo descrito. Esse componente guia a aplicação dos padrões juntamente com o grafo de fluxo de aplicação.

Com o objetivo de melhorar os padrões da linguagem o analista pode pesquisar outros padrões do mesmo domínio ou de um domínio próximo para auxiliá-lo na definição dos padrões da linguagem. Dessa forma, ele irá obter por meio desses outros padrões soluções que podem ser empregadas nos padrões que estão sendo definidos. Durante a pesquisa, o analista pode descobrir que os padrões por ele definido são variantes de outros padrões, ou complementam outra linguagem de padrões. Assim, essa pesquisa também é importante porque a linguagem de padrões pode fazer referência a outros padrões ou linguagens de padrões, fornecendo outras alternativas de solução caso ela não seja adequada. $\mathrm{O}$ analista também pode procurar por padrões de análise e projeto que melhorem as soluções propostas, complementando a linguagem de padrões com referências aos padrões ou adotando os padrões como parte da linguagem.

A validação da linguagem finaliza o processo de criação de uma linguagem de padrões a partir do modelo de classes de um domínio. A atividade 1.4 tem por objetivo validar a linguagem de padrões por intermédio de sua aplicação a diferentes sistemas do domínio estudado. Basicamente, essa atividade é constituída pelo estudo do documento de requisito da aplicação a ser modelada, estudo e aplicação da linguagem de padrões com base no documento de requisitos e avaliação do modelo de classe, confrontando os requisitos desejados com os modelos de classes da aplicação. Quando mais aplicações forem modeladas com a linguagem de padrões melhor será sua validação, além de contribuir para a melhora da própria linguagem, pois novas características podem ser incorporadas. A Seção 3.6 exemplifica de forma mais detalhada a atividade 1.4 utilizando uma linguagem de padrões específica para sistemas de leilões virtuais, apresentada na Seção 3.5.

\subsection{A Linguagem de Padrões para Leilões Virtuais}

A Linguagem de Padrões LV (Linguagem de Padrões para Leilões Virtuais) aplica-se ao desenvolvimento de sistemas para gestão de vendas por intermédio de leilões virtuais. Os leilões virtuais são um tipo SIbWeb empregados no comércio eletrônico que vêm ganhando popularidade (Bapna et al., 2001; Huhns e Vidal, 1999; Isakowitz et al., 1998; Wellman e Wurman, 1998). Existem vári- 
os tipos de leilões que oferecem vários motivos para sua utilização, como apresentado na Seção 2.5 (Heck e Vervest, 1998; Kumar e Feldman, 1998b).

O desenvolvimento da Linguagem de Padrões LV foi baseado em três sistemas de leilões existentes na Internet: eBay ${ }^{4}$, iBazar ${ }^{5}$ e Arremate.com ${ }^{6}$ (Ré e Masiero, 2001). Esses três sistemas foram utilizados para a aplicação do processo proposto neste capítulo, resultando na linguagem apresentada no Apêndice A.

A Figura 3.13 mostra o relacionamento entre os padrões da linguagem. Os dez padrões da linguagem podem ser divididos em duas categorias principais. A primeira categoria - Padrões Requeridos - possui padrões que representam requisitos essenciais para que um recurso possa ser leiloado. Esses padrões requeridos devem ser sempre aplicados a todos os sistemas de leilões. A segunda categoria - Padrões Opcionais - possui padrões apenas desejáveis mas que não são estritamente necessários.

\subsubsection{Exemplo de um Padrão da Linguagem de Padrões LV}

A seguir é apresentado o exemplo do padrão GERENCIAR A EMPRESA LEILOEIRA, pertencente à Linguagem de Padrões LV. Pode-se observar na Figura 1 e na Figura 2 desse padrão que existem, em algumas classes que compõem a estrutura do padrão, reticências “...”, indicando a existência de métodos, operações e atributos pertencentes a outros padrões e que, portanto, foram omitidos por estarem presentes em outros padrões da linguagem.

\section{Gerenciar a Empresa Leiloeira}

\section{Contexto}

Sua aplicação gerencia leilões de recursos que serão leiloados por partes origem; várias partes destino oferecerão lances para conseguir adquirir os recursos. Para tanto, é necessário o estabelecimento de regras para intermediar o processo de comercialização. Fica a critério dessa entidade intermediária estabelecer ou não taxas de uso do sistema e taxas de comercialização dos recursos. A empresa leiloeira é quem determina os parâmetros gerais de funcionamento de todo o processo de negociação por meio de leilões.

\footnotetext{
${ }^{4}$ http: / / www . ebay.com.

${ }^{5}$ http: //WwW.ibazar.com.br.

${ }^{6}$ http: //www. arremate.com.br.
} 


\section{Problema}

Como seu sistema gerencia as regras da empresa leiloeira no processo de leilão?

\section{Influências}

- Armazenar informações da empresa leiloeira é imprescindível para a comercialização por meio de leilões.

- É necessário o estabelecimento de várias regras gerais sobre a empresa leiloeira.

- É necessário que se estabeleça como e quais taxas devem ser pagas pelas partes negociantes.

- Armazenar diferentes tipos de taxas demanda mais espaço e processamento, no entanto, proporciona maior flexibilidade.

\section{Estrutura}

A Figura 2 mostra o diagrama de classes do padrão GERENCIAR A EMPRESA LEILOEIRA.

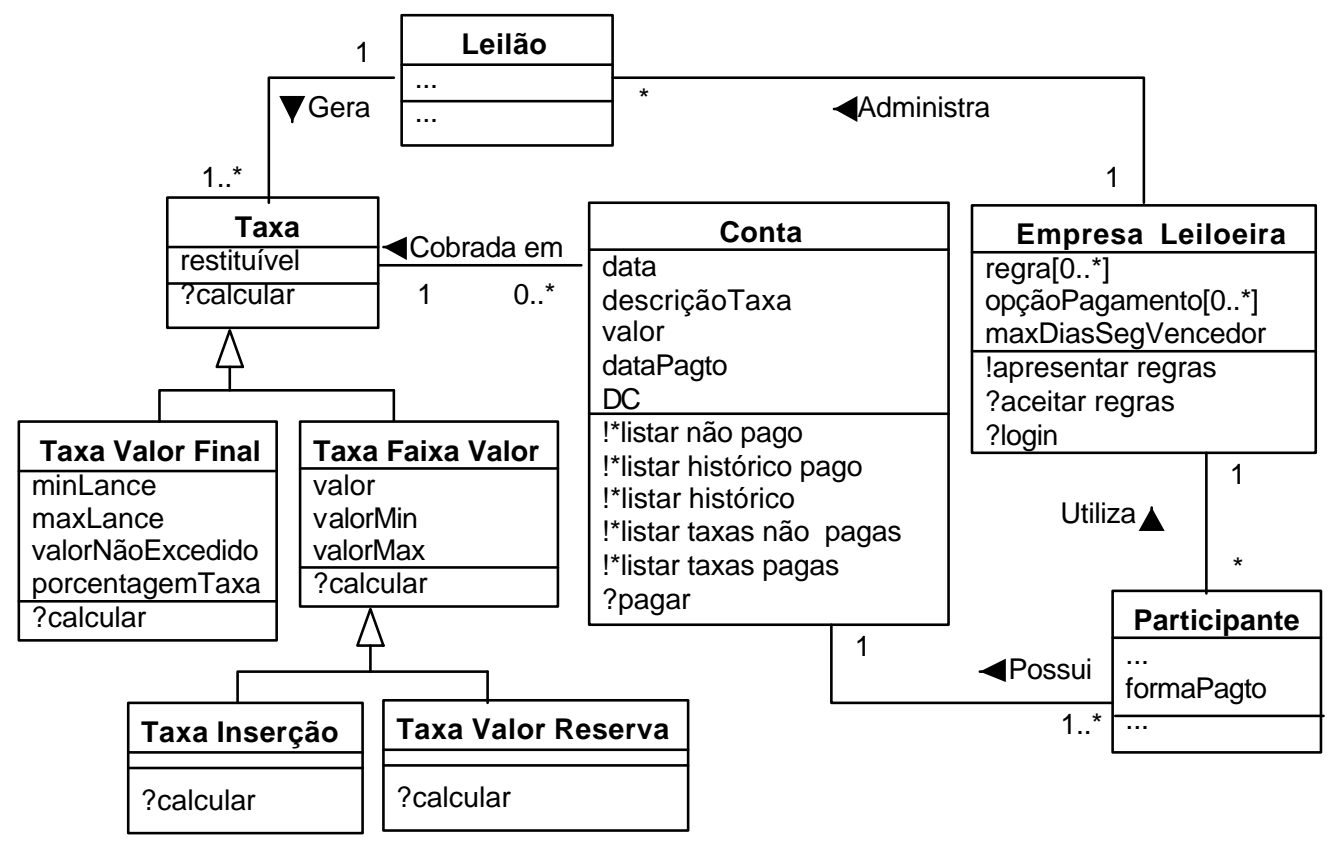

Figura 1: Estrutura do padrão GERENCIAR A EMPRESA LEILOEIRA

\section{Participantes}

- classe Leilão e classe Participante: Como descrito no padrão LeILOAR o Recurso.

- classe Empresa Leiloeira: Representa o próprio sistema, isto é, a empresa leiloeira que faz a intermediação das transações. Nessa classe são armazenados alguns parâmetros de funcionamento geral do processo de negociação por meio de leilões, como por exemplo, o prazo para que seja permitido que a parte destino possa requerer dados de 
contato de um segundo ganhador de um leilão (atributo maxDiasSegVencedor). O atributo regras armazena as regras gerais de conduta da parte origem, da parte destino e da empresa leiloeira. Esse atributo trata de aspectos legais e contratuais do serviço prestado pela empresa leiloeira que devem ser aceitos (operação ! apresentar regras e operação ?aceitar regras) pelas partes origem e destino para que possam utilizar o sistema de leilões.

- classe Taxa: É uma classe abstrata que representa taxas que podem ser cobradas pela empresa leiloeira. O atributo restituível indica se essa é uma taxa que pode ser restituída para o participante. Essa classe e todas as suas especializações são opcionais, pois as taxas podem ser cobradas ou não, dependendo da aplicação.

- classe Taxa Valor Final: Representa uma taxa cobrada com base em porcentagem (atributo porcentagemTaxa) sobre o valor final do lance vencedor com qual o leilão foi encerrado.

- classe Taxa Faixa Valor: É uma classe abstrata que representa uma taxa calculada com base em valores limite (atributo valorMin, atributo valorMax) e um valor fixo (atributo valor).

- classe Taxa Inserção: Representa uma taxa calculada com base em valores limite sobre o valor do preço inicial de um recurso (atributo preçoInicial). Essa taxa é cobrada quando um recurso é posto em leilão e, geralmente, não é restituível.

- classe Taxa Valor Reserva: Representa uma taxa calculada com base em valores limite sobre o preço de reserva de um recurso (atributo preçoReserva). Essa taxa somente é cobrada em leilões do tipo classe Lei lão com Reserva e geralmente é restituível caso a transação se concretize.

- classe Conta: Representa as taxas cobradas e as possíveis restituições feitas a um participante. Portanto, os valores (atributo valor) podem ser de crédito ou débito para um participante (atributo DC). A utilização dessa classe é diretamente ligada à utilização da classe Taxa. Ela só pode ser aplicada se a classe Taxa também for aplicada.

\section{Exemplo}

A Figura 2 apresenta um exemplo do padrão GERENCIAR A EMPRESA LEILOEIRA utilizado pelo site de leilões virtuais Arremate.com. O sistema de leilões desse site possui apenas a classe Taxa de Sucesso (que é uma instanciação da classe Taxa Valor Final). O sistema implementa uma regra de pagamento de taxas em que, quando a conta de um cliente atingir um valor limite, ele recebe um aviso constando do montante que deve pagar. Além da taxa sobre o valor final do leilão, o eBay implementa outros tipos de taxas, tais como: classe Taxa Valor Reserva e classe Taxa Inserção. Quando o cliente atrasa o pagamento de sua conta por um período previamente estabelecido, a utilização do sistema é bloqueada. O iBazar não cobra qualquer tipo de taxa e sua utilização é gratuita.

\section{Variantes}

Alguns sistemas de leilões permitem acesso a empresas de entrega, recebimento do pagamento e entrega e recebimento do pagamento. As informações dessas empresas são armazenadas na classe Empresa Leiloeira.

Existem sistemas que disponibilizam alguns descontos de taxas ou isenção de taxas devido a estratégias de marketing estabelecidas pela empresa proprietária do sistema. Um exemplo é a 


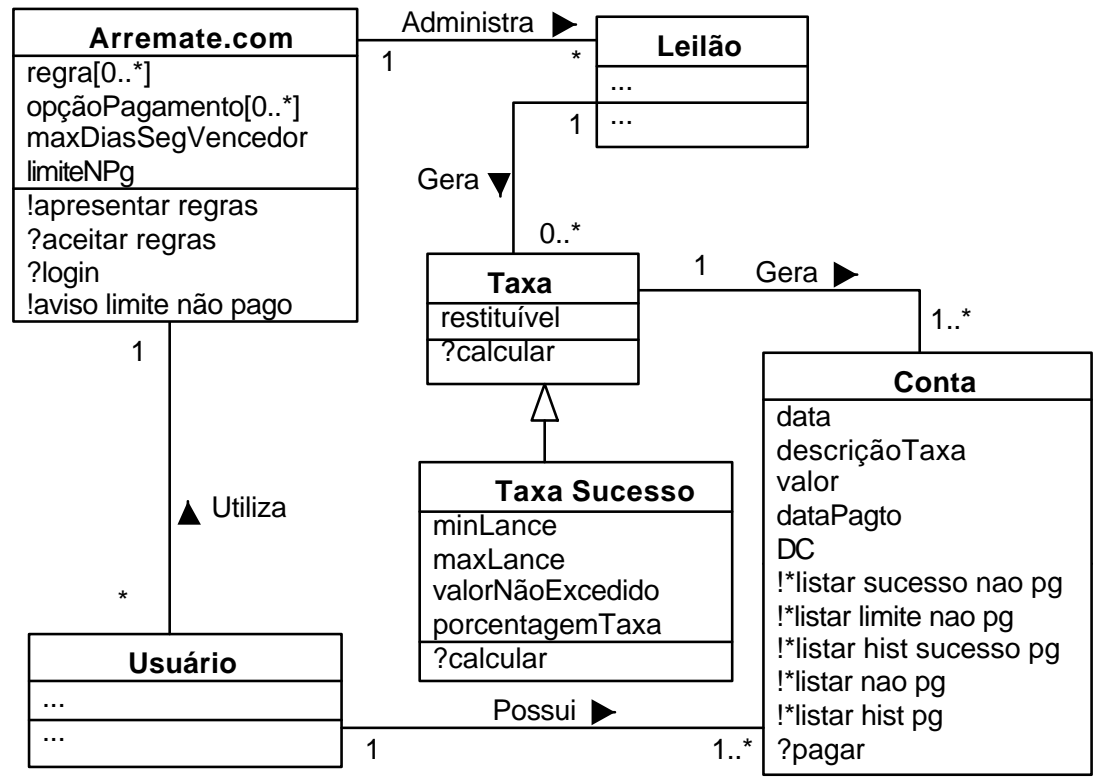

Figura 2: Exemplo do padrão GERENCIAR A EMPRESA LEILOEIRA

isenção da taxa de inserção se a parte origem colocar novamente um recurso em leilão por um número variável de vezes, durante um período de tempo preestabelecido, enquanto ele não for vendido. Os parâmetros de tempo, número de vezes, se é uma isenção da taxa ou um desconto parcial são armazenados na classe Empresa Leiloeira.

\section{Próximos Padrões}

Após aplicar o padrão GeRENCIAR A EMPRESA LEILOEIRA utilize o padrão GERENCIAR REPUTAÇÕES.

\subsection{Exemplo de Uso da Linguagem de Padrões para Lei- lões Virtuais}

Nesta seção é apresentado o uso da Linguagem de Padrões LV para a modelagem de um sistema com a mesma funcionalidade do sistema de leilões virtuais iBazar. Esse sistema, como apresentado na Seção 3.5, foi um dos sistemas-base do processo de criação do modelo de classes do domínio de aplicações dos SIbWebs proposto na Seção 3.3. A aplicação da linguagem de padrões resultou no modelo de classes ilustrado na Figura 3.16.

Conforme ilustrado na Figura 3.10, da Seção 3.4, os itens necessários para a validação de uma linguagem de padrões são a própria linguagem de padrões e uma especificação de requisitos referente a um sistema do domínio. O primeiro passo para a criação do modelo de classes do sistema do domínio é estudar a linguagem de padrões e o documento de requisitos (Ré et al., 2001; 
Ré e Masiero, 2001). É necessário estudar a linguagem de padrões para conhecer o domínio da aplicação e como aplicar os padrões para obter a solução desejada. Conhecer todos os requisitos da especificação é importante por que eles provavelmente estão dispersos na especificação, ou seja, as funções relacionadas aos requisitos podem estar representadas em diferentes pontos da linguagem de padrões, necessitando de conhecimento detalhado da especificação. Portanto, conhecer bem esses dois documentos capacita o analista a verificar a adequação da linguagem de padrões aos requisitos.

A aplicação da linguagem gera um diagrama de classes que cresce gradualmente, acomodando classes provenientes dos padrões que estão sendo aplicados. A linguagem é auto-explicativa e guia o analista durante toda sua aplicação, fornecendo diferentes alternativas de solução. A Figura 3.14 apresenta um diagrama de classes parcial exemplificando a aplicação dos padrões IDENTIFICAR o ReCURso e Leiloar o ReCURSo da linguagem de padrões. Para cada classe do modelo de classes existe uma respectiva indicação referenciando qual o participante e padrão do qual ela é uma instanciação. Essa indicação consiste de "P\#n:papel”, onde: "n" é o número do padrão e “papel” é o participante pertencente àquele padrão (Vlissides et al., 1996).

Os padrões IDENTIFICAR O RECURSO e LEILOAR O RECURSO, cuja aplicação é apresentada na Figura 3.14, possuem basicamente funções relacionadas ao recurso e a detalhes do leilão. $\mathrm{O}$ padrão IDENTIFICAR O RECURSO trata mais especificamente da representação do recurso e das formas como ele pode ser classificado. Já o padrão LEILOAR O RECURSO, além de estar focado nos vários tipos de leilões, também trata dos detalhes dos participantes, estabelecendo um relacionamento entre o leilão, a parte origem e o recurso. Pode-se notar na Figura 3.14 que o sistema do site iBazar oferece dois tipos específicos de leilão, o leilão normal e o leilão com preço de reserva. No entanto, a Linguagem de Padrões LV oferece mais alguns tipos (leilão de compra, leilão holandês e leilão múltiplo) que, juntamente com os mostrados no exemplo, oferecem apoio a uma gama razoável de tipos de leilões que podem ser utilizados na Web.

Como mostrado na Figura 3.13, o padrão HABILITAR FAVORITOS é um padrão opcional da linguagem e não foi utilizado pois não é adequado aos requisitos do sistema de leilões do site iBazar, como pode-se observar na Figura 3.14. É importante notar esse fato, pois esse caso exemplifica que uma linguagem de padrões possui vários caminhos que podem ser seguidos e o analista deve, por meio do grafo de fluxo (Figura 3.14) e do componente "Próximos Padrões", verificar todos os caminhos adequados para alcançar a solução.

É possível notar pela Figura 3.14 alguns atributos e operações que estão realçadas com uma cor diferente. Essa notação indica que esses elementos do diagrama, sejam eles classes, atributos, relacionamentos, métodos ou operações, foram adicionados para complementarem o modelo com elementos que representam funções necessárias para atender a requisitos dos sistemas-base. Por exemplo, os requisitos apresentados no Quadro 3.5 requerem a inserção de novos atributos 


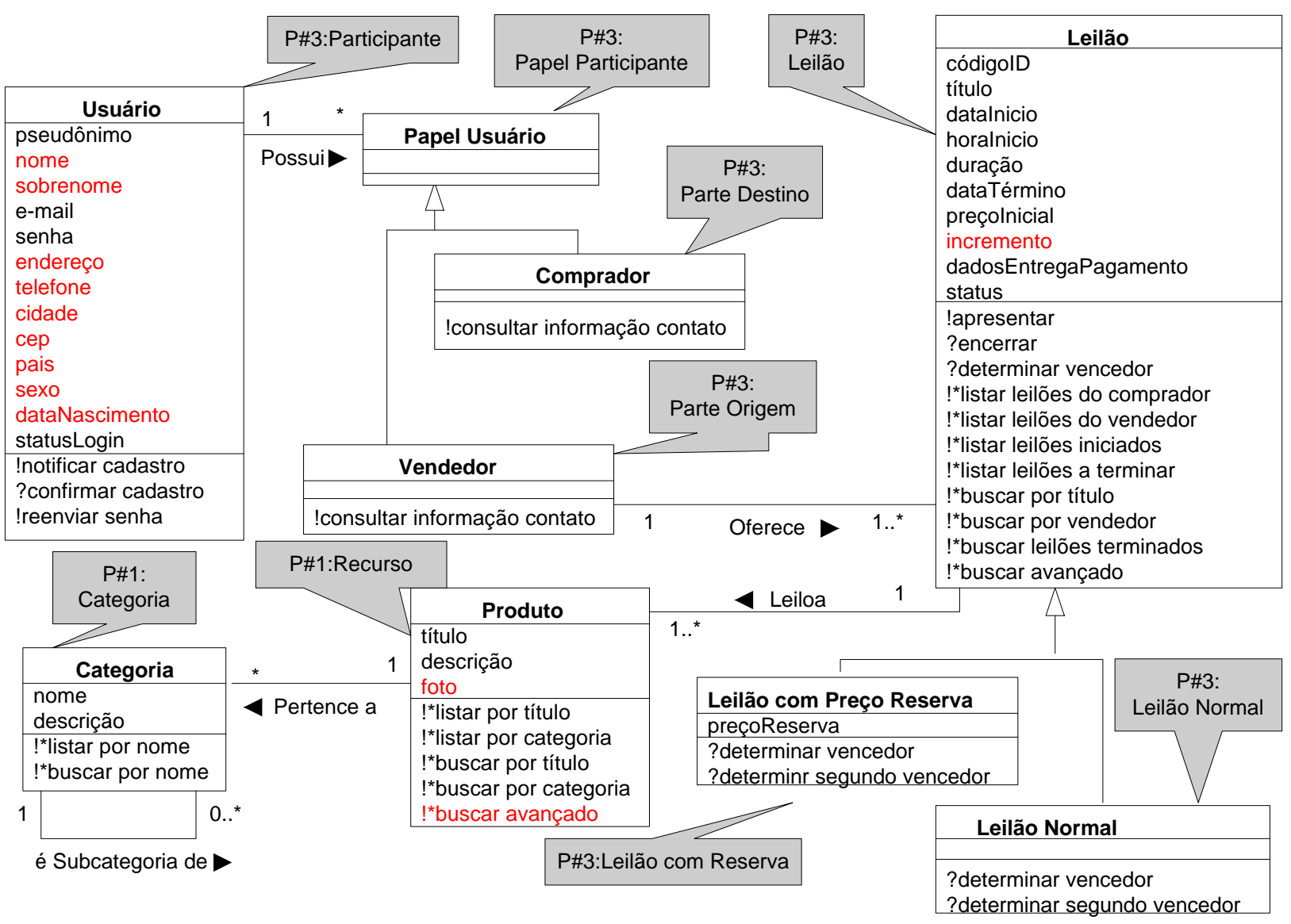

Figura 3.14: Exemplo da Aplicação dos Padrões 1 e 3 da Linguagem de Padrões LV.

(nome, sobrenome, endereço, cidade, estado, CEP, país, sexo, data de nascimento) e operações (buscar avançado).

Quadro 3.5: Parte dos Requisitos do Sistema de Leilões Virtuais iBazar.

3.1.1 O sistema deve permitir a inserção e alteração de usuários, cadastrando-os no sistema com algumas informações necessárias: nome, sobrenome, endereço eletrônico, pseudônimo, senha (no mínimo quatro caracteres), endereço, cidade, estado, telefone, CEP, país, sexo e data de nascimento...

3.2.1 O sistema deve permitir a um vendedor inserir recursos no sistema e criar um novo leilão, que a princípio é um leilão normal, requerendo as seguintes informações: categoria e subcategoria do recurso, título do leilão, descrição do recurso, foto do recurso...

No Quadro 3.5 e da Figura 3.14 é possível observar que um padrão, por exemplo, o padrão IDENTIFICAR O RECURSO, atende a vários requisitos dispersos ao longo da especificação de re- 
quisitos. Pode-se observar também que um requisito pode ser atendido por mais de um padrão, como por exemplo o requisito 3.2.1, que é atendido pelo padrão IDENTIFICAR O RECURSO e pelo padrão LEILOAR O RECURSO.

Podem ocorrer casos em que o requisito é atendido apenas parcialmente ou não atendido pela linguagem de padrões e a solução para satisfazer o requisito seja mais elaborada, requerendo maior tempo. Assim deve-se marcar quais requisitos foram plenamente atendidos, quais foram os requisitos parcialmente atendidos e quais não foram atendidos para que esses dois últimos sejam analisados posteriormente pelo analista. Assim, torna-se possível que o analista complemente o modelo de classes da aplicação instanciada com as entidades que representem os requisitos ainda não satisfeitos.

A Figura 3.15 mostra a inserção de outras classes, provenientes da aplicação dos padrões PROMOVER Negociação, Gerenciar LAnCES e Gerenciar a EMPresa Leiloeira, no modelo de classes apresentado anteriormente na Figura 3.14. O sistema de leilões do iBazar oferece aos compradores e vendedores um meio de incentivar a comercialização por intermédio de um canal de comunicação que promove a negociação entre as partes. O padrão PROMOVER NEGOCIAÇÃo trata diretamente das funções relacionadas a esse canal de comunicação. Além de permitir que qualquer participante tire suas dúvidas com relação a um leilão especifico diretamente com o vendedor do recurso, o padrão oferece a consulta dessas dúvidas por outros participantes, esclarecendo ainda mais a descrição do leilão dada pelo vendedor.

O padrão GERENCIAR LANCES tem por objetivo representar as funções relacionadas aos lances. Da mesma forma que podem existir diferentes tipos de leilões em um sistema, podem existir também diferentes tipos de lances. O leilão holandês e o leilão com preço de reserva, por exemplo, exigem diferentes tipos de lances, cada um com detalhes específicos referentes às regras implementadas em cada tipo de leilão. Os tipos de leilão oferecidos pelo sistema do site iBazar não necessitam de tipos específicos de lances. Existe outra função que também é coberta pelo padrão GERENCIAR LANCES, a marcação de um leilão por parte de um participante, identificando-o como um leilão que causou interesse. Esses leilões marcados ficam à disposição do participante para que ele possa acompanhá-los de maneira mais fácil.

Um exemplo de aplicação do padrão GERENCIAR A EMPRESA LEILOEIRA também pode ser observado na Figura 3.15. Esse padrão possui classes opcionais que podem ser aplicadas ou não. A classe Taxa ou qualquer uma de suas especialização são consideradas opcionais, pois podem existir sistemas de leilões virtuais que não cobram por seus serviços. Conseqüentemente a classe Conta e o atributo formaPagamento da classe Participante também são opcionais, porque não existem taxas a serem cobradas. Esse é exatamente o caso do sistema de leilões do site iBazar, 
no qual os participantes podem efetuar suas comercializações livremente, sem que o iBazar cobre qualquer taxa pelo uso do sistema ${ }^{7}$.

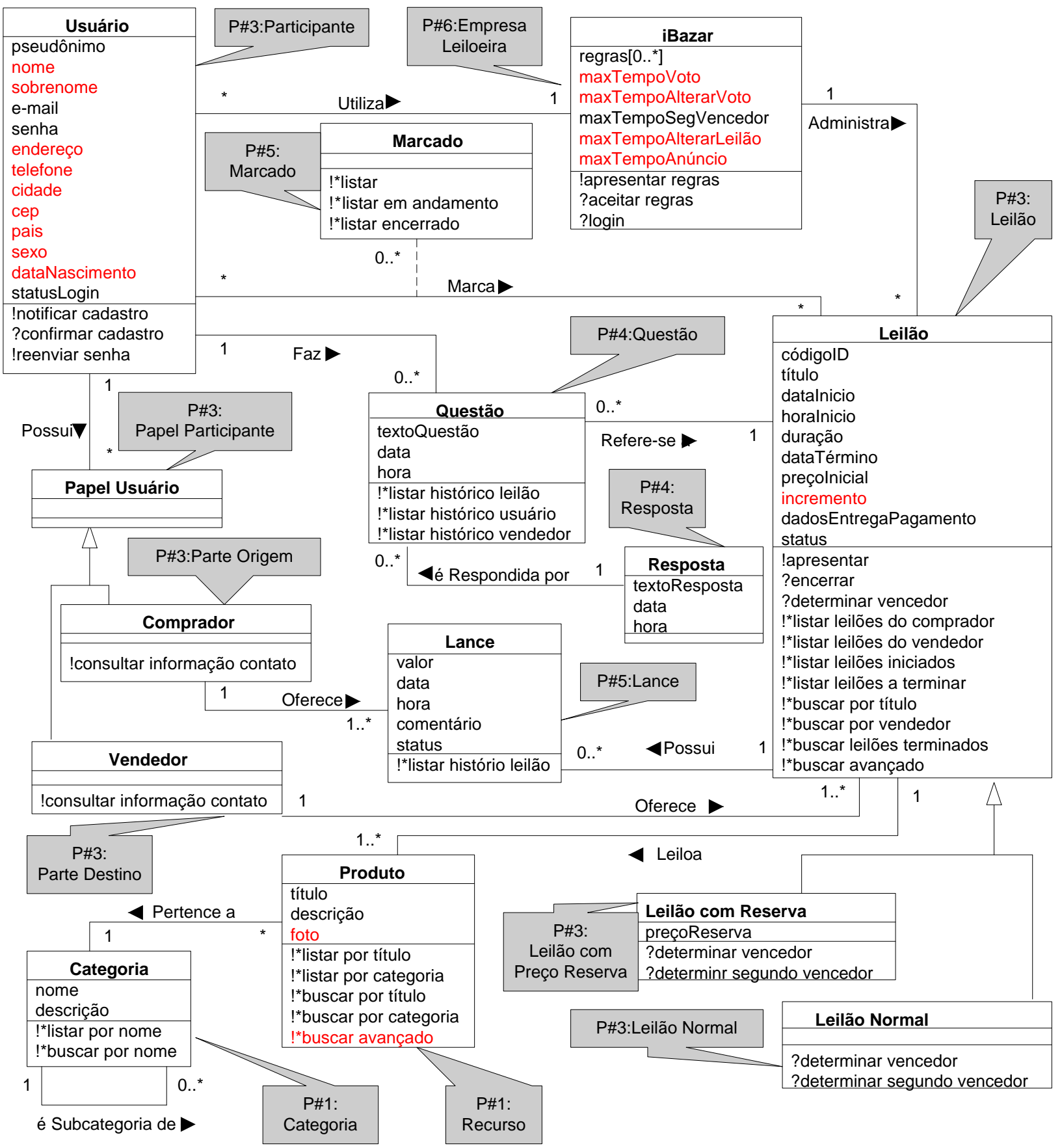

Figura 3.15: Exemplo da Aplicação dos Padrões 4,5 e 6 da Linguagem de Padrões LV.

${ }^{7}$ É importante notar que as regras de funcionamento dos leilões e suas funcionalidades apresentadas neste trabalho e nos documentos produzidos durante seu desenvolvimento podem ter sido alterados com o decorrer do tempo, de acordo com as estratégias de negócio das empresas proprietárias do sistema. 
Apesar de possuir muitas classes opcionais, o padrão GERENCIAR A EMPRESA LEILOEIRA é extremamente importante para o funcionamento geral do sistema. É nesse padrão que são tratados os parâmetros gerais de funcionamento do sistema, como por exemplo, as regras que regem como os participantes podem participar dos leilões, quais as responsabilidades dos participantes e o papel da empresa leiloeira no processo de comercialização (regras [0 . * ]). Outro exemplo, mostrado na Figura 3.15, é o atributo maxTempoAlterarleilão que foi inserido no modelo de classes para atender a um requisito que informa a permissão de alteração do leilão por um determinado período, a partir do seu cadastramento no sistema.

O modelo de classes completo para o sistema do site iBazar é apresentado na Figura 3.16. Esse modelo contém, além das classes mostradas na Figura 3.15, as classes provenientes dos padrões Gerenciar Reputações, Habilitar Mensagens e Gerenciar Anúncio. O sistema de leilões virtuais do site iBazar, bem como os outros sistemas-base, possui um mecanismo para tentar estabelecer o grau de idoneidade de um participante por meio das comercializações que ele efetua por intermédio do sistema. O padrão GERENCIAR REPUTAÇõES implementa esse mecanismo que gerencia as reputações dos participantes permitindo que compradores e vendedores votem uns nos outros, de maneira positiva ou negativa, de acordo com o leilão em que comercializaram um recurso. Assim, os participantes podem, a qualquer momento, consultar as reputações de outros participantes.

O padrão Habilitar Mensagens, presente na Figura 3.16, lida com as mensagens enviadas pelo sistema aos participantes, por exemplo: mensagem de fim de leilão, mensagem informando quem é o vencedor de um leilão, mensagem informando que um leilão terminou e mensagens contendo propaganda da empresa leiloeira. Assim, ao efetuar login no sistema o participante é avisado das mensagens e pode verificá-las. Na Figura 3.16 também pode ser observada a aplicação do padrão GERENCIAR ANÚNCIO. Esse padrão tem por objetivo controlar a apresentação dos leilões no sistema, para "chamar" a atenção do participante para os recursos que estão presentes no sistema para serem comercializados.

Após a aplicação de todos os padrões da linguagem que atendem aos requisitos do sistema, é necessário complementar o modelo por meio da adição de novas classes, atributos, relacionamentos, métodos ou operações para atender aqueles requisitos parcialmente atendidos ou não atendidos. Essa foi a estratégia utilizada para a validação do sistema do site iBazar, de forma que após a aplicação da linguagem não foi necessário complementar o modelo de classes resultante. Assim, pôde ser constatado que a Linguagem de Padrões LV cobriu os requisitos da especificação, provendo a funcionalidade necessária ao sistema.

Obviamente, outros sistemas não tomados como base devem ser instanciados para avaliar a linguagem de padrões. Eventuais aspectos não cobertos devem ser analisados quanto à viabilidade de serem incorporados e, portanto, estenderem-na. É possível também encontrar erros, que devem 
levar a correções na linguagem de padrões. Deve-se observar que nem todas as extensões devem ser incorporadas, pois pode ser o caso de que elas pertençam a outros subdomínios e, assim, ficariam melhores em outras linguagens de padrões.

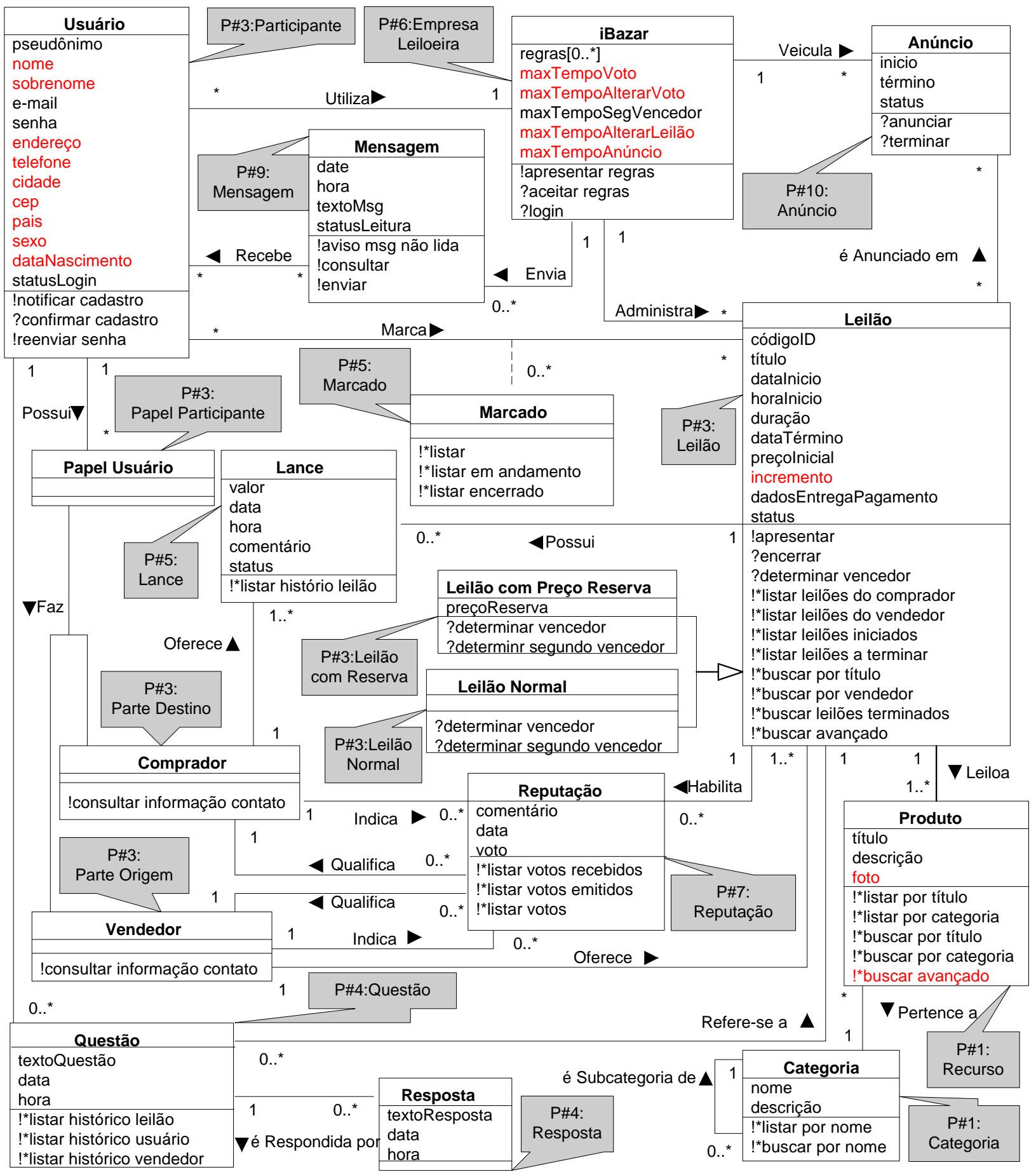

Figura 3.16: Exemplo da Aplicação dos Padrões 7,9 e 10 da Linguagem de Padrões LV. 


\subsection{Considerações Finais}

O processo genérico para o redesenvolvimento de SIbWebs foi contextualizado e dois de seus subprocessos foram apresentados detalhadamente neste capítulo: a criação de um modelo do domínio por meio de engenharia reversa e a criação de uma linguagem de padrões com base no modelo criado no processo anterior.

O processo foi ilustrado com a criação da Linguagem de Padrões LV, que trata do domínio de leilões virtuais, no qual tomou-se como sistemas-base os sistemas de leilões do iBazar, Arremate.com e eBay. Por meio da engenharia reversa baseada na interface Web desses três sistemas e auxiliado por documentos produzidos durante a condução do processo, foram criados os modelos de classe das aplicações e, analisando a similaridade das classes, o modelo do domínio. Algumas dificuldades de aplicação do processo foram encontradas durante a engenharia reversa baseada na interface Web, como por exemplo, o fato de SIbWebs serem alterados com maior frequiência do que os sistemas de informação tradicionais, implicando em maior esforço do analista. As mudanças são mais freqüentes em aspectos ligados à interface Web do que em relação às regras de negócio. Porém, ainda que com menor frequiência, estas também sofrem alterações. Além do maior esforço, essas mudanças dificultam a elicitação dos requisitos do sistema, podendo implicar em erros na especificação de requisitos.

Por intermédio do modelo de classes do domínio e de diretrizes para determinar as funções principais presentes no modelo foi possível determinar os padrões da linguagem e o fluxo de aplicação desses padrões. Finalizando o capítulo, apresentou-se na íntegra um padrão da linguagem, com o objetivo de fornecer uma visão da forma da linguagem de padrões, bem como uma aplicação específica da Linguagem de Padrões LV, usada para exemplificar sua utilização e também para auxiliar em sua validação.

A Linguagem de Padrões LV é aplicável quando torna-se necessário a criação de sistemas que têm por objetivo gerenciar a comercialização de produtos por intermédio de leilões virtuais. A linguagem oferece apoio a quatro tipos de leilões, como apresentado na Seção 3.6 e constitui a base para a adição de novos tipos de leilões pela extensão de sua funcionalidade, como por exemplo os apresentados na Figura 2.5. Apesar dessa base passível de extensão, adicionar a funcionalidade disponibilizada por alguns tipos de leilões pode apresentar maiores dificuldades e, em alguns casos, pode ocorrer a impossibilidade de extensão por implicar em alterações em demasia na linguagem de padrões.

Como exemplificado neste capítulo, o processo proposto pode ser utilizado para, a partir de um modelo do domínio, criar uma linguagem de padrões, que por sua vez possibilita o desenvolvimento de aplicações do mesmo domínio. O modelo de classes do domínio, produto intermediário do processo geral, pode ser utilizado para a criação de frameworks. No entanto, para esse fim, a 
linguagem de padrões forma um arcabouço que fornece maiores subsídios ao desenvolvimento. $\mathrm{O}$ processo genérico de desenvolvimento de frameworks e detalhes específicos do Framework Qd+, desenvolvido com base na Linguagem de Padrões LV, são apresentados no próximo capítulo. 


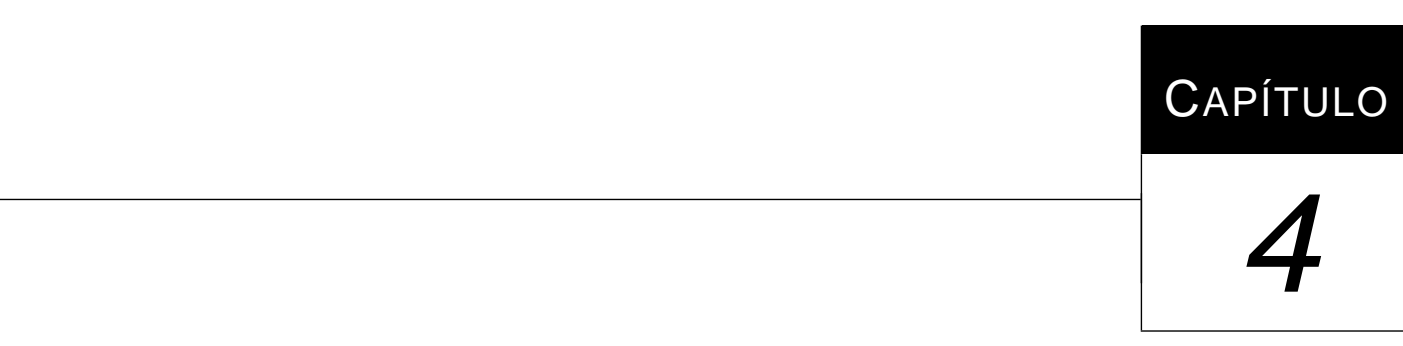

\section{O Subprocesso de Construção e o Framework Qd+}

\subsection{Considerações Iniciais}

Este capítulo tem foco no Framework Qd+, mostrando tanto os subprocessos ${ }^{1}$ de construção e instanciação, por meio de exemplos baseados no modelo de classes apresentado na Seção 3.6, como também a utilização da Linguagem de Padrões LV como base para esses processos. A construção do Framework Qd+ seguiu os passos da proposta de Braga e Masiero (2002b) que, dentre outras opções, apóia a identificação dos pontos variáveis, projeto, implementação e validação de frameworks caixa branca. A proposta apresentada por Braga e Masiero (2002a) foi utilizada como base para a instanciação do Framework Qd+, contudo, adaptações foram necessárias para atender suas características específicas.

Na Seção 4.2 é apresentado o subprocesso de construção do Framework Qd+ e nela são discutidos alguns métodos de desenvolvimento de padrões e o método em que foram baseadas as atividades de construção do Framework Qd+. Mostra-se na Seção 4.3 um exemplo de instanciação do Framework Qd+ contendo algumas de suas principais funções, juntamente com ilustrações dos formulários referentes a essas funções, em que pode-se ter uma idéia da sua interface com o usuário.

\footnotetext{
${ }^{1}$ Quando não houver necessidade de diferenciar a hierarquia, os termos processo e subprocesso serão usados como sinônimos.
} 


\subsection{O Processo de Construção do Framework Qd+}

Foram propostos na literatura vários métodos de desenvolvimento de frameworks, como por exemplo, os propostos por Bosch et al. (1999), Pree (1995, 1999) e Schmid (1997, 1999). Neste trabalho é utilizado o processo de construção e instanciação de frameworks caixa branca baseado em uma linguagem de padrões proposto por Braga e Masiero (2002b) cujo foco, semelhante à abordagem de Bosch et al. (1999), é na análise do domínio. Nesse processo uma linguagem de padrões é utilizada para capturar o domínio da aplicação e guiar o desenvolvimento do framework, identificando inicialmente os pontos variáveis, para minimizar os ciclos de iteração e ao mesmo tempo facilitar o aprendizado e uso do framework. Esse processo é dividido em três atividades principais, sendo a primeira atividade uma análise do domínio para capturar e descrever os principais requisitos do framework. O modelo de análise do domínio é então utilizado para o projeto arquitetural e posterior refinamentos.

Como mostrado na Figura 3.1 do Capítulo 3, além da linguagem de padrões poder ser utilizada como um guia no desenvolvimento de sistemas específicos, ela fornece uma considerável base de conhecimento para o desenvolvimento de frameworks de software orientados a objetos (Braga e Masiero, 2000). Além do framework codificar esse conhecimento de projeto para um particular domínio, o relacionamento entre a sua arquitetura e a linguagem de padrões facilita a instanciação de novas aplicações, fazendo com que seja necessário apenas o conhecimento da linguagem de padrões para a instanciação de novas aplicacões (Braga e Masiero, 2002a; Johnson, 1997).

O primeiro passo da abordagem é caracterizado pela criação de uma linguagem de padrões a partir de conhecimento do analista e de sistemas específicos. Esse primeiro passo da abordagem é genérico para qualquer domínio de aplicação. O processo de criação da Linguagem de Padrões LV, apresentado na Seção 3.4, segue a abordagem de reuso de Braga e Masiero (2002b), com as adaptações necessárias ao domínio específico, os leilões virtuais. Esse passo foi apresentado na Seção 3.4.

Para o desenvolvimento do framework para o domínio de sistemas de leilões virtuais foi utilizado o segundo passo do processo apresentado na Figura 4.1. Esse passo, como mostra a Figura 4.2, é constituído dos seguintes subpassos: identificação dos pontos variáveis, projeto do framework, implementação do framework e validação do framework.

\subsubsection{Identificação dos Pontos Variáveis}

A identificação dos pontos variáveis a partir da linguagem de padrões é o primeiro passo do processo proposto por Braga e Masiero (2001) e é constituído de cinco subpassos: 


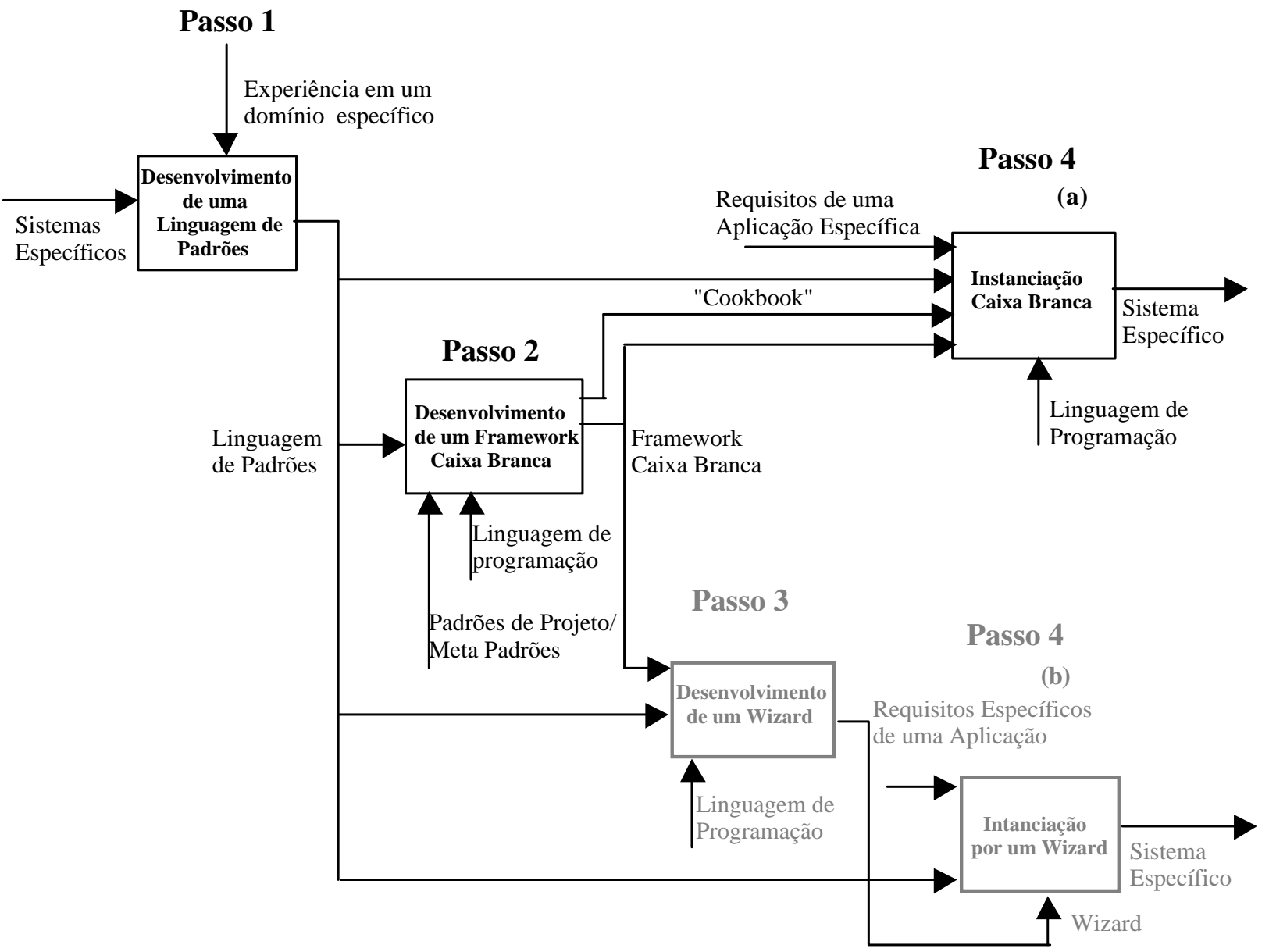

Figura 4.1: Abordagem para Construção e Instanciação de Frameworks (Braga e Masiero, 2002b).

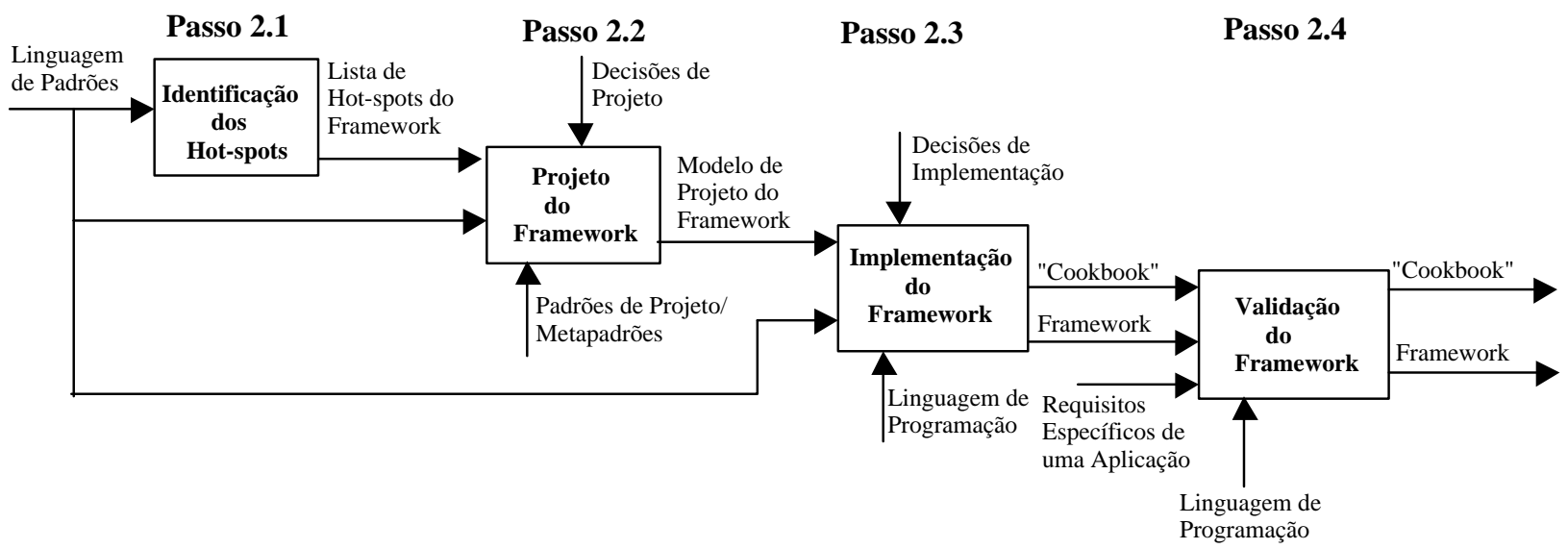

Figura 4.2: Processo para Construção de frameworks Baseado em uma Linguagem de Padrões (Braga e Masiero, 2002b). 
- analisar o grafo da linguagem: o objetivo principal desse passo é encontrar os pontos variáveis derivados de padrões opcionais observando-se os diferentes modos de aplicação dos padrões;

- analisar cada padrão: deve-se analisar individualmente cada componente dos padrões da linguagem, como por exemplo, "variantes", "subpadrões", "implementação", "estrutura" e "participantes", que podem mostrar soluções alternativas, aspectos variáveis dos padrões, alternativas de implementação da solução e diferentes atributos, relacionamentos ou métodos para diferentes comportamentos necessários ao framework;

- refinar a lista de pontos variáveis: nesse passo deve-se refinar a especificação dos pontos variáveis objetivando identificar pontos variáveis não explícitos na linguagem de padrões, adicionar informações para seu projeto e implementação e utilizá-los para melhorar a linguagem de padrões;

- criar uma lista de referência cruzada dos pontos variáveis: visa a identificar inconsistências na lista de pontos variáveis, e assim, encontrar mais alguns pontos variáveis e melhorar o framework e a linguagem de padrões; e

- analisar requisitos não funcionais: deve-se considerar tanto os requisitos não funcionais relacionados à portabilidade, usabilidade, segurança e confiabilidade, como também requisitos relacionados à flexibilidade do framework.

O resultado do passo 2.1 do processo apresentado na Figura 4.2 é uma lista dos pontos variáveis do framework, cada qual composto de um código de identificação, uma descrição do ponto variável, o tipo do ponto variável, a origem do ponto variável na linguagem de padrões (opcional) e o padrão da linguagem em que o ponto variável foi identificado. Os tipos em que os pontos variáveis podem ser classificados indicam o que deve ser feito para obter a aplicação desejada a partir do framework:

ESCOLHA_PARTIC estabelece que existirá uma escolha entre os participantes de um padrão, isto é, o usuário do framework terá que escolher quais participantes serão utilizados em uma instanciação em particular;

PADRÃO_OPCIONAL determina que todo o padrão pode ser opcionalmente utilizado em aplicações específicas;

PARTIC_OPCIONAL permite que um participante de um padrão não seja usado em uma instanciação em particular;

RELACIONAMENTO determina a mudança de relacionamento entre classes de acordo com os requisitos específicos de uma aplicação; 
COMPORTAMENTO estabelece a mudança de comportamento para que uma ou mais classes atendam a requisitos específicos; e

PROPAGAÇÃO permite que uma escolha feita previamente em um padrão seja propagada em outros padrões.

Tabela 4.1: Lista Parcial dos pontos variáveis do Framework Qd+

\begin{tabular}{|c|c|c|c|c|c|}
\hline $\begin{array}{l}\text { Número } \\
\text { do } \\
\text { ponto } \\
\text { variá- } \\
\text { vel }\end{array}$ & Nome & Descrição & Tipo & $\begin{array}{l}\text { Origem na } \\
\text { Linguagem de } \\
\text { Padrões }\end{array}$ & $\begin{array}{l}\text { Número } \\
\text { do } \mathrm{Pa}- \\
\text { drão }\end{array}$ \\
\hline$\overline{1}$ & $\begin{array}{l}\text { Categorização } \\
\text { de Recursos }\end{array}$ & $\begin{array}{l}\text { Os recursos podem ser categorizados segundo vários critéri- } \\
\text { os de classificação que podem ser simples ou de forma ani- } \\
\text { nhada. }\end{array}$ & ESCOLHA_PARTIC & $\begin{array}{l}\text { Participantes, } \\
\text { Variantes }\end{array}$ & $\overline{11}$ \\
\hline 2 & $\begin{array}{ll}\text { Taxação } & \text { de } \\
\text { Serviços } & \end{array}$ & $\begin{array}{l}\text { Uma empresa leiloeira pode optar por cobrar determinadas } \\
\text { taxas sobre seus serviços, tornando-as opcionais. }\end{array}$ & ESCOLHA_PARTIC & Participantes & 6 \\
\hline 3 & $\begin{array}{lr}\text { Registro } & \text { das } \\
\text { Taxas } & \text { do } \\
\text { Usuário } & \end{array}$ & $\begin{array}{l}\text { As taxas eventualmente cobradas pela empresa leiloeira de- } \\
\text { vem ser registradas individualmente para cada usuário. Por- } \\
\text { tanto, a conta do usuário fica condicionada à cobrança de } \\
\text { taxas. }\end{array}$ & PROPAGAÇÃO & $\begin{array}{l}\text { Participantes, } \\
\text { Grafo de Flu- } \\
\text { xo, Próximos } \\
\text { Padrões }\end{array}$ & 6 \\
\hline 4 & $\begin{array}{l}\text { Restituição } \\
\text { das Taxas }\end{array}$ & $\begin{array}{l}\text { Pode-se restituir uma taxa cobrada, porém é necessário que } \\
\text { essas taxas existam ficando assim o padrão GERENCIAR } \\
\text { RESTITUIÇÃo condicionado às taxas utilizadas em uma } \\
\text { aplicação específica. }\end{array}$ & PROPAGAÇÃO & $\begin{array}{l}\text { Participantes, } \\
\text { Grafo de Flu- } \\
\text { xo, Próximos } \\
\text { Padrões }\end{array}$ & 6 \\
\hline$\ldots$ & $\begin{array}{l}\text { Mensagens } \\
\text { para os Usuá- } \\
\text { rios } \\
\ldots\end{array}$ & $\begin{array}{l}\text { Em uma aplicação específica pode ser desejável utilizar o } \\
\text { envio de mensagens aos usuários, portanto, caso esse seja o } \\
\text { caso, o padrão HABILITAR MENSAGENS deve ser aplicado. } \\
\text {... }\end{array}$ & PADRÃO_OPCIONAL & $\begin{array}{l}\text { Grafo de Flu- } \\
\text { xo, Próximos } \\
\text { Padrões } \\
\ldots\end{array}$ & 7 \\
\hline
\end{tabular}

A Tabela 4.1 apresenta a lista parcial de pontos variáveis encontrados na Linguagem de Padrões LV. O ponto variável "Categorização de Recursos" refere-se ao fato de que um recurso pode ser categorizado segundo vários critérios de classificação e subclassificação, como pode ser observado no Quadro 4.1 e no Quadro 4.2. Por exemplo, para produtos de informática, os recursos podem ser agrupados por sua natureza (hardware, software), em um segundo nível pelo seu tipo (periféricos de entrada, CPUs ou notebooks) e em um terceiro nível pelos fabricantes ou marcas. Podem existir ainda, outros critérios, como por exemplo: itens que podem fazer parte de coleções pessoais de usuários ou itens que podem ser caracterizados como bons para presentear, que formam outros critérios de classificação sem subníveis. Para conseguir tal comportamento em uma aplicação específica é necessário estabelecer os critérios de classificação e seus subníveis por meio da escolha de quais participantes do padrão utilizar. Como é necessária a escolha de quais participantes devem ser usados, esse ponto variável é do tipo "ESCOLHA_PARTIC".

Quadro 4.1: Parte da Descrição do Participante Categoria.

Representam categorias em que os recursos podem ser agrupados... Usualmente, no máximo três níveis de agrupamento de uma mesma classificação são permitidos. 
Quadro 4.2: Parte do Componente "Variantes" do Padrão IDENTIFICAR O RECURSO.

\begin{abstract}
Este padrão é uma variação do padrão Identificar o Recurso proposto por (Braga et al., 1999).... Quando vários níveis de um mesmo critério de classificação são necessários existe um conjunto de objetos aninhados (Johnson e Woolf, 1998)... Para melhorar a categorização, os recursos podem ser classificados por mais que um grupo, resultando em grande flexibilidade...
\end{abstract}

O segundo ponto variável da Tabela 4.1, “Taxação de Serviços”, refere-se às diferentes taxas que uma empresa leiloeira pode definir para os leilões, como apresentado na descrição do ponto variável. Essas taxas podem variar de acordo com a aplicação específica que se deseja instanciar, como pode ser observado na Seção 3.5.1, que apresenta na íntegra o padrão GERENCIAR A EMPRESA LEILOEIRA. O ponto variável é classificado, então, como "ESCOLHA_PARTIC", pois o tipo de taxa escolhido refere-se diretamente a quais participantes devem ser aplicados em uma instanciação específica.

Existe uma dependência entre o ponto variável "Taxação de Serviços", que refere-se à escolha dos participantes que representam diretamente as taxas usadas em uma aplicação específica, e o ponto variável "Registro das Taxas do Usuário". A não definição de taxa alguma implica na inexistência de cobrança sobre os serviços prestados e, portanto, implica na não existência de registros de taxas individualmente para cada usuário. A decisão tomada no ponto variável "Taxação de Serviços" faz com que um participante da estrutura do padrão GERENCIAR A EMPRESA LEILOEIRA, a classe Conta, não seja aplicado. O ponto variável "Registro das Taxas do Usuário" é um exemplo de propagação dos efeitos de uma decisão em um mesmo padrão, e como tal, pode ser classificado como "PROPAGAÇÃO”.

A classificação "PROPAGAÇÃO", que no ponto variável "Registro das Taxas do Usuário" caracteriza a dependência entre participantes de um mesmo padrão, mostra no ponto variável "Restituição das Taxas" que a decisão tomada em um padrão também pode ter efeitos não somente em participantes de sua própria estrutura mas também na estrutura de outros padrões da linguagem. $\mathrm{O}$ ponto variável "Restituição das Taxas" torna explícito que, ao não se estabelecer taxa alguma no ponto variável "Taxação de Serviços”, não deve-se aplicar o padrão GERENCIAR RESTITUIÇÃo. Estabelecido esse comportamento, o tipo de ponto variável "PROPAGAÇÃO" também caracteriza o ponto variável "Restituição das Taxas".

O ponto variável "Mensagens para os Usuários", de forma análoga ao segundo ponto variável da Tabela 4.1, refere-se também à flexibilidade de aplicação de uma linguagem de padrões, porém, nesse ponto variável, a opcionalidade refere-se a todo o padrão. Esse ponto variável identifica que o padrão HABILITAR MENSAgENS, como ilustrado no Quadro 3.4 e na Figura 3.13, pode ou não ser aplicado e, por conseguinte, é classificado como "PADRÃO_OPCIONAL". 
Utilizando a Linguagem de Padrões LV na identificação dos pontos variáveis foi possível encontrar dezessete pontos variáveis distribuídos entre as várias classificações anteriormente citadas (detalhes no Apêndice B). Os pontos variáveis formam, juntamente com a própria Linguagem de Padrões LV, a base principal para o projeto e posterior construção do Framework Qd+, conforme apresentado na Seção 4.2.2.

\subsubsection{Projeto do Framework}

Com os pontos variáveis e a linguagem de padrões como base, o Projeto do Framework foi o passo seguinte na abordagem de desenvolvimento de frameworks caixa branca (passo 2.2), sendo composto de três subpassos: projeto arquitetural, projeto das classes e documentação. Esses passos são explicados e exemplificados nas sessões seguintes.

\subsubsection{Arquitetura do Framework}

O projeto arquitetural é necessário na construção de frameworks para que sejam tomadas decisões de projeto de alto nível, como por exemplo, com relação à persistência dos dados, à interface gráfica com o usuário e segurança, visando a definição da arquitetura que melhor se adequa aos requisitos do framework e ao ambiente ao qual ele é projetado.

A arquitetura comumente usada para a execução de aplicações para a Web é a arquitetura de três camadas (3-tier), na qual existe um navegador na máquina cliente, que corresponde à camada de apresentação, um servidor de Web ou servidor HTTP, que corresponde à camada de aplicação, e um servidor de banco de dados, que corresponde à camada de persistência.

As camadas de apresentação, de aplicação e de persistência são, na realidade, camadas lógicas. A camada de apresentação contém todas as classes de interface e é a única camada visível aos usuários e, portanto, é a que mais sofre alterações. Essa camada exibe o estado atual do sistema ao usuário, permite a entrada de dados, a navegação, a propagação de eventos gerados pelo usuário e a requisição de páginas ou ativação de tarefas que devem ser processadas na camada de aplicação.

A camada de aplicação é responsável pela lógica do negócio, o que inclui algoritmos e regras procedimentais, e define o comportamento do sistema, ou seja, nessa camada intermediária as requisições são interpretadas e processadas e, em seguida, as respostas são enviadas para a máquina cliente. Caso seja necessário, o acesso, a criação ou a destruição de algum objeto armazenado na base de dados, é feito pela camada persistente, que utiliza comandos SQL (Structured Query Language). A camada persistente correspondente à lógica de manipulação de dados e de conexão com o SGBD (Sistema Gerenciador de Banco de Dados) e é responsável pelo armazenamento físico dos objetos do domínio em uma base permanente. Essa camada possui forte potencial para ser reutilizada. 
A linguagem de desenvolvimento utilizada no Framework Qd+ foi o Smalltalk, que foi escolhido por ser amplamente conhecido na comunidade de padrões de software e frameworks e também por ser a mesma linguagem de programação utilizada no desenvolvimento do Framework GREN, do qual o Framework Qd+ é uma extensão. O Visualworks 5i.4nc é um ambiente de desenvolvimento baseado na linguagem Smalltalk que proporciona portabilidade, pois existem distribuições para Windows(95/98/ME/NT/2000), PowerMac, Intel Linux, AIX, SGI Irix, Compaq UNIX, HPUX e Solaris. Ele dispõe dos recursos necessários para que sistemas de informação baseados na Web possam ser desenvolvidos normalmente, necessitando apenas de uma ferramenta que auxilie na criação de páginas HTML estáticas, ou seja, o projeto gráfico. Inicialmente o Framework Qd+ estava sendo desenvolvido com o Visualworks 5i.3nc e a única alternativa de implementação disponível era por meio do Visualwave. Posteriormente foi lançada uma nova versão do Visualworks, a 5i.4nc, possibilitando a utilização de três diferentes maneiras de implementar sistemas de informação baseados na Web (Cincom, 2001a,b):

- Smalltalk Server Pages: É um servidor de páginas Web, no qual é possível inserir instruções Smalltalk no código HTML. Esse servidor Web faz parte do Visualworks 5i.4nc Web Tool Kit e o permite a uso da sintaxe do Java Server Pages 1.1 da Sun Microsystems e a sintaxe do Active Server Pages 3.0 da Microsoft.

- Smalltalk Servlets: Utiliza o mesmo princípio dos Servlets Java da Sun Microsystems versão 2.2 e também faz parte do Visualworks 5i.4nc Web Tool Kit. O Servlets são aplicações que funcionam no servidor aceitando requisições HTTP e enviando respostas HTTP às requisições.

- Visualwave: É um conjunto de classes que transformam uma aplicação desenvolvida de maneira tradicional no Visualworks, uma ferramenta visual de construção de interfaces denominada UIPainter, em páginas HTML.

Visando ao reuso e compatibilidade com o Framework GREN foi utilizado o mesmo banco de dados, o MySQL. O MySQL é um gerenciador e um servidor de banco de dados relacional, implementado em $\mathrm{C}$ e $\mathrm{C}++$, que utiliza o SQL padrão para o acesso e a manipulação dos dados armazenados. Esse SGBD possui as vantagens de ser multiplataforma, podendo ser executado sobre sistemas operacionais como Linux, Unix e Windows NT/9X, e de possuir código aberto, podendo ser modificado e adaptado pelos desenvolvedores, de acordo com as necessidades específicas das suas aplicações.

Além desse conjunto de tecnologias, o Framework Qd+ utiliza o padrão Model-View-Controller, em que as funções da aplicação são separadas da apresentação ao usuário e se comunicam por meio de um controle, que constitui uma camada intermediária. Essa abordagem pode perfeitamente ser 
empregada na maioria das aplicações Web, pois se adapta perfeitamente à arquitetura de três camadas. Assim, o Framework Qd+ apresenta os mesmos elementos da arquitetura genérica de três camadas e beneficia-se das características do Model-View-Controller.

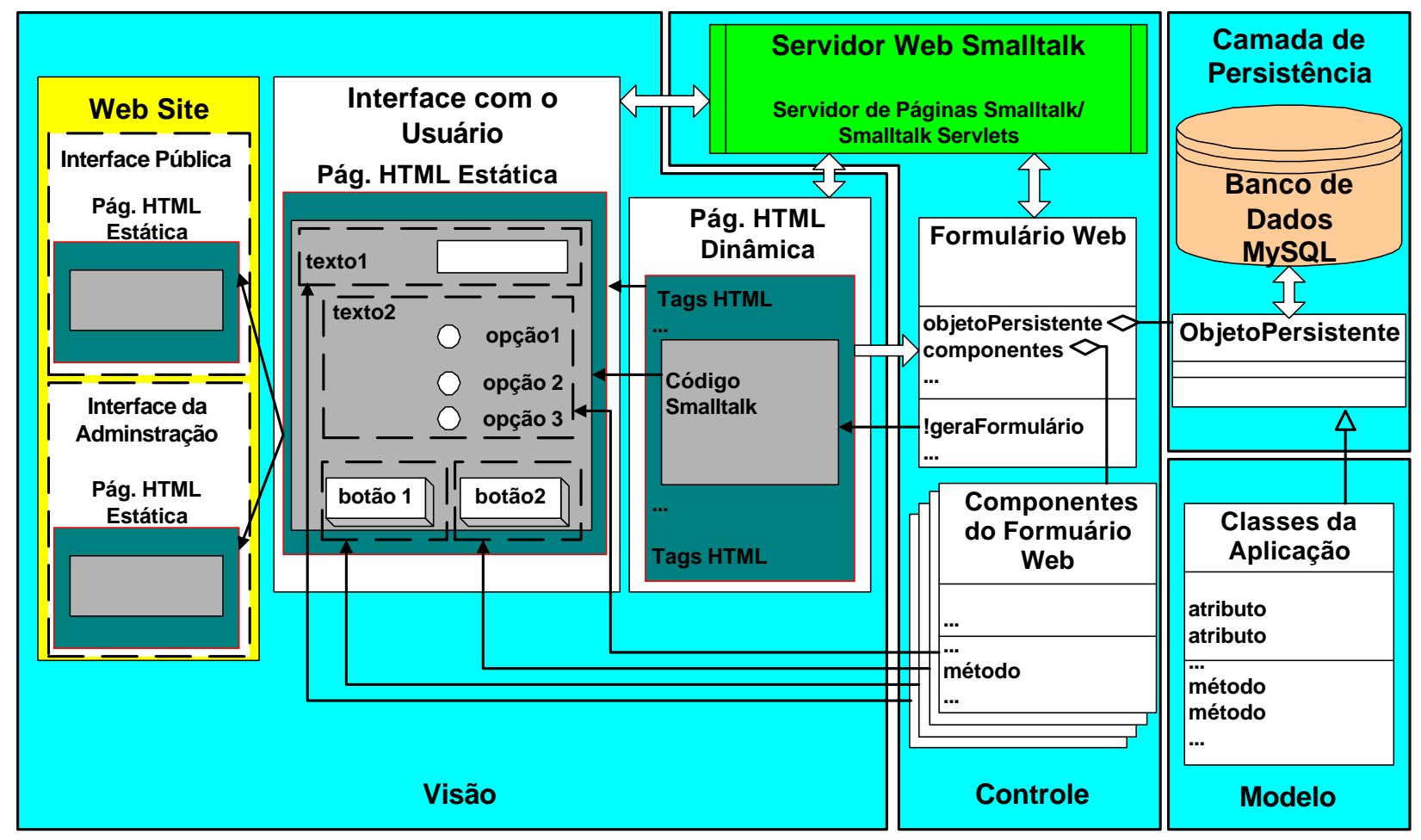

Figura 4.3: Arquitetura do Framework Qd+.

Como pode ser observado na Figura 4.3, o Framework Qd+ possui a camada de apresentação, representada pela "Visão"; a camada da aplicação, representada pelo "Controlador", pelo "Modelo" e pelo "Servidor Web Smalltalk"; e a camada de persistência, representada pelas "Classes da Aplicação", pelo "Objeto Persistente" e pelo "Banco de Dados MySQL".

Analogamente à arquitetura de três camadas, podem ser observados os elementos estruturais que compõem o Model-View-Controller: o modelo, representado pelas "Classes da Aplicação"; a visão, representada pelas "Páginas HTML Estáticas" e pelas "Páginas HTML Dinâmicas”; e o controle, representado pelo "Servidor Web Smalltalk", pelo "Formulário Web" e pelos "Componentes do Formulário Web".

O "modelo" possui as classes da aplicação que implementam as regras de negócio. Registrar um usuário, colocar um bem em um leilão, oferecer lances e verificar a reputação de usuários são exemplos de operações implementadas nas classes da aplicação que estão disponíveis no sistema. O "modelo" utiliza as funções do objeto persistente para ter acesso ao banco de dados, já que Smalltalk é uma linguagem orientada a objeto e o MySQL é um banco de dados relacional. 
A “visão” possui páginas HTML dinâmicas, ou seja, a página HTML apresentada no navegador como interface com o usuário é gerada em tempo de execução e é dividida em dois tipos, segundo a classe de usuários que os utilizam: a interface pública e a interface de administração. A interface pública disponibiliza a interface para as operações do domínio de leilões relacionadas às classes da aplicação, tais como, registrar o usuário, colocar um bem em um leilão, oferecer lance e verificar a reputação de usuários, por exemplo. A interface de administração é responsável por oferecer à empresa leiloeira a interface para lidar com os parâmetros de funcionamento dos leilões, como por exemplo, o tempo para registrar uma reclamação, o tempo de anúncio dos leilões e os atributos da empresa leiloeira. Essa interface de administração é visível apenas para a empresa leiloeira.

O "controle" é constituído pelo servidor Web Smalltalk, que é responsável por lidar com as requisições HTTP e as devidas respostas ao usuário, pelas especializações da classe Formulário $\mathrm{Web}^{2}$, que constituem a interface entre as classes da aplicação e a página HTML dinâmica e pelas especializações da classe Componentes do Formulário Web, que possuem código HTML para gerar os elementos da página, como por exemplo, botões e caixas de texto.

Embora essa arquitetura permita liberdade no projeto gráfico das páginas HTML, somente as especializações da classe Formulário Web (Figura 4.3) manipulam e controlam os componentes diretamente ligados ao modelo de classes da aplicação. Existe o mínimo possível de código Smalltalk inserido em páginas HTML, diminuindo a possibilidade de erros, melhorando a manutenibilidade e separando o projeto gráfico das funcionalidades do modelo de classes. Da mesma forma existe o mínimo possível de código HTML inserido em classes Smalltalk, proporcionando os mesmos benefícios.

\subsubsection{Projeto das Classes do Framework}

O primeiro passo para o projeto das classes do Framework Qd+ foi a criação de um diagrama de classes combinando todas as classes de cada padrão. O diagrama contendo as classes de projeto foi estudado e refinado para possibilitar generalizações/especializações e tornar o framework o mais genérico possível e também objetivando a utilização de padrões de projeto ou metapadrões. Essa investigação envolveu não apenas decisões de projeto, mas também a aplicação de técnicas usadas em implementação de frameworks.

Um exemplo contendo parcialmente o modelo de classes do projeto do Framework Qd+ ((Ré e Masiero, 2002)) pode ser observado na Figura 4.5. Essa figura apresenta as classes de projeto necessárias à implementação do padrão IDENTIFICAR O RECURSO, cuja estrutura é apresentada na Figura 4.4. Pode-ser observar que as classes do framework (Figura 4.5) geralmente são diferentes das classes contidas no padrão (Figura 4.4). É necessário um detalhamento maior e um número

\footnotetext{
${ }^{2}$ A classe Formulário Web, apresentada na arquitetura completa do Framework Qd+, foi efetivamente implementada como sendo a classe ObjectForm, mostrada no Quadro 4.3.
} 
maior de elementos para implementar a solução proposta pelo padrão; para atender à arquitetura do framework; para satisfazer a características específicas do framework; para tratar detalhes de implementação tradicionais; e para tratar detalhes de implementação próprios de um framework.



Figura 4.4: Exemplo do Componente "Estrutura" do Padrão IDENTIFICAR O RECURSO.

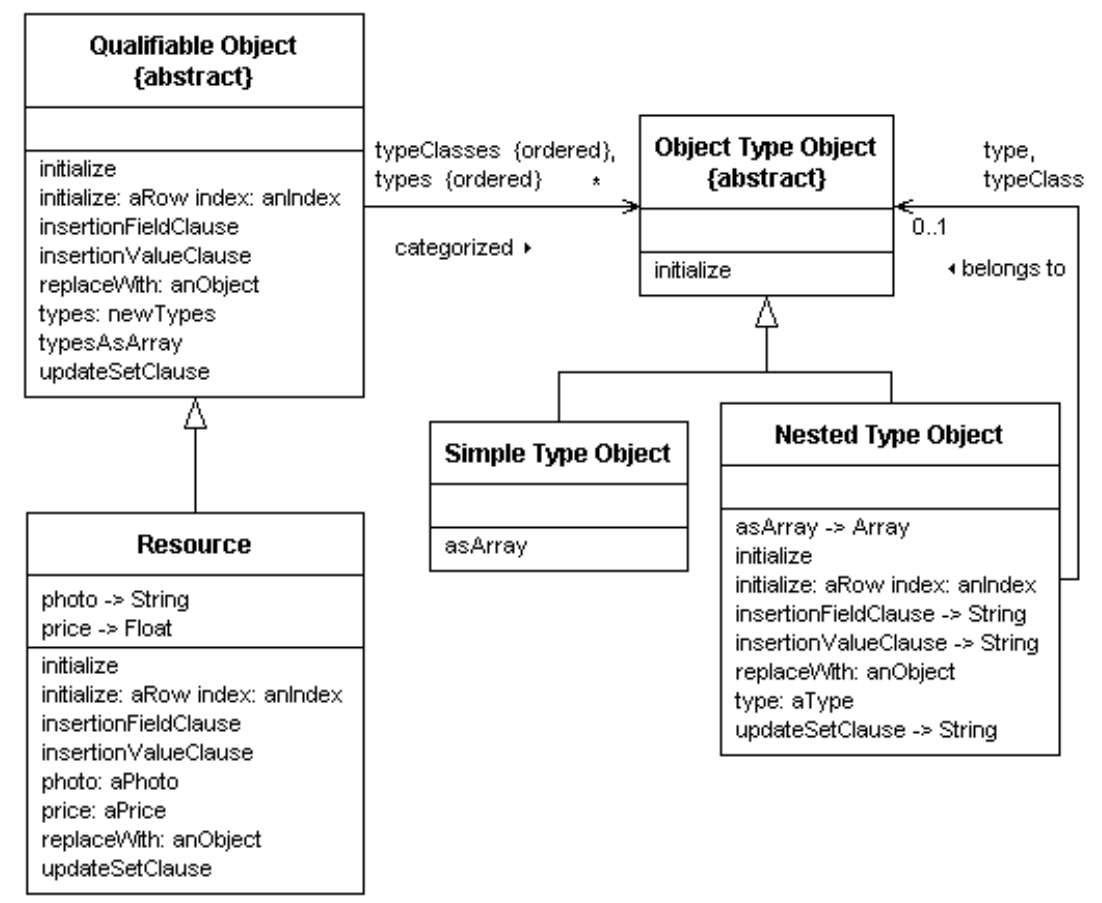

Figura 4.5: Exemplo de Classes do Framework Qd+ que Representam o Padrão IDENTIFICAR O RECURSO.

A classe Qualifiable object ${ }^{3}$ (Figura 4.5), por exemplo, foi adicionada ao Framework Qd+ atendendo a um requisito específico: a compatibilidade com o Framework GREN. O Framework GREN possui não apenas um tipo de recurso que pode ser qualificado, mas vários tipos de recurso (Braga et al., 1999). Isso explica porque existe apenas uma especialização da classe Qualifiable object, a classe Resource, como mostra a Figura 4.5.

\footnotetext{
${ }^{3}$ Os nomes das classes são apresentados em inglês porque foi dessa forma que o Framework Qd+ foi implementado, seguindo o mesmo padrão do Framework GREN. Além disso, é importante esclarecer que todas as figuras utilizadas neste capítulo possuindo termos em inglês foram obtidas diretamente de uma ferramenta de documentação utilizada como apoio ao projeto e implementação do Framework Qd+.
} 
Como exemplo de utilização da lista de pontos variáveis no projeto do framework pode-se observar a Figura 4.5. Para atender ao ponto variável "Categorização de Recursos" (Tabela 4.1) foram utilizadas as classes Object Type object, Simple Type object e Nested Type object. Esse conjunto de classes forma a representação da classe Categoria no nível de projeto. A classe Simple Type object é necessária para atender a qualquer instanciação em que os critérios de classificação do recurso não tenham subníveis, como discutido na Seção 4.2.1. A classe Nested Type object é destinada a atender qualquer instanciação nos quais vários níveis e subníveis de classificação sejam necessários, também discutido na Seção 4.2.1. A classe object Type object é uma classe abstrata e permite que qualquer aplicação de suas especializações seja possível, atendendo com maior flexibilidade ao ponto variável "Categorização de Recursos".

O conjunto de classes formado pela classe object Type object, pela classe Simple Type object e pela classe Nested Type object também pode ser usado como um exemplo da utilização de padrões de projeto neste passo da abordagem. Essas classes constituem uma aplicação do padrão "Multiple Type Object" proposto por Johnson e Woolf (1998). O padrão "Multiple Type Object" oferece soluções para problemas relacionados à classificação de um objeto por vários outros objetos, considerando especialmente o aninhamento dos objetos classificadores.

\subsubsection{Implementação do Framework}

O passo seguinte para a construção do framework foi a implementação das classes utilizando o modelo de classes produzido no passo anterior. O passo de implementação do framework possui três subpassos: implementar as classes da aplicação (apresentado na Seção 4.2.3.1), implementar as classes de interface (apresentado na Seção 4.2.3.2) e documentar o framework (apresentado na Seção 4.2.3.3).

\subsubsection{Implementação das Classes da Aplicação}

As classes do Framework Qd+ foram implementadas de acordo com a arquitetura apresentada na Figura 4.3. A Figura 4.6 apresenta simplificações em relação à arquitetura mostrada na Figura 4.3. Enquanto a arquitetura completa, apresentada na Figura 4.3, considera o ambiente em que o framework é utilizado, a Web, a arquitetura simplificada apresenta apenas as classes implementadas no Visualworks e as páginas HTML dinâmicas, desconsiderando o banco de dados, o servidor Web e a visão do usuário por meio do navegador. É possível observar por intermédio da Figura 4.6, que as classes do Framework Qd+ são divididas em três camadas diferentes: a camada de classes de interface com o banco de dados, a camada de classes da aplicação (que implementam as regras de negócio), e a camada de classes de controle da interface com o usuário. 


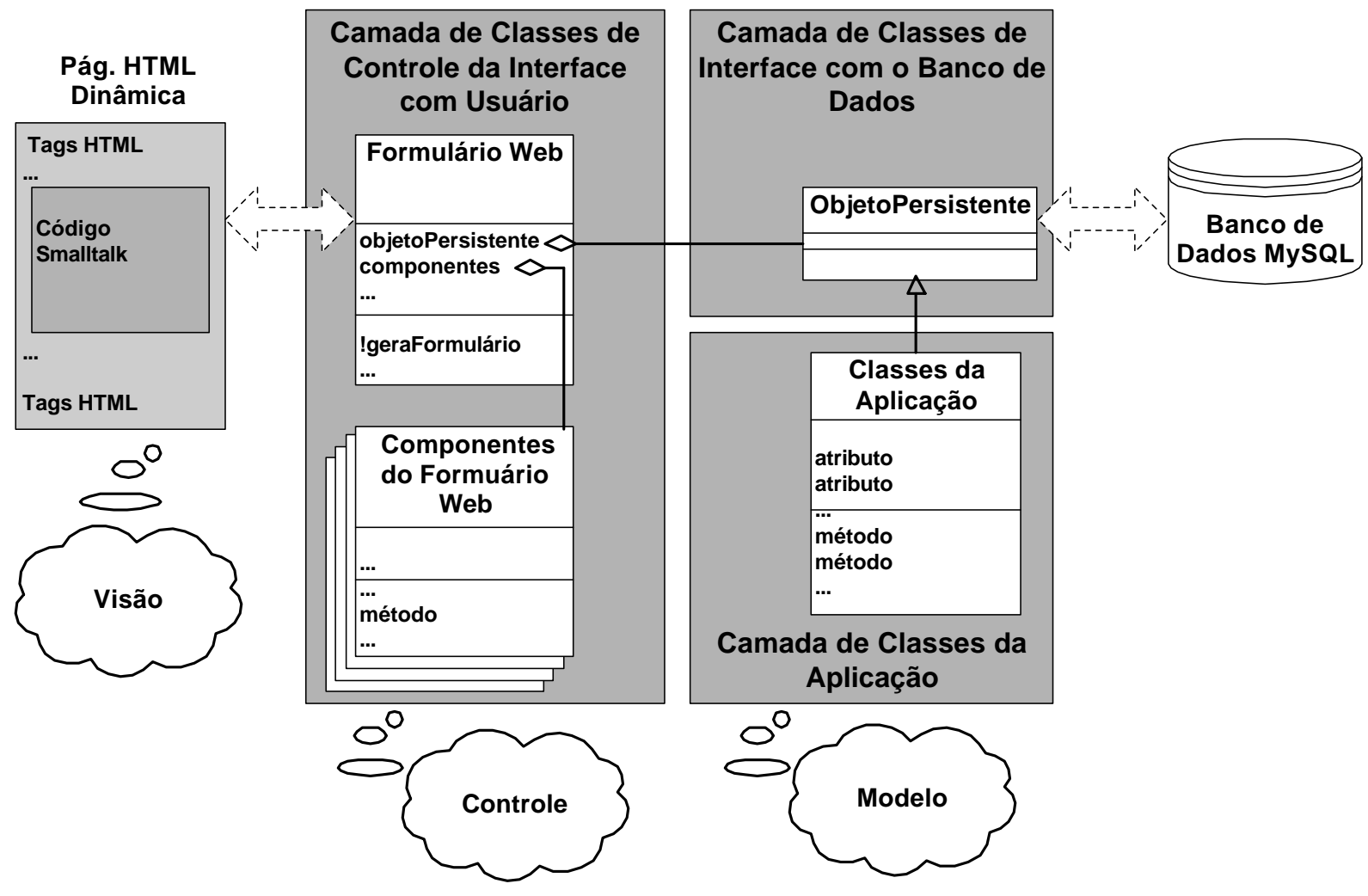

Figura 4.6: Arquitetura Simplificada do Framework Qd+.

A camada de classes responsável pela interface com o SGBD encapsula métodos e atributos que implementam principalmente funções tradicionais de inclusão, recuperação, alteração e exclusão de dados. Essas classes são necessárias porque o banco de dados MySQL é relacional e, portanto, a conversão de objetos para dados do modelo relacional e de dados do modelo relacional para objetos é imprescindível. Para tanto, os métodos da classe Connection Manager e da classe Persistent object (classe objeto Persistente da Figura 4.7) utilizam comandos SQL, possibilitando que se utilize apenas esses métodos para qualquer operação que acesse o banco de dados. A classe Connection Manager trata apenas da conexão com o SGBD enquanto que a classe Persistent object possui métodos que manipulam comandos SQL, de forma a executar as operações tradicionais anteriormente citadas. Um fato importante é que a classe Persistent object trata da conexão com o SGBD utilizando a classe Connection Manager, o que possibilita às classes da aplicação usar apenas a classe Persistent object para efetuar as operações com o SGBD.

As classes da aplicação são especializações da classe Persistent object e, como tal, possuem os recursos necessários para o acesso ao banco de dados Figura 4.7. As classes dessa camada contêm as regras de negócio dos leilões virtuais e segue a mesma linha de implementação do Framework GREN. 


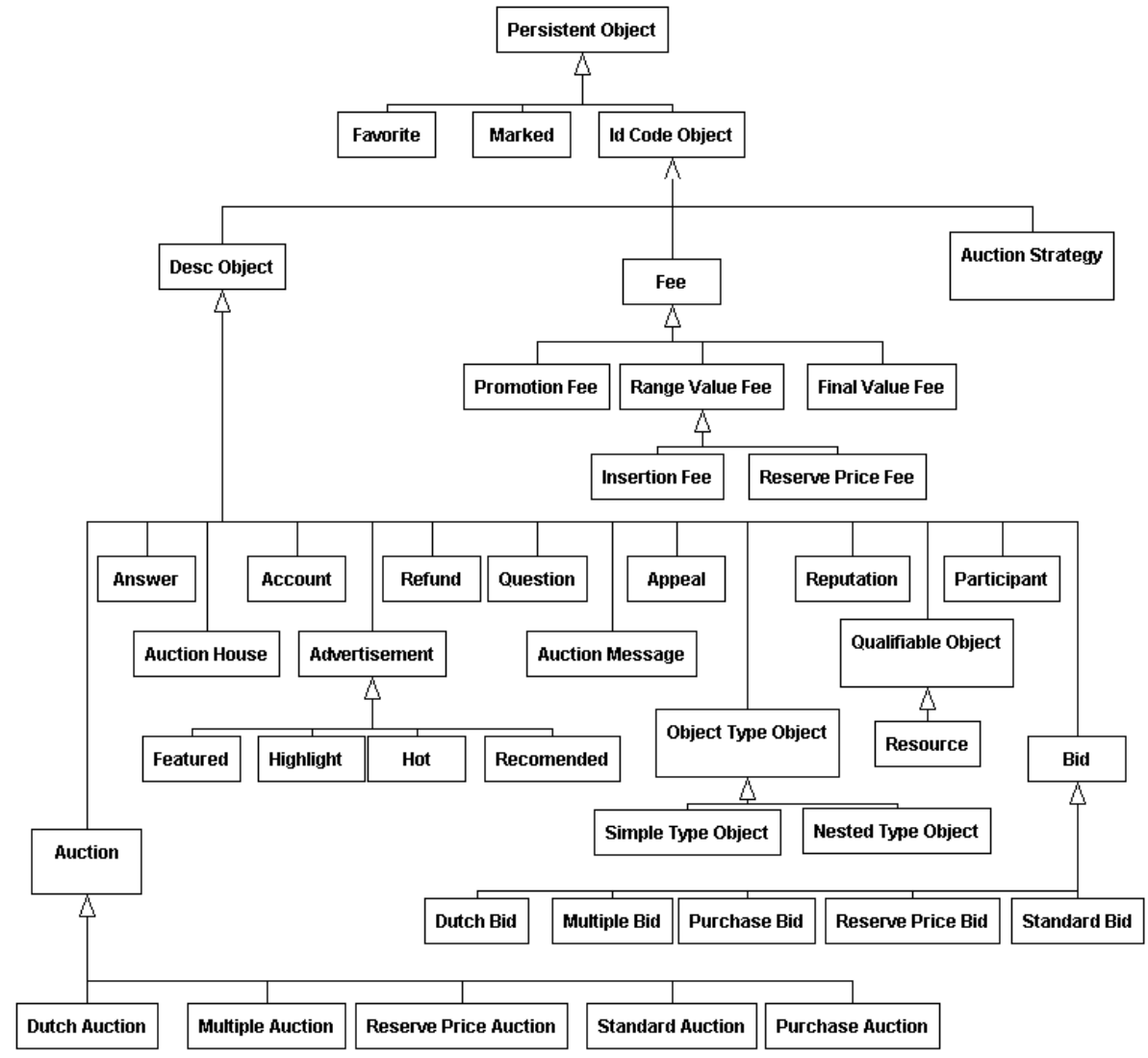

Figura 4.7: Hierarquia de Classes do Modelo de Classes do Framework Qd+.

\subsubsection{Implementação das Classes de Interface com o Usuário}

No Framework Qd+ a interface com o usuário não foi totalmente implementada por meio do Visualworks, pois sistemas de informação baseados na Web são instanciados a partir do framework, e portanto, ele necessita de uma interface que seja operacional na Web. Devido a esse fato foi preciso utilizar código HTML juntamente com código Smalltalk para atender a tal imposição, formando páginas HTML dinâmicas.

Existem classes que fazem a ligação entre os elementos HTML que são apresentados aos usuários e os atributos e métodos das classes da aplicação, as especializações da classe Formulário Web. A classe Formulário Web (Figura 4.6) controla globalmente a execução de operações nas páginas HTML referentes às classes da aplicação e, para isso, possui: os métodos para o controle de sessão com o usuário, a referência para a página HTML a ele relacionada dinamicamente e os componentes a serem apresentados para o usuário. Para cada página HTML apresentada ao usuário deve haver uma especialização da classe Formulário Web correspondente (Quadro 4.3 (a)) e cada uma dessas especializações possui um conjunto de componentes que são especializações da classe Componentes do Formulário Web que geram código HTML referente a, por exemplo, botões, caixas de texto, botões de checagem, etc. Esses componentes são 
ligados a atributos e métodos das classes da aplicação que se deseja apresentar ao usuário. Portanto, uma especialização específica da classe Formulário Web e seu conjunto de componentes definem quais operações são acessíveis aos usuários e quais dados são apresentados em uma determinada página. Podem haver várias especializações da classe Formulário Web referentes a uma mesma classe da aplicação, pois podem haver diferentes visões para os usuários, como por exemplo, quando há diferentes níveis de acesso ou diferentes listagens de objetos de uma mesma classe.

Quadro 4.3: Exemplo da Hierarquia de Parte de uma Instanciação.

(a) Hierarquia da classe UserForm.

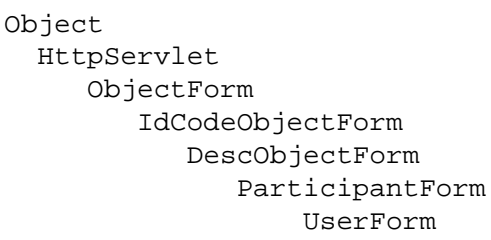

(b) Hierarquia da classe User.



A Figura 4.8 é um exemplo de página HTML gerada utilizando o esquema de execução estabelecido pela arquitetura anteriormente apresentada. A página HTML é um exemplo simples que ilustra a visão do usuário ao se cadastrar no sistema para poder participar dos leilões. Essa página HTML estática é resultado do processamento de uma página HTML dinâmica pelo servidor Smalltalk. O Quadro 4.4 (a) apresenta parte do código do arquivo "UserForm.ssp", que é a página HTML dinâmica que originou a página HTML estática (Quadro 4.4 (b)) da Figura 4.8. Observando parte do código do arquivo "UserForm.ssp" é possível constatar a sintaxe utilizada pelo servidor Web Smalltalk para determinar quando o código é HTML e quando o código é Smalltalk. Todo o código que estiver entre $<\%$ e $\%$ é código Smalltalk e deve ser processado pelo servidor Web antes de ser enviado ao usuário. O trecho de código da linha 3 até a linha 8 (Quadro 4.4 (a)) é responsável por iniciar ou recuperar uma instância da classe UserForm (Quadro 4.3 (a) e Figura 4.7) e inseri-la na sessão do usuário como sendo o formulário Web que está sendo executado.

A página HTML dinâmica executada pelo usuário também é armazenada na sessão do usuário (linha 10 do Quadro 4.4 (a)) e, assim, por meio desse trecho de código a classe UserForm é ligada à sua página HTML correspondente. A linha 12 (Quadro 4.4 (a)) invoca um método ("formName") que retorna o título da página a ser exibido ("New Users”). Essa chamada ao método está entre $<\%=$ e $\%$, o que indica ao servidor Smalltalk que o resultado desse método deve ser inserido como saída na página HTML estática, como pode ser visto na linha 5 do Quadro 4.4 (b). O Quadro 4.4 (b) apresenta o resultado do processamento do mesmo trecho de código do arquivo "UserForm.ssp" (Quadro 4.4 (a)) pelo servidor Smalltalk. 
Além do exemplo de código fonte apresentado no Quadro 4.4, na Figura 4.8 existem anotações que indicam o código fonte de alguns elementos apresentados no navegador do usuário. É possível observar, por exemplo, qual o método invocado para gerar o código HTML de um botão. Essa é a forma utilizada para que os resultados dos métodos sejam inseridos na página HTML estática.



Figura 4.8: Página de Registro de Novos Usuários do Sistema Referente a uma Instanciação do Framework Qd+.

\subsubsection{Documentação do Framework}

Este subpasso trata da documentação do framework, tornando claro o mapeamento das classes obtidas no subpasso anterior com a linguagem de padrões. O objetivo deste subpasso é facilitar a instanciação do framework utilizando como ferramenta a linguagem de padrões. Várias formas de documentação podem ser utilizadas, como por exemplo, a proposta por Braga e Masiero (2002b), 
Quadro 4.4: Exemplo com Parte do Código do Arquivo "UserForm.ssp".

(a) Página HTML dinâmica.

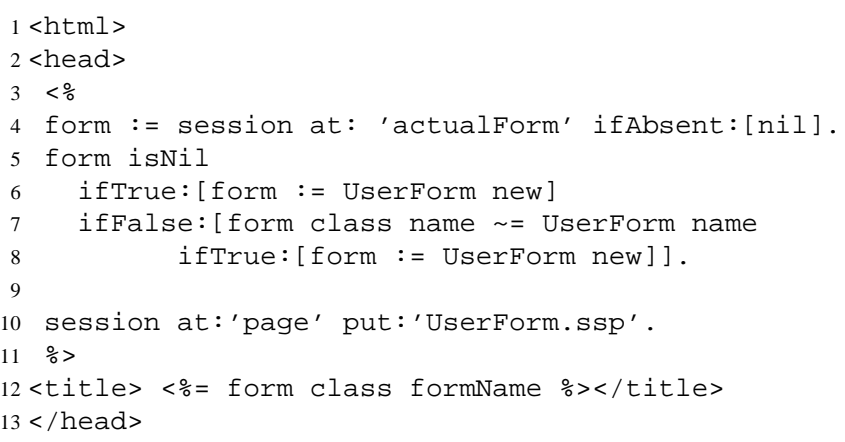

em que várias tabelas contendo o mapeamento dos padrões e variantes aplicadas com as correspondentes classes do framework que devem ser especializadas para produzir uma aplicação específica. Assim, com o histórico de aplicações dos padrões a um sistema específico consulta-se as tabelas para mostrar quais classes devem ser especializadas e métodos devem ser sobrepostos.

No Framework Qd+ isso pode ser feito por meio da consulta à documentação na forma de páginas HTML gerada automaticamente por uma ferramenta utilizada no projeto e implementação, a Simply Objects Modeler R3.2 da Adaptive Arts ${ }^{4}$, que baseia-se no comentário do código fonte (Ré e Masiero, 2002). Os comentários contidos no código fonte esclarecem quais classes representam as classes presentes na estrutura dos padrões e indicam quais métodos devem ser sobrepostos.

\subsubsection{Validação do Framework}

A validação do Framework Qd+ foi feita por meio de uma especificação de requisitos utilizadas para o desenvolvido da Linguagem de Padrões LV. Com a especificação e a linguagem de padrões foi possível instanciar e testar o framework. Ao testar o framework deve-se checar se as instâncias do domínio que o framework se propõem a apoiar estão de acordo com a especificação correspondente, e assim, verificar se ele atende aos propósitos a que foi construído. O processo de instanciação do Framework Qd+ é apresentado na Seção 4.3.1.

Instanciações adicionais devem ser feitas para melhorar e generalizar o framework e a Linguagem de Padrões LV. A única forma de validar um framework é por meio de instanciações (Bosch et al., 1999) e, portanto, quanto mais aplicações específicas forem instanciadas melhor é sua validação.

\footnotetext{
${ }^{4}$ http: / / www . adaptive-arts.com.
} 


\subsection{Exemplo de Instanciação do Framework}

\subsubsection{Processo de Instanciação}

Os passos utilizados para a instanciação do Framework Qd+ foram baseados, com algumas adaptações, na proposta de Braga e Masiero (2002a): análise do sistema, implementar as classes específicas e testar o sistema resultante. A análise do sistema consiste em utilizar o modelo de classes no nível de análise produzido por meio da linguagem de padrões (Figura 3.16) para criar uma lista contento o histórico dos padrões aplicados, para que, posteriormente, fosse utilizada como uma lista de checagem auxiliando na verificação e busca das classes do Framework Qd+ a serem utilizadas. A Tabela $4.2^{5}$ apresenta um exemplo que possui parcialmente o histórico de aplicação dos padrões para o sistema de leilões virtuais iBazar, conforme apresentado na Seção 3.6. A tabela apresenta o participante e padrão que foi aplicado e, quando for o caso o padrão variante utilizado. A última coluna indica qual superclasse do framework foi usada de acordo com o participante utilizado.

Tabela 4.2: Lista Parcial do Histórico de Aplicação dos Padrões da Linguagem de Padrões LV aos Requisitos do Sistema de Leilões Virtuais iBazar.

\begin{tabular}{|c|c|c|c|c|}
\hline Padrão & Variante & Participante & Classe da Aplicação & $\begin{array}{l}\text { Superclasse do fra- } \\
\text { mework }\end{array}$ \\
\hline \multirow[t]{4}{*}{ Identificar o Recurso } & \multirow[t]{4}{*}{ Múltiplos Tipos } & Recurso & Produto & Resource \\
\hline & & Categoria & Categoria & SimpleType \\
\hline & & Categoria & Subcategoria & MultipleType \\
\hline & & Categoria & Subsubcategoria & MultipleType \\
\hline \multirow[t]{6}{*}{ Leiloar o Recurso } & & Participante & Usuário & Participant \\
\hline & & Vendedor & Vendedor & Participant \\
\hline & & Comprador & Comprador & Participant \\
\hline & & Leilão & Leilão & $\begin{array}{l}\text { ReservePriceAuction, } \\
\text { StandardAuction }\end{array}$ \\
\hline & & $\begin{array}{l}\text { Leilão com Preço de } \\
\text { Reserva }\end{array}$ & $\begin{array}{l}\text { Leilão com Preço de } \\
\text { Reserva }\end{array}$ & ReservePriceAuction \\
\hline & & Leilão Normal & Leilão Normal & ReservePriceAuction \\
\hline & & & & \\
\hline
\end{tabular}

Com a tabela preenchida foi possível especializar as classes a partir das superclasses corretas e assim adicionar as classes, atributos e métodos provenientes do modelo de classes. Para implementar as classes do Framework Qd+ e completar sua instanciação foram criadas as classes da aplicação identificadas no histórico dos padrões e os atributos marcados com cores diferentes nos modelos de classes e seus devidos métodos get e set, programados os scripts para criação das tabelas do banco de dados, criadas as classes dos formulários, criados os arquivos com código

\footnotetext{
${ }^{5}$ Detalhes da versão em inglês da Linguagem de Padrões LV podem ser encontrados em Ré et al. (2001) e da versão em português no Apêndice A.
} 
HTML para visualização dos formulários, compilada e executada a aplicação ${ }^{6}$ e, por fim, testada a aplicação. É importante lembrar que o processo de instanciação é o mesmo tanto para a interface pública como para a interface de administração do Framework Qd+.

Para exemplificar os passos de instanciação do Framework Qd+ é utilizado o diagrama de classes apresentado na Figura 3.16 da Seção 3.6. Primeiramente foram implementadas as classes da aplicação, como por exemplo, a classe Product e a classe User (Tabela 4.2), cuja hierarquia é apresentada, respectivamente, no Quadro 4.5 e no Quadro 4.3(b). As classes foram criadas e seus atributos adicionados, juntamente com os métodos set e get, como apresentado na Tabela 4.3. Em seguida as operações foram implementadas, como o caso da Advanced Search, que executa de maneira conjunta as mesmas funções das outras duas operações de busca da classe Product, a search by categorye a search by title.

Quadro 4.5: Hierarquia da classe Product na Instanciação.

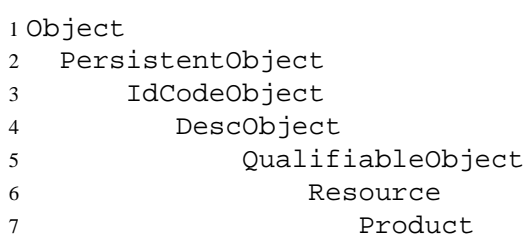

Tabela 4.3: Lista Parcial dos Atributos da Instanciação do iBazar.

\begin{tabular}{|l|l|l|l|}
\hline Classe do framework & Atributo & Método Set & Método Get \\
\hline Product & foto & photo: & photo \\
\hline User & name & description: & description \\
\hline User & address & address: & address \\
\hline User & phone & phone: & phone \\
\hline User & city & city: & city \\
\hline User & zipCode & zipCode: & zipCode \\
\hline User & country & country: & country \\
\hline User & birthDate & birthDate: & birthDate \\
\hline$\ldots$ & $\ldots$ & $\ldots$ & $\ldots$ \\
\hline
\end{tabular}

Devido à necessidade de inserção de novos atributos em algumas classes do Framework Qd+ (Tabela 4.3), foram obrigatoriamente sobrepostos alguns métodos para auxiliar a camada de persistência em suas operações tradicionais, como por exemplo o método insertionFieldClause, que indica quais atributos devem ser gravados em uma operação de criação, o método insertionvalueclause, que possui quais os valores dos atributos a serem gravados e o método updateSetclause, que mostra os atributos e seus valores para uma operação de alteração.

\footnotetext{
${ }^{6}$ Para executar aplicações Web no Visualworks é necessário executar algumas atividades e configurar alguns componentes para que o servidor Web funcione. Todas as instruções estão presentes nos manuais do Visualworks Cincom (2001a,b).
} 
A Figura 4.9 apresenta, além das especializações da instanciação, o conteúdo parcial do código fonte desses três métodos que são utilizados para todos os objetos persistentes do Framework $\mathrm{Qd}+$.

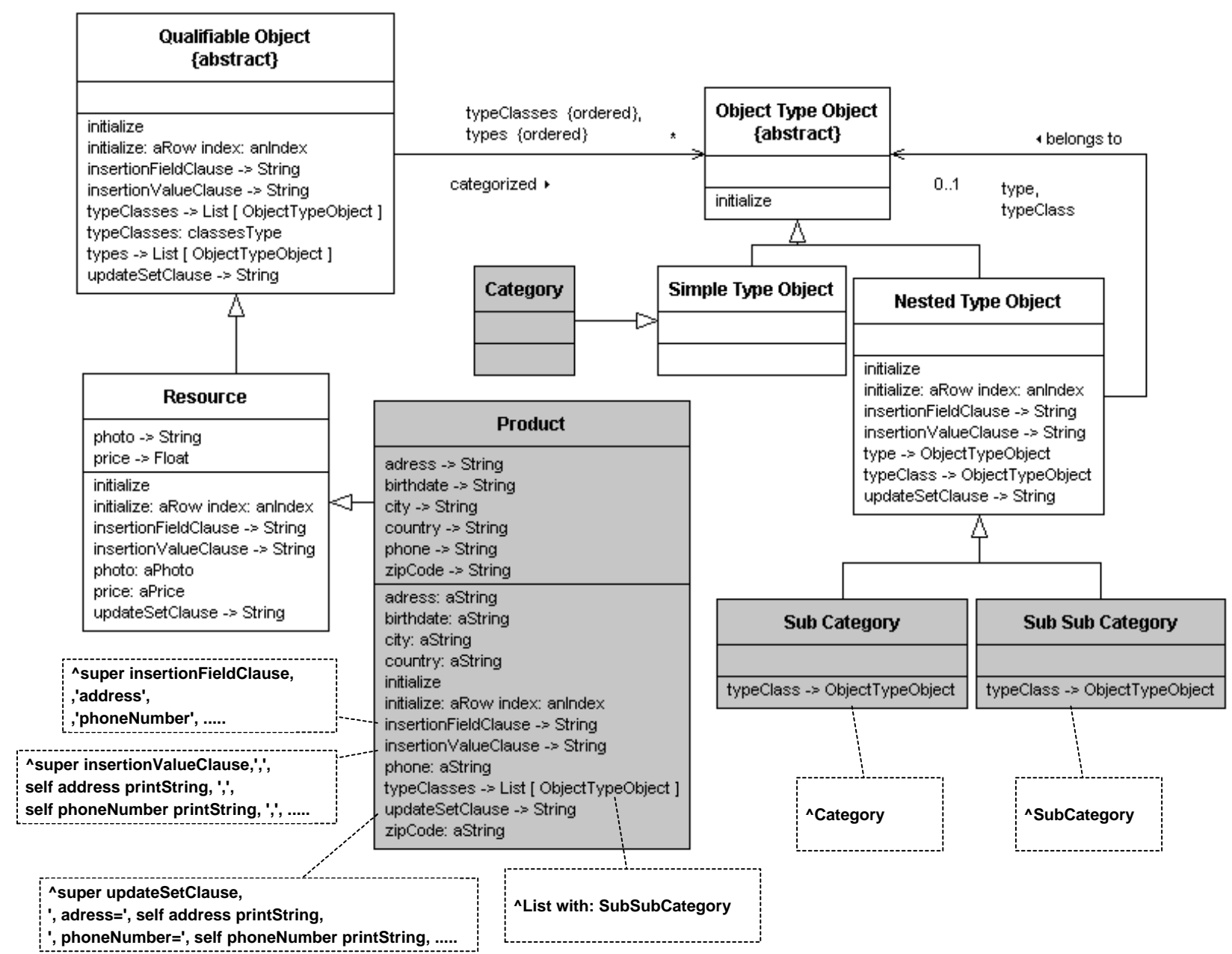

Figura 4.9: Instanciação do padrão IDENTIFICAR O RECURSO.

Outro exemplo de métodos que são sobrepostos são os métodos initialize e initialize:index:, responsáveis, no caso do primeiro método, por iniciar os atributos de um objeto no momento de sua criação e, no caso do segundo método, pela recuperação dos atributos por meio da camada de persistência.

Ao contrário dos métodos que são sobrepostos algumas vezes, existem outros métodos que devem ser sobrepostos para atender uma necessidade específica do padrão implementado, como por exemplo, o método auctionHouseType da classe User, que informa qual especialização da classe AuctionHouse (classe IBazarAuctionHouse) deve ser utilizada pela classe User em uma instanciação específica. Outro exemplo são os métodos typeclass das classes SubSubCategory e SubCategory informando qual é a classe que contém os objetos do seu 
aninhamento que são respectivamente SubCategory e Category, no caso apresentado na Figura 4.9 .

Após todas as classes da aplicação terem sido implementadas foi necessário escrever os scripts para a criação das tabelas do banco de dados de acordo com os atributos adicionados nas classes concretas da instanciação. O Framework Qd+ possui uma coleção de arquivos contendo scripts para a criação das tabelas referentes às classes que devem ser persistidas. Assim, para cada classe na hierarquia apresentada na Figura 4.7 existe um arquivo que contém o script para gravação de seus atributos.

A Tabela 4.2 e a Tabela 4.3 foram utilizadas como uma lista de checagem para escrever os scripts da instanciação. O Quadro 4.6 mostra parcialmente alguns scripts utilizados para criação das tabelas referente às classes apresentadas na Tabela 4.2. Nesse quadro é possível perceber alguns atributos referentes a generalizações, por exemplo, idCode e description, que pertencem, respectivamente, à classe IdCodeobject e à classe Descriptionob ject. É possível perceber, observando o Quadro 4.6, atributos referentes ao funcionamento específico de um padrão, como por exemplo, o object Type, que indica qual a próxima classe de aninhamento da classe MultipleTypeObject, e o category, que indica qual é a classe de objetos que categoriza a classe Product. Assim, com a conclusão da escrita dos arquivos contento os scripts, foi utilizada a opção de execução de scripts do banco de dados MySQL (MySQL, 2000).

Quadro 4.6: Exemplo com Código Fonte Parcial de Alguns Scripts dos Objetos Persistentes.

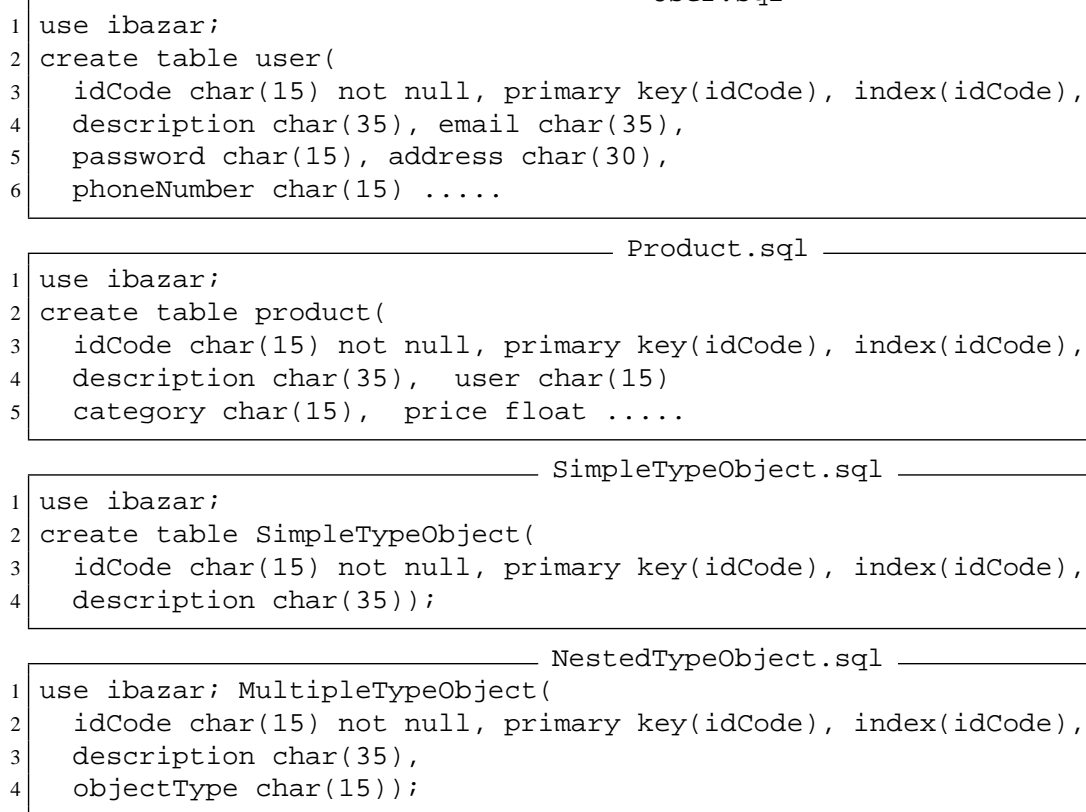


Com as classes da aplicação implementadas e os scripts referentes aos objetos persistentes escritos para que a camada de persistência possa efetuar operações tradicionais no banco de dados, o passo seguinte foi implementar as classes de controle, ou seja, as especializações da classe ObjectForm (detalhes na Seção 4.2.3.2). As classes de controle são a base para a apresentação do formulário ao usuário. A classe UserForm, cuja página HTML associada é apresentada no Quadro 4.4 e na Figura 4.8, possui os componentes necessários para ligar a apresentação HTML aos atributos e métodos da classe User (Tabela 4.3).

\begin{tabular}{|c|}
\hline User Form \\
\hline  \\
\hline 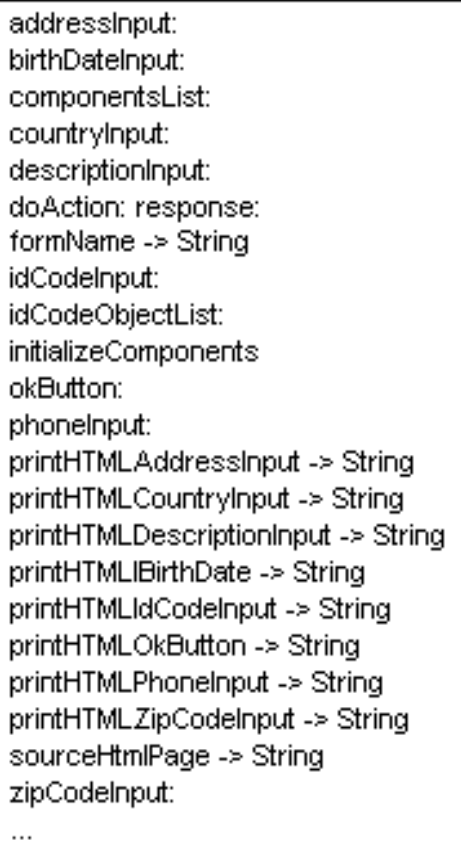 \\
\hline
\end{tabular}

Figura 4.10: Parte dos Métodos e Atributos da classe UserForm.

A Figura 4.10 apresenta a classe UserForm implementando o controle sobre a visão do usuário (Figura 4.8) que permite o cadastro de novos usuários no sistema de leilões. $\mathrm{O}$ atributo idCodeobjects é uma lista contendo os objetos derivados do modelo de classes da aplicação usados para a apresentação ao usuário, no caso específico da classe UserForm trata-se de um objeto da classe User. Os atributos com terminação "control”, como por exemplo, EditBoxControl, 
DateEditBoxControl e SubmitButton, são componentes do formulário Web representado pela classe UserForm. Portanto, geram código HTML para a interface com o usuário além de, no caso específico de componentes relacionados a atributos da classe da aplicação, automaticamente atualizar esses atributos quando as classes de formulário Web, por exemplo, a classe UserForm, recebem uma requisição. Para que um componente automaticamente atualize um atributo foi necessário, sobrepondo-se o método initializeComponents, que ele fosse criado e recebesse os parâmetros referentes ao atributo. Geralmente, para ligar esses componentes a atributos da classe da aplicação basta fornecer o objeto a ser relacionado, os métodos set e get para ter acesso a seu atributo específico, um nome que o identifica dentro da página HTML e um rótulo para ser apresentado na página HTML, como mostrado na Figura 4.10. Esses parâmetros são fornecidos ao componente que gera o código HTML desejado (EditBoxControl) e, por fim, esse componente é adicionado à lista de componentes automaticamente controlados também no método initializeComponents, representado pelo atributo componentsList.

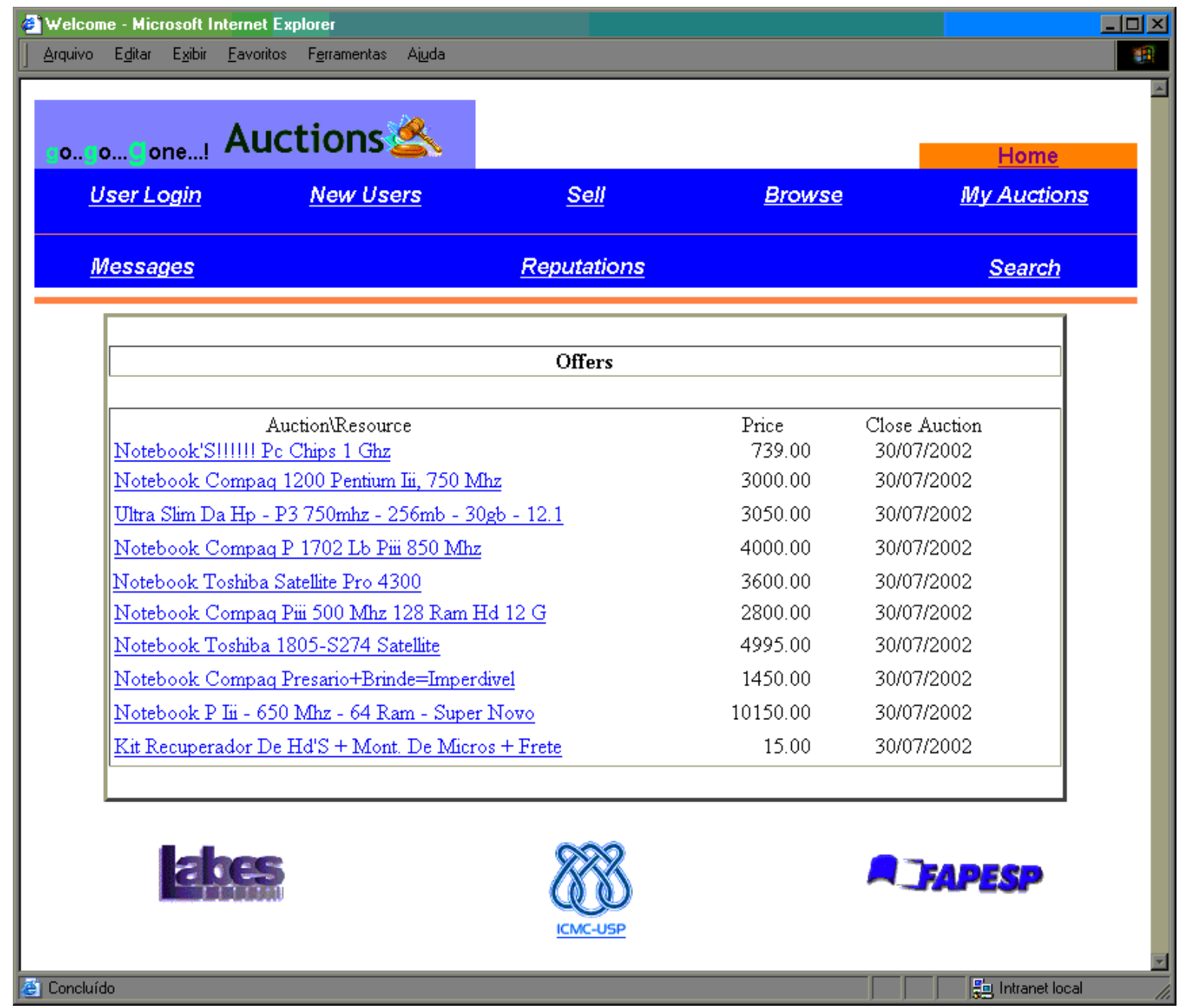

Figura 4.11: Página Principal do Sistema de Leilões Virtuais Instanciado. 
Os componentes relacionados a métodos das classes da aplicação, como por exemplo, o componente SubmitButton, que representa o botão okButton, não foram adicionados à lista que controla automaticamente os componentes. Como esse botão é relacionado a um método e não a um atributo da classe da aplicação, ele foi tratado individualmente, assim como todos os componentes desse tipo devem ser tratados. Quando um usuário envia uma requisição, o acionamento desse botão é determinado no método doAction: e o método da classe da aplicação a ele relacionado é invocado. No método doAction: é que as ações dos usuários requisitando operações são reconhecidas e tratadas.

A página mostrada na Figura 4.8 pode ser acessada pelo menu da página principal do sistema de leilões virtuais apresentada na Figura 4.11. A página principal possui um menu com ligações que possibilitam acesso a todas as outras páginas do sistema, dentre elas, a de cadastro de criação de novos leilões (Sell), navegação entre as categorias (Browse), os detalhes dos leilões do usuário (My Auctions) e a de login de usuários (User Login), entre outras. A Figura 4.12 apresenta a página de login, em que o usuário deve informar o seu apelido (NickName) e sua senha (Password). O login é necessário para que o usuário tenha acesso a algumas operações que exijam sua identificação, como por exemplo consultar seus próprios leilões, ler suas mensagens e colocar um produto em leilão.

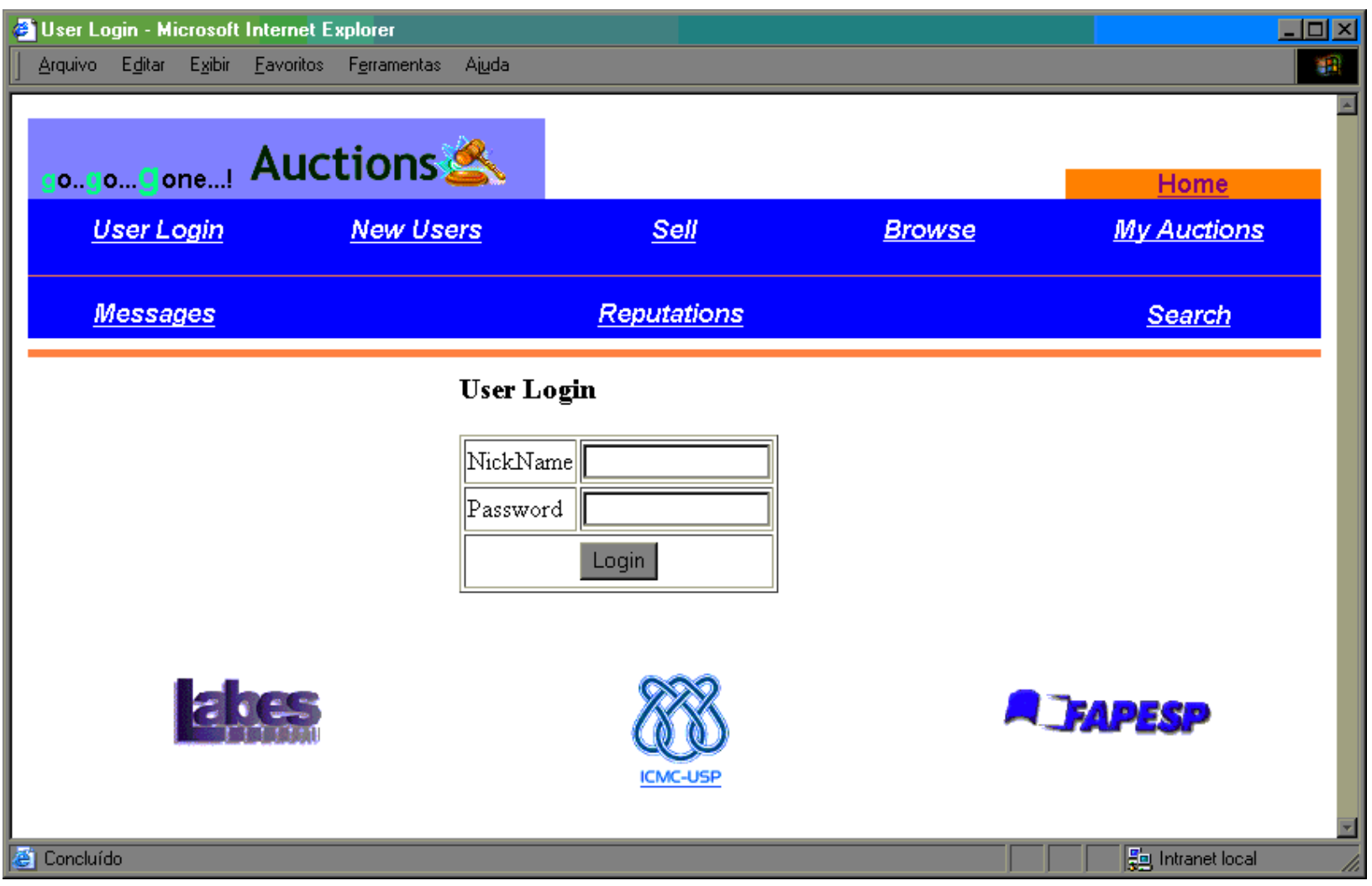

Figura 4.12: Página de Login do Usuário. 
A página que possibilita a execução da operação que cria um leilão pode ser acessada por meio da ligação Sell do menu principal. Como pode ser observado na Figura 4.13, tanto os atributos dos leilões, como por exemplo Description, Date to start, Time to start e Transport Detail, entre outros, como os atributos do produto, por exemplo, Product Description, Price e Category, são informados na mesma página.

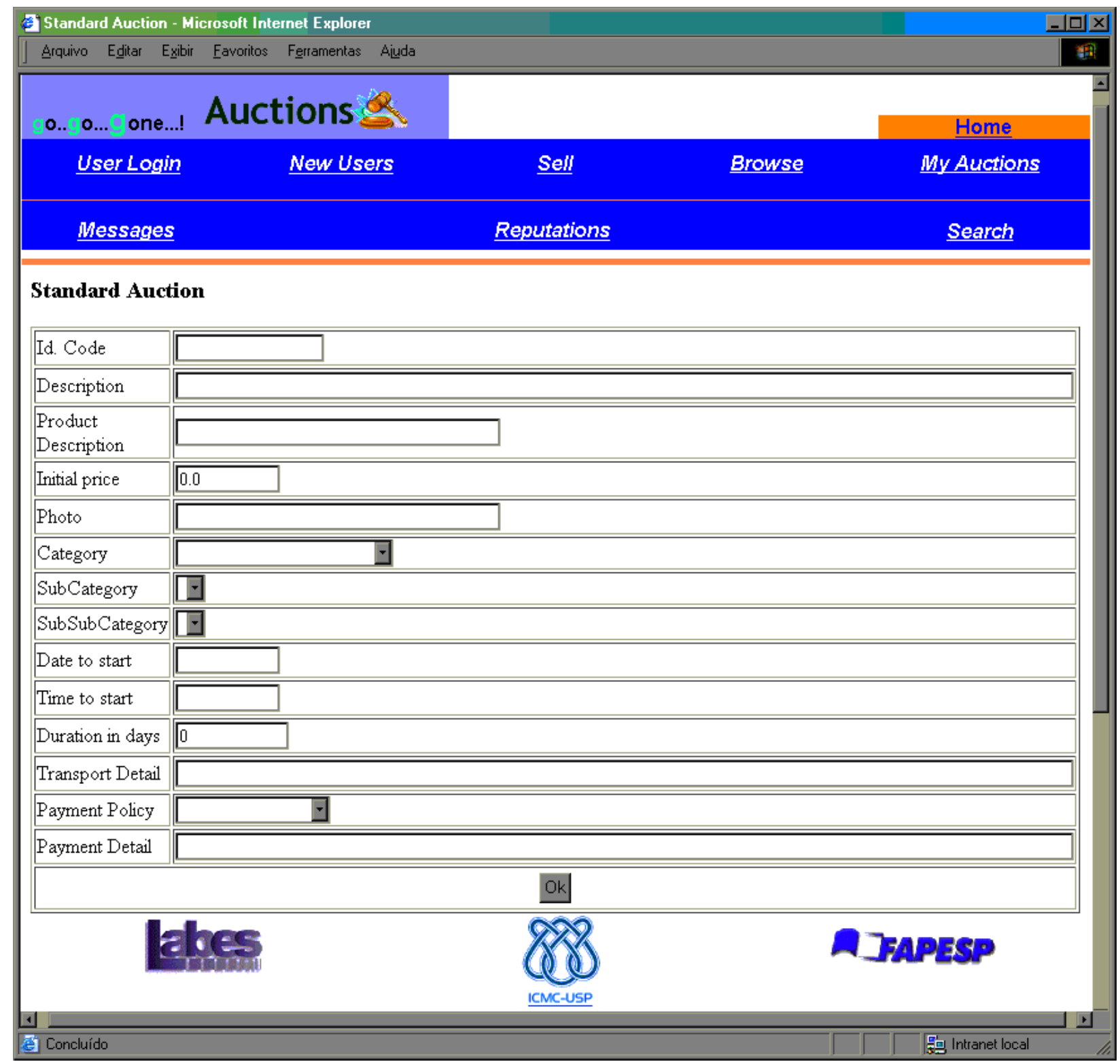

Figura 4.13: Página de Criação de um Leilão Normal.

Para finalizar a instanciação do Framework Qd+ foi necessário testar a aplicação resultante para verificar se funciona de maneira correta e atende aos requisitos necessários. É importante notar que novos requisitos não suportados pela Linguagem de Padrões LV e, conseqüentemente, nem pelo Framework Qd+ devem ser analisados, pois podem ser utilizados para melhorar ambos. Outra 
alternativa para incorporar as funções referentes aos requisitos não apoiados é alterar diretamente a aplicação instanciada.

\subsection{Considerações Finais}

A proposta de Braga e Masiero (2002a,b) oferece apoio não somente a construção de frameworks, mas também a sua instanciação, ambos com auxílio de uma linguagem de padrões. Essa abordagem foi utilizada neste trabalho para a construção e instanciação do Framework Qd+ com base na Linguagem de Padrões LV, sendo o processo de instanciação adaptado especificamente ao Framework Qd+. Para exemplificar o processo de instanciação foi utilizado o modelo de classes obtido por meio da Linguagem de Padrões LV, apresentado na Figura 3.16. 


\subsection{Considerações Iniciais}

O presente trabalho propõe um processo para construção de framework para apoio ao desenvolvimento de sistemas de informação baseados na Web. O processo inclui três outros subprocessos: a engenharia reversa de sistemas de informação baseados na Web, que possibilita a modelagem do domínio da aplicação; a criação de uma linguagem de padrões, que permite a utilização de um modelo de domínio como base para seu desenvolvimento; e a construção e instanciação do framework, seguindo a proposta de Braga e Masiero (2002a,b). O processo foi ilustrado usando-se o domínio dos SIbWebs e foram criadas a Linguagem de Padrões LV e o Framework Qd+, ambos para apoiar o desenvolvimento de aplicações de leilões virtuais.

\subsection{Resultados e Contribuições}

Os principais resultados e contribuições deste trabalho são os processos de engenharia reversa de SIbWebs e de criação de linguagens de padrões baseados em um modelo de classes do domínio e, como produto direto deste processo a Linguagem de Padrões LV, com a qual, utilizando a abordagem de criação de frameworks proposta por Braga e Masiero (2002a,b), pôde-se criar o Framework Qd+. 
O processo de engenharia reversa de SIbWebs tem como resultado, partindo da análise de sistemas-base existentes na Internet, um modelo de classes do SIbWeb. O aspecto original deste processo é o uso da interface Web como fonte para a engenharia reversa. Combinando-se a engenharia reversa de vários SIbWebs de um mesmo domínio, é possível recuperar um modelo de análise genérico do domínio

O processo de criação de uma linguagem de padrões a partir de um modelo de classes contém as principais diretrizes para execução dessa atividade. Como se trata de assunto recente, não há na literatura proposta de processos explícitos e detalhados para essa finalidade.

A Linguagem de Padrões LV, obtida seguindo o processo acima e a partir do modelo do domínio de sistemas de gestão de leilões virtuais é um produto relevante, pois está disponível para que outros profissionais possam acelerar seu conhecimento sobre o domínio e para usá-la no desenvolvimento de outras aplicações do domínio.

Outro resultado é o conjunto de classes que compõem o Framework Qd+. Ele pode apoiar a instanciação de novas aplicações no domínio dos sistemas de gestão de leilões virtuais e pode também ser integrado ao Framework GREN.

\subsection{Trabalhos Futuros}

Como um dos trabalhos futuros propõe-se a integração entre o Framework GREN e o Framework Qd+, implementando classes de interface Web para o Framework GREN e utilizando as classes e a experiência adquirida com o desenvolvimento do Framework Qd+. Além das classes de interface, seria necessário que algumas classes da aplicação fossem novamente implementadas em ambos os frameworks para completar a integração.

Novas instanciações de sistemas de leilões virtuais, com base em novos requisitos e em requisitos obtidos em outros sistemas existentes na Internet, poderiam ser utilizados para validar de forma mais rigorosa o Framework Qd+. Adicionalmente, essas instanciações poderiam ser usadas como feedback para melhorar tanto a Linguagem de Padrões LV como o Framework Qd+. Outras instanciações poderiam ser feitas com requisitos semelhantes a sistemas de leilões virtuais, mas não exatamente leilões virtuais, para generalizar ainda mais a linguagem de padrões e, posteriormente o Framework Qd+.

Com mais instanciações seria possível se aproximar cada vez mais de um framework caixa preta e, assim, com a experiência adquirida nessas novas instanciações e as classe concretas, desenvolver um wizard para facilitar as instanciações do Framework Qd+. Ao pesquisar as instanciações e o processo de construção do Framework Qd+ e do Framework GREN, poderiam ser pesquisadas estratégias para construção de wizards. 
Uma ferramenta de auxílio à engenharia reversa poderia ser desenvolvida como apoio ao processo de rastrear as páginas e elicitar os requisitos. Essa ferramenta poderia ser útil também na modelagem específica de aspectos relacionados à própria interface Web com o objetivo de reusar elementos da interface. 
Aarsten, A.; Elia, G.; Menga, G. Pattern languages of program design, capítulo G++ : A pattern Language for Computer-Integrated Manufactoring. In: Coplien e Schmidt (1995), p. 91-118, 1995.

AleXAnder, C. A pattern language. New York - NY, USA: Oxford University Press, 1977.

AleXAnDer, C. The timeless way of building. New York - NY, USA: Oxford University Press, 1979.

Alexander, C.; Ishikawa, S.; Silverstein, M. A pattern language: Towns, buildings, construction. New York - NY, USA: Oxford University Press, 1977.

Appleton, B. Patterns and software: Essential concepts and terminology. On-Line. Disponível em: http://www. enteract.com/ bradapp/docs/patterns-intro.html. Consultado em 30/07/2002., 1997.

Bapna, R.; Goes, P.; Gupta, A. Insights and analyses of online auctions. Communications of the ACM, v. 44, n. 11, p. 42-50, 2001.

Biggerstaf, T. J.; Richter, C. Reusability framework, assessment, and directions. IEEE Software, v. 4, n. 2, p. 41-49, 1987.

Booch, G. Object-oriented analysis and design with applications. 2 ed. Addison-Wesley, 1994.

Booch, G.; Rumbaugh, J. Unified method for object-oriented development. Rational Software Corporation, 1996.

Bosch, J.; Molin, P.; Mattsson, M.; Bengtsson, P.; Fayad, M. E. Building application frameworks: Object-oriented foundations of framework design, capítulo Framework Problems and Experiences. In: Fayad et al. (1999), p. 55-82, 1999.

BOYD, L. Pattern languages of program design 3, capítulo Business Patterns of Association Objects. In: Martin et al. (1998), p. 395-408, 1998. 
Bradac, M.; Fletcher, B. Pattern languages of program design 3, capítulo A Pattern Language for Developing Form Style Windows. In: Martin et al. (1998), p. 347-357, 1998.

Braga, R. T. V.; Germano, F. S. R.; Masiero, P. C. A family of patterns for business resource management. In: 5th Annual Conference on Pattern Languages of Programs (PLOP'98), Washington University in St. Louis - Missouri, USA, on-Line. Disponível em : http://jerry.cs.uiuc.edu/ plop/plop98/final_submissions. Consultado em 30/07/2002., 1998.

Braga, R. T. V.; Germano, F. S. R.; Masiero, P. C. A pattern language for business resource management. In: 6th Pattern Languages of Programs Conference (PLoP'99), Monticello IL, USA, 1999.

BragA, R. T. V.; MASIERO, P. C. GREN: Um framework para gestão de recursos de negócios. ICMC/USP - Sao Carlos, working Document (in Portuguese), 2000.

BragA, R. T. V.; MASIERO, P. C. Identification of framework hot spots using pattern languages. In: 16th Brazilian Symposium on Software Engineering (SBES), Rio de Janeiro - RJ -Brazil, 2001.

BragA, R. T. V.; MASiero, P. C. A pattern language-based technology for software reuse. In: International Conference on Computer Science, Software Engineering, Information Technology, e-Business, and Applications (ACIS), Foz do Iguacu - Brazil, to appear, 2002a, p. 305-310.

Braga, R. T. V.; Masiero, P. C. A process for framework construction based on a pattern language. In: 26th Annual International Computer Software and Applications Conference (COMPSAC 2002), Oxford-England, to appear, 2002b.

BRUgali, D.; SyCARA, K. Frameworks and pattern languages: an intriguing relationship. ACM Computing Surveys (CSUR), v. 32, n. 1, p. 2, 2000.

Buschmann, F.; Meunier, R.; Rohnert, H.; Sommerlad, P.; Stal, M. Pattern-oriented software architecture : A system of patterns. New York - NY, USA: John Wiley \& Sons, 1996.

Carey, J.; Carlson, B.; Graser, T. San franciso design patterns: Blueprints for business software. Reading - MA, USA: Addison-Wesley, 2000.

Chikofsky, E. J.; Cross, J. H. Reverse engineering and design recovery: A taxonomy. IEEE Software, v. 7, n. 1, p. 7-13, 1990.

Cincom, S. Visualwave application developers guide. Cincom Systems, release 5i.4, n. p460107-03, Cincinnati-Ohio, EUA, 2001a.

Cincom, S. Visualwave server configuration guide. Cincom Systems, release 5i.4, n. p46-011003, Cincinnati-Ohio, EUA, 2001b.

COAD, P. Object-oriented patterns. Communications of the ACM, v. 35, n. 9, p. 152-159, 1992.

CoAd, P.; North, D.; Mayfield, M. Object models: Strategies, patterns and applications. 2 ed. Upper Saddle River - NJ, USA: Prentice-Hall, 1997. 
CoAd, P.; Yourdon, E. Object-oriented analysis. 2 ed. Englewood Cliffs, NJ - USA: Prentice Hall/Yourdon Press Computing Series, 1991.

Coleman, D.; Arnold, P.; Bodoff, S.; Dollin, C.; Gilchrist, H.; Hayes, F.; JeremaES, P. Desenvolvimento orientado a objetos: O método FUSION. Rio de Janeiro, RJ: Editora Campus, 1996.

Coplien, J. Pattern languages of program design 4, capítulo A Pattern Language for Writers' Workshops Reading - MA, USA: Addison-Wesley, p. 557-580, 1999.

CoPlien, J.; SCHMidT, D. C. Pattern languages of program design. Reading-MA, USA: Addison-Wesley, 1995.

Coplien, J. O. The patterns handbook: Techniques, strategies, and applications, capítulo Software Design Patterns: Common Questions and Answers Cambridge University Press, p. 311320, 1998.

Costa, R. M. Fusion-RE/I: Um método de engenharia reversa para auxiliar à manutenção de software. Dissertação de Mestrado, ICMC/USP, 1997.

Cunningham, W. Pattern languages of program design, capítulo The CHECKS Pattern Language of Information Integrity. In: Coplien e Schmidt (1995), p. 145-155, 1995.

Cunningham, W. Pattern languages of program design 2, capítulo EPISODES: A Pattern Language of Competitive Development. In: Vlissides et al. (1996), p. 371-388, 1996.

DAVIS, A. M. Principles of software development. New York - NY, USA: McGraw-Hill, 1995.

ENGEBRETSEN, O. Internet auction models. University of Minnesota. On-Line. Disponível em : http://ids.csom.umn.edu/faculty/kauffman/courses/8420/Projects/ Engebretsen/internet_auction_models.htm. Consultado em 30/07/2002., 1999.

FAYAD, M.; SCHMIDT, D. C. Object-oriented application frameworks. Communications of the $A C M$, v. 40, n. 10, p. 32-38, 1997.

FAYAd, M. E.; E.Johnson, R.; SchmidT, D. C. Building application frameworks: Objectoriented foundations of framework design. New York - NY, USA: John Wiley \& Sons, 1999.

FAYAD, M. E.; JoHnson, R. E. Domain-specific application frameworks: Frameworks experience by industry. New York - NY, USA: John Wiley \& Sons, 2000.

FOWLer, M. Analysis patterns. Menlo Park-CA, USA: Addison-Wesley, 1997.

Gamma, E.; Helm, R.; Johnson, R.; Vlissides, J. Design patterns: Elements of reusable object-oriented software. Massachusetts: Addison Wesley, 1994.

GomAA, H. Reusable software requirements and architectures for families of systems. Journal of Systems and Software, p. 189-202, 1996. 
HARRISON, N. B. The language of shepherds: A pattern language for shepherding. In Proceedings of the 6th Conference on Patterns Language of Programming (PLoP'1999), 1999, Lucent Technologies. On-Line. Disponível em: http://jerry.cs.uiuc.edu/ plop/plop99/proceedings/harrison/shepherding4\%.pdf. Consultado em 30/07/2002, 1999.

Heck, E.; Vervest, P. How should CIOs deal with web-basead auctions? Communications of the $A C M$, v. 41, n. 7, p. 99-100, 1998.

Huhns, M. N.; VidAL, J. M. Online auctions. IEEE Internet Computing, v. 3, n. 3, p. 103-105, 1999.

Isakowitz, T.; Bieber, M.; Vitali, F. Web information systems. Communications of the $A C M$, v. 41, n. 7, p. 78-80, 1998.

ISO/IEC9126 Information technology - software product evaluation - quality characteristicas and guidelines for their use. 1991.

JACOBSOn, I. Object-oriented software engineering. Reading, MA - USA: Addison-Wesley, 1998.

Johnson, R.; Foote, B. Designing reusable classes. Journal of Object Oriented Programming, v. 1, n. 2, p. 22-35, 1998.

Johnson, R.; Woolf, B. Pattern languages of program design 3, capítulo Type-Object. In: Martin et al. (1998), p. 47-65, 1998.

Johnson, R. E. Documenting frameworks using patterns. In: Proceedings of the Conference on Object-Oriented Programming Systems, Languages, and Applications (OOPSLA'92, 1992, p. 63-72.

Johnson, R. E. Frameworks = (components + patterns). Communications of the ACM, v. 40, n. 10, p. 39-42, 1997.

Johnson, R. E.; Russo, V. F. Reusing object-oriented designs. Rel. Téc. UIUCDCS 911696, University of Illinois, Urbana - Champaign, on-Line. Disponível em: ftp: / / st . cs . uiuc.edu/pub/papers/frameworks/reusable-oo-design.ps. Consultado em 30/07/2002., 1991.

Kerth, N. Pattern languages of program design, capítulo Caterpillar's Fate: A pattern Language for Transformation from Analysis to Design. In: Coplien e Schmidt (1995), p. 293-320, 1995.

Kerth, N. L.; Cunningham, W. Using patterns to improve our architectural vision. IEEE Software, v. 14, n. 1, p. 53-59, 1997.

Kumar, M.; Feldman, S. T. Business negotiations on the internet. In: INET'98, Geneva, Switzeland, 1998a.

Kumar, M.; Feldman, S. T. Internet auctions. In: 3rd USENIX Workshop on Electronic Commerce, Boston - MA, USA, 1998b. 
LARMAn, C. Applying UML and patterns: An introduction to object-oriented analisys and design. Upper Saddle River - NJ, USA: Prentice-Hall, 1997.

Martin, R. C.; Riehle, D.; Buschmann, F. Pattern languages of program design 3. Reading - MA, USA: Addison-Wesley, 1998.

VOn Mayrhauser, A. Software engineering: Methods and management. Boston-MA, USA: Academic Press, Inc, 1990.

Meszaros, G. Pattern languages of program design 3, capítulo A Pattern Language for Pattern Writing. In: Martin et al. (1998), p. 529-574, 1998.

MYSQL Reference manual for version 3.21.29-gamma. Disponível em 09/10/2000 na URL: http://web.mysql.com/, 2000.

PREE, W. Design patterns for object-oriented software development. Reading - MA, USA: Addison-Wesley, 1995.

PREE, W. Building application frameworks: Object-oriented foundations of framework design, capítulo Hot-spot-driven Development. In: Fayad et al. (1999), p. 379-393, 1999.

Pressman, R. S. Software engineering: A practitioner's approach. 5 ed. Boston-MA, USA: McGraw-Hill, 2000.

Prieto-Diaz, R.; Arango, G. Domain analysis and software system modeling. IEEE Computer Science, 1991.

Ré, R.; Braga, R. T. V.; Masiero, P. C. A pattern language for online auctions. In: 8th Conference on Pattern Languages of Programs (PLoP'2001), Monticello-IL, EUA, 2001, p. $1-18$.

RÉ, R.; MASIERO, P. C. Requirements specification for online auctions: Arremate.com, iBazar and eBay. ICMC/USP - Sao Carlos, SP, Brazil, working Document (in Portuguese), 2001.

RÉ, R.; MASIERo, P. C. Documento de referência às classes do framework qd+. ICMC/USP - Sao Carlos, SP, Brazil, working Document (in Portuguese). On-Line. Disponível em: www . icmc.sc.usp.br/ rr/qdmdocumentation. Consultado em 30/07/2002., 2002.

RAPPA, M. Business models on the Web. On-Line. Disponível em: http://www . ecommerce.ncsu.edu/topics/models/models . html. Consultado em 30/07/2002., 2000.

RECK, M. Types of electronic auctions. In: Information and Communications Technologies in Tourism (ENTER'94), Wien - NY, USA, 1994, p. 236-243.

Riehle, D.; Zullighoven, H. Pattern languages of program design, capítulo A Pattern Language for Tool Construction and Integration Based on the Tools and Materials Metaphor. In: Coplien e Schmidt (1995), p. 9-42, 1995. 
Riehle, D.; Zullighoven, H. Theory and practice of object systems, v. 2, capítulo Understanding and Using Patterns in Softwre Development New York - NY, USA: John Wiley \& Sons, 1996.

Roberts, D.; Johnson, R. Pattern languages of program design 3, capítulo Evolving Frameworks: A Pattern Language for Developing Object-Oriented Frameworks. In: Martin et al. (1998), p. 471-486, 1998.

Rumbaugh, J. Object-oriented modeling and design. Prentice Hall International, 1991.

Rumbaugh, J.; Jacobson, I.; Booch, G. The unified modeling language reference manual. Massachusetts: Addison-Wesley, 1999.

SAGE, A. P. Systems engineering and systems management for reengineering. Journal Systems and Software, v. 30, n. 1, p. 03-25, 1995.

Sane, A. The elements of pattern style. In Proceedings of the 2th Conference on Pattern Languages of Programming (PLoP'95), 1995.

Schmid, H. A. Systematic framework design by generalization. Communications of the ACM, v. 40, n. 10, p. 48-51, 1997.

SCHMID, H. A. Building application frameworks: Object-oriented foundations of framework design, capítulo Framework Design by Systematic Generalization. In: Fayad et al. (1999), p. 353-378, 1999.

Schmidt, D. C.; FAyAd, M.; Johnson, R. E. Software patterns. Communications of the $A C M$, v. 39, n. 10, p. 36-39, 1996.

SommerVILle, I. Software engineering. Reading-MA, USA: Addison-Wesley, 1996.

StePhen, R. M.; Lynn, M. M. Software migration and reengineering: A pilot project in reenginnering. Journal Systems and Software, v. 30, n. 1, 1995.

Turine, M. A. S.; Masiero, P. C. Especificação de requisitos: Uma introdução. Rel. Téc., Instituto de Ciências Matemáticas e de Computação - ICMC/USP, 1996.

Vlissides, J.; Coplien, J.; KeRTh, N. Pattern languages of program design 2. Reading MA, USA: Addison-Wesley, 1996.

Waters, R. C.; Chikofsky, E. J. Reverse engineering: Progress along many dimensions. Communications of the ACM, v. 37, n. 5, p. 22-25, 1994.

Wellman, M. P.; Wurman, P. R. Real time issues for internet auctions. In: First IEEE Workshop on Dependable and Real-Time E-Commerce Systems, Denver, CO - USA, 1998.

ZhaO, L.; Foster, T. Pattern languages of program design 3, capítulo A Pattern Language of Transport Systems (Point and Route). In: Martin et al. (1998), p. 409-430, 1998. 


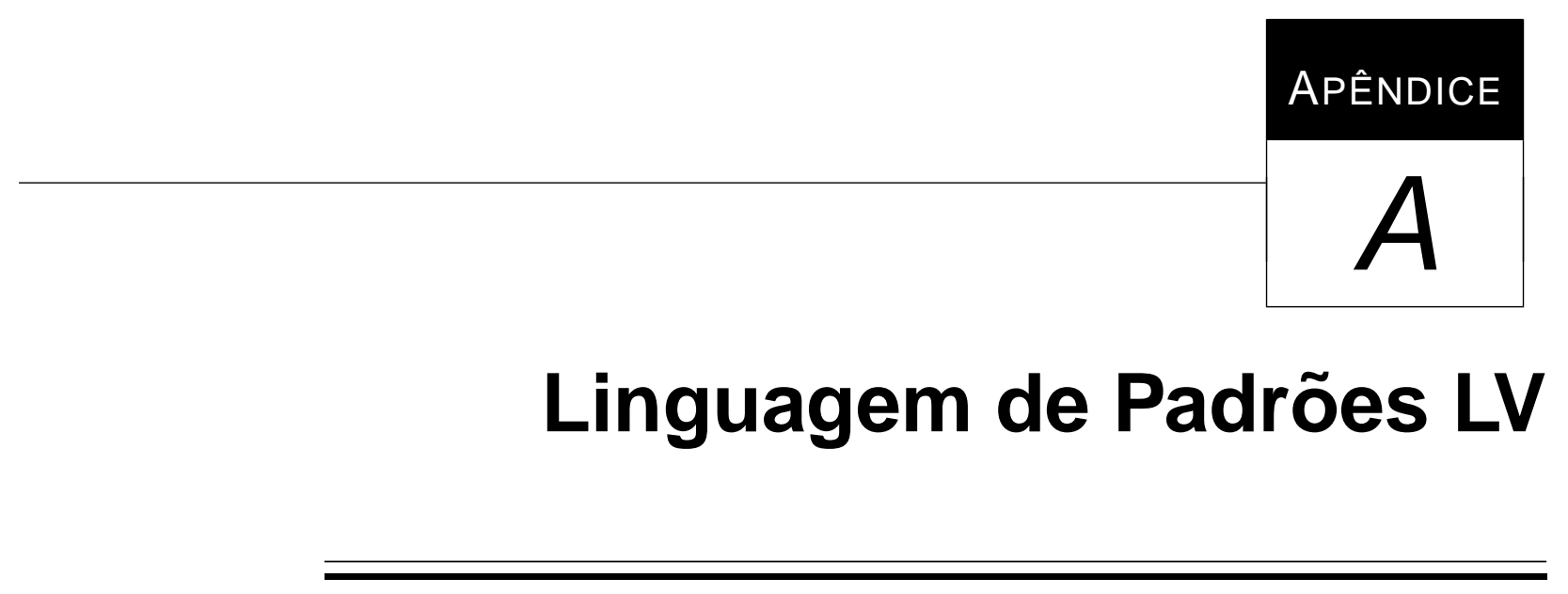




\section{Uma Linguagem de Padrões para Leilões Virtuais}

\section{Grafo do Fluxo de Aplicação dos Padrões}

\section{Padrões Requeridos}

\section{Padrões Opcionais}

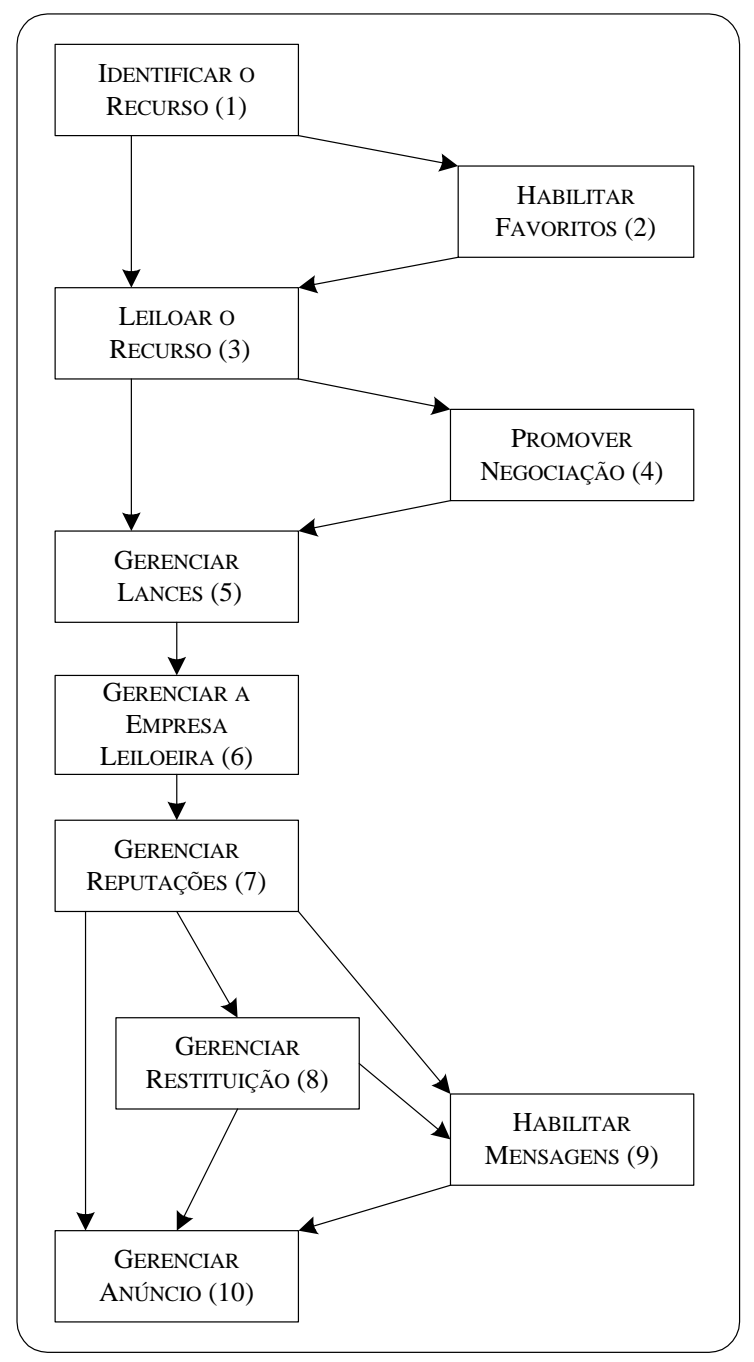

Figura 1: Grafo do Fluxo de Aplicação dos Padrões

\section{Padrões da Linguagem}

\section{IDENTIFICAR O RECURSO}

\section{Contexto}

Seu sistema de negócio lida com um tipo de transação comercial específica: os leilões. Essas transações referemse, por exemplo: a comercialização de produtos ou serviços de um modo geral, tais como passagens aéreas, estadia em hotéis, pacotes de viagem, cds, livros, obras de arte, itens de coleção, que podem ser chamados de recursos. Esses recursos de negócio são gerenciados por sistema específicos que apóiam a comercialização entre clientes, sejam eles pessoas físicas ou jurídicas. Dessa forma, os sistemas de leilões apóiam a comercialização entre diferentes tipos de consumidores e para uma grande variedade de recursos . Em alguns casos os leilões tornam-se a melhor forma de comercializar recursos, tais como: quando o vendedor não sabe qual o real preço do recursos, para recursos perecíveis, obras de arte ou recursos colecionáveis e para queima de ponta de estoque.

\section{Problema}

Como você representa os recursos de negócio leiloados pelo sistema?

\section{Influências}

- Recursos de negócio têm, em geral, atributos ou qualidades em comum. Armazenar informações pertinentes a cada recurso em particular é importante para as empresas envolvidas em seu gerenciamento.

- Recursos de negócio podem ser classificados em diversas "categorias". Por exemplo, em uma casa de leilões de itens de informática, os recursos podem estar agrupados primeiramente pela sua natureza (hardware ou software), em segundo nível pelo tipo (periféricos, CPUs ou notebooks) e, em um terceiro nível pela marca ou fabricante de notebooks. Esse agrupamento é necessário para facilitar a procura de recursos desejados e encontrar-los de diferentes modos. Dessa forma, justifica-se a separação em duas ou mais classes. O espaço necessário para manter esses atributos para todo recurso e a redundância obtida 
são indesejáveis. Entretanto, a separação pode aumentar o tempo de processamento, já que uma classe precisará referenciar outra e essa referência deve ser cuidada pelo sistema. Isso deve ser levado em consideração na otimização do desempenho do sistema.

\section{Portanto:}

Deve-se criar uma classe para descrever o recurso e também classes adicionais para as categorias de recurso.

\section{Estrutura}

A Figura 2 mostra o diagrama de classes do padrão IDENTIFICAR O RECURSO.

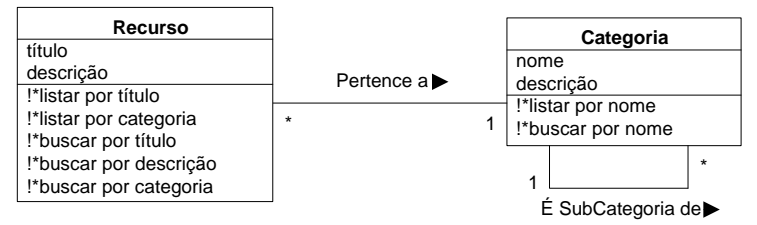

Figura 2: Estrutura do padrão IDENTIFICAR O RECURSO

\section{Participantes}

- Recurso: representa o recurso de negócio gerenciado pela aplicação, definindo todas as suas características importantes. Outros atributos podem ser adicionados de acordo com a instância particular o recurso, utilizando por exemplo, o padrão PROPERTIES ${ }^{1}$.

- Categoria: representa as categorias em que os recursos são agrupados, permitindo uma listagem de recurso por categoria e a operação de busca por categoria de recurso. Geralmente, são permitidos no máximo três níveis de agrupamento.

\section{Exemplo}

A Figura 3 apresenta um exemplo do padrão IDENTIFICAR o RECURSO que é utilizado pelo site de leilões virtuais iBazar. Essa é uma aplicação direta do padrão, possuindo apenas um atributo adicional (foto). O sufixo [0..1] denota que um produto leiloado pode possuir ou não uma foto. $\mathrm{O}$ Arremate.com e o eBay possuem diferentes tipos de categorização, apresentados na seção Variantes.

\section{Variantes}

Esse padrão é uma variante do padrão IDENTIFICAR O RECURSO proposto por Braga et. al. ${ }^{2}$. O padrão originalmente proposto por Braga et al. apresenta mais alguns atributos e operações. Quando vários níveis de agrupamento

${ }^{1}$ Foote, B. e Yoder, J. (1998). Metadata and active object-models. PLoP'98 and EuroPLoP'98 Conference, Technical Report \#wucs-98-25, Dept. of Computer Science, Washington University Department of Computer Science, September 1998.

${ }^{2}$ Braga, R. T. V., Germano, F. S. R., e Masiero, P. C. (1999). A pattern language for business resource management. In 6th Pattern Languages of Programs Conference (PLoP'99), Monticello - IL, USA.

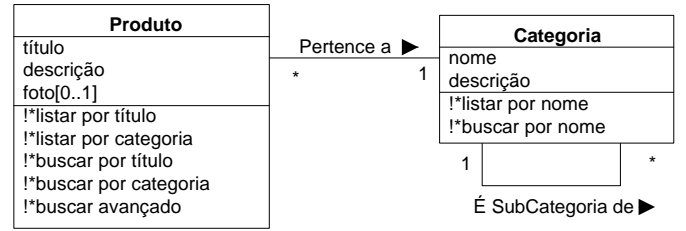

Figura 3: Exemplo do padrão IDENTIFICAR O RECURSO

são necessários denomina-se "objetos com tipos aninhados" (nested type objects) ${ }^{3}$.

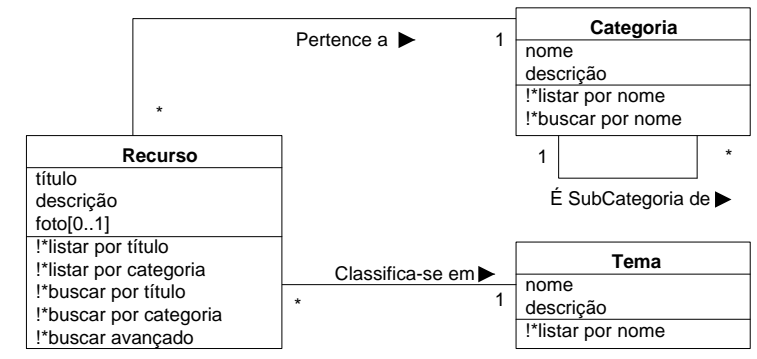

Figura 4: Variante do padrão IDENTIFICAR O RECURSO

Para melhorar a categorização, recursos podem ser classificados por mais do que um grupo, resultando em uma maior flexibilidade. Essa variante é denominada “objetos com múltiplos tipos" (multiple type objects), de forma análoga aos "objetos com tipos aninhados" apresentados no padrão principal. Para cada categoria desejada cria-se uma classe associada à classe Recurso. Um exemplo desse padrão é encontrado no eBay. Produto possui duas classes representando dois tipos de categorização, Categoria e Tema, como mostrado na Figura 4. A classe Tema agrupa recursos que possuem alguma característica em comum, por exemplo: itens de coleção, futebol ou culinária, porém, essa categorização é independente da Categoria. Produtos de diferentes categorias podem pertencer ao mesmo Tema, como por exemplo: um processador de alimentos pode ser incluído na Categoria "eletro-eletrônicos" e, ao mesmo tempo pode ser incluído no Tema "cozinha". Assim, essa característica poderia ser atendida pelo padrão principal, que permite apenas o aninhamento de categorias.

\section{Padrões Relacionados}

Esse padrão é também uma aplicação do padrão ACCOUNTABILITY ${ }^{4}$.

\footnotetext{
${ }^{3}$ Johnson, R. Wollf, B. (1998). Type-Object, pages 47-65. Pattern Languages of Program Design 3, Martin, R.C., Riehle, D., Buschmann, F. - Addison-Wesley, Reading-MA, USA.

${ }^{4}$ Fowler, M. (1997). Analysis Patterns. Addison-Wesley, Menlo Park-CA, USA.
} 


\section{Próximos Padrões}

Após usar o padrão IDENTIFICAR o RECURSO, tente utilizar o padrão HABILITAR FAVORITOS. Caso ele não seja aplicável utilize o padrão LEILOAR o RECURSO.

\section{Habilitar Favoritos}

\section{Contexto}

Sua aplicação lida com recursos já identificados que foram categorizados. Em alguns sistemas pode-se desejar que algumas das categorias de recurso sejam agrupadas pelo cliente por serem as que mais lhe interessam. Essa opção de identificar as categorias de recursos favoritas pode ajudar a estabelecer um perfil de consumo dos clientes. Assim, observando-se esse perfil de consumo dos clientes, pode-se enviar ofertas de recursos como uma forma de direcionar a comercialização de recursos.

\section{Problema}

Como sua aplicação permite que categorias de recurso de maior interesse sejam estabelecidas pelos clientes?

\section{Influências}

- É desejável que se ofereça maneiras rápidas de acesso a recursos mais desejados pelo cliente.

- Armazenar informações sobre o perfil dos clientes é uma boa estratégia para direcionar a veiculação de propaganda de tipos específicos de recursos. Esse tipo de estratégia, além de importante para a empresa proprietária do sistema, oferece uma comodidade aos clientes, fornecendo-lhes apenas informações sobre recursos que têm maior chance de interessar-lhes.

- É importante balancear os benefícios e as desvantagens de enviar muitas ofertas aos usuários, que podem se incomodar com as constância dessas ofertas. As ofertas devem atrair os consumidores a visitar freqüentemente o site do sistema de leilões.

\section{Portanto:}

Deve-se criar classes para agrupar as categorias de recurso preferidas pelos participantes.

\section{Estrutura}

A Figura 5 mostra o diagrama de classes do padrão HABILITAR FAVORITOS.

\section{Participantes}

- Participante: Representa a parte - organização ou pessoa - que pretende leiloar ou adquirir um recurso.

- Categoria: Como descrito no padrão IDENTIFICAR O RECURSO.

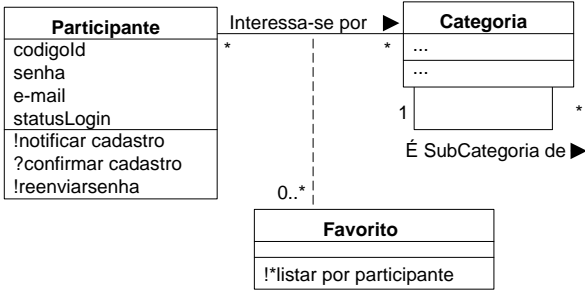

Figura 5: Estrutura do padrão HABILITAR FAVORITOS

- Favorito: Representa as categorias de recursos selecionadas pelo participante como interessantes.

\section{Exemplo}

A Figura 6 apresenta um exemplo do padrão HABILITAR FAVORITOS utilizado pelo site de leilões virtuais eBay. As categorias de recursos que mais interessam ao cliente são armazenadas pela classe Favorito. O eBay determina que apenas quatro categorias preferidas possam ser armazenadas. O Arremate.com e o iBazar não possuem o conceito de categorias preferidas dos clientes.

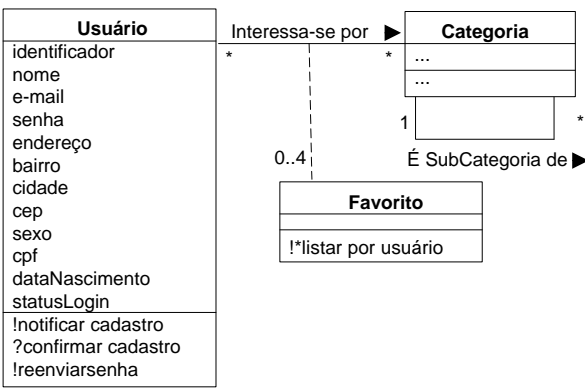

Figura 6: Exemplo do padrão HABILITAR FAVORITOS

\section{Próximos Padrões}

Após usar o padrão HABILITAR FAVORITOS, utilize o padrão LEILOAR O RECURSO. Observe também o padrão HABILITAR MENSAGENS, que permite à empresa leiloeira enviar mensagens aos participantes, e o padrão GERENCIAR ANÚNCIO, que permite à empresa leiloeira controlar o anúncio dos leilões.

\section{LEILOAR O RECURSO}

\section{Contexto}

Sua aplicação lida com recursos que já foram identificados e categorizados. O leilão de recursos pode ser considerado como uma transferência de propriedade, em que um recurso pertencente a uma parte passa a pertencer a outra parte. Em uma negociação por intermédio de um leilão o recurso é colocado à venda por uma parte negociante e várias 
outras partes tentam comprá-lo pelo menor preço possível. Existem vários tipos de leilão, fornecendo assim várias opções para as partes negociantes, cada uma com suas próprias regras para determinar qual das partes compradoras participantes da negociação será a vencedora.

\section{Problema}

Como voce lida com os diferentes tipos de leilões da sua aplicação?

\section{Influências}

- É necessário armazenar informações sobre os participantes, tanto para fornecer as informações necessárias ao processo de comercialização como para o próprio funcionamento do sistema.

- É importante disponibilizar vários tipos de leilão, observando os que sejam adequados a certos tipos de recurso, a quantidade de recursos colocados em leilão, a própria eficiência e limitações dos tipos de leilão, tendo em vista o meio em que a negociação ocorre: a Internet.

- Em alguns casos a parte origem pode desejar alterar as informações de um leilão ou mesmo o tipo do leilão. É necessário que se estabeleçam regras para alteração das informações para que os participantes não sejam prejudicados.

- Regras de cancelamento do leilão devem ser estabelecidas para que os participantes não sejam prejudicados.

\section{Portanto:}

Deve-se criar classes representando os diferentes tipos de leilões e diferenciar os papéis dos participantes nos leilões.

\section{Estrutura}

A Figura 7 mostra o diagrama de classes do padrão LEILOAR O RECURSO.

\section{Participantes}

- Participant: Representa a parte - organização ou pessoa - que pretende leiloar ou adquirir um recurso. Existem duas especializações dessa classe: Parte Origem e Parte Destino (detalhes abaixo). É importante notar que o mesmo participante pode representar ambos os papéis em diferentes leilões. Essa característica é assegurada pelo uso do padrão RoLES ${ }^{5}$. O atributo statusLogin indica

\footnotetext{
${ }^{5}$ Coad, P., North, D., e Mayfield, M. (1997). Object Models: Strategies, Patterns and Applications. Prentice-Hall, Upper Saddle River-NJ, USA, 2 edition.

${ }^{6}$ Fowler, M. (1997). Dealing with roles. Proceedings of the 4 th Annual Conference on the Pattern Languages of Programs, Monticello, Illinois, USA, September 2-5, 1997.
}

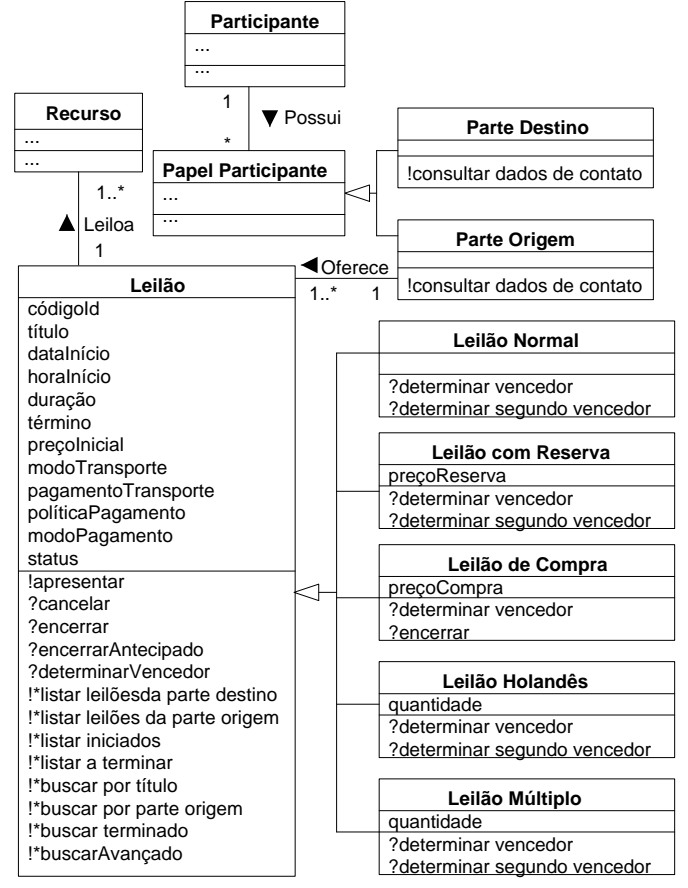

Figura 7: Estrutura do padrão LEILOAR O RECURSO

se o participante forneceu seu codigoId e senha e, portanto, pode participar efetivamente dos leilões. Durante o projeto do sistema deve existir uma política de segurança ${ }^{7}$, não considerada nessa linguagem de padrões. Essa classe possui alguns atributos básicos, porém outros atributos podem ser adicionados, dependendo da instância particular do participante.

- Papel do Participante: É o papel desempenhado por um participante em um leilão específico (detalhes abaixo).

- Parte Origem: Representa a parte proprietária do recurso antes da conclusão da transação.

- Parte Destino: Representa a parte que oferece lances e que pode tornar-se o proprietário do recurso após o término do leilão.

- Recurso: Como descrito no padrão IDENTIFICAR O RECURSO.

- Leilão: Classe abstrata que representa os detalhes do processo de leilão de um recurso. Esta classe possui todos os detalhes básicos necessários para que possa ser realizado um leilão, qualquer que seja o seu tipo.

\footnotetext{
${ }^{7}$ Yoder, J. e Barcalow, J. (1997). Architectural patterns for enabling application security. In Proceedings of the 4th Conference on Patterns Language of Programming (PLoP'97), 1997. 2.
} 
A implementação das regras de alteração é controlada por esta classe como, por exemplo, quais informações podem ser alteradas. Existem outros atributos para garantir essas regras, tais como: quantas vezes podem ser alteradas as informações de um leilão, qual o prazo para que um leilão possa ser alterado e, se pode ser alterado apenas se nenhum lance tiver sido dado. Esses atributos, que servem como parâmetros para o funcionamento do leilão, são armazenados na classe Empresa Leiloeira do padrão GERENCIAR A EMPRESA LEILOEIRA. Podem ser adicionados nesta classe e na classe Empresa Leiloeira outros atributos que dependem dos detalhes e funcionalidades que se deseja estabelecer em uma instância específica do leilão. Esse comportamento pode ser implementado utilizando-se o padrão STRATEGY ${ }^{8}$.

- Leilão Normal: É o tipo mais comum de leilão, em que várias partes destino oferecem lances para conseguir adquirir o recurso oferecido pela parte origem. $\mathrm{O}$ vencedor do leilão é quem oferece o lance de valor mais alto. Após o encerramento do leilão e determinação do vencedor, os dados de contato são disponibilizados para a consulta (consultar dados de contato). A classe leilão possui uma operação determinar segundo vencedor, a qual, caso ocorra algum problema com a negociação com o primeiro vencedor (determinar vencedor), permite à parte origem concluir a transação com o segundo vencedor, que é quem ofereceu o valor mais alto logo abaixo do primeiro vencedor. Este tipo de leilão não admite que múltiplos itens de um recurso sejam comercializados.

- Leilão com Reserva: Nesse tipo de leilão a parte origem define, além do preço inicial (precoInicial), um preço de reserva (preçoReserva) que não é visível às outras partes participantes do leilão. Podem ser dados lances menores do que o preço de reserva, mas a parte origem não é obrigada a negociar o recurso se o leilão for encerrado com um valor abaixo do preço de reserva. Neste caso o leilão será encerrado sem um vencedor e nenhuma das partes participantes do leilão receberá as informações de contato. Para que um leilão com reserva tenha um vencedor, é preciso que o lance final tenha sido igual ou superior ao preço de reserva. O preço de reserva pode ser diminuído pela parte origem durante o leilão mas não pode ser aumentado.

- Leilão de Compra: Nesse tipo de leilão a transação é concluída quando um certo preço de compra do re-

${ }^{8}$ Coad, P. (1992). Object-oriented patterns. Communications of the ACM, 35(9):152-159. curso é atingido, isto é, o leilão é encerrado automaticamente (encerrar). Assim, quem dá o lance com o valor igual ou superior ao preço de compra é imediatamente declarado vencedor. O tipo de leilão representado por essa classe não admite que sejam comercializados múltiplos itens de um mesmo recurso. Essa é uma classe opcional já que proporciona uma funcionalidade que pode ser desejada ou não.

- Leilão Holandês: Esta classe representa os detalhes de um tipo de leilão especializado em comercialização de múltiplos itens de um mesmo recurso. A parte origem estabelece um preço inicial e as várias partes participantes oferecem além dos lances, a quantidade de itens do recurso que deseja adquirir. Podem haver múltiplos lances de múltiplos compradores com valores e quantidades distintos. As regras para determinação dos vencedores são:

- as partes destino que ofereceram os lances com valores mais altos vencem. Os vencedores vão pagar pelo recurso o lance vencedor final de valor mais baixo. Isto quer dizer que todos pagarão o mesmo valor;

- caso ocorra empate entre esses vencedores (o valor dos lances é mesmo mas as quantidades do recurso são diferentes) o desempate é feito por ordem de lance. A parte origem que perdeu no desempate leva a quantidade restante dos itens. Ainda assim, todos pagarão o valor do lance vencedor final de valor mais baixo.

Esta é uma classe opcional, já que pode-se também utilizar a classe Leilão Múltiplo para comercializar múltiplos itens.

- Leilão Múltiplo: O funcionamento deste tipo de leilão é parecido com o Leilão Normal. No entanto, ele admite que múltiplos itens de um mesmo recurso sejam comercializados. Dessa forma, várias partes destino podem adquirir uma certa quantidade de itens de um recurso. Todos os lances são classificados por ordem de preço, depois por quantidade, e por último por horário. Ou seja, os lances com o valor mais alto ganham dos lances com valor mais baixo. No caso de lances com o mesmo valor, ganha o lance dado com a maior quantidade de itens do recurso. Se tiverem sido dados lances no mesmo valor e quantidade, quem tiver dado o lance primeiro é o vencedor. Esta classe é opcional já que alguns sistemas de leilões utilizam-se do Leilão Holandês para comercializar múltiplos itens.

\section{Exemplo}

A Figura 8 apresenta um exemplo do padrão LEILOAR O RECURSO utilizado pelo site de leilões virtuais Arrema- 
te.com, que utiliza o Leilão Múltiplo tanto para leiloar múltiplos itens de um recurso como para um único item de um recurso. Existem também outros dois tipos de leilões utilizados pelo Arremate.com, o Leilão com Reserva e o Leilão Ganhador (no padrão principal ele é apresentado como Leilão de Compra). Ao contrário do Arremate.com, o eBay utiliza o Leilão Holandês para comercializar múltiplos itens de um recurso e o Leilão Normal para os leilões de apenas um item. O eBay também disponibiliza aos clientes o Leilão com Reserva e o Leilão de Compra. O iBazar disponibiliza apenas o Leilão Normal e o Leilão com Reserva.

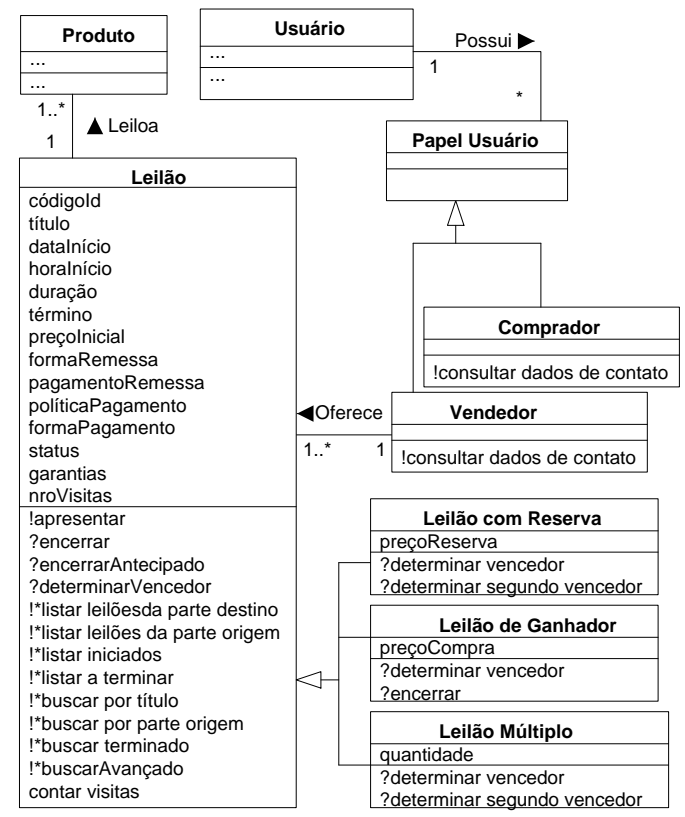

Figura 8: Exemplo do padrão LEILOAR O RECURSO

\section{Variantes}

Para que a linguagem de padrões seja adequada a vários tipos de leilões, novas classes representando as regras dos leilões podem ser adicionadas especializações da classe Leilão. Esses novos tipos de leilões podem precisar de novos atributos e métodos.

Em alguns sistemas o Leilão Normal é substituído pelo Leilão Múltiplo. Nesse caso o Leilão Múltiplo é utilizado tanto para leilões com um único item como para vários itens de um mesmo recurso.

A forma usada por sistema de leilões para proteger-se contra possíveis usuários de má fé é solicitando um documento, como por exemplo o CPF. No entanto, em alguns sistemas de leilões o usuário deve informar o número do cartão de crédito para poder cadastrar-se no sistema de leilões. E ainda, em outros sistemas não é necessária nenhuma informação mais específica do usuário.
Em alguns sistemas de leilões é permitido cancelar o leilão enquanto que em outros sistemas isso não é possível. Existem regras de cancelamento para que um leilão possa ser excluído, como por exemplo: somente em um tempo determinado após a inclusão do leilão, por motivos permitidos ou simplesmente por vontade da parte origem. De forma análoga, deve haver regras para a alteração dos dados de um leilão. Além dos exemplos citados no caso do cancelamento, alguns sistemas permitem que a parte origem possa apenas adicionar informações e não retirar ou alterar as já incluídas anteriormente. Os parâmetros para as regras de cancelamento e alteração são armazenados na classe Empresa Leiloeira do padrão GERENCIAR A EMPRESA LEILOEIRA.

\section{Padrões Relacionados}

Esse padrão é uma aplicação dos padrões AsSOCIATIONOBJECT e TIME-ASSOCIATION e, também, é uma combinação da aplicação dos padrões ITEM-TRANSACTION e PARTICIPANT-TRANSACTION ${ }^{5}$. Pode-se utilizar o padrão de projeto STRATEGY ${ }^{8}$ para implementar os diferentes tipos de leilão.

\section{Próximos Padrões}

Após aplicar o padrão LEILOAR O RECURSO tente utilizar o padrão Promover NegociaÇÃo. Caso esse padrão não seja aplicável utilize o padrão GERENCIAR LANCES.

\section{Promover Negociação}

\section{Contexto}

Sua aplicação lida com recursos que foram identificados, categorizados e estão sendo comercializados por tipos já definidos de leilões. Talvez seja necessário que os clientes esclareçam dúvidas quanto a esses recursos ou quanto às informações de algum dos leilões em que desejam dar lances. As dúvidas são esclarecidas diretamente pela parte origem. Esse tipo de comunicação entre as partes é semelhante a uma negociação tradicional e proporciona um canal direto entre as partes participantes do leilão, causando um certo clima de competitividade benéfico ao leilão.

\section{Problema}

Como sua aplicação apóia a negociação entre as partes negociantes de um leilão?

\section{Influências}

- Estabelecer regras para divulgar as perguntas e respectivas respostas é útil para o esclarecimento de detalhes dos recursos que estão sendo leiloados. Dessa forma, todos podem se beneficiar das respostas, não somente o autor das perguntas.

- Utilizar uma lista de discussão para a comunicação entre as partes negociantes ajuda a esclarecer dúvi- 
das mas, não existe correspondência explícita entre as questões e um leilão específico. Assim, para recuperar questões/respostas de um particular leilão, seria necessário procurar entre várias mensagens da lista de discussão.

- Estabelecer regras de incentivo para que a parte origem responda às perguntas é importante para aumentar as chances de oferecimento de lances. Quanto mais detalhes sobre o recurso e sobre as informações do leilão maior as chances da negociação. Além do que, de certa forma mostra o interesse real da parte origem em comercializar o recurso. Os incentivos podem ser em forma de desconto em possíveis taxas ou determinados tipos de promoção de leilões.

\section{Portanto:}

Deve-se criar classes para representar as questões e suas respectivas respostas sobre os leilões.

\section{Estrutura}

A Figura 9 mostra o diagrama de classes do padrão PROMOVER NEGOCIAÇÃO.

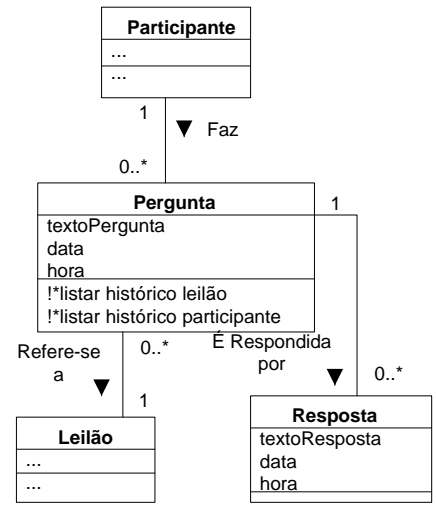

Figura 9: Estrutura do padrão PROMOVER NEGOCIAÇÃo

\section{Participantes}

- Participante: Como descrito no padrão LeILOAR O RECURSO.

- Leilão: Como descrito no padrão LeILOAR O RECURSO.

- Pergunta: Representa as perguntas eventualmente feitas pela Participante a uma Parte Origem sobre algum Leilão. Essas perguntas são referentes a detalhes dos leilões ou dúvidas da parte destino.

- Resposta: Representa as respostas dadas pela parte origem referente a perguntas sobre seus leilões.

\section{Exemplo}

A Figura 10 apresenta um exemplo do padrão PROMOVER NEGOCIAÇÃo utilizado pelo site de leilões virtuais Arremate.com. O eBay e o iBazar utilizam a mesma solução para oferecer um canal de negociação entre as partes negociantes.



Figura 10: Exemplo do padrão Promover NEGoCIAÇÃO

\section{Próximos Padrões}

Após aplicar o padrão Promover NEgociaÇão utilize o padrão GERENCIAR LANCES.

\section{GERENCIAR LANCES}

\section{Contexto}

Sua aplicação lida com alguns tipos de leilões de recursos já estabelecidos, fornecendo uma infraestrutura de negociação. O meio usado pelas partes destino para adquirir recursos em um leilão é o oferecimento de lances. Esses lances vão, juntamente com as regras de fechamento de cada tipo de leilão, determinar o vencedor ou vencedores do leilão. Os lances possuem regras que dependem do tipo de leilão, tais como quantidade e valor de incremento do lance. As partes destino possuem uma lista de leilões que são marcados por serem considerados importantes. Os leilões que se encontram nessa lista podem ser acessados mais facilmente e acompanhados com maior atenção.

\section{Problema}

Como sua aplicação lida com os diferentes tipos de lances relacionados com os vários tipos de leilões?

\section{Influências}

- Armazenar informações dos lances oferecidos é importante para determinar o vencedor ou vencedores do leilão. No caso do tipo de leilão admitir múltiplos 
vencedores, os dados destes lances serão utilizados no processo de desempate.

- Deve-se garantir que as regras impostas pelo tipo de leilão sejam aplicadas aos lances. Podem haver leilões que necessitem de tipos especiais de lances.

- Deve-se estabelecer regras para o cancelamento dos lances para que os participantes do leilão não sejam prejudicados. Essas regras devem cobrir tanto o cancelamento do lance pela parte origem como pela parte destino.

\section{Portanto:}

Deve-se adicionar ao leilão uma maneira de permitir lances e marcar os leilões preferidos.

\section{Estrutura}

A Figura 11 mostra o diagrama de classes do padrão GERENCIAR LANCES.

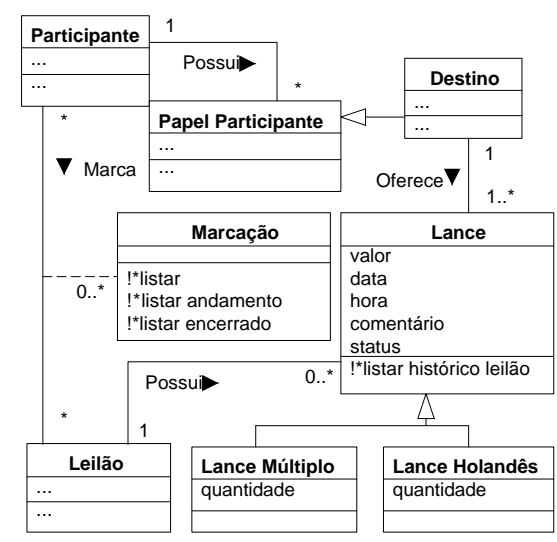

Figura 11: Estrutura do padrão GERENCIAR LANCES

\section{Participantes}

- Participante: Como descrito no padrão LeILOAR o RECURSO.

- Parte Destino: Como descrito no padrão LeILOAR O RECURSO.

- Papel do Participante: Como descrito no padrão LeILoAR o RECURSo.

- Leilão: Como descrito no padrão LeILOAR o RECURSO.

- Lance: Representa os detalhes dos lances oferecidos durante a fase de leilão do recurso. Esta classe possui os atributos básicos necessários, porém podem ser adicionados outros atributos dependendo das funcionalidades e detalhes desejados em uma instância específica da aplicação. Essa característica pode ser implementada utilizando o padrão PROPERTIES ${ }^{1}$.
- Lance Holandês: Representa os lances oferecidos quando o tipo de leilão utilizado é o leilão Holandês. Portanto, essa é uma classe opcional e deve ser utilizada apenas quando o tipo de leilão utilizado for o Leilão Holandês.

- Lance Múltiplo: Representa os lances oferecidos quando o tipo do leilão utilizado é o leilão Múltiplo. Portanto, essa é uma classe opcional que deve existir apenas quando o tipo de leilão utilizado for o Leilão Múltiplo.

- Marcação: Representa os leilões que partes destino possam "marcar" para acompanhar o andamento dos lances e assim, ter acesso a eles de maneira mais rápida. Dessa forma, os leilões de maior interesse da parte destino podem ser localizados facilmente.

\section{Exemplo}

A Figura 12 apresenta um exemplo do padrão GERENCIAR LANCES utilizado pelo site de leilões virtuais iBazar. A marcação de leilões é oferecida também pelo Arremate.com e pelo eBay. O ibazar também não permite que lances sejam cancelados. Nenhum dos tipos de leilão disponibilizados pelo iBazar aceita que sejam comercializados múltiplos itens porém, admite que se utilize o Leilão com Reserva. Portanto, a classe Lance, que armazena os dados necessários para os lances normais, é suficiente para atender aos requisitos de leilões com apenas um item do recurso. O Aremate.com possui o funcionamento semelhante ao iBazar, com exceção que possui a opção de leiloar múltiplos itens do recurso por meio do Leilão Múltiplo. Assim, é necessário que a classe Lance Múltiplo seja utilizada. Adicionalmente, o Arremate.com implementa regras de incremento e oferece o serviço de lance automático (detalhes na sessão Variantes). O eBay implementa regras de incremento e lance automático, além de permitir que lances sejam cancelados e múltiplos itens sejam leiloados por meio do Leilão Holandês. O eBay permite também que apenas partes destino selecionadas possam oferecer lances (detalhes na sessão Variantes).

\section{Variantes}

Conforme apresentado no padrão LEILOAR O RECURSO, podem ser adicionados vários tipos de leilão e para apoiar esses vários tipos, caso eles sejam efetivamente adicionados, deve ser possível adicionar novos tipos de lances. Caso um tipo de leilão adicionado como uma especialização da classe Leilão necessite de um tipo específico de lance, esse tipo de lance deve ser adicionado como uma especialização da classe Lance.

Além dos variantes que são resultantes dos possíveis tipos de lance, existem outros variantes deste padrão. A Figura 13 mostra a classe Lance Automático que 


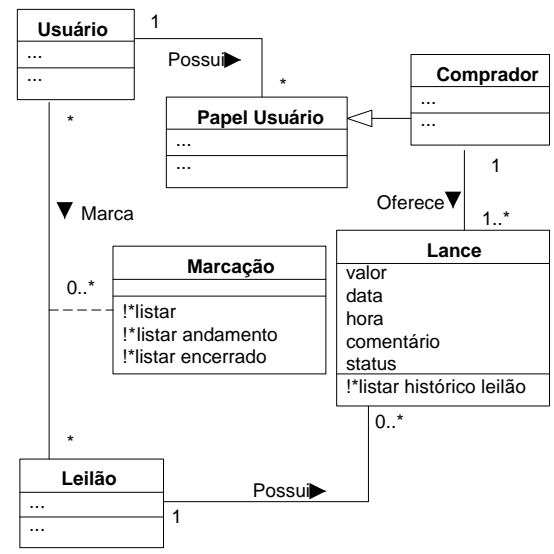

Figura 12: Exemplo do padrão GERENCIAR LANCES

representa o mecanismo de oferecimento automático de lances. Assim, a aplicação fornece também um mecanismo para que os lances sejam oferecidos automaticamente segundo parâmetros estabelecidos pela parte destino, e assim facilitar a negociação para a parte destino. Esse mecanismo é acionado pela parte destino, por meio da operação habilitar lance automático, assumindo como valor limitante superior o valor do atributo valorLimitelance. Quando a parte destino escolhe a opção de oferecimento automático de lances o próprio sistema se encarrega de dar um novo lance cada vez que outra parte destino oferecer um lance maior. Ou seja, o mecanismo oferece um lance imediatamente superior ao lance anterior porém, sem ultrapassar o valor limite estabelecido pela parte destino.

Outra variante, também apresentada na Figura 13, refere-se ao estabelecimento de regras de incremento dos lances, executadas pelo método ver incremento lance. Essa opção é importante quando se deseja que os lances tenham um valor proporcional ao valor total do recurso. Essa opção afeta o mecanismo de lance automático, que deve obedecer também às regras de incremento do lance. Dessa forma, o mecanismo de oferecimento automático de lances irá dar um lance imediatamente superior ao lance anterior. Porém, o valor do lance deve ser permitido pelas regras de incremento e não ultrapassar o valor limite.

Um leilão pode ter seu acesso limitado a algumas partes destino previamente determinadas pela parte origem. Como exemplo, essa opção pode ser escolhida caso se deseje definir um público específico para certos tipos de recursos. Nesse caso, a classe Aprovado, mostrada na Figura 13, representa as partes destino habilitadas a participar de um determinado leilão. Assim, somente as partes destino previamente estabelecidas podem dar lances nesse leilão.

Em alguns sistemas de leilões existe a possibilidade de

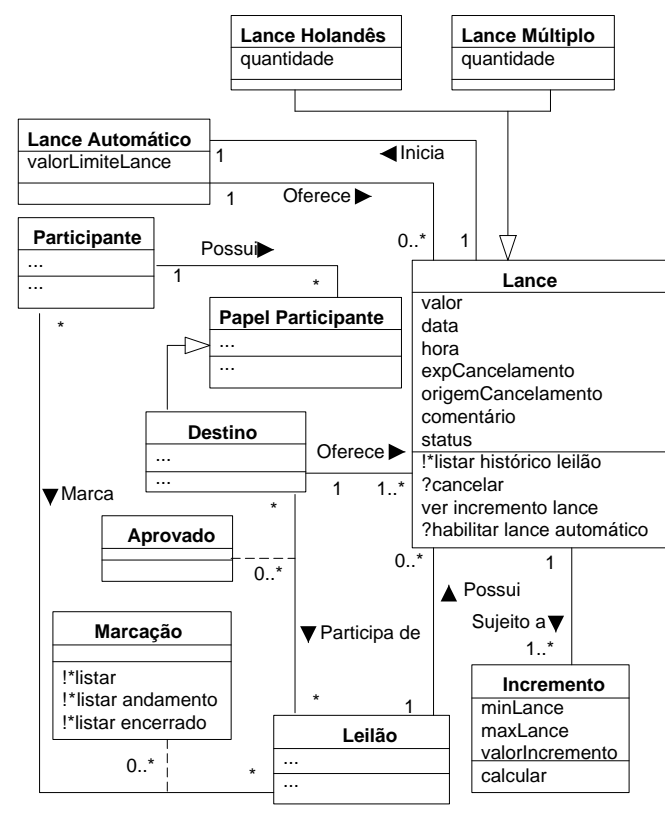

Figura 13: Variação do padrão GERENCIAR LANCES

cancelar lances, com diferentes regras para os cancelamentos. Existem regras para controlar quem pode cancelar um lance; se é necessário um tempo limite para o cancelamento; se existem alguns motivos específicos permitidos; se explicações são necessárias, etc. Novos atributos e métodos que sejam necessários para atender a essas funcionalidades devem ser armazenados e implementados na classe Lance e na classe Empresa Leiloeira.

\section{Próximos Padrões}

Após aplicar o padrão GERENCIAR LANCES utilize o padrão GERENCIAR A EMPRESA LEILOEIRA.

\section{GERENCIAR A EMPRESA LEILOEIRA}

\section{Contexto}

Sua aplicação gerencia leilões de recursos que serão leiloados por partes origem; várias partes destino oferecerão lances para conseguir adquirir os recursos. Para tanto, é necessário o estabelecimento de regras para intermediar o processo de comercialização. Fica a critério dessa entidade intermediária estabelecer ou não taxas de uso do sistema e taxas de comercialização dos recursos. A empresa leiloeira é quem determina os parâmetros gerais de funcionamento de todo o processo de negociação por meio de leilões.

\section{Problema}

Como seu sistema gerencia as regras da empresa leiloeira no processo de leilão? 


\section{Influências}

- Armazenar informações da empresa leiloeira é imprescindível para a comercialização por meio de leilões.

- É necessário o estabelecimento de várias regras gerais sobre a empresa leiloeira.

- É necessário que se estabeleça como e quais taxas devem ser pagas pelas partes negociantes.

- Armazenar diferentes tipos de taxas demanda mais espaço e processamento, no entanto, proporciona maior flexibilidade.

\section{Portanto:}

Deve-se adicionar classes que lidam com o cálculo das taxas e também com as regras da empresa leiloeira.

\section{Estrutura}

A Figura 14 mostra o diagrama de classes do padrão GERENCIAR A EMPRESA LEILOEIRA.

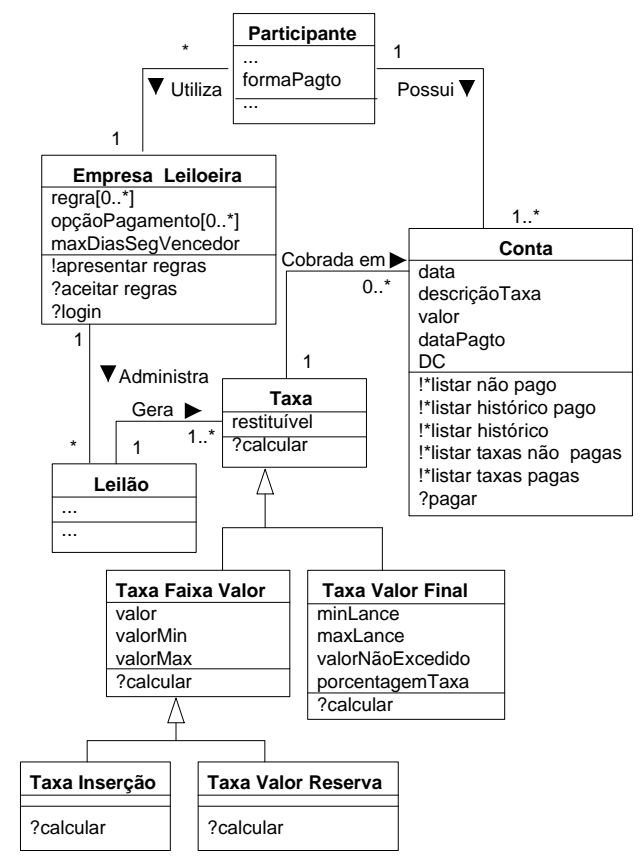

Figura 14: Estrutura do padrão GERENCIAR A EMPRESA LEILOEIRA

\section{Participantes}

- Leilão: Como descrito no padrão LEILOAR O RECURSO.

- Participante: Como descrito no padrão LeILOAR o RECURSO.
- Empresa Leiloeira: Representa o próprio sistema, isto é, a empresa leiloeira faz a intermediação das transações. Nessa classe são armazenados alguns parâmetros de funcionamento geral do processo de negociação por meio de leilões, como por exemplo, o prazo para que seja permitido que a parte destino possa requerer dados de contato de um segundo ganhador de um leilão (maxDiassegVencedor). $\mathrm{O}$ atributo regras armazena as regras gerais de conduta da parte origem, da parte destino e da empresa leiloeira. Esse atributo trata de aspectos legais e contratuais do serviço prestado pela empresa leiloeira que devem ser aceitos (apresentar regras e aceitar regras) pelas partes origem e destino para que possam utilizar o sistema de leilões.

- Taxa: É uma classe abstrata que representa taxas que podem ser cobradas pela empresa leiloeira. $\mathrm{O}$ atributo restituível indica se essa é uma taxa que pode ser restituída para o participante. Essa classe e todas as suas especializações são opcionais, pois as taxas podem ser cobradas ou não, dependendo da aplicação.

- Taxa Valor Final: Representa uma taxa cobrada com base em porcentagem (porcentagemTaxa) sobre o valor final do lance vencedor com qual o leilão foi encerrado.

- Taxa Faixa Valor: É uma classe abstrata que representa uma taxa calculada com base em valores limite (valorMin, valorMax) e um valor fixo (valor).

- Taxa Inserção: Representa uma taxa calculada com base em valores limite sobre o valor do preço inicial de um recurso (preçoInicial). Essa taxa é cobrada quando um recurso é posto em leilão e, geralmente, não é restituível.

- Taxa Valor Reserva: Representa uma taxa calculada com base em valores limite sobre o preço de reserva de um recurso (preçoReserva). Essa taxa somente é cobrada em leilões do tipo Leilão com Reserva e geralmente é restituível caso a transação se concretize.

- Conta: Representa as taxas cobradas e as possíveis restituições feitas a um participante. Portanto, os valores (valor) podem ser de crédito ou débito para um participante (DC). A utilização dessa classe é diretamente ligada à utilização da classe Taxa. Ela só pode ser aplicada se a classe Taxa também for aplicada.

\section{Exemplo}

A Figura 15 apresenta um exemplo do padrão GERENCIAR A EMPRESA LEILOEIRA utilizado pelo site de leilões 
virtuais Arremate.com. O sistema de leilões desse site possui apenas a Taxa de Sucesso (que é uma instanciação da Taxa Valor Final). O sistema implementa uma regra de pagamento de taxas em que, quando a conta de um cliente atingir um valor limite, ele recebe um aviso constando do montante que deve pagar. Além da taxa sobre o valor final do leilão, o eBay implementa outros tipos de taxas, tais como: Taxa Valor Reserva e Taxa Inserção. Quando o cliente atrasa o pagamento de sua conta por um período previamente estabelecido, a utilização do sistema é bloqueada. O iBazar não cobra qualquer tipo de taxa, sua utilização é gratuita.

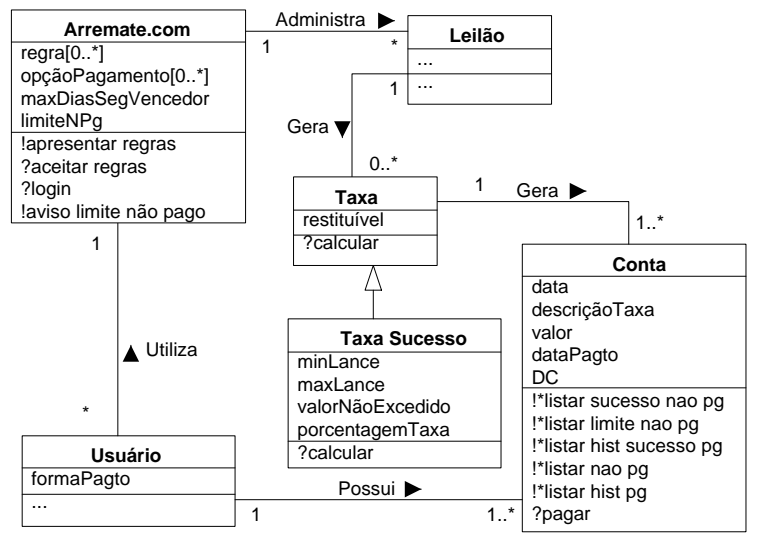

Figura 15: Exemplo do padrão GERENCIAR A EMPRESA LEILOEIRA

\section{Variantes}

Alguns sistemas de leilões disponibilizam acesso a empresas de entrega, recebimento do pagamento e entrega e recebimento do pagamento. As informações dessas empresas são armazenadas na classe Empresa Leiloeira.

Existem sistemas que disponibilizam alguns descontos de taxas ou isenção de taxas devido a estratégias de propaganda estabelecidos pela empresa proprietária do sistema. Um exemplo é a isenção da taxa de inserção se a parte origem colocar novamente um recurso em leilão por um número variável de vezes, durante um período de tempo preestabelecido, enquanto ele não for vendido. Os parâmetros de tempo, número de vezes, se é uma isenção da taxa ou um desconto parcial são armazenados na classe Empresa Leiloeira.

\section{Próximos Padrões}

Após aplicar o padrão GERENCIAR A EMPRESA LEILOEIRA utilize o padrão GERENCIAR REPUTAÇÕES.

\section{Gerenciar RePUtaÇÃo}

\section{Contexto}

Sua aplicação lida com o leilão dos recursos oferecidos pela parte origem, que são disputados pelas diversas partes destino por meio de lances. A transação ocorre quando o leilão é encerrado e o vencedor é declarado. Após a conclusão, tanto a parte origem quanto a parte destino podem fornecer ao sistema um voto que classifica como foi a conclusão da transação com a outra parte. Essas avaliações da reputação são necessárias para proteger as partes negociantes, já que tanto uma parte origem quanto uma parte destino podem emitir um voto. Assim, as reputações de todas as partes negociantes ficam disponíveis no sistema para serem consultadas a qualquer momento. Esse é o modo de saber quais são as partes negociantes que possuem uma boa reputação e, portanto, são mais confiáveis.

\section{Problema}

Como sua aplicação pode fornecer subsídios para que as partes possam avaliar a confiabilidade umas das outras?

\section{Influências}

- Somente as partes que participaram de uma transação podem opinar umas sobre as outras e assim fornecer informações verdadeiras. Assim, existem leilões em que múltiplas partes destino são vencedoras e, portanto, deve-se implementar regras específicas nesse caso.

- Manter dados confidencias sob sigilo é importante tanto para a empresa proprietária do sistema como para seus clientes.

- Fornecer um meio de defesa para ambas as partes e armazenar os argumentos de todas as partes envolvidas é imprescindível para proteger os clientes ${ }^{9}$.

\section{Portanto:}

Deve-se adicionar ao leilão um modo de tratar as reputações dos participantes.

\section{Estrutura}

A Figura 16 mostra o diagrama de classes do padrão GERENCIAR REPUTAÇÃO.

\section{Participantes}

- Participante: Como descrito no padrão LeILOAR o RECURSO.

- Parte Origem: Como descrito no padrão LEILOAR o ReCuRso.

- Parte Destino: Como descrito no padrão LeILOAR o RECURSO.

\footnotetext{
${ }^{9}$ Resnick, P., Zeckhauser, R., Friedman, E., e Kuwabara, K. (2000) Reputations systems. Communications of the ACM, 43(12):15-48.
} 


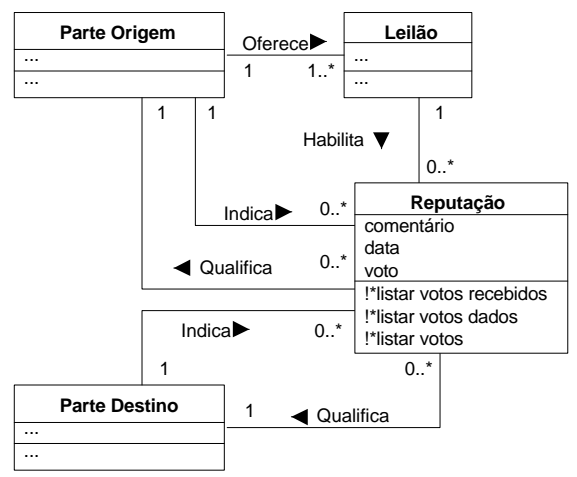

Figura 16: Estrutura do padrão GERENCIAR REPUTAÇÃO

- Leilão: Como descrito no padrão Leiloar o RECURSO.

- Reputação: Representa o voto dado por uma parte origem a uma parte destino e vice-versa, avaliandose mutuamente após o fechamento do leilão.

\section{Exemplo}

A Figura 17 apresenta um exemplo do padrão GERENCIAR REPUTAÇÕES utilizado pelo site de leilões virtuais iBazar. Tanto no iBazar como no eBay e no Arremate.com, as partes que concluíram a negociação podem gerar avaliações. Esses votos podem ser visualizados pelos outros clientes. Somente o eBay implementa uma opção de tornar a lista pública. Assim, todos os clientes podem consultar qualquer reputação ou manter seus votos sob sigilo para que apenas quem emitiu possa consultá-los.

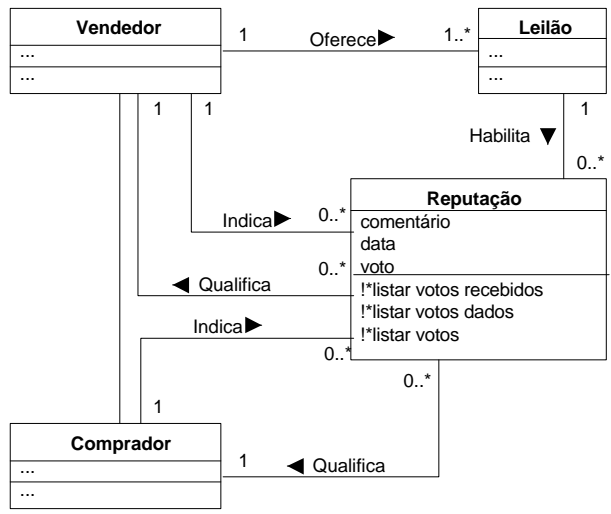

Figura 17: Exemplo do padrão GERENCIAR REPUTAÇãO

\section{Variantes}

Uma variação do funcionamento da avaliação é tornar a avaliação pública ou não, de forma que todos podem consultar a avaliação ou somente quem as emitiu. Essa opção faz com que o cliente tenha a flexibilidade de tornar sua opinião com relação a outros negociantes pública ou deixá-la sob sigilo para utiliza-la em novos negócios. A maioria dos sistemas incentiva a avaliação pública para que exista um ambiente de negociação mais seguro para os clientes que utilizam leilões virtuais.

Em alguns sistemas a avaliação pode ter seu valor alterado segundo algumas regras que variam de sistema para sistema, como por exemplo: a alteração pode ser feita apenas uma vez, dentro de um determinado período preestabelecido ou pode ser feita a qualquer momento. Os parâmetros dessas regras, tais como quantas vezes pode ser alterado ou o período em que pode ser alterado, devem ser armazenados na classe Empresa Leiloeira do padrão EMPRESA LEILOEIRA. Outros parâmetros, como por exemplo se o voto já foi alterado ou não deve ser armazenado na classe Reputação.

\section{Próximos Padrões}

Se no padrão Gerenciar a EMPResa Leiloeira a classe Taxa ou qualquer uma de suas especializações foi utilizada aplique o padrão Gerenciar Restituição. Caso contrário tente utilizar o padrão Habilitar MENSAGENS. Se o padrão Habilitar MEnSAGEns não for aplicável utilize o padrão GERENCIAR ANÚNCIO.

\section{Gerenciar Restituição}

\section{Contexto}

Sua aplicação lida com o leilão de recursos em que taxas são determinadas pela empresa leiloeira. Algumas dessas taxas são restituíveis em alguns casos, dentre eles quando uma transação não se concretiza por desistência da parte destino. Nesses casos deve-se fornecer um meio pelo qual a parte que se sentiu lesada possa pedir a restituição das taxas já faturadas devido à não concretização da negociação. Por sua vez, a parte acusada deve ter o direito de defesa do pedido de restituição. Assim, por intermédio das informações do pedido de restituição e o respectivo pedido de apelação, a empresa leiloeira pode tomar uma decisão sobre a restituição ou não das eventuais taxas. Após o caso julgado a empresa leiloeira indica se o pedido de restituição procede, devolvendo as taxas à parte origem e emitindo um voto de avaliação negativo para a parte destino. Caso contrário as taxas não serão devolvidas e a parte origem recebe um voto de avaliação negativo.

\section{Problema}

Como sua aplicação pode fornecer meios para o ressarcimento de taxas cobradas indevidamente?

\section{Influências}

- Armazenar os dados referentes ao pedido de restituição de uma das partes e o respectivo pedido de apelação da outra é importante para a tomada de decisão 
da empresa leiloeira.

- É necessário que sejam restituídas as taxas corretas de acordo com cada tipo de leilão e política de negócios da empresa leiloeira.

- Permitir uma avaliação da reputação das partes é imprescindível para proteger negociantes idôneos.

\section{Portanto:}

Deve-se criar classes que permitam controlar os pedidos de restituições e apelações dos participantes.

\section{Estrutura}

A Figura 18 mostra o diagrama de classes do padrão GERENCIAR RESTITUIÇÃO.

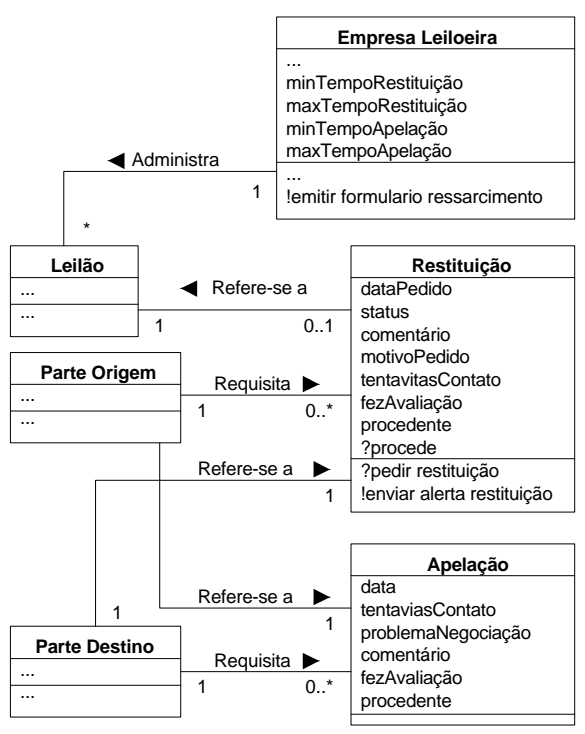

Figura 18: Estrutura do Padrão Gerenciar RestituiÇÃO

\section{Participantes}

- Leilão: Como descrito no padrão LeILOAR o RECURSO.

- Parte Origem: Como descrito no padrão LeILOAR o RECURSO.

- Parte Destino: Como descrito no padrão LeILOAR O RECURSO.

- Restituição: Representa o pedido de restituição, por uma das partes negociantes, das taxas referentes a um leilão de recurso cuja transação não foi concretizada. Esse pedido pode ser feito toda vez que, após o encerramento de um leilão e posterior determinação do vencedor, não ocorra a concretização do negócio. A parte origem pode então pedir que as taxas sejam restituídas. $\mathrm{O}$ atributo fezAvaliação indica se a parte origem forneceu um voto de avaliação sobre a reputação da parte destino.

- Apelação: Representa o pedido de apelação de uma parte destino referente a um pedido de restituição feito por uma parte origem. Quando ocorre um pedido de restituição, a parte acusada tem o direito de se defender fornecendo informações sobre o porque da não concretização da negociação. O atributo fezAvaliação indica se a parte destino forneceu um voto de avaliação sobre a reputação da parte origem.

- Empresa Leiloeira: Como descrito no padrão GERENCIAR A EMPRESA LEILOEIRA.

\section{Exemplo}

A Figura 19 apresenta um exemplo do padrão GERENCIAR RESTITUIÇÃO utilizado pelo site de leilões virtuais Arremate.com. Caso o vendedor e o comprador não consigam chegar a um acordo, o vendedor tem um prazo mínimo e máximo para poder pedir o reembolso das taxas faturadas sobre uma comercialização não concluída. O sistema emite um aviso ao comprador sobre a reclamação do vendedor, que tem um prazo para responder, por intermédio do formulário de apelação. A empresa leiloeira julga o caso e decide se o reembolso é procedente ou não. Caso seja procedente o comprador recebe um voto negativo da empresa leiloeira, caso contrário o vendedor recebe um voto negativo em sua reputação. O eBay utiliza praticamente o mesmo procedimento, aceita o pedido de restituição, aguarda uma resposta da parte destino e um possível entendimento entre as partes, caso contrário julga e emite um parecer. Caso ocorra a restituição o comprador recebe um voto negativo e caso contrário o vendedor recebe o voto negativo. O iBazar, por ser gratuito não possui tratamento de restituição.

\section{Padrões Relacionados}

Esse padrão é uma aplicação do padrão AssociATIONOBJECT $^{10}$ ou TIME-AsSOCIATION ${ }^{5}$, TRANSACTIONSubSEQuent Transaction e PARTICIPANTTRANSACTION ${ }^{5}$.

\section{Próximos Padrões}

Após usar o padrão GERENCIAR RESTITUIÇÃo, tente utilizar o padrão Habilitar MEnSAGEns. Caso esse padrão não seja aplicável utilize o padrão GERENCIAR ANÚNCIO.

\footnotetext{
${ }^{10}$ Boyd, L. (1998). Business Patterns of Association Objects, pages 395-408. Pattern Languages of Program Design 3, Martin, R.C., Riehle, D. , Buschmann, F. - Addison-Wesley, Reading - MA, USA.
} 


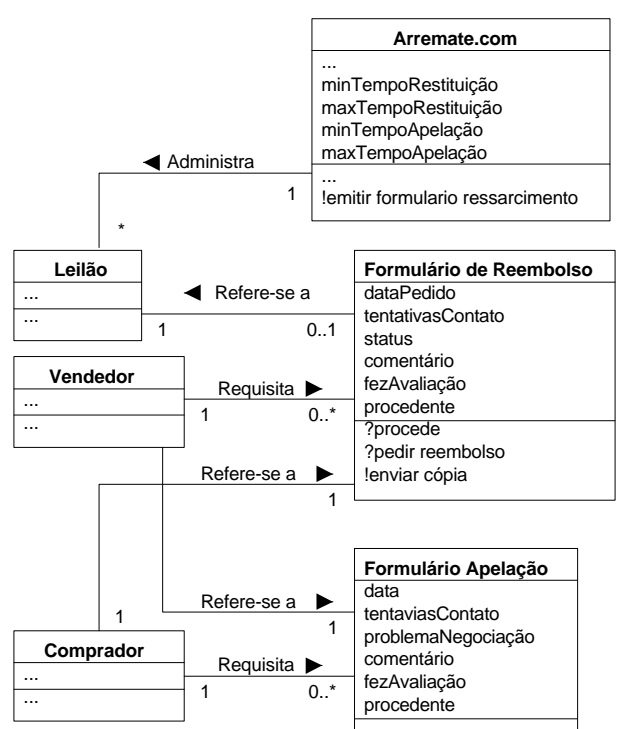

Figura 19: Exemplo do padrão Gerenciar RestituiÇÃO

\section{Habilitar Mensagens}

\section{Contexto}

Sua aplicação lida com a negociação de recursos por meio de leilões. Nesse tipo de negociação ocorrem vários eventos como, por exemplo, o início do leilão, os lances, o término e a determinação dos vencedores. Muitos desses eventos devem ser informados aos clientes por meio de mensagens, para que eles possam acompanhar todas as fases dos leilões. Além das mensagens que são diretamente ligadas aos leilões pode haver mensagens que têm outros fins como propaganda, mudanças nos leilões e promoções.

\section{Problema}

Como sua aplicação gerencia as mensagens enviadas aos clientes?

\section{Influências}

- Armazenar as mensagens enviadas aos clientes é importante para que eles tenham um histórico dos eventos dos leilões. Esse histórico pode ser uma importante fonte de informação para que eles possam tomar decisões com relação aos leilões em que estão participando.

- É desejável deixar que os clientes configurem as regras de recebimento de mensagens, para que assim possam determinar quais mensagens consideradas importantes.

- As mensagens tornam-se um canal direto com os cli- entes, tornando-se útil para a empresa leiloeira tanto como um simples canal de comunicação quanto para estabelecer um meio de veiculação de propaganda. Dessa forma, as mensagens tornam-se uma ferramenta na estratégia de propaganda.

\section{Portanto:}

Deve-se adicionar uma classe que trate das mensagens enviadas aos participantes.

\section{Estrutura}

A Figura 20 mostra o diagrama de classes do padrão HABiLitar Mensagens.

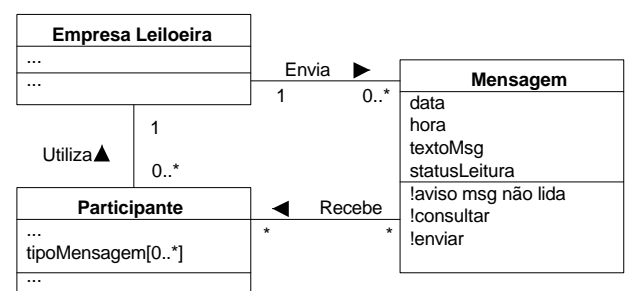

Figura 20: Estrutura do padrão HABILITAR MENSAGENS

\section{Participantes}

- Participante: Representa a parte - empresa ou pessoa - que pretende leiloar um recurso (origem) e partes interessadas em adquirir um recurso (destino). Nessa classe devem ser armazenadas as opções de quais mensagens o participante deseja receber (tipoMensagem). Essas opções referem-se a mensagens de eventos que ocorrem no leilão, por exemplo, início de um leilão, término de um leilão, vencedor de um leilão, lance enviado, lance maior enviado por outro participante, etc.

- Empresa Leiloeira: Como descrito no padrão GERENCIAR A EMPRESA LEILOEIRA.

- Mensagem: Representa as mensagens armazenadas que são enviadas para o participante. Essas mensagens são disponibilizadas para que possam ser consultadas a qualquer momento tanto diretamente pelo sistema como por meio de correio eletrônico.

\section{Exemplo}

A Figura 21 apresenta um exemplo do padrão HABILITAR MENSAGENS utilizado pelo site de leilões virtuais iBazar, que não apresenta a opção de configuração dos tipos de mensagens. O cliente não pode definir quais são as mensagens que ele deseja ou não receber. Todas as mensagens são armazenadas e podem ser retiradas apenas quando o cliente desejar. O cliente é avisado de novas mensagens recebidas toda vez que efetuar o procedimento de login no 
sistema. A opção de configuração de tipos de mensagens desejadas pelo cliente é oferecida tanto no eBay como no Arremate.com. O Arremate.com não armazena o histórico de mensagens do cliente, ele apenas envia as mensagens pelo correio eletrônico.

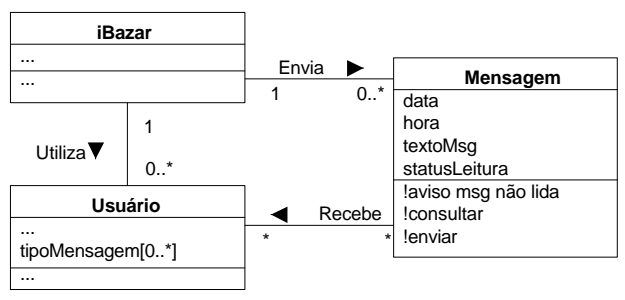

Figura 21: Exemplo do padrão HaBILITAR MENSAGENS

\section{Padrões Relacionados}

Esse padrão é uma aplicação dos padrões ASSOCIATIONOBJECT $^{10}$ e AsSOCIATION ${ }^{5}$.

\section{Próximos Padrões}

Após aplicar o padrão HABILITAR MENSAGENS utilize o padrão GERENCIAR ANÚNCIO.

\section{Gerenciar Anúncio}

\section{Contexto}

Sua aplicação lida com negociação por meio de leilões de recursos, que são anunciados segundo algumas formas disponibilizadas pelo empresa leiloeira. Essas formas promovem e anunciam o leilão com o intuito de atrair a atenção de partes destino possivelmente interessadas em adquirir um recurso. A parte origem define, dentre as opções fornecidas pela empresa leiloeira, a forma de anúncio que mais lhe interessa. Assim, os leilões são anunciados com diferentes formas de destaque e características de apresentação diferenciadas, dependendo das formas de anúncio que ele possui.

\section{Problema}

Como sua aplicação gerencia os anúncios dos leilões?

\section{Influências}

- Estabelecer regras de anúncio que categorizem os vários tipos de leilões é importante para promover a comercialização de recursos e para promover o empresa leiloeira. Quanto mais atrativos forem os anúncios dos leilões maior a chance de atrair novos clientes e, portanto, aumentar o número de negociações.

- É importante que exista uma política de anúncios para leilões que chamam com maior intensidade a atenção dos clientes e, assim, estabelecer uma estratégia de anúncios que promova os outros leilões.

\section{Portanto:}

Deve-se adicionar ao leilão classes que lidam com os diferentes tipos de anúncio.

\section{Estrutura}

A Figura 22 mostra o diagrama de classes do padrão GERENCIAR ANÚNCIO.

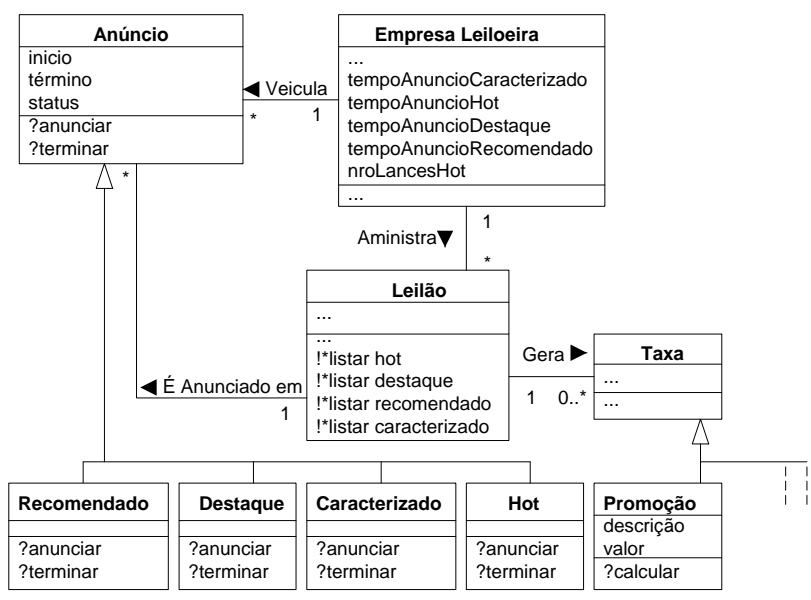

Figura 22: Estrutura do padrão GERENCIAR ANÚNCIO

\section{Participantes}

- Empresa Leiloeira: Como descrito no padrão GERENCIAR A EMPRESA LEILOEIRA.

- Leilão: Como descrito no padrão LeILOAR o RECURSO.

- Anúncio: Representa a forma como um leilão é anunciado. Esta classe armazena as regras dos anúncios, bem como possui alguns dados para veicular efetivamente os anúncios. Como exemplo de regras pode-se citar: o leilão deve ter todas as perguntas respondidas, o cliente não pode ter avaliação negativa, deve possuir um tipo especial de promoção, o leilão deve ser de um tipo (com reserva, holandês, etc) específico, ou simplesmente ser escolhido por ser um recurso que chame a atenção dos clientes. Essas regras podem ser implementadas para todos as especializações dessa classe.

- Recomendado: Representa os leilões que são escolhidos pelo sistema, dentre alguns leilões candidatos estabelecidos por regras de negócio da empresa leiloeira, para serem anunciados na área de maior destaque em páginas do site.

- Destaque: Representa os leilões que são escolhidos pelo sistema para serem anunciados em uma área destacada em páginas do site. 
- Caracterizado: Representam leilões que têm alto nível de visibilidade nas páginas. Podem ser anunciados na página principal, nas páginas de busca ou na navegação por entre as categorias.

- Hot: Representa os leilões que possuem um bom número de lances, dessa forma chamando a atenção de partes destino. $\mathrm{O}$ número de lances para que um leilão possa ser classificado como Hot deve ser representado pelo atributo nroLancesHot na classe Empresa Leiloeira. Os leilões Hot podem ser colocados em uma área de destaque na página principal do site.

- Promoção: Representa várias formas simples de como um leilão pode ser apresentado (em negrito, com fotos ao lado das listagens, em posições de destaque nas listagens, etc.). Essas formas são diretamente vinculadas a taxas. Portanto, esta é uma classe que representa não somente tipos de anúncio simplificados, mas também as taxas de serviço referentes a esses tipos. Esses tipos de promoção podem ser usados na estratégia de anúncios mais elaborados (Caracterizado, Destaque, Recomendado). Por exemplo, um leilão só pode ser anunciado como Caracterizado se possuir um determinado tipo de promoção.

- Taxa: Como descrito no padrão Gerenciar A EMPRESA LEILOEIRA.

\section{Exemplo}

A Figura 23 apresenta um exemplo do padrão GERENCIAR ANÚNCIO utilizado pelo site de leilões virtuais eBay. $\mathrm{O}$ eBay possui dois tipos especiais de anúncio, o caracterizado e o hot.

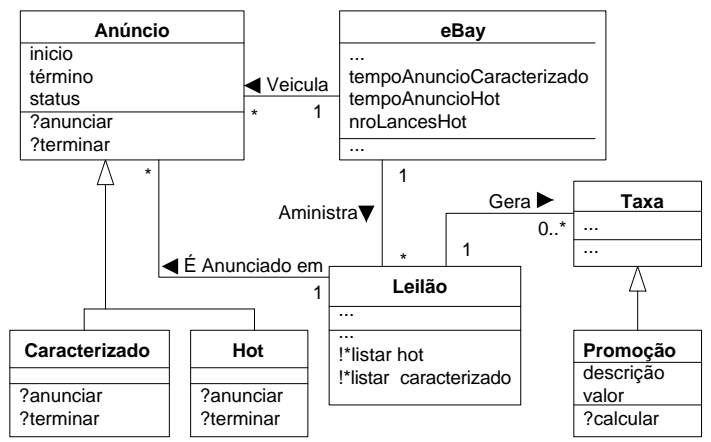

Figura 23: Exemplo do padrão GERENCIAR ANÚNCIO

Para que um leilão seja anunciado como caracterizado ele deve ter um tipo de promoção chamado "caracterizado na página principal". A empresa leiloeira determina o tempo do anúncio do leilão e a ordem em que os leilões são anunciados. O Arremate.com possui três tipos de anúncio e implementa suas próprias regras de anúncio, no entanto seu funcionamento é similar ao do eBay. $\mathrm{O}$ iBazar não possui distinção de anúncio entre os leilões e portanto utiliza a classe Anúncio para veicular os anúncios de todos os leilões. O funcionamento dos anúncios é similar ao do eBay e Arremate.com.

\section{Padrões Relacionados}

Esse padrão é uma aplicação do padrão ASSOCIATIONOBJECT $^{10}$ e TIME-AsSOCIATION ${ }^{5}$.

\section{Próximos Padrões}

Fim da análise de seu sistema. 
APÊNDICE

\section{$B$}

\section{Lista de Pontos Variáveis}

Lista Completa dos Pontos Variáveis do Framework Qd+.

\begin{tabular}{|c|c|c|c|c|c|}
\hline $\begin{array}{l}\text { Número } \\
\text { do } \\
\text { ponto } \\
\text { variá- } \\
\text { vel }\end{array}$ & Nome & Descrição & Tipo & $\begin{array}{l}\text { Origem na } \\
\text { Linguagem de } \\
\text { Padrões }\end{array}$ & $\begin{array}{l}\text { Número } \\
\text { do } \\
\text { Padrão }\end{array}$ \\
\hline 1 & $\begin{array}{l}\text { Definir } \\
\text { categorias } \\
\text { favoritas }\end{array}$ & $\begin{array}{l}\text { Permitir que o usuário, no momento do registro, escolha } \\
\text { quais são suas categorias de recurso preferidas. }\end{array}$ & PADRÃO_OPCIONAL & $\begin{array}{l}\text { Grafo de Flu- } \\
\text { xo, Próximos } \\
\text { Padrões }\end{array}$ & 1 \\
\hline 2 & $\begin{array}{l}\text { Permitir } \\
\text { negociações } \\
\text { entre os } \\
\text { participantes }\end{array}$ & $\begin{array}{l}\text { Permitir que os usuários possam perguntar sobre detalhes } \\
\text { dos leilões diretamente aos seus devidos proprietários e estes } \\
\text { poderem retornar várias respostas às perguntas. }\end{array}$ & PADRÃO_OPCIONAL & $\begin{array}{l}\text { Grafo de Flu- } \\
\text { xo, Próximos } \\
\text { Padrões }\end{array}$ & 2 \\
\hline 3 & $\begin{array}{l}\text { Restituição } \\
\text { das Taxas }\end{array}$ & $\begin{array}{l}\text { Pode-se restituir uma taxa cobrada, porém é necessário que } \\
\text { essas taxas existam, ficando assim o padrão GERENCIAR } \\
\text { RESTITUIÇÃo condicionado às taxas utilizadas em uma } \\
\text { aplicação específica. }\end{array}$ & PROPAGAÇÃO & $\begin{array}{l}\text { Participantes, } \\
\text { Grafo de Flu- } \\
\text { xo, Próximos } \\
\text { Padrões }\end{array}$ & 6 \\
\hline 4 & $\begin{array}{l}\text { Mensagens } \\
\text { para os } \\
\text { usuários }\end{array}$ & $\begin{array}{l}\text { Em uma aplicação específica pode ser desejável utilizar o } \\
\text { envio de mensagens aos usuários, portanto, se este for o caso, } \\
\text { o padrão HABILITAR MENSAGENS deve ser aplicado. }\end{array}$ & PADRÃO_OPCIONAL & $\begin{array}{l}\text { Grafo de Flu- } \\
\text { xo, Próximos } \\
\text { Padrões }\end{array}$ & 7 \\
\hline 5 & $\begin{array}{l}\text { Categorização } \\
\text { de Recursos }\end{array}$ & $\begin{array}{l}\text { Os recursos podem ser categorizados segundo vários critéri- } \\
\text { os de classificação que podem ser simples ou de forma ani- } \\
\text { nhada. }\end{array}$ & ESCOLHA_PARTIC & $\begin{array}{l}\text { Participantes, } \\
\text { Variantes }\end{array}$ & 1 \\
\hline
\end{tabular}

continua na próxima página... 
Tabela B.1: Lista Completa dos Pontos Variáveis do Framework Qd+ (continuação)

\begin{tabular}{|c|c|c|c|c|c|}
\hline $\begin{array}{l}\text { Número } \\
\text { do } \\
\text { ponto } \\
\text { variá- } \\
\text { vel }\end{array}$ & Nome & Descrição & Tipo & $\begin{array}{l}\text { Origem na } \\
\text { Linguagem de } \\
\text { Padrões }\end{array}$ & $\begin{array}{l}\text { Número } \\
\text { do } \\
\text { Padrão }\end{array}$ \\
\hline 6 & $\begin{array}{l}\text { Alteração dos } \\
\text { detalhes de } \\
\text { um leilão }\end{array}$ & $\begin{array}{l}\text { Permitir que se estabeleça quais as regras para a alteração de } \\
\text { detalhes do leilão. Geralmente, os detalhes dos leilões po- } \\
\text { dem ser alterados por um tempo predeterminado ou até que } \\
\text { receba lances. Portanto, deve-se possibilitar que em uma ins- } \\
\text { tanciação seja determinada uma das alternativas: não permi- } \\
\text { tir alteração, permitir a alteração em um determinado perío- } \\
\text { do após o cadastro do leilão ou permitir a alteração até que } \\
\text { um lance tenha sido dado. }\end{array}$ & COMPORTAMENTO & Participantes & 3 \\
\hline 7 & $\begin{array}{l}\text { Determinar os } \\
\text { tipos de lei- } \\
\text { lões apoiados }\end{array}$ & $\begin{array}{l}\text { Deve-se permitir quais tipos de leilões, dentre os existentes } \\
\text { na linguagem, podem ser utilizados em uma instanciação es- } \\
\text { pecífica. }\end{array}$ & ESCOLHA_PARTIC & $\begin{array}{l}\text { Participantes, } \\
\text { Estrutura }\end{array}$ & 3 \\
\hline 8 & $\begin{array}{l}\text { Cancelamento } \\
\text { de leilões }\end{array}$ & $\begin{array}{l}\text { Permitir que se estabeleça quais as regras para o cancela- } \\
\text { mento de leilões. Geralmente, os leilões podem ser cancela- } \\
\text { dos por um tempo predeterminado ou até que receba lances. } \\
\text { Portanto, deve-se possibilitar que em uma instanciação seja } \\
\text { determinada uma das alternativas: não permitir o cancela- } \\
\text { mento, permitir o cancelamento em um determinado período } \\
\text { após o cadastro do leilão, permitir o cancelamento até que } \\
\text { um lance tenha sido dado ou permitir o cancelamento sem } \\
\text { qualquer restrição. }\end{array}$ & COMPORTAMENTO & Variantes & 3 \\
\hline 9 & $\begin{array}{l}\text { Definir os ti- } \\
\text { pos de lances }\end{array}$ & $\begin{array}{l}\text { Os lances sempre são relacionados aos tipos de leilões habi- } \\
\text { litados em uma instanciação específica. }\end{array}$ & PROPAGAÇÃO & $\begin{array}{l}\text { Participantes, } \\
\text { Estrutura }\end{array}$ & 5 \\
\hline 10 & $\begin{array}{l}\text { Suportar } \\
\text { mecanismo } \\
\text { de lance } \\
\text { automático }\end{array}$ & $\begin{array}{l}\text { Possibilitar que um mecanismo de lance automático seja uti- } \\
\text { lizado para oferecer lances melhores e, assim, auxiliar os } \\
\text { compradores. O mecanismo deve obedecer a um montan- } \\
\text { te estabelecido pelo comprador no momento em que entra } \\
\text { em funcionamento. }\end{array}$ & PARTIC_OPCIONAL & Variantes & 5 \\
\hline 11 & $\begin{array}{l}\text { Verificador de } \\
\text { incremento } \\
\text { mínimo }\end{array}$ & $\begin{array}{l}\text { Mecanismo que verifica qual o incremento mínimo que um } \\
\text { comprador pode oferecer em um leilão em relação ao melhor } \\
\text { lance previamente oferecido. }\end{array}$ & PARTIC_OPCIONAL & Variantes & 5 \\
\hline 12 & $\begin{array}{l}\text { Aprovar ou re- } \\
\text { provar partici- } \\
\text { pantes }\end{array}$ & $\begin{array}{l}\text { Mecanismo que permite a um vendedor definir quais com- } \\
\text { pradores podem oferecer lances em seus leilões. O vendedor } \\
\text { pode escolher, exclusivamente, entre aprovar os comprado- } \\
\text { res para oferecer lances ou reprovar compradores para ofe- } \\
\text { recer lances. Assim, no momento da instanciação deve-se } \\
\text { escolher entre permitir uma lista de compradores aprova- } \\
\text { dos, permitir uma lista de compradores não aprovados ou } \\
\text { não existir lista de aprovados nem reprovados. }\end{array}$ & PARTIC_OPCIONAL & Variantes & 6 \\
\hline 13 & $\begin{array}{ll}\text { Taxação de } \\
\text { serviços }\end{array}$ & $\begin{array}{l}\text { Uma empresa leiloeira pode optar por cobrar determinadas } \\
\text { taxas sobre seus serviços, tornando-as opcionais. }\end{array}$ & ESCOLHA_PARTIC & Participantes & 6 \\
\hline
\end{tabular}

continua na próxima página... 
Tabela B.1: Lista Completa dos Pontos Variáveis do Framework Qd+ (continuação)

\begin{tabular}{|l|l|l|l|l|l|}
\hline $\begin{array}{l}\text { Número } \\
\text { do } \\
\text { ponto } \\
\text { variá- } \\
\text { vel }\end{array}$ & Nome & Descrição & Tipo & $\begin{array}{l}\text { Origem } \\
\text { Linguagem de } \\
\text { Padrões }\end{array}$ & $\begin{array}{l}\text { Número } \\
\text { do } \\
\text { Padrão }\end{array}$ \\
\hline 14 & $\begin{array}{l}\text { Registro } \\
\text { das taxas do } \\
\text { usuário }\end{array}$ & $\begin{array}{l}\text { As taxas eventualmente cobradas pela empresa leiloeira de- } \\
\text { vem ser registradas individualmente para cada usuário. Por- } \\
\text { tanto, a conta do usuário fica condicionada à cobrança de } \\
\text { taxas. }\end{array}$ & PROPAGAÇãO & $\begin{array}{l}\text { Participantes, } \\
\text { Grafo de Flu- } \\
\text { xo, Próximos } \\
\text { Padrões }\end{array}$ & 6 \\
\hline 15 & $\begin{array}{l}\text { Visibilidade } \\
\text { do voto de } \\
\text { reputação }\end{array}$ & $\begin{array}{l}\text { Permitir que, ao dar um voto sobre a reputação, um usuário } \\
\text { possa escolher entre deixá-lo visível a outros usuário ou não. }\end{array}$ & PARTIC_OPCIONAL & Variantes & 7 \\
\hline 16 & $\begin{array}{l}\text { Alteração } \\
\text { de voto de } \\
\text { reputação }\end{array}$ & $\begin{array}{l}\text { Permitir a alteração de um voto dado por um número de ve- } \\
\text { zes predeterminado ou por um período predeterminado. }\end{array}$ & COMPORTAMENTO & Variantes & 7 \\
\hline 17 & $\begin{array}{l}\text { Definir tipo de } \\
\text { anúncio }\end{array}$ & $\begin{array}{l}\text { Possibilitar a escolha de quais tipos de anúncio podem ser } \\
\text { utilizados em uma aplicação específica. }\end{array}$ & ESCOLHA_PARTIC & $\begin{array}{l}\text { Participantes, } \\
\text { Estrutura }\end{array}$ & 10 \\
\hline
\end{tabular}


APÊNDICE

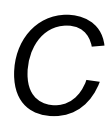

Hierarquia de classes do Framework

Qd+

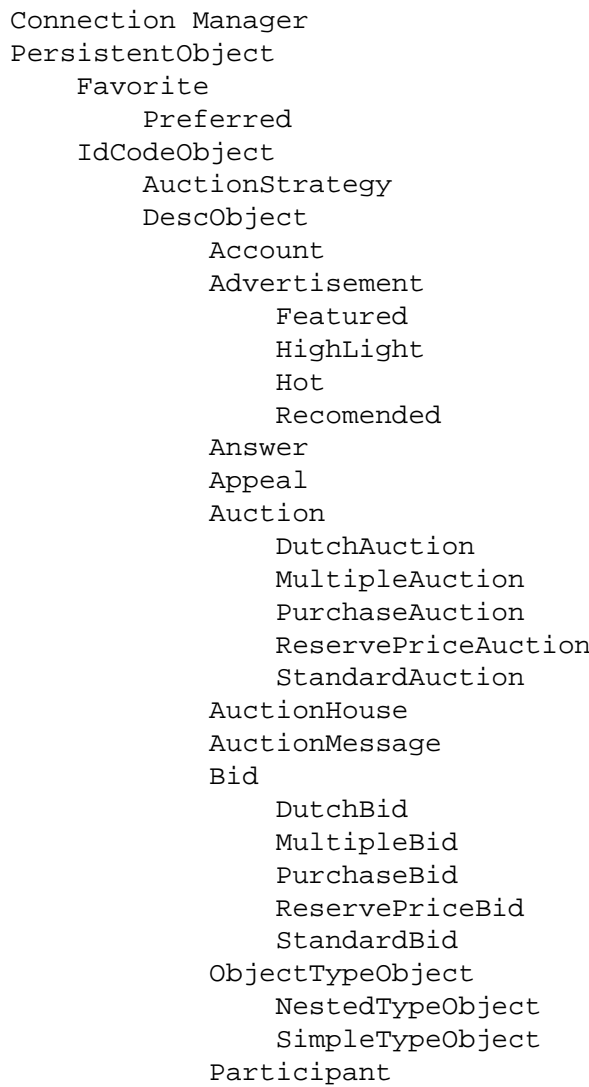


User

Qualifiableobject

Resource

Product

Question

Refund

Reputation

Fee

FinalValuefee

Promotionfee

RangeValueFee

Insertionfee

ReservePriceFee

Marked

objectForm

IdCodeObjectForm

DescObjectForm

AdvertisementForm

FeaturedForm

Hight LightForm

HotForm

RecomendedForm

AnswerForm

AppealForm

Auctionform

DutchAuctionForm

MultipleAuctionForm

PurchaseAuctionForm

ReservePriceAuctionForm

StandardAuctionform

SearchAuctionForm

ListAuctionForm

AuctionHouseForm

ShowRulesForm

AuctionMessageForm

BidForm

DutchBidForm

MultipleBidForm

PurchaseBidForm

ReservePriceBidForm

StandardBidForm

NestedTypeobjectForm

ParticipantForm

UserForm

QualifiableObjectForm

ResourceForm

QuestionForm

RefundForm

ReputationForm

ListReputation

SimpleTypeobjectForm

FeeForm

FinalValueFeeForm

PromotionFeeForm

RangeValueFeeForm

InsertionFeeForm

ReservePriceFeeForm

UserLoginForm

MarkedForm

ListMarkedForm

WebComponentControl

CheckBoxControl

CheckBoxGroupControl

Selectioncontrol

SubmitButton

EditBoxControl

EditBoxDateControl

EditBoxFloatControl

EditBoxpasswordControl 
EditBoxTimeControl

LabelControl

ListControl

SelectionListControl

RadioGroupControl 